\title{
Local renin angiotensin systems and peripheral ischemia
}

Citation for published version (APA):

Nelissen-Vrancken, H. J. M. G. (1992). Local renin angiotensin systems and peripheral ischemia.

[Doctoral Thesis, Maastricht University]. Rijksuniversiteit Limburg.

https://doi.org/10.26481/dis.19920625hn

Document status and date:

Published: 01/01/1992

DOI:

10.26481/dis.19920625hn

Document Version:

Publisher's PDF, also known as Version of record

\section{Please check the document version of this publication:}

- A submitted manuscript is the version of the article upon submission and before peer-review. There can be important differences between the submitted version and the official published version of record.

People interested in the research are advised to contact the author for the final version of the publication, or visit the DOI to the publisher's website.

- The final author version and the galley proof are versions of the publication after peer review.

- The final published version features the final layout of the paper including the volume, issue and page numbers.

Link to publication

\footnotetext{
General rights rights.

- You may freely distribute the URL identifying the publication in the public portal. please follow below link for the End User Agreement:

www.umlib.nl/taverne-license

Take down policy

If you believe that this document breaches copyright please contact us at:

repository@maastrichtuniversity.nl

providing details and we will investigate your claim.
}

Copyright and moral rights for the publications made accessible in the public portal are retained by the authors and/or other copyright owners and it is a condition of accessing publications that users recognise and abide by the legal requirements associated with these

- Users may download and print one copy of any publication from the public portal for the purpose of private study or research.

- You may not further distribute the material or use it for any profit-making activity or commercial gain

If the publication is distributed under the terms of Article $25 \mathrm{fa}$ of the Dutch Copyright Act, indicated by the "Taverne" license above, 
LOCAL RENIN ANGIOTENSIN SYSTEMS AND PERIPHERAL ISCHEMIA 


\title{
LOCAL RENIN ANGIOTENSIN SYSTEMS AND PERIPHERAL ISCHEMIA
}

\author{
Proefschrift
}

\begin{abstract}
ter verkrijging van de graad doctor
aan de Rijksuniversiteit Limburg te Maastricht, op gezag van Rector Magnificus, Prof. mr. M.J. Cohen, volgens het besluit van het College van Dekanen, in het openbaar te verdedigen op donderdag, 25 juni 1992 om 16.00 uur
\end{abstract}

\author{
door \\ Henrica Johanna Maria Gerardine Nelissen-Vrancken
}

geboren te Maastricht in 1962 
Promotores

Prof. dr. H.A.J. Struijker Boudier

Prof. dr. J.F.M. Smits

Beoordelingscommissie Prof. dr. J.W. Arends, voorzitter

Dr. F.H.M. Derkx, Erasmus Universiteit, Rotterdam

Dr. W.H. van Gilst, Rijksuniversiteit Groningen

Prof. dr. P.W. de Leeuw

Prof. dr. G.J. van der Vusse

CIP-DATA KONINKLIJKE BIBLIOTHEEK, DEN HAAG

Nelissen-Vrancken, Henrica Johanna Maria Gerardine

Local renin angiotensin systems and peripheral ischemia /

Henrica Johanna Maria Gerardine Nelissen-Vrancken. -

[S.I. ; s.n.]. - III.

Thesis Maasiricht. - With ref. - With a summary in Dutch.

ISBN 90-9005094-9

NUGI 746/731

Subject headings: renin angiotensin systems /

peripheral ischemia / antihypertensives.

Het onderzoek beschreven in dit proefschrift werd mede mogelijk gemaakt door financiële steun van de firma Servier Benelux.

De uitgave van dit proefschrift werd mede mogelijk gemaakt door financiële steun van de firma Bristol-Myers Squibb Nederland.

Met dank aan iedereen die heeft meegewerkt aan de tot standkoming van dit proefschrift. 
voor mijn ouders 


\section{CONTENTS}

1. Introduction

1.1 General introduction

1.2 Renin angiotensin system 2

1.2.1 Angiotensinogen 2

1.2.2 Renin 2

1.2.3 Angiotensin converting enzyme 4

1.2.4 Angiotensin II 5

1.2.5 Angiotensin II and angiotensin (1-7) 7

1.3 Angiotensin II receptors 8

1.3.1 Localization 9

1.3.2 Second messengers 9

1.4 Pharmacology of the renin angiotensin system 9

1.4.1 Renin-inhibitors 9

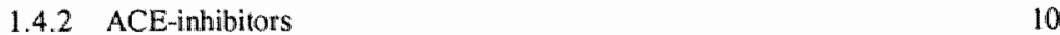

$\begin{array}{ll}\text { 1.4.3 Angiotensin II antagonists } & 12\end{array}$

$\begin{array}{lll}1.5 & \text { The RAS in cardiowascular homeostasis and pathophysiology } & 12\end{array}$

1.6 Ischemia of skeletal muscle 13

$\begin{array}{ll}\text { 1.6.1 Chronic peripheral arterial disease } & 13\end{array}$

$\begin{array}{ll}\text { 1.6.2 Pathophysiology } & 14\end{array}$

$\begin{array}{ll}\text { 1.6.3 Therapy } & 17\end{array}$

1.7 The aim of the present thesis 20

2. Materials and methods 21

2.1 Animals 21

2.2 Surgery 21

2.2.1 Coronary artery ligation 21

2.2.2 Implantation of electromagnetic flow probe 22

2.2.3 Implantation of Doppler flow probes 22

2.2.4 Implantation of catheters

2.2.5 Chronic hindlimb ischemia 25

2.2.6 Femoral artery isolation 25

2.3 Measurements 25

2.3.1 Hemodynamic measurements 25

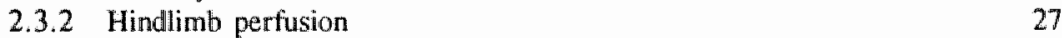

$\begin{array}{ll}\text { 2.3.3 Acute hindlimb ischemia } & 27\end{array}$

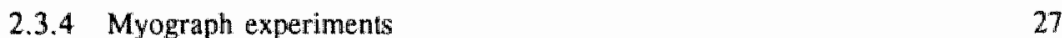

2.4 Histology 28

$\begin{array}{ll}2.4 .1 & \text { Infarct size measurements }\end{array}$

2.4.2. Skeletal muscle 29

2.4.3 Femorallartery 3\|

2.5 Plasma ACE activity 32

2.6 DNA content 32

2.7 Statistics 33

2.8 Drugs 33 
3. Central and regional hemodynamic effects of non-hypotensive doses of ACE-inhibitors in hypertension and hearl failure

3.1 Introduction 35

3.2 Materials and methods 36

3.2.1 Animals 36

3.2 .2 Surgery $\quad 36$

3.2.3 Measuring protocols $\quad 37$

$\begin{array}{ll}3.2 .4 \text { Infarct size } & 38\end{array}$

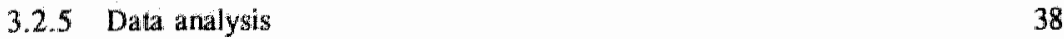

$\begin{array}{lll}3.3 & \text { Results } & 39\end{array}$

3.3.1 Central hemodynamies $\quad 39$

3.3.2 Regional hemodynamics 39

3.4 Discussion 41

4. Hindlimb perfusion model $\quad 45$

4.1 Introduction $\quad 45$

4.2 Hindlimb perfusion model $\quad 46$

4.2 .1 Surgery $\quad 46$

4.2.2 Perfusion 46

4.2 .3 Measurements 4.8

4.2.4 Perfusion characteristics 49

4.2 .5 Responsiveness 49

4.2 .6 Calculations 51

5. Angiotensin converting enzyme inhibition in perfused hindlimbs and in vivo 53

5.1 Introduction 53

5.2 Materials and methods $\quad 54$

5.2 .1 Animals $\quad 54$

5.2 .2 Surgery $\quad 54$

5.2 .3 Measuring protocols $\quad 54$

5.2 .4 Data analysis $\quad 55$

5.3 Results 55

5.3.1 Dose comparison $\quad 55$

$\begin{array}{lr}5.3 .2 \text { Hindlimb experiments } & 56\end{array}$

5.4 Discussion $\$ 9$

6. Vascular responsiveness in acute and chronic ischemic skeletal muscle 63

$\begin{array}{ll}6.1 & \text { Introduction } \\ 6.2 & 63\end{array}$

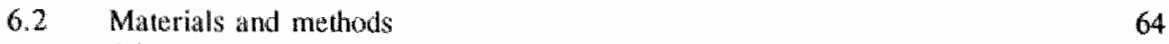

6.2.1 Animals 64

$\begin{array}{lll}6.2 .2 & \text { Surgery } & 65\end{array}$

6.2 .3 Measuring protocols 65

$\begin{array}{ll}6.2 .4 \text { Data analysis } & 65\end{array}$

6.3 Results 66

6.3.1 Acute ischemia 66

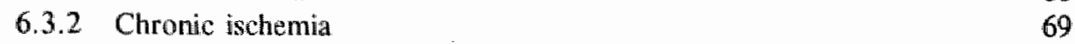

$\begin{array}{lll}6.4 \text { Discussion } & 70\end{array}$ 
7. Skeletal muscle ischemia and antihypertensive therapy 73

7.1 Introduction 73

7.2 Materials and methods 75

$\begin{array}{ll}7.2 .1 \text { Animals } & 75\end{array}$

7.2.2 Dose finding studies 75

7.2.3 Hindlimb experiments 75

7.2.4 Data anallysis 76

7.3 Results 77

7.3.1 Dose findings studies 77

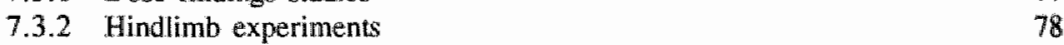

$\begin{array}{lll}7.4 & \text { Discussion } & 80\end{array}$

8. Morphology and reactivity of isolated femoral arteries of animals with skeletall muscle ischemia $\quad 85$

8.1 Introduction 85

8.2 Materials and methods 86

8.2.1 Animals $\quad 86$

$\begin{array}{lll}8.2 .2 & \text { Swrgery } & 87\end{array}$

$\begin{array}{ll}\text { 8.2.3 Measuring protocols } & 87\end{array}$

8.2.4 Histology and morphometry 88

$\begin{array}{ll}\text { 8.2.5 DNA content } & 89\end{array}$

8.2.6 Data analysis $\quad 89$

8.3 Results $\quad 89$

8.3.1 Blood pressure measurements $\quad 89$

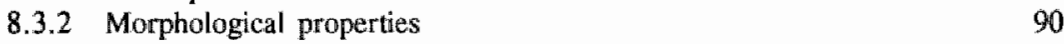

$\begin{array}{ll}\text { 8.3.3 Maximal contractility } & 91\end{array}$

8.3.4 Contractile responses to depolarizing and
pharmacological stimuli

8.3.5 Responses to relaxing interventions 93

8.4 Discussion 97

9. Chronic ischemia and neovascularization 10॥

9.1 Introduction 101

$\begin{array}{ll}9.2 & \text { Materials and methods } \\ & 102\end{array}$

$\begin{array}{lll}9.2 .1 & \text { Animals } & 102\end{array}$

$\begin{array}{ll}9.2 .2 & \text { Surgery and treatment } 103\end{array}$

9.2.3 Skeletal muscle preparation 103

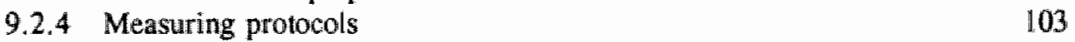

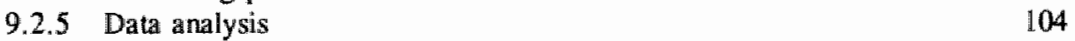

$\begin{array}{lll}9.3 & \text { Results } & 104\end{array}$

$\begin{array}{ll}\text { 9.3.1 Chronic ischemia } & 104\end{array}$

$\begin{array}{ll}\text { 9.3.2 Therapy } & 105\end{array}$

$\begin{array}{lll}9.4 \text { Discussion } & 107\end{array}$

10. General discussion $\quad 111$

10.1 General 111

10.2 Local renin angiotensin systems $\quad 112$

10.3 ACE-inhibitors and local renin angiotensin systems 112 
10.4 Ischemia of skeletal muscle:

pathophysiology and compensatory mecthanisms

10.4.1 Structural vascular alterations

10.4.2 Alterations of receptor-linked mechanisms

10.4.3 Ultrastructural alterations in blood vessels and skeletal muscle

10.5 Ischemia of skeletal muscle: therapy

10.6 General conclusion and outlook 119

$\begin{array}{ll}\text { References } & 121\end{array}$

$\begin{array}{ll}\text { Summary } & 139\end{array}$

$\begin{array}{ll}\text { Samenwatting } & 141\end{array}$

$\begin{array}{ll}\text { Curriculum vitae } & 143\end{array}$ 


\section{CHAPTER 1}

\section{Introduction}

\subsection{GENERAL INTRODUCTION}

The first observations concerning the renin angiotensin system were made by Tigerstedt and Bergman (1898). These investigators derived a substance from kidneys and showed that it raised blood pressure following injection. They named the substance renin and suggested an endocrine role for it by release from the kidney into the blood and action on the peripheral vasculature. These observations were followed by the identification of hypertensin by BraunMenendez et al. (1939) and angiotonin by Page and Helmer (1940). Hypertensin and angiotonin turned out to be the same substance and their names were changed in angiotensin in 1958. The discovery of angiotensin I and angiotensin converting enzyme lasted until 1954 and 1956 (Skeggs et al., 1954, 1956).

Until recently, the renin angiotensin system was supposed to have only an endocrine role. Each component of the system, angiotensinogen from liver, renin from kidney and angiotensin converting enzyme from lung, was released from its specific tissue into the blood, ultimately resulting in the production of angiotensin II. Constriction of the cerebral and peripheral vasculature, stimulation of aldosterone production in the adrenal gland and anti-natriuresis, and water retention are the major endocrine functions of angiotensin II. Recently, in molecular biological experiments renin angiotensin systems have also been demonstrated in many tissues, where they exert autocrine and paracrine influences on local tissue function. 


\subsection{RENIN ANGIOTENSIN SYSTEM}

The renin angiotensin system (RAS) is constituted by a cascade of enzymatic reactions, which is depicted in figure 1 .1. The localisation of the components of the circulating and local RAS is illustrated for the vascular wall in figure 1.2. The different components of the RAS are described below.

\subsubsection{Angiotensinogen}

Angiotensinogen is the precursor to the angiotensin peptides and the only known naturally occurring renin substrate. The products of the reaction between angiotensinogen and renin are angiotensin I and des(angiotensin I)-angiotensinogen (figure 1.1).

Synthesis of blood-borne angiotensinogen occurs predominantly in hepatocytes and to a lesser extent in adipocytes and astrocytes. Intracellular concentrations of angiotensinogen are low, because it is mostly localized in blood and other extracellular fluids (Lynch and Peach, 1991). Blood-borne angiotensinogen can be stimulated by estrogen (Kunapuli et al., 1987), glucocorticoids (Kunapuli et al., 1987) and thyroxin (review Lynch and Peach, 1991). Furthermore, angiotensin II has been described to inhibit angiotensinogen production in a human hepatoma cell line (Coezy et al., 1989) and to increase angiotensinogen production in the liver of the rat (Iwao et al., 1990; Nakamura et al., 1990; Lynch and Peach, 1991).

Besides production of angiotensinogen in hepatocytes, angiotensinogen has been proposed to be synthesized locally in a diversity of tissues. This has been demonstrated by mRNA synthesis of angiotensinogen in cardiac tissue (Kunapuli et al., 1987; Lindpaintner et al., 1990; Lindpaintner and Ganten, 1991), brain (Kunapuli et al., 1987), vessel wall (Naftilan et al., 1991), kidney, adrenal gland, lung, ovary and testes (Lenz et al., 1989) (review Dzau et al., 1986; Lynch and Peach, 1991). Local mRNA synthesis for angiotensinogen is affected by inflammation, sodium depletion (Iwao et al., 1990; Lindpaintner et al., 1990; Naftilan et al., 1991), glucocorticoids (Kunapuli et al., 1987; Lindpaintner et al., 1990), insulin and angiotensin converting enzyme inhibitor treatment (Iwao et al, 1990) (review Dzau et al., 1986; Lindpaintner and Ganten, 1991).

\subsubsection{Renin}

The enzyme renin cleaves angiotensinogen into angiotensin I and des(angiotensin I)-angiotensinogen (figure 1.1). As for angiotensinogen, the existence of both local and circulating renin has been described. The synthesis of renin in the juxtaglomerular cells of the kidney (Hackenthal et al., 1990) is mainly responsi- 


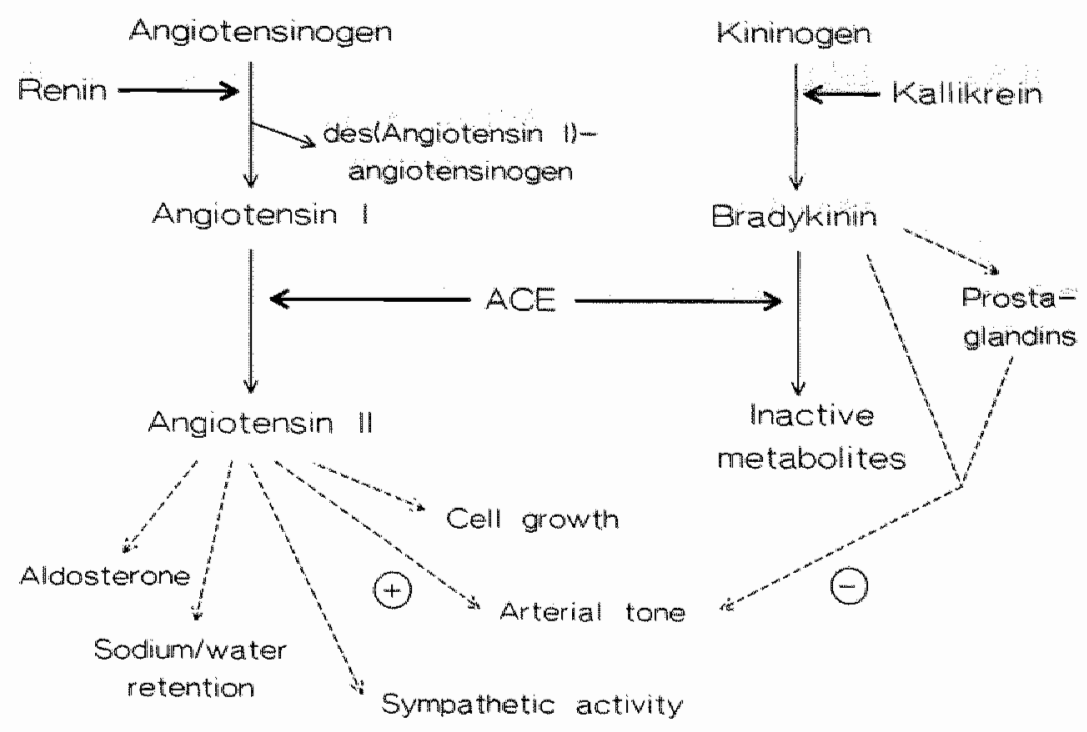

Figure 1.1 The renin-angiotensin system and its major effects.

ble for the blood-borne renin and thus for the plasma renin activity. The bloodborne renin can be taken up by many tissues (Campbell, 1989).

Not only renin gene expression, but also renin synthesis has been demonstrated in multiple tissues, such as cardiomyocytes in atria and ventricles of the heart (Lindpaintner and Ganten, 1991), arterial endothelial and smooth muscle cells, brain, adrenal gland and testes (review Campbell, 1989; Inagami et al., 1989; Hackenthal et al., 1990). This local renin production has been proposed to be part of local auto- and/or paracrine tissue angiotensin systems (Dzau, 1988; Lindpaintner and Ganten, 1991).

Renin release from the kidney is mainly regulated by the renal perfusion pressure, but can also be influenced by for instance sodium-depletion, $\beta$ adrenergic agonists and antagonists, vasopressin, angiotensin II, atrial natriuretic peptide, prostaglandins (Bugge et al., 1990), dopamine, kinins and histamine (review Dzau et al., 1988; Hackenthal et al., 1990). Furthermore, local renin gene expression and mRNA synthesis can also be influenced by sodium depletion, androgen or estrogen (Navot et al., 1987), angiotensin converting enzyme inhibitors (Nakamura et al., 1990) and calcium entry blocker therapy (review Dzau et al., 1986, 1988; Lindpaintner and Ganten, 1991).

The majority of circulating renin is present in the inactive form prorenin (review Dzau et al., 1988; Derkx, 1987). As for renin, the kidney is mainly responsible for the production of blood-borne prorenin. Prorenin has been suggested to serve as a reservoir for conversion to renin by a membrane-bound and intracellular serine protease (Dzau, 1989). Proteases like trypsin, plasmin, 
kallikrein and cathepsin B have been described to activate prorenin (review Hsueh and Baxter, 1991). Besides conversion of prorenin to active renin in the kidney, conversion may occur extracellularly in the blood or intracellularly after uptake into peripheral tissues. Furthermore, local synthesis of prorenin has been proposed in eyes (Danser et al., 1989), reproductive tissues (Laragh, 1989; Lenz et al., 1989; Sealey and Rubattu, 1989) and the adrenal glands (Inagami et al., 1989). In these tissues prorenin has been suggested to have intrinsic catalytic activity without conversion to renin (review Sealey and Rubattu, 1989; Hsueh and Baxter, 1991). Incubation of prorenin at $0^{\circ} \mathrm{C}$ or at $\mathrm{pH} 3.3$ results in a conformation change and exposure of the active site. At normal conditions $\left(37^{\circ} \mathrm{C}, \mathrm{pH} 7.4\right)$ only a small degree $(\leq 3 \%)$ of prorenin is in the active form. However, since the concentration of prorenin in many extrarenal sources is high, the contribution of the active form of prorenin in the conversion of angiotensinogen into angiotensin I becomes important in these tissues. Plasma levels of prorenin can vary with physiological changes, such as the menstrual cycle and pregnancy (Sealey and Rubattu, 1989), but also under pathological conditions, such as diabetes mellitus and renin-secreting tumors (review Hsueh and Baxter, 1991).

\subsubsection{Angiotensin converting enzyme}

The angiotensin converting enzyme (ACE) is the enzyme mainly responsible for the conversion of angiotensin I into angiotensin II as well as for the degradation of bradykinin (figure 1.1). ACE can also cleave other peptide substrates, such as enkephalins, neurotensin, substance $P$ and the luteinizing hormonereleasing hormone (Ehlers and Riordan, 1989; Erdös, 1990). Other angiotensin II generating enzymes important for the conversion of angiotensin I into angiotensin II are a chymostatin-sensitive angiotensin II generating enzyme (CAGE; Okunishi et al., 1984, 1987; Ideishi et al., 1990b; Okamura et al., 1990; Urata et al., 1990b), kallikrein (Maruta and Arakawa, 1983; Ideishi et al., 1990a), trypsin (Arakawa and Maruta, 1980; Lanzillo et al., 1986), cathep$\sin \mathrm{G}$ and tonin (review Dzau, 1989). These enzymes are important for the generation of angiotensin II in for instance the heart (Gondo et al., 1989; Urata et al., 1990a,b), and in cells with acidic pH (Dzau, 1989). CAGE is distributed predominantly in adventitia of vascular smooth muscle cells, whereas ACE mainly in the endothelial cells of the blood vessels (Okunishi et al., 1987; Dzau, 1989).

Local production of ACE has been demonstrated in endothelial cells, but also in vascular smooth muscle cells, cardiac tissues, testes, intestines, kidney and brain (Cushman et al., 1989b; Duggan et al., 1989; Morin et al., 1989; Ralevic et al., 1989; Correa et al., 1990; Ikemoto et al., 1990; Pipili-Synetos et al., 1990; Yamada et al., 1991). Quantitatively, circulating ACE is produced 


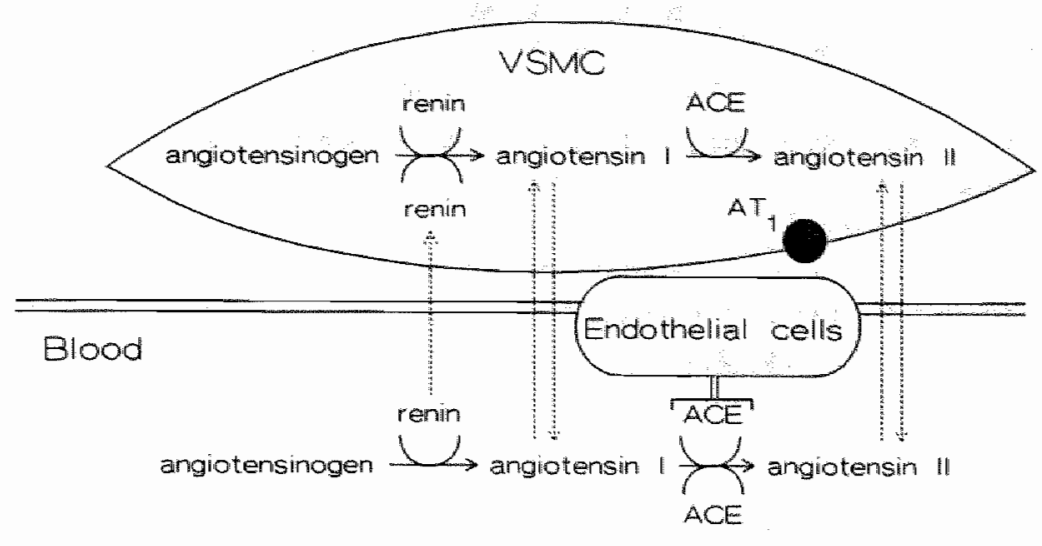

$\longrightarrow$ conversion

trans.........n tramsoort

Figure 1.2 Components of the circulating RAS and of the local RAS in the vessel wall. NSMC: vascular smooth muscle cells,.

predominantly in endothelial cells of the lung.

Two different isozymes of ACE are present in endothelial cells (160-170 kD) and testes (100-110 kD; Ehlers et al., 1989; Hubert et al., 1991; Kumar et al., 1991). Furthermore, a neuronal and endothelial form of ACE has been found in pig brain (Williams et al., 1991). These latter isozymes were not different with respect to substrate specificity or inhibitor sensitivity.

ACE activity in endothelial cells can be influenced for instance by atrial natriuretic factor (Kawaguchi et al., 1989, 1990b), cations and Na,K-ATPase (Dasarathy and Fanburg, 1989), platelet-activating factor (Kawaguchi et al., 1990a), ACE-inhibitors (Ikemoto et al., 1990), glucocorticoids and dexamethasone (Dasarathy et al., 1990).

\subsubsection{Angiotensin II}

Circulating angiotensin II is mainly generated by ACE on endothelial cells of lung. Furthermore, local generation and subsequent secretion of angiotensin II by peripheral vascular tissues also contribute to the amount of circulating angiotensin II (Mizuno et al., 1988b, 1989; Admiraal et al. 1991). Moreover, local angiotensin II generation has been described in a variety of tissues, such as heart, Leydig celis, uterus, brain, kidney, adrenal gland and endothelial cells of blood vessels (Lindpaintner et al., 1988; Mizuno et al., 1988b; Unger et al., 1988; Horiba et al., 1990). 
Both circulating and local angiotensin II seem to play an important role in long-term blood pressure regulation. In contrast to the endocrine activity of circulating angiotensin II, local angiotensin II has also auto- and paracrine activity, which are important for tissue function (review Dzau, 1987a, 1988).

Besides vasoconstriction by stimulation of angiotensin II receptors, angiotensin II may also increase arterial blood pressure by activation of the sympathetic nervous system or by potentiation of the circulatory responses to sympathetic stimulation. Furthermore, it regulates blood pressure by stimulation of aldosterone secretion and sodium and water retention in the kidney (Hall et al., 1986; Melby, 1986; Dargie, 1990).

Heart: major targets of angiotensin II in the heart are the myocytes, autonomic nerves and coronary vessels (review Lindpaintner and Ganten, 1991). Angiotensin II has inotropic and chronotropic effects, both directly and by facilitation of sympathetic nervous influences. The direct inotropic and chronotropic effects of angiotensin II are predominantly mediated by its effect on calcium homeostasis and transmembranous calcium conductance. The facilitation of the sympathetic nervous system is based on an increase in the amount of neurotransmitter released from presynaptic nerve terminals (Ball, 1989).

Kidney and adrenals: angiotensin II has several intrarenal actions, including stimulation of renal tubular reabsorption, and vasoconstriction of renal blood vessels (review Hall et al., 1986; Dzau, 1988; Romero and Knox, 1988). Indirectly, angiotensin II stimulates secretion of aldosterone in the adrenalls. The vasoconstriction of efferent arterioles by angiotensin II stabilizes glomerular filtration rate (GFR) and decreases renal blood flow and peritubular capillary oncotic pressure (Keil et al., 1989; Li and Zimmerman, 1990). These contribute to increased sodium and water reabsorption by increasing filtration fraction and capillary colloid osmotic pressure. The direct effects of angiotensin II on renal tubular sodium reabsorption and thus sodium retention are probably induced by activation of $\mathrm{Na}^{+} / \mathrm{H}^{+}$-antiporter or $\mathrm{Na}, \mathrm{K}$-ATPase by angiotensin II (Brown and Douglas, 1989).

Brain: in brain, the major functions of angiotensin II are control of blood volume, regulation of the reproductive hormones and the activity as neurotransmitter (review Phillips, 1987).

Brain angiotensin II increases blood pressure by releasing vasopressin and increasing sympathetic nerve activity, and induces thirst and sodium appetite (Brody et al., 1978). The brain angiotensin II induces natriuresis and inhibits aldosterone release. These effects are in contrast to peripheral actions of angiotensin II, but cerebral angiotensin II regulates only brain sodium and not plasma sodium levels. 
Cerebral angiotensin II regulates the (cyclic) reproductive activity by influencing the release of sex hormones by the hypothalamo-pituitary axis. The neurotransmitter activity of angiotensin II is associated with interactions between angiotensin II and for instance catecholamines, serotonin and opoids.

Vascular smooth muscle cells: in vascular smooth muscle cells angiotensin II has several effects on ion metabolism. Sodium transport into the cells has been described to increase by alteration of the sodium permeability (Brock et al., 1982) and activation of $\mathrm{Na}^{+} / \mathrm{H}^{+}$-antiporter (Kuriyama et al., 1988), which is accompanied by an activation of the $\mathrm{Na}^{+} / \mathrm{K}^{+}$pump (Brock et al., 1982; Bingham Smith and Brock, 1983). Furthermore, angiotensin II has been proposed to increase intracellular free calcium directly (Pratt et al., 1989; Kem et al., 1991; Van Heiningen et al., 1991) or indirectly by the increase in intracellular sodium (Bova et al., 1990). The increased calcium concentration may in turn play a role in stimulation of Na-K-Cl cotransport (Owen and Ridge, 1989).

Growth: growth promoting activities of angiotensin II are described for cardiac tissue, vascular smooth muscle cells, fibroblasts and adrenal cortex (review Re and Rovigatti, 1988; Lindpaintner and Ganten, 1991; Schelling et al., 1991). Both in heart and vessel wall angiotensin II can play a role in hyperplasia (Scott-Burden et al., 1990; Daemen et al., 1991) and hypertrophy (Geisterfer et al., 1988) by stimulation of DNA, RNA and protein synthesis. Furthermore, angiotensin II induces the proto-oncogenes $c$-myc, $c$-jun and $c$-fos, which are involved in cell growth (Re and Rovigatti, 1988; Brown, 1989; Naftilan et al., 1989; Paquet et al., 1990; Powell et al., 1990; Itoh et al., 1991; Morgan and Baker, 1991). Also neovascularization (Fernandez et al., 1985; Le Noble et al., 1991) and stimulation of extracellular matrix protein synthesis (Scott-Burden et al., 1990; Kato et al., 1991; Van Krimpen et al., 1991a) have been described.

\subsubsection{Angiotensin III and angiotensin (1-7)}

Degradation of angiotensin II results in two biologically active heptapeptides, des-Asp ${ }^{1}$-angiotensin II (angiotensin III) and des-Phe ${ }^{8}$-angiotensin II (angiotensin (1-7); review Goodfriend, 1991). Angiotensin III stimulates aldosterone secretion and angiotensin (1-7) stimulates vasopressin release, whereas both peptides stimulate prostaglandin formation. Angiotensin (1-7) is localized in plasma and adrenal gland, but predominantly in brain (Chappell et al., 1989; Kohara et al., 1991). It has been suggested to represent an active member of angiotensin peptides of the brain. Furthermore, angiotensin (1-7) is not only generaled from cleavage of angiotensin II, but also of angiotensin I through a pathway independent of ACE (Kohara et al., 1991). 


\subsection{ANGIOTENSIN II RECEPTORS}

With the discovery of potent, highly selective nonpeptide angiotensin II receptor antagonists, the existence of subtypes of the angiotensin II receptor could be demonstrated. The angiotensin II receptor subtypes are classified as the $\mathrm{AT}_{1}$-receptor (previous names: $\mathrm{AII}-1, \mathrm{AII}-\mathrm{B}$ or $\mathrm{AII}_{\alpha}$ ) and the $\mathrm{AT}_{2}$-receptor (previous names: AII-2, AII-A or $\mathrm{All}_{\beta}$ ) (Bumpus et al., 1991). The receptor subtypes are also distinguishable by their sensitivity to the disulfide reducing agent dithiotreitol (DTT). This substance has been described to inhibit strongly the $\mathrm{AT}_{1}$-receptor (Chiu et al., 1989b; Rogg et al., 1990; Speth and Kim, 1990) and to enhance the binding to the $\mathrm{AT}_{2}$-receptor (Rogg et al., 1990).

Table 1.1 Occurence of $A T_{I^{-}}$and $A T_{2}$-receptors.

\begin{tabular}{|c|c|c|}
\hline Tissue & $A T_{I}$ & $A T_{2}$ \\
\hline Human myocardium (normal) & + & ++ \\
\hline Human myocardium (ischemia)" & + & +++ \\
\hline Human renal antery" & + & + \\
\hline Human adrenal contex $x^{2,3}$ & $+1++$ & + \\
\hline Human urerus ${ }^{2,3}$ & - & + \\
\hline Human vascular smooth muscle cells ${ }^{3}$ & + & - \\
\hline Rabbit myocardium ${ }^{12}$ & + & + \\
\hline Rabbit kidney 2,13 & + & $\infty$ \\
\hline Rabbit adrenal cortex $x^{2,13}$ & $+1+t$ & + \\
\hline Rabbit adrenal medulla $a^{2,13}$ & - & - \\
\hline Rat adrenal cortex $2,3,4,6,9,10$ & $+/ t+$ & + \\
\hline Rat adrenal medulla $2,4,6,9$ & $-1+$ & $+1++$ \\
\hline Rat cerebral arteries (young) 5 & - & +++ \\
\hline Ral cerebral arteries (adult $)^{5}$ & - & + \\
\hline Rat brain ${ }^{2,8,11}$ & + & + \\
\hline Rat kidney & + & - \\
\hline Rai liver, 7 & ++ & $+1 /=$ \\
\hline Rat wterus ${ }^{2,3}, 4$ & $+1+t$ & + \\
\hline Rat vascular smooth muscle cells $2,3,4$ & + & - \\
\hline \multicolumn{3}{|c|}{ 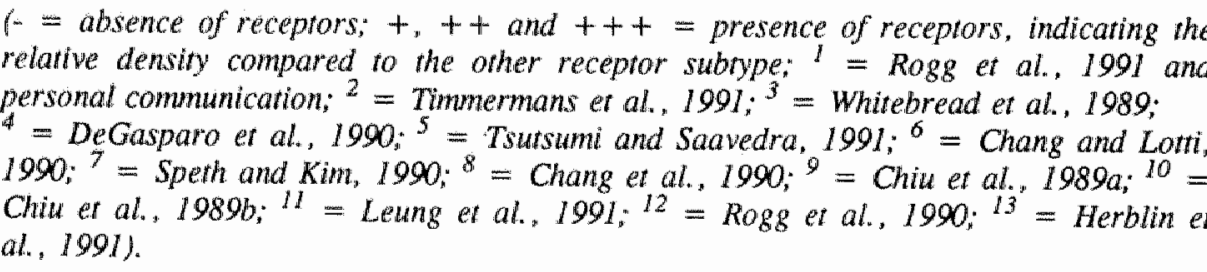 } \\
\hline
\end{tabular}




\subsubsection{Localization}

The distribution of the two angiotensin II receptor subtypes differs in tissues. The occurrence of $\mathrm{AT}_{1^{-}}$and $\mathrm{AT}_{2}$-receptor in a variety of tissues in different species is presented in table $\mathbb{1}, 1$.

\subsubsection{Second messengers}

The transmembrane signaling pathways of the $\mathrm{AT}_{1}-$ and $\mathrm{AT}_{2}$-receptor are not the same. The $\mathrm{AT}_{1}$-receptor is coupled to phospholipase $\mathrm{C}$ via a pertussis toxinsensitive G-protein. Stimulation of phospholipase $C$ induces the conversion of phosphatidylinositol $\left(\mathrm{PIP}_{2}\right)$ into inositoltriphosphate $\left(\mathrm{IP}_{3}\right)$ and diacylglycerol (DAG). $\mathrm{IP}_{3}$ results in a fast mobilization of calcium from intracellular stores and a slow increase in influx of extracellular calcium, whereas DAG activates protein kinase $\mathrm{C}$. Furthermore, the $\mathrm{AT}_{1}$-receptor has been described to be coupled to adenylyl cyclase via an inhibitory G-protein, resulting in an inhibition of cAMP accumulation. In contrast, stimulation of the $\mathrm{AT}_{2}$-receptor does not result in $\mathrm{IP}_{3}$ production, intracellular calcium mobilization or stimulation of adenylyl cyclase or guanylyl cyclase activity. The effector pathway of the $\mathrm{AT}_{2}$ receptor is not yet known (Baker et al., 1989; Linz et al., 1990; Ullian and Linas, 1990; Lindpaintner and Ganten, 1991; Pucell et al., 1991).

\subsection{PHARMACOLOGY OF THE RENIN ANGIOTENSIN SYSTEM}

\subsubsection{Renin-inhibitors}

As renin has a unique substrate specificity, renin-inhibitors may be specific agents for blocking the RAS. Recently, the interest in the therapeutic use of renin-inhibitors has increased, since orally active renin-inhibitors became available (lizuka et al., 1990). Acute hypotensive effects of these inhibitors have been demonstrated to be comparable to those of ACE-inhibitors and angiotensin II antagonists (Wood et al., 1990) and seem to be independent of circulating angiotensin II (Van den Meiracker et al., 1990). However, the chronic therapeutic effects of renin-inhibitors may be limited by generation of angiotensin II directly from angiotensinogen. Enzymes involved in these angiotensin II generating pathways are cathepsin $\mathrm{G}$, tonin, elastase and tissue plasminogen activator (t-PA; Dzau, 1989). 


\subsubsection{ACE-inhibitors}

ACE-inhibitors are potent inhibitors of both local and circulating ACE and thus prevent conversion of angiotensin I into angiotensin II and degradation of bradykinin. ACE-inhibitors can be divided into three structurally different groups (table 1.2; Fyhrquist, 1986; Ondetti, 1988), the sulphydryl compounds (e.g. captopril, zofenopril), the carboxyalkyldipeptides (e.g. enalapril, lisinopril, zabicipril) and the phosphoric acid compounds (e.g. fosinopril). Binding with zinc, an important component of the active site of $\mathrm{ACE}$, is critical for the inhibitory actions of these drugs (Ondetti, 1988). The SH group of the sulphydryl compounds, the carboxyl group of the carboxyalkyldipeptides and the phosphinic acid group of the phosphorus-containing compounds interact with the zinc ion.

Because of oral bioavailability, most ACE-inhibitors are prodrug esters and must be hydrolyzed in vivo for inhibitory activity. Differences in activity of the ACE-inhibitors depend not only on bioavailability, but also on potency and on diffusion into the various tissues in which ACE is located (Mizuno et al., 1988a, 1990; Cushman et al., 1989a,b; Grima et al., 1991; Grover et al., 1991; Higashimori et al., 1991). Both the conversion-site of the inactive prodrug (liver or other tissues) and the lipophilicity of the active drug (table 1.2) are important for the ability of the ACE-inhibitors to diffuse into tissues (Cushman et al., 1989b). Differences in local and systemic ACE-inhibition by several structurally different ACE-inhibitors has been demonstrated by Cushman et al. $(1989 \mathrm{a}, \mathrm{b})$ in a diversity of tissues. Diffusion of the ACE-inhibitors into the tissues is important for the therapeutic effects of the ACE-inhibitors, as inhibition of local ACE and not the inhibition of circulating $A C E$ is mainly responsible for antihypertensive and other effects (Cohen and Kurz, 1982; Smits and Struyker-

Table 1.2 Structural and lipophilicity characteristics of several ACE-inhibirors.

\begin{tabular}{|c|c|c|c|}
\hline Name & Type & Prodrug & $\log P$ \\
\hline captoprill & sulphydryl compound & no & $1.016^{1}$ \\
\hline zofenopril & sulphydryl compound & yes & $3.121^{1}$ \\
\hline enalaprill & carboxyallolpeptide & yes & $0.161^{1}$ \\
\hline lisinopril & carboxyalkylpepride & no & $-2.439^{\prime}$ \\
\hline zabicipril & carboxyalkylpeptide & yes & $0.02^{2}$ \\
\hline perindopril & carboxyalkylpeptide & yes & $0.554^{l}$ \\
\hline fosinopril & phosphar-containing & yes & $>2^{I, 3}$ \\
\hline
\end{tabular}


Boudier, 1984; Unger et al., 1985; Dzau, 1987a; Unger and Gohlke, 1990).

The therapeutic consequences of ACE-inhibition mainly depend on prevention of angiotensin II formation, but also inhibition of bradykinin degradation and stimulation of prostaglandin synthesis may contribute (Omata et al., 1987; Katayama et al., 1989; Schrör, 1990; Guivernau et al., 1991). Furthermore, during ACE-inhibition other angiotensin II generating enzymes, such as CAGE, kallikrein and trypsin, may become important (Ideishi et al., 1990a).

ACE-inhibitors are predominantly used in hypertension and congestive heart failure. In hypertensive patients, ACE-inhibitors decrease blood pressure with little changes in heart rate and cardiac output (review Brunner et al., 1987; Williams, 1988). Furthermore, ACE-inhibition results in redistribution of blood flow to kidney, heart and brain. The antihypertensive effect of ACE-inhibitors is independent of plasma renin activity, as the antihypertensive effect could also be observed in anephric patients (Man in 't Veld et al., 1980) and predominantly depends on inhibition of local ACE (Cohen and Kurz, 1982; Smits and Struyker-Boudier, 1984; Unger et al., 1985; Dzau, 1987a; Unger and Gohlke, 1990). Besides blood pressure reduction, the main effect of ACE-inhibitors in patients with congestive heart failure is improvement of cardiac function (review Nicholls, 1988; Jessup, 1989), resulting in a reduction of mortality in congestive heart failure (Swedberg and Kjekshus, 1988). The reduction in blood pressure may cause a decline in renal function, which occurs more frequentlly in longeracting ACE-inhibitors than in shorter-acting ACE-inhibitors (review Suki, 1989).

In both diseases, ACE-inhibitors have profound effects on cardiac structure. In hypertension, ACE-inhibition results in regression of cardiac hypertrophy, which is the most important cardiac structural alteration in this disease (Weber and Janicki, 1989). In heart failure, a complex pattern of structural changes occurs, consisting of ventricular dilatation, hypertrophy and increased extracellular matrix deposition (Pfeffer and Braunwald, 1990). This complex of changes, generally referred to as remodeling can be inhibited by ACE-inhibitors (Baur et al., 1991; Pinto et al., 1991; Van Krimpen et al., 1991a). For sulphydryl-ACEinhibitors, part of this action has been attributed to the radical-scavenging character of this group ( $\mathrm{Li}$ and Chen, 1987; Przyklenk and Kloner, 1989).

The most important adverse effects of ACE-inhibitors are hypotension, renal hemodynamic dysfunction, coughing and angioedema (review Ryden, 1988; Williams, 1988). Severe hypotension may occur upon co-administration with diuretics and/or low salt intake. The deterioration of renal function occurs mainly in patients, who already have a compromised renal function due to for instance renal artery stenosis and nephrosclerosis. Coughing is an irritating adverse effect and often requires cessation of treatment. It has been proposed to depend on bradykinin or prostaglandin production, but also stimulation of vagal fibers has been suggested. 


\subsubsection{Angiotensin II antagonists}

Antagonists of angiotensin II can be divided into four subgroups (Zimmerman, 1989; Timmermans et al, 1991). The first group represents the peptide angiotensin II receptor antagonists, such as saralasin and CGP 42112A. Saralasin has a chemical structure similar to angiotensin II and also possess some partial agonistic properties. In contrast, CGP $42112 \mathrm{~A}$ preferentially binds to the $\mathrm{AT}_{2}$-receptor (Bumpus et al., 1991). The therapeutic use of these substances has been limited mainly by the lack of oral bioavailability.

The second group represents monoclonal antibodies, such as KAA8, which inhibit hemodynamic responses to angiotensin II and III (Wong et al., 1989; Zimmerman, 1989). Prevention of circulating angiotensin II from reaching its receptor site has been suggested to be responsible for the antihypertensive actions of this monoclional antibody. Because of the nature of antibodies, these drugs have no therapeutic value.

As a third and fourth group, non-peptide angiotensin II antagonists, which block the angiotensin II receptors, have been developed (Timmermans et al., 1990). The development of these antagonists resulted in definite evidence for the presence of angiotensin receptor subtypes. This evidence has been based on binding site analyses using the two groups of nonpeptide angiotensin receptor antagonists: inhibition of the $\mathrm{AT}_{1}$-receptor by the biphenylimidazoles, typified by DuP753, and inhibition of the $\mathrm{AT}_{2}$-receptor by the tetrahydroimidazopyridines, typified by substances like PD 123177 (Chiu et al., 1990; Bumpus et al., 1991). As these compounds are also orally active and are true competitive angiotensin III receptor antagonists, this group of substances represents a new class of effective antihypertensive agents (Chiu et al., 1989a; Chang and Lotti, 1990; Dudley et al., 1990; Timmermans et al., 1990; Bumpus et al., 1991).

\subsection{THE RAS IN CARDIOVASCULAR HOMEOSTASIS AND PATHOPHYSIOLOGY}

Both circulating and local renin angiotensin systems play an important role in cardiovascular homeostasis (review Dzau, 1987a, 1988). The circulating renin angiotensin system has endocrine effects, whereas the local systems exert autocrine and paracrine influences on tissue functions. The major functions are long-term regulation of arterial pressure, volume homeostasis (Hall et al., 1986; Dzau, 1987a), cardiac function (Lindpaintner and Ganten, 1991) and structure (Dzau and Gibbons, 1987; Re and Rovigatti, 1988; Nagano et al., 1991).

Local renin angiotensin systems have been suggested to play not only a role in physiological but also in several pathological states, such as hypertension (Miyazaki et al., 1986; Hollenberg and Williams, 1988; Samani et al., 1989; 
Schiffrin, 1989), chronic congestive heart failure, acute myocardial ischemia and post-infarction adaptive processes (Cody, 1986; Dzau, 1987b; Francis, 1989; Linz et al., 1989; Dargie, 1990; Hirsch et al., 1990; Lindpaintner and Ganten, 1991). In hypertension a role of vascular angiotensin II in vascular tone, vascular hyperplasia and hypertrophy, and compliance has been suggested (review Brunner et al., 1987; Unger et al., 1989). In heart failure and other cardiac diseases cardiac angiotensin II seems to be involved in regulation of coronary blood flow (Van Gilst et al., 1988), disturbances in myocardial

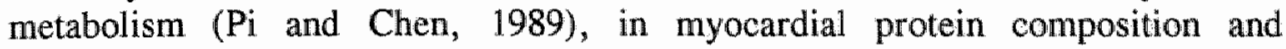
transcriptional control, in the pathologically shifted myosin isozyme profile (Pauletto et al., 1989) and the ventricular dysrhythmia ( $\mathrm{Li}$ and Chen, 1987; Fleetwood et al., 1991). Furthermore, a role in ventricular remodeling following myocardial infarction, which implies myocyte hypertrophy, myocardial fibrosis and rearrangement of the extracellular matrix, has been suggested (review Przyklenk and Kloner, 1989; Weber and Janicki, 1989; Hirsch et al., 1990; Lindpaintner and Ganten, 1991; Morgan and Baker, 1991). Recently, increased cardiac ACE activity and mRNA expression in rats (Hirsch et al, 1991) and humans (Hirsch et al., 1990), and increased synthesis of angiotensin II in dogs (Santos et al., 1990) following induction of experimental heart failure has been demonstrated. Furthermore, in failing human hearts Urata et al (1989) showed no changes in angiotensin III receptor density, whereas Rogg et al (1991 and personal communication) observed an increase in $\mathrm{AT}_{2}$-receptors and a decrease in $\mathrm{AT}_{1}$-receptors. The peripheral compensatory responses following myocardial infarction are mainly mediated by the kidney. Therefore, also other local renin angiotensin systems besides the cardiac system may be involved in the beneficial effects of ACE-inhibitors in heart failure (Dzau, 1987b; Hirsch et al., 1990).

Little is known about the role of the local renin angiotensin system in peripheral arterial occlusive disease, which results in ischemia of skeletal muscle. As angiotensin II has been suggested to stimulate neovascularization (Fernandez et al., 1982, 1985; Wang and Prewitt, 1990; Le Noble et al., 1991), it may be involved in the development of collaterals in peripheral arterial disease. Furthermore, synthesis of ACE in hypoxic endothelial cells of lung (King et al., 1989) and ischemic cardiac cells (Santos et al., 1990; Hirsch et al., 1991) has been shown to increase. This suggest that local ACE may also be influenced in the vasculature of ischemic skeletal muscles.

\subsection{ISCHEMIA OF SKELETAL MUSCLE}

\subsubsection{Chronic peripheral arterial disease}

One of the major overt manifestations of chronic peripheral arterial disease of 
the lower extremities in humans is intermittent claudication. The most common cause is slowly progressive atherosclerosis of which the severity defines the degree of ischemia of the skeletal muscles in the legs and therefore the clinical presentation. Incidence rates rise sharply with age and are higher in men than in women (Kannel and McGee, 1985).

Intermittent claudication has three diagnostic features, independently of the origin of the obstruction in the legs (Hertzer, 1991). Symptoms like a decreased walking distance or pain free interval are sudden in onset and occur at a consistent level of exercise. The symptoms resolve within 2-3 minutes after discontinuing exercise and occur again at approximately the same distance once activity has been resumed.

The principal complicating risk factors of intermittent claudication are age, ischemic heart disease and hypertension, cerebrovascular disease and continued smoking. The number of simultaneously existing risk factors relate closely with the prognosis of patients with ischemia of the legs (Hughson et al., 1978; Spittell, 1990).

\subsubsection{Pathophysiology}

The pathophysiological consequences of skeletal muscle ischemia have been investigated extensively both in patients and in animal models (humans: reviews Verstraete, 1982; Radack and Wyderski, 1990; Hertzer, 1991; animals: Conrad et al., 1971; Riegger et al., 1988; Verheyen et al., 1989, 1991; Hudlicka and Price, 1990b; Vanhoutte, 1990; Galt and Cronenwett, 1991). Endurance training, chronic electrical stimulation and (partial) occlusion of the vascular bed result in a discrepancy between blood flow and oxygen demand and thus in ischemic situations of skeletal muscle (Elander et al., 1985; Harris et al., 1986). A critical point for inadequate support of the metabolic demand of resting tissue has been suggested to be a flow reduction of 50-60\% (Kwasnik et al., 1991).

Once ischemia of skeletal muscle has been established, several acute and chronic hemodynamic, metabolic and ultrastructural changes follow (table 1.3).

\section{Hemoctynamic changes}

Occlusion of the major arteries in the extremities results in a reduction in blood flow and pressure (Folkow and Sivertsson, 1968; Williams and Saelens, 1983). A compensatory increase in blood flow occurs within minutes by a reflex vasodilatation of preexisting vessels, and over days by proliferation of new vessels and enlargement in collateral artery size (Conrad et al., 1971; Fernandez et al., 1985; Barie and Mullins, 1988). The reflex vasodilatation has been suggested to be independent of innervation (Barie and Mullins, 1988). 
Table 1.3 Acute and chronic hemodynamic, smuctural and ulrastruchural adaptations in ischemia of skeletal muscle.

\begin{tabular}{|c|c|c|c|}
\hline & minutes & hours & days - weeks \\
\hline hemodynamics & dilaration & -- & $\begin{array}{l}\text { moreased blood } \\
\text { supply }\end{array}$ \\
\hline metabolism & muscle $p H \downarrow$ & $\begin{array}{l}\text { glycogen, ATP } \\
\text { lactate, IMP }\end{array}$ & $\begin{array}{l}\text { muscle fiber type: } \\
I \text { and } I I b \quad \downarrow, I I a\end{array}$ \\
\hline $\begin{array}{l}\text { wascular } \\
\text { structure }\end{array}$ & $\ldots$ & $-\cdots$ & $\begin{array}{l}\text { vascular media } \\
\text { thickness and cross } \\
\text { sectional area } \\
\text { vessel growth }\end{array}$ \\
\hline ultrastructure & $\begin{array}{l}\text { membranes and } \\
\text { cellular organelles } \\
\text { damage } \\
\left(\mathrm{Ca}^{2+}\right]_{i} \text { overload }\end{array}$ & $\begin{array}{l}\text { infiltration lymphocytes } \\
\text { and macrophages, } \\
\text { sensirivity and } \\
\text { reactivity } \uparrow\end{array}$ & $\begin{array}{l}\text { regeneranion muscle } \\
\text { fibers }\end{array}$ \\
\hline
\end{tabular}

\section{Metabolic changes}

Limitation of skeletal muscle blood flow results acutely in several metabolic changes. One of the metabolic adaptations following ischemia is a decreased resting muscle $\mathrm{pH}$. This effect on muscle $\mathrm{pH}$ has been described to depend on severity of flow limitation and duration of ischemic conditions (Heppenstall et al., 1986; Kwasnik et al., 1991).

Furthermore, blood flow reduction alters intracellular purine metabolism and glycogen content (Hanzlikova and Gutmann, 1979; Elander et al., 1985; Harris et al., 1986; Heppenstall et al., 1986; Idström et al., 1990). The major metabolic events are a decreased glycogen and phosphocreatine level, an increased lactate level and a temporary preservation of the intracellular nucleotide pool. This latter is associated with a decrease in the adenosine triphosphate (ATP) level and an increase in inosine-5'-monophosphate (IMP). The reversibility of altered intracellular metabolites also depends on duration of ischemia.

A compensatory mechanism of the skeletal muscles which occurs within days to weeks is alterations in fiber type distribution in the skeletal muscles. In patients with intermittent claudication the medial head of the gastrocnemius muscle showed a shift from type IIb (glycolytic)-muscle fibers to type Ila (oxidative glycolytic)-muscle fibers (Hammarsten et al., 1980) and a smal] decrease in type I (oxidative)-muscle fibers (Clyne et al., 1982, 1985). 


\section{Changes of the vasculature}

Changes in structure and ultrastructure mainlly develop in a later phase than acute metabolic changes following ischemia of skeletal muscle. The changes can be divided in adaptation of pre-existing vessels and development of collateralls.

Pre-existing vessels: within a few hours after ischemia of skeletal muscle ultrastructural damage to microvascular membranes has been described (Gidlöf et al., 1987). In atherosclerosis, and therefore probably also in intermittent claudication, the behavior of the endothelium is abnormal due to previous injury and regeneration of endothelial cells (Vanhoutte, 1990). These endothelial cells have lost the ability to release endothelium-derived relaxing factors (EDRF) and therefore atherosclerotic vessels show a larger vasoconstrictor response than normal vessels to for instance serotonin. Such an increased reactivity to serotonin has not only been described in atherosclerosis but also in ischemic vessels in an animal model for skeletal muscle ischemia (Verheyen et al., 1981).

Furthermore, a regression of the arterial wall to lumen ratio has been observed in chronic ischemic and hypotensive hindlimbs following chronic occlusion of one of the major supplying arteries in the hindlimb (Folkow and Sivertsson, 1968; Bund et al., 1991).

Collaterals: the proliferation of new vessels is a long-term adaptation mechanism occuring over days to weeks (Fernandez et al., 1982, 1985; Barie and Mullins, 1988). Development of collaterals has been visualized by making corrosion casts in animals with chronic ischemia of skeletal muscle (Conrad et al., 1971; Verheyen et al., 1984). However, this development was not reflected in an increase in capillarity in glycolytic and oxidative glycolytic muscles in rats (Hudlicka and Price, 1990a). In contrast, capillary growth has been observed in the oxidative soleus muscle (Hanzlikova and Gutmann, 1979). In patients with intermittent claudication the influence of ischemia on capillarity in the medial head of the gastrocnemius muscle was ambiguous (Hammarsten et al., 1980; Clyne et al., 1982, 1985). Development of new capillaries has been demonstrated also in hypoxic situations following endurance training (Hudlicka, 1982), chronic electrical stimulation of skeletal muscles (Myrhage and Hudlicka, 1978; Hudlicka, 1982; Hudlicka and Price, 1990b) and simulated high altitude (Prewitt et al., 1986).

The collaterals developed in chronic ischemia of skeletal muscles have been described to be hyperreactive and hypersensitive to several vasoconstrictor agents compared to the normal vascular bed. These differences in reactivity have been suggested to be related to differences in ultrastructure and electro-mechanical coupling mechanisms (Williams, 1980; Verheyen et al., 1988, 1989, 1991).

Furthermore, collateral arteries have been proposed to have an inefficient innervation of the vascular smooth muscle cells by adrenergic nerve endings in 
contrast to normal arteries (Williams and Saelens, 1983), probably inducing hypersensitivity of post-synaptic receptors in collaterals. The lower content of noradrenaline in adrenergic neurons was associated with a decreased uptake and an increased efflux of noradrenaline in sympathetic neurons (Williams, 1991).

\section{Ulirastructural and structural changes of skeletal muscle}

Degenerative changes of several skeletal muscles, such as myofibrillar damage and enlargement of mitochondria, have been observed in ischemia (Ludatscher et al., 1981), accompanied with a reduction of contractility (Hanzli ikova and Gutmann, 1979). Muscle fiber injury has been extensively described following exercise (review Armstrong et al., 1991). The initial phase in this type of injury is a disturbance of the normal permeability barrier of cell membranes and basal lamina, resulting in an overload of intracellular $\mathrm{Ca}^{2+}$. Increased calcium levels activate $\mathrm{Ca}^{2+}$-dependent proteolytic and phospholytic pathways, which respectively degrade structure and contractile proteins and membrane phospholipids. In the second phase phagocytic cells are active at the damaged site, whereafter muscle fibers regenerate.

\subsubsection{Therapy}

The most common cause of intermittent claudication is atherosclerosis, which is also responsible for cardiac and cerebral complications (Verstraete, 1982; Kriessmann, 1990). To prevent complications, patients with intermittent claudication have to be treated for the underlying illness before treatment of the presenting symptoms.

\section{Underlying illness}

The first treatment guidelines for patients with intermittent claudication are loss of weight in combination with an appropriate diet, giving up smoking, physical exercise and correction of a high blood pressure (see hypertension and intermittent claudication).

A relevant diet for patients consists of a reduction of polysaturated fats, cholesterol and low molecular weight carbohydrates intake. The consequent loss of excessive body weight diminishes muscle energy during exercise and is therefore beneficial.

Smoking is the highest single risk factor for chronic obstructive peripheral arterial disease of the lower extremities. The incidence and also the progression of intermittent claudication is closely related to the amount of cigarette smoking. Furthermore, the success rate of reconstructive vascular surgery is much lower in smoking patients. Therefore, cessation of smoking is one of the most important first treatment guidelines (Verstraete, 1982; Radack and Wyderski, 1990).

Physical exercise above the usual daily activity results in an improvement in 
pain-free walking capacity in patients with untreated intermittent claudication. Suggested mechanisms for this improvement are an increased oxidative metabolic capacity of the ischemic leg, an altered walking technique, changes in pain tolerance, increased capillarization of the vascular bed of the skeletal muscles, a slight decrease in blood viscosity or improvement of abnormal hemorheology and thus blood flow (Verstraete, 1982; Radack and Wyderski, 1990).

In normal men and women physical exercise increased capillarity of skeletal muscles (Zumstein et al., 1983). An increase in capillarity has also been observed after electrical stimulation of normal or ischemic skeletal muscles of rats, due to an increased blood flow (Myrhage and Hudlicka, 1978; Hudlicka and Price, 1990b). In contrast, improved exercise tolerance after training of rats with chronic ischemia of skeletal muscles has been suggested to depend on local adaptations within the muscle, not requiring an increase in muscle blood flow (Erney et al., 1991).

\section{Intermittent claudication}

For symptomatic treatment of intermittent claudication several methods are available. Possible surgical interventions are angioplasty, transluminal atherectomy and aortofemoral bypass (Verstraete, 1982; Graor and Whitlow, 1990; Kram et al., 1991; Rosenschein et al., 1991). However, less than 30\% of the patients can be considered for these methods of treatment (Kriessmann, 1990). Therefore, alternatives for treatment are drug therapy and walking training.

Drug therapy can be divided into drugs which alter blood viscosity and red cell deformation, inhibitors of platelet function, thrombolytics and vasodilators (Verstraete, 1982). Thrombolytic agents, such as streptokinase, are mostly considered in patients with acute limb ischemia (Earnshaw, 1991). Recently, also long term treatment with anticoagulants and drugs inhibiting platelet function, such as aspirin or dipyridamole, has been described to be useful for patients with intermittent claudication (Giansante et al., 1990).

In patients with peripheral obstructive arterial disease whole blood viscosity is increased, resulting in a progressive fall in tissue perfusion. Beneficial effect on blood viscosity has been observed with clofibrate (Verstraete, 1982). Other drugs, which alter blood viscosity by improvement of red cell deformation, are substances like the xanthine derivatives pentoxifylline, oxpentifylline and torbafylline, buflomedil and the polydeoxyribonucleotide drug defibrotide (Cameron et al., 1988; Hudlicka and Price, 1990a; Strano et al., 1991).

Blood viscosity is a minor determinant of flow, whereas radius of the blood vessels has major influence on flow. Therefore, vasodilatation is more likely to restore normal exercise tolerance in patients with intermittent claudication.

\section{Hypertension and intermittent claudication}

As described above, treatment of hypertension in patients with intermittent 
claudication is one of the first treatment guidelines. Vasodilatation has been proposed to be beneficial for increasing blood flow in ischemic limbs. However, in practice, antihypertensive therapy can evoke or worsen symptoms of intermittent claudication.

Both in clinical and experimental hypertension, treatment with $\beta$-blockers (Smits et al., 1982; Van Baak et al., 1985; Roberts et al., 1987b) or ACEinhibitors (Novo et al., 1982; Richer et al., 1983, 1987; Ferrara et al., 1984; Smits and Struyker-Boudier, 1984; Ventura et al., 1985; Roberts et al., 1987b) has been described to reduce, to increase or to have no effect on skeletal muscle blood flow. In contrast, calcium entry blockers have been described to reduce vascular resistance and thereby increase blood flow in skeletal muscle of hypertensive patients and animals (review Struyker-Boudier et al., 1989).

Blood flow in skeletal muscle of hypertensive patients with intermittent claudication reacts differently from that in patients with uncomplicated hyperten sion. In the former group, $\beta$-blockers and calcium entry blockers have no effect or decrease blood flow. This results in unchanged or worsened symptoms in these patients (Lepäntalo, 1984; Hiatt et al., 1985; Roberts et al., 1987a; Angersbach and Nicholson, 1988; Bernardi et al., 1988). This contrast between hypertensive patients and hypertensive patients with intermittent claudication may be due to the "steal" phenomenon. Non-specific vasodilatation results in a predominant increase of blood flow to the non-ischemic skeletal muscles and a further decrease in the ischemic skeletal muscles. Chronic treatment with the ACE-inhibitor captopril, however, has no effect or even improves exercise tolerance in hypertensive patients with intermittent claudication (Catalano and Libretti, 1985; Roberts et al., 1987a; Bernardi et al., 1988). An increase in blood flow in ischemic skeletal muscle has been demonstrated for enalapril by Sonecha et al. (1990). The beneficial effects of captopril have been suggested to be the consequence of preferential vasodilatation of the collaterals (Bernardi et al., 1988). Differences in activation of local renin angiotensin systems in ischemic and non-iscehmic limbs may contributed to preferential vasodilatation of collaterals.

The influence of antihypertensive therapy in intermittent claudication on development of collaterals in skeletal muscle is not yet clear. In normal animals increase in flow in skeletal muscle following chronic treatment with dipyridamole (Tornling et al., 1980; Ljungqvist et al., 1984) and the vasodilators prazosin (Dawson and Hudlicka, 1989; Ziada et al., 1989), adenosine (Ziada et al., 1984), HWA 285 (Ziada et al., 1984) and isoprenaline (Sillau and De Lourdes Philippi, 1987) resulted in an increased capillarity of skeletal muscle. However, an increase in skeletal muscle blood flow following chronic treatment with pentoxifylline or torbafylline in animals with chronic ischemia of skeletal muscle resulted not in an increase in capillarity (Hudlicka and Price, 1990a). 


\subsection{THE AM OF THE PRESENT THESIS}

The aim of the present thesis is to investigate the functional role of local renin angiotensin systems (RAS) in normal and pathophysiological situations related to ischemia.

The role of local RAS in the regulation of regional blood flow in conscious animals with hypertension or myocardial infarction has been investigated with two structurally different ACE-inhibitors, captopril and enalaprilate, at nonhypotensive doses (chapter 3 ).

The investigations in chapter 3 suggested a role for local RAS in the regulation of regional blood flow and therapeutic effects of ACE-inhibitors. Further investigations concerning local RAS were required. Therefore, an animal model was used to investigate local RAS without interference of circulating components of the RAS (chapter 4). In this animal model the functional role of vascular ACE in exogenous angiotensin I responses and the inhibition of vascular ACE by four structurally different ACE-inhibitors, captopril, enalaprilate, lisinopril and zabiciprilate, were investigated (chapter 5).

As local RAS have been suggested to play a role in ischemic situations of heart and brain, this system may play also a role in ischemia of skeletal muscle. Therefore, an animal model was used in which skeletal muscle ischemia was induced by partial occlusion of the common iliac artery. First of all, changes in reactivity of the ischemic vascular bed and the role of the local RAS were investigated following acute and chronic ischemia (chapter 6). The role of local RAS in chronic ischemia of skeletal muscle was further elucidated by analysis of reactivity of the ischemic vascular bed following chronic treatment with the ACE-inhibitors captopril and zabiciprilate, the $\mathrm{AT}_{1}$-receptor antagonist DuP753 or the calcium entry blocker felodipine (chapter 7).

Changes in reactivity may depend on structural changes due to a decreased flow and pressure in the ischemic vascular bed, but may also depend on changes in ultrastructure or receptor coupled mechanisms. These possibilities were investigated in vitro with femoral arteries of the ischemic and contralateral vascular bed (chapter 8 ).

Blood flow in the ischemic muscles has been suggested to be restored by development of collaterals, which implies recruitment of pre-existing vessels and growth of new vessels. To investigate the role of neovascularization in ischemic muscles, capillarity was determined in two metabolic different skeletal muscles, the gastrocnemius and soleus muscle. Furthermore, the role of local RAS in neovascularization was elucidated by chronic treatment with the drugs described above (chapter 9 ).

Data obtained in the different studies in this thesis will be integrated and discussed (chapter 10). 


\section{CHAPTER 2}

\section{Materials and methods}

\section{$2.1 \quad$ ANIMALS}

In all experiments described in this thesis, male adult Wistar-Kyoto (WKY) or spontaneously hypertensive rats (SHR) were used. Animals were derived from the original WKY and SHR strains and bred at the Central Animal Facilities of the University of Limburg (Maastricht, the Netherlands). The animals weighed between 250-350 gram at the start of the experiments.

They were housed in groups of up to 4 rats and had free access to standard lab food (Hope Farms, type RMH-TM, Woerden, the Netherlands) and tap water. After implantation of experimental instruments, rats were housed separately.

\subsection{SURGERY}

\subsubsection{Coronary artery ligation}

Myocardial infarction was induced in Wistar-Kyoto rats by ligation of the left descending coronary artery (Pfeffer et al., 1979; Schoemaker et al., 1990). Animals were anesthetized with pentobarbital $(60 \mathrm{mg} / \mathrm{kg}$ i.p.) and the trachea was intubated (PE-240). Skin and muscle overlying the 4th left intercostal space 
were separated and cut. To prevent ventricular arrhythmias, $2 \mathrm{mg} / \mathrm{kg}$ lidocaine was given prophylactically i.m. (Lepràn et al., 1983). After starting respiration with room air $(60$ strokes $/ \mathrm{min}$, tidal volume $3 \mathrm{ml})$, the thorax was opened and the heart was exteriorized. A 6-0 silk suture was passed under the left descending coronary artery near the origin of the pulmonary artery. After returning the heart to its normal position, the suture was tied. The ribs were pulled together with 3-0 silk and muscles (5-0 silk) and skin (3-0 silk) were sutured separately. The animals were allowed to recover from surgery for 4 weeks.

\subsubsection{Implantation of electromagnetic flow probe}

Cardiac output (CO) was measured with an electromagnetic (EM) flow probe (Smith and Hutchins, 1979; Smits et al., 1982). Rats were anesthetized with pentobarbital (60 mg/kg i.p.) and the trachea was intubated (PE-240). The skin and muscles overlying the 3 rd right intercostal space were separated and cut. After starting respiration with room air ( 60 strokes $/ \mathrm{min}$, tidal volume $3 \mathrm{ml}$ ), the thorax was opened. The ribs were spread with a small retractor and the aorta was dissected free. An EM-probe (2.7mm; Skalar, Delft, the Netherlands) was placed around the ascending aorta just above the heart. The thorax was closed by pulling the ribs together with 3-0 silk and the probe cable was fixed to the ribs. Muscles were sutured separately with 5-0 silk. The probe cable was guided to the neck, where the connector was fixed to the skin. The skin was sutured (3-0 silk) and subatmospheric intrathoracic pressure was restored by inserting a silastic drain through a stab wound between the 6th and 7th rib and application of a negative pressure of $10 \mathrm{~cm} \mathrm{H}_{2} \mathrm{O}$. The surgery was carried out under aseptic conditions. The animals were allowed to recover from surgery for 3-6 days.

\subsubsection{Implantation of Doppler flow probes}

Regional blood flows were measured using a $20 \mathrm{MHz}$ directional pulsed Doppler system with miniaturized flow probes (Haywood et al., 1981; Smits and Struyker-Boudier, 1984). The animals were anesthetized with pentobarbital (60 $\mathrm{mg} / \mathrm{kg}$ i.p.) and the abdomen was opened. Intestines were carefully put aside in saline-wetted gauze. The left renal artery, the superior mesenteric artery and the abdominal aorta, distal to the iliolumbar arteries, were dissected free. The Doppler flow probes $(0.6-1.2 \mathrm{~mm})$ were placed on these arteries and the cables were guided out of the abdomen after being fixed to the abdominal wall. The cables of the renal flow probe were also fixed to the renal capsule. After closing the abdomen the cables were guided to the neck. They were connected to a miniature connector, which was mounted on the animal's skull with jeweller's screws and dental cement. The animals were allowed to recover from surgery for 3-6 days. 


\subsubsection{Implantation of catheters}

\section{Arterial blood pressure: abdominal aorta}

To perform direct measurement of blood pressure, animals were equipped with a catheter constructed from a $7-\mathrm{cm}$ piece of $\mathrm{PE}-10$ tubing, heat-sealed to a $12.5-\mathrm{cm}$ piece of PE-50 tubing. The other end of the PE-50 tubing was heatsealed to a $1-\mathrm{cm}$ piece of PE-100 tubing. A $5-\mathrm{cm}$ piece of vinyl tubing (Serva TT63) was slid over the PE-100 tubing and fixed tightly with 2-0 silk. Finally, the PE-10 tubing was bent into a J-shape by dipping it into boiling water, and cut to a length of $4 \mathrm{~cm}$.

The abdominal aorta was cannulated via either the left or right femoral artery. Under light ether anesthesia, a small incision was made in the groin and the femoral artery was freed from connective tissue. After clamping the artery with 4-0 silk sutures, a small hole was cut in the vessel and the PE-10 catheter inserted. The tip was advanced for $4 \mathrm{~cm}$ into the artery so that its tip was approximately $1 \mathrm{~cm}$ above the bifurcation and below the renal arteries. The catheter was secured to the artery (4-0 silk) and to the underlying hindlimb muscle (3-0 silk) and guided subcutaneously to the neck where it was exteriorized and anchored to the neck muscle with a 2-0 silk suture. The catheter was filled with $0.9 \% \mathrm{NaCl}$, containing 5-15 IU heparin $/ \mathrm{ml}$, and closed with a metal plug. The animals were allowed to recover from catheter implantation surgery for at least one day.

\section{Arterial blood pressure: carotid artery}

To perform direct measurement of blood pressure in animals with a partial occlusion of the left common iliac artery, animals were equipped with a catheter constructed from a 3-cm piece of PE-50 tubing, heat-sealed to a 1-cm piece of PE-100 tubing. A 5-cm piece of vinyl tubing (Serva TT63) was slid over the PE-100 tubing and fixed tightly with 2-0 silk.

The left carotid artery was cannulated under light ether anesthesia. A small incision was made in the throat and the left carotid artery was freed from connective tissue. After clamping the artery with 4-0 silk sutures, a small hole was cut in the vessel and the PE-50 catheter was inserted for $2.5 \mathrm{~cm}$. The catheter was secured to the artery and exteriorized in the neck in the same way as described for the abdominal aorta catheter. The catheter was filled with $0.9 \%$ $\mathrm{NaCl}$, containing 5-15 IU heparin/ml, and closed with a metal plug.

\section{Arterial blood pressure: saphenous artery}

To perform direct measurements of blood pressure in both saphenous arteries in animals with a partial occlusion of the left common iliac artery (section 2.2.5), animals were acutely equipped with catheters constructed from a $40-\mathrm{cm}$ piece of PE-10 tubing slid over an injection needle $(0.3 \mathrm{~mm})$. 
The saphenous arteries were cannulated under light ether anesthesia. Therefore, an incision was made in the calf of both hindlimbs and the saphenous arteries were freed from connective tissue. After clamping the artery with 4-0 silk sutures and dilatation of the vessel with lidocain $\left(X y l o c a r \mathbb{R}^{\mathbb{R}}, 20 \mathrm{mg} / \mathrm{ml}\right)$, the needle was inserted into the vessel and fixed with the silk sutures. The catheter was connected to a low-volume displacement pressure transducer (section 2.3.1).

\section{Central venous pressure}

The catheter for central venous pressure (CVP) measurements was constructed of a 10-cm piece of Silastic (602-175) tubing slid over a $21-\mathrm{cm}$ piece of PE-50 tubing. The PE-50 tubing was bent at the end in a J-shape as described above. Two small rims were made at $12.5 \mathrm{~cm}$ from the J-shape in order to suture the catheter to the neck muscle.

The thoracic vena cava was cannulated via either the right or left femoral vein. Under light ether anesthesia, a small incision was made in the groin and the femoral vein was freed from connective tissue. After clamping the vein with 4-0 silk, a small hole was cut in the vessel. The Silastic tubing was cut to the appropriate length, measured from the hole in the vessel to the lower point of the sternum. After inserting the Silastic tubing, the catheter was secured with silk and exteriorized in the neck in the same way as described for the abdominal aorta catheter. The catheter was filled with $0.9 \% \mathrm{NaCl}$, containing 5-15 IU heparin/ml, and closed with a metal plug.

\section{Intravenous drug administration}

For intravenous (i.v.) injections of drugs, the animals were equipped with a catheter, constructed of a $7-\mathrm{cm}$ piece of PE-10 tubing, heat-sealed to a $20-\mathrm{cm}$ piece of PE-50 tubing. The PE-10 tubing was bent in a J-shape as described above and cut to a length of $4 \mathrm{~cm}$. Two rims were made $12.5 \mathrm{~cm}$ from the seal between PE-10 and PE-50 in order to suture the catheter to the neck muscle.

The vena cava inferior was cannulated via either the right or left femoral vein. Under light ether anesthesia, a small incision was made in the groin and the femoral vein was freed from connective tissue. After clamping the vein with 4-0 silk, a small hole was cut in the vessel and the PE-10 catheter was inserted for $4 \mathrm{~cm}$. After securing the catheter to the vessel and underlying hindlimb muscle, it was guided to the neck as described for the abdominal aorta catheter. The catheter was filled with $0.9 \% \mathrm{NaCl}$, containing $5-15 \mathrm{IU}$ heparin/ml, and closed with a metal plug. 


\subsubsection{Chronic hindlimb ischemia}

The abdomen was opened under light ether anesthesia. The left common iliac artery was dissected free. Partial occlusion of the artery was performed by firmly tying a stainless steel wire $(0.15$ or $0.3 \mathrm{~mm})$ against the side of the vessel with a 4-0 silk suture, which resulted in complete occlusion of the vessel lumen. The stainless steel wire was then removed, leaving the silk suture ligature intact and allowing the vessel to expand to the diameter of the wire. To avoid normal blood supply to the left hindlimb, in addition the left iliolumbar artery was occluded completely with a 4-0 silk suture (personal communication Dr $\mathrm{H}$. Nievelstein, Solvay Duphar, Weesp, the Netherlands). After closing the abdomen (3-0 silk) the animals were allowed to recover for 4 weeks before hindlimb perfusion experiments or blood pressure measurements. In hindlimb perfusion experiments, in detail described in chapter 4 , the degree of ischemia was computed as

$$
\% \text { residual flow }=\frac{F_{L}}{F_{R}} * 100 \%
$$

where $\mathrm{F}_{\mathrm{L}}=$ basal left flow; $\mathrm{F}_{\mathrm{R}}=$ basal right flow in the hindlimb perfusion experiments.

\subsubsection{Femoral artery isolation}

The left and right femoral arteries of animals with chronic ischemia of left hindlimb were isolated 4 weeks after chronic ischemia surgery (section 2.2.5) and immediatedly after blood pressure measurements in the saphenous arteries (section 2.3.1). The femoral arteries were isolated from the peritoneum to the trifurcation of the deep femoral, the saphenous and the superficial epigastric arteries. The femoral vessels were divided into a proximal and distal segment. The proximal segment was used for determination of DNA content (section 2.6), whereas 1 to $2 \mathrm{~mm}$ of the distal segment was used in myograph experiments (section 2.3.4).

\subsection{MEASUREMENTS}

\subsubsection{Hemodynamic measurements}

After recovery from surgery, the animals were placed in plastic experimental cages $(22 \times 13 \times 13 \mathrm{~cm})$ on sawdust, and connected to the measuring equipment.

Cardiac output: the EM-probe was connected to a sine-wave electromagnetic flow meter (Transflow 601 system, type MDL400, Skalar, Delft, the Nether- 
lands). Late diastolic flow was taken to be zero and mean blood flow was used as a measure for $\mathrm{CO}$. Furthermore, heart rate (HR) was obtained from the flow signal. Signals were recorded on a Grass 7D polygraph (Grass Instruments, Quincy, Mass, USA) or by a real-time data processing system (Instrumental Services of the University of Limburg, Maastricht, the Netherlands). Mean signals were obtained by low-pass filtering $(0.5 \mathrm{~Hz})$ of the signal.

Regional blood flows: the Doppler flow probes, placed on renal and mesenteric artery and abdominal aorta, were connected to a 4-channel $20-\mathrm{MHz}$ directional pulsed Doppler system (Bio-engineering Resource Facility, University of Iowa, Iowa City, la, USA). Renal (RF), mesenteric (MF) and hindquarter blood flow (HQF) were measured as $\mathrm{kHz}$ Doppler shift, which is directly and linearly proportional to volume flow (Haywood et al., 1981). Zero blood flow was determined electronically and mean flows were obtained by low-pass filtering $(0.5 \mathrm{~Hz})$. Signals were recorded on a computerized processing system.

Arterial blood pressure: the catheter was connected to a low-volume displacement pressure transducer (CP-01, Century Technology Company, Inglewood, CA, USA; 150PC flow-thru pressure sensor, Micro Switch, Freeport, Ill, USA). The transducer was calibrated from 0 to $200 \mathrm{mmHg}$ using a mercury manometer. The signal was recorded on a Grass 7D polygraph (Grass Instruments, Quincy, Mass, USA) or on a computerized system. Low-pass filtering $(0.5 \mathrm{~Hz})$ of the signal resulted in mean arterial pressure (MAP). In some experiments, HR was obtained from the pulsatile signal using a tachograph (Grass polygraph).

Saphenous artery blood pressure: measurements were performed under light ether anesthesia. Furthermore, the procedure of blood pressure measurements was similar to arterial blood pressure measurements. The catheter was connected to an identical low-volume displacement pressure transducer as described above, which was calibrated with a mercury manometer from 0 to $120 \mathrm{mmHg}$. Recordings of the signals were made on a Grass $7 \mathrm{D}$ polygraph.

Central venous pressure: the procedure of CVP measurements was similar to arterial blood pressure measurements. The catheter was connected to an identical low-volume displacement transducer as described above, which was calibrated for CVP with a water manometer from 0 to $20 \mathrm{~cm} \mathrm{H}_{2} \mathrm{O}$. Recordings of the signals were made on a Grass $7 \mathrm{D}$ polygraph or on a computerized system. Mean pressure was obtained by low-pass filtering $(0.5 \mathrm{~Hz})$ of the pulsatile signal.

\section{Calculations: hemodynamic measurements}

Tolal peripheral resistance (TPR) was calculated from MAP, CVP and CO according to

$$
T P R=\frac{(M A P-C V P)}{C O}
$$


Renal (RR), mesenteric (MR) and hindquarter resistances (HQR) were calculated from MAP and corresponding flows.

\subsubsection{Hindlimb perfusion}

For hindlimb perfusion experiments a modified preparation of Ross (1972) was used. Surgery, perfusion, measurements, calculations and other characteristics of hindlimb perfusion experiments will be described in detail in chapter 4 .

\subsubsection{Acute hindlimb ischemia}

After initiating the hindlimb perfusion (section 4.2.1) the preparation was allowed to equilibrate. Partial occlusion of the left common iliac artery was performed by placing a tantalum clip $(0.2 \mathrm{~mm}$; Ligaclip LC100; Ethicon, Norderstedt, Germany) on the vessel or by firmly tying a stainless steel wire $(0.3 \mathrm{~mm})$ against the side of the vessel with a 4-0 silk suture, which resulted in complete occlusion of the vessel lumen. The stainless steel wire was then removed, leaving the silk suture intact and allowing the vessel to expand to the diameter of the wire. To calculate the degree of ischemia, blood flow in the left common iliac artery was obtained just before partial occlusion and 30 minutes after occlusion. Hindlimb perfusion experiments were started 45 minutes after partial occlusion.

\section{Calculations: acute ischemia}

Degree of ischemia of the left hindlimb was computed as

$$
\% \text { residual flow }=\frac{F_{\text {Lbefore }}}{F_{\text {Laffer }}} * 100 \%
$$

where $\mathrm{F}_{\mathrm{Lbefore}}=\mathrm{F}_{\mathrm{L}}$ before ischemia; $\mathrm{F}_{\mathrm{Lafter}}=\mathrm{F}_{\mathrm{L}} 30$ min after ischemia.

\subsubsection{Myograph experiments}

The femoral artery segments (1-2 mm lenght; section 2.2.6) were mounted horizontally in a myograph (Mulvany and Halpern, 1977; De Mey et al., 1989). The vessel segments were fixed with two stainless steel wires $(40 \mu \mathrm{m})$. One of the wires was connected to an isometric force transduced (Kistler Morse DSC6, Seattle, Wa, USA) and the other to a displacement device. The myograph chamber contained a Krebs-Ringer solution (KRB; $\mathrm{NaCl}$ : $118.5 \mathrm{mM} ; \mathrm{MgSO}_{4}$ : $1.2 \mathrm{mM} ; \mathrm{KH}_{2} \mathrm{PO}_{4}: 1.2 \mathrm{mM} ; \mathrm{NaHCO}_{3}: 25 \mathrm{mM} ; \mathrm{CaCl}_{2}: 2.5 \mathrm{mM} ; \mathrm{KCl}: 4.7 \mathrm{mM}$; glucose: $11.1 \mathrm{mM}$ ), which was maintained at $37^{\circ} \mathrm{C}$ and gassed with $95 \% \mathrm{O}_{2}$ and $5 \% \mathrm{CO}_{2}$. For calcium-free $\mathrm{KRB}, \mathrm{CaCl}_{2}$ was excluded. To obtain high 
$\mathrm{KRB}$, all $\mathrm{NaCl}$ was replaced by an equimolar amount of $\mathrm{KCl}$. Potassium concentrations between 5.9 and $125 \mathrm{mM}$ in KRB were prepared by appropriate mixing of normal KRB and high potassium KRB.

In all experiments, a segment of the right and left femoral artery from the same rat were mounted in the same chamber and were studied in parallel. Recordings of the levels of force were made on a recorder (MC6624, Graphtec, USA).

\section{Calculations: myograph experiments}

Wall tension was computed as

$$
W T=\frac{\text { force }}{2 * L}
$$

where $W T=$ wall tension $(\mathrm{mN} / \mathrm{mm}) ; \mathrm{L}=$ lenght of wessel segment $(\mathrm{mm})$; (Mulvany and Warshaw, 1979).

Wall tension in calcium-free KRB could not be reduced by any vasodilator tested and represented resting wall tension (RWT). From wall tension during activation of the vessel segments at a defined diameter RWT was subtracted to obtain active wall tension $\left(A W T_{D}\right)$. Optimal diameter $\left(D_{\text {op }}\right)$ was the diameter at which the largest AWT ( $A W T_{\text {max }}$ ) could be recorded.

The diameter of resting vessels exposed to a transmural pressure of 100 $\mathrm{mmHg}\left(\mathrm{D}_{100}\right)$ was determined as the intercept of the curve fitted according to (5) with the isobar derived from Laplace's law (6) at $100 \mathrm{mmHg}$.

$$
R W T=A * e^{a D}
$$

where $\mathrm{RWT}=$ resting wall tension $(\mathrm{mN} / \mathrm{mm}) ; \mathrm{A}=$ constant; $\beta=$ index for stiffness of the resting vascular wall $\left(\mathrm{mm}^{-1}\right) ; D=$ lumen diameter $(\mathrm{mm})$; (Freslon and Guidicelli, 1985).

$$
W T=P * \frac{D}{2}
$$

where WT $=$ wall tension $(\mathrm{mN} / \mathrm{mm}) ; \mathrm{P}=$ constant transmural pressure of 100 $\mathrm{mmHg}\left(13.3 \mathrm{mN} / \mathrm{mm}^{2}\right) ; \mathrm{D}=\|$ umen diameter $(\mathrm{mm})$.

\section{$2.4 \quad$ HISTOLOGY}

\subsubsection{Infarct size measurements}

At the end of the central and regional hemodynamic experiments the rats with induced myocardial infarction were anesthetized with pentobarbital and hearts were arrested in diastole with a saturated $\mathbb{K C l}$ solution i.v. The hearts were 
excised and washed in saline, vessels and atria were removed and ventricles were quickly frozen $\left(-80^{\circ} \mathrm{C}\right)$ to be cut into slices of $1 \mathrm{~mm}$ from apex to base. The slices were stained with nitro blue tetrazolium (NBT) according to Lepràn et al (1983). Briefly, the slices were incubated in $1 \mathrm{mg} / \mathrm{ml} \mathrm{NBT}$ in $0.1 \mathrm{M}$ Sörensen phosphate buffer $\left(\mathrm{KH}_{2} \mathrm{PO}_{4}: 0.02 \mathrm{M} ; \mathrm{Na}_{2} \mathrm{HPO}_{4}: 0.08 \mathrm{M} ; \mathrm{pH}=7.4\right)$ at $37^{\circ} \mathrm{C}$ for approximately $15 \mathrm{~min}$, and subsequently placed in distilled water. This procedure stains all tissue that was vital at the time of death. The free wall of the right ventricle was removed from each slice. Color pictures were taken from the remaining left ventricle slices including the septum. The lengths of the infarcted circumference $\left(\mathrm{IC}_{\mathrm{en}}\right)$ and the total circumference $\left(\mathrm{TC}_{\mathrm{en}}\right)$ of the endocardial surface and the lengths of the infarcted circumference $\left(\mathrm{IC}_{\mathrm{ep}}\right)$ and the total circumference $\left(\mathrm{TC}_{\mathrm{ep}}\right)$ of the epicardial surface were determined by planimetry (Pfeffer et al., 1985). For all slices of one heart, $I C_{\text {en }}, T_{e n}, I C_{e p}$ and $T_{\text {sp }}$ were summarized, whereafter infarct size of endocardial and epicardial surfaces were calculated. Final infarct size was expressed as percentage of left ventricular circumference, calculated as the average of endocardial and epicardial infarct size (Schoemaker et al., 1991).

$$
\text { INFARCT SIZE }=\left[\frac{\sum\left(I C_{e n}\right)}{\sum\left(T C_{e n}\right)}+\frac{\sum\left(I C_{e p}\right)}{\sum\left(T C_{e p}\right)}\right] * 0.5 * 100 \%
$$

\subsubsection{Skeletal muscle}

\section{Skeletal muscle: staining}

After hindlimb perfusion experiments or blood pressure measurements, soleus (SOL) and gastrocnemius muscle (GAS) of both hindlimbs were excised, frozen in liquid nitrogen and stored at $-20^{\circ} \mathrm{C}$. Sections $(12 \mu \mathrm{m})$ from SOL and GAS were cut transversely on the cryostat microtome (Cryostat 1720, Leitz-Wetzlar, Germany), and stained for alkaline phosphatase within capillary endothelium, using indoxyl-tetrazolium staining (Ziada et al., 1984).

After fixation in acetone for 5 min at $4^{\circ} \mathrm{C}$, muscle slides were stained in 30 $\mathrm{ml}$ buffer $\mathrm{A}\left(\mathrm{MgSO}_{4}: 6.9 \mathrm{mM} ; \mathrm{NaBO}_{2}: 27.5 \mathrm{mM}\right)$, containing $1 \mathrm{mg} / \mathrm{ml}$ nitroblue tetrazolium and $0.2 \mathrm{mg} / \mathrm{ml} 4$-chloro 3-indolyl phosphate p-toluidine salt

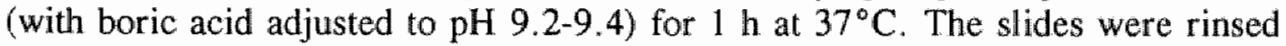
with buffer $\mathrm{A}$ and post-fixed in sucrose-buffered formalin (4\% formaldehyde; 300 mOsmol sucrose; $\mathrm{pH} \mathrm{7.3)}$ for $5 \mathrm{~min}$. After rinsing with water, the slides were counterstained with eosin $(0.1 \% \mathrm{w} / \mathrm{v}$ eosin in $70 \%$ alcohol) for $1-2 \mathrm{sec}$, rinsed with water and mounted with Immumount ${ }^{R}$ (Shandon, Runcorn, England). 
To distinguish between type I and type II-muscle fibers, GAS muscle slides were also stained for type II-muscle fibers with antimyosin type I $R_{11} D_{10}$. Therefore, muscle slides were dehydrated with alcohol $(70 \%, 96 \%$ and $100 \%)$, placed in $0.3 \% \mathrm{H}_{2} \mathrm{O}_{2}$ in methanol for 20 min to block endogenous peroxidase, rinsed with Tris Buffered Saline (TBS; $\mathrm{NaCl}$ : $137 \mathrm{mmol} / \mathrm{l}$; Tris: $5 \mathrm{mmol} / \mathrm{l}$; with $\mathrm{HCl}$ adjusted to $\mathrm{pH} 7.6$ ) and preincubated with normal rabbit serum for 20 min. After removing the serum, slides were incubated with a monoclonal antibody $\mathrm{R}_{11} \mathrm{D}_{10}$ (Centocor Europe, Leiden, the Netherlands; $1: 10000$ in TBS/1\% bovine serum albumin (BSA) $10.1 \%$ Tween $20 ; \mathrm{pH} \mathrm{7.6)}$ for $45 \mathrm{~min}$, followed by incubation with a polyclonal Rabbit AntiMouse PerOxidase labeled antibody (RAMPO; Dako, Glostrup, Denmark; $1: 200$ in TBS/1\% BSA/0.1\% Tween 20; $\mathrm{pH}$ 7.6) for $45 \mathrm{~min}$ to visualize the monoclonal antibody $R_{11} \mathrm{D}_{10}$. Before and after incubation with the polyclonal antibody RAMPO, the slides were rinsed 3 times with TBS for $5 \mathrm{~min}$. The slides were stained in $9 \mathrm{ml}$ Tris buffer (Tris:

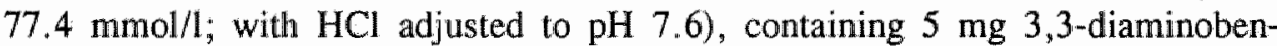
zidin, $1 \mathrm{ml} 0.1 \mathrm{~N}$ imidazol and $5 \mu \mathrm{l} 30 \% \mathrm{H}_{2} \mathrm{O}_{2}$ for $3-5 \mathrm{~min}$. After rinsing with water, the slides were counterstained with eosin, rinsed with water and mounted with Immumount ${ }^{\mathrm{R}}$.

\section{Skeletal muscle: measurements}

The origin of all samples for morphometry was blinded to the investigator. The number of capillaries and fibers in SOL and GAS of both hindlimbs were counted microscopically ( $250 \mathrm{X}$ magnification), using a graphic tablet, optically projected into a standard microscope and coupled to a computer (KONTRON, DIGITAL). Furthermore, fiber size was measured in SOL and GAS and total muscle size in SOL of both hindlimbs. In each section of SOL, 8 randomly chosen fields were counted (encompassing $\approx 250-600$ fibers), whereas in each section of GAS, 10 randomly chosen fields only in the type II-muscle fiber part were counted (encompassing $\approx 300-500$ fibers).

\section{Skeletal muscle: calculations}

Capillary to fiber ratio (C/F) was computed for each SOL and GAS muscle and total number of fibers in SOL was computed as

$$
F_{\text {toral }}=\frac{F}{F S} * M S
$$

where $F_{\text {total }}=$ total fiber number; F/FS $=$ fiber number/field size; MS = total muscle size $\left(\mu \mathrm{m}^{2}\right)$. 


\subsubsection{Femoral artery}

Femoral artery: staining

Vessel segments fixed ( $4 \%$ phoshate buffered formalin, $\mathrm{pH} 7.4$ ) at the optimal diameter at the end of the experiments in the myograph (section 2.3.4) were embedded in paraffin (Paraplast ${ }^{+}$, Sherwood, St. Louis, Missouri, USA) and cross sectioned ( $4 \mu \mathrm{m}$; microtome type 820 , American Optical, USA; Boonen et al., 1991; De Mey et al., 1991). The sections were stained for elastin, using a modified Elastin-Van Gieson staining method.

After dissolving the paraffin in xylene ( 2 times for $5 \mathrm{~min}$ ), the slides were stained in Lawson solution (Boom, Meppel, the Netherlands) for 30 min at room temperature. The staining was differentiated in $70 \%$ alcohol, whereafter the slides were rinsed with water. After dehydration with alcohol $(70 \%, 96 \%$ and $100 \%$ ), the slides were rinsed with xylene and mounted with Entellan ${ }^{\mathbb{R}}$ (Merck, Darmstadt, Germany).

Furthermore, comparable sections were stained with hematoxylin-eosin (1-2 $\mathrm{sec})$, rinsed with water and mounted with Entellan ${ }^{\mathbb{R}}$.

\section{Femoral artery: measurements}

In the sections stained with Elastin-Van Gieson, internal circumference (IC) was measured by edge tracking of the internal elastic lamina, and media cross sectional area (CSA) was determined by planimetry of the area enclosed between the internal and external elastic lamina (Boonen et al., 1991; De Mey et al., 1991). Therefore, the slides were optically projected into a standard microscope (50 X magnification; Zeiss Axioskop, Germany) coupled to a computer by a video camera (VS 450, Stemmer, Germany). Measurements were performed using commercially available software (JAVA, Jandell, San Francisco, Ca, USA).

In the sections stained with hematoxylin-eosin the number of the arterial smooth muscle cell nuclei was counted using a standard microscope (400 X magnification). The nuclear density (ND) was calculated from the number of nuclei and cross sectional area (CSA).

\section{Femoral artery: calculations}

The lumen diameter of the femoral artery (presumed to be a circular preparation) was computed as

$$
D_{\text {opt }}=\frac{I C}{\pi}
$$

where $D_{\text {opt }}=$ optimal lumen diameter; $I C=$ internal circumference. 
Mean media thickness was determined from

$$
C S A=\pi\left(\frac{D_{o p t}}{2}+M_{b}\right)^{2}-\pi\left(\frac{D_{o p t}}{2}\right)^{2}
$$

where CSA $=$ cross sectional area; $D_{\text {opt }}=$ optimal lumen diameter; $M_{t}=$ mean media thickness.

Active wall stress was determined only in vessel segments fixed at optimal diameter $\left(D_{\text {opip }}\right)$ in myograph experiments (section 2.3.4). Active wall stress was computed as

$$
A W S=\frac{A W T}{M_{r}}
$$

where AWS = active wall stress; $\mathrm{AWT}=$ active wall tension (section 2.3.4); $\mathrm{M}_{\mathrm{t}}=$ mean media thickness.

\subsection{PLASMA ACE ACTIVITY}

Heparinized blood samples were drawn into vials, centrifuged at $4^{\circ} \mathrm{C}$ to separate plasma from blood cells and frozen at $-20^{\circ} \mathrm{C}$ until assayed or immediately analyzed after blood sampling if plasma contained captopril.

Plasma samples were assayed using a commercial available radioassay test set (Ventrex Labs, Portland, Maine, USA). After dilution of $50 \mu \mathrm{l}$ plasma with $200 \mu \mathrm{l}$ of $0.05 \mathrm{M}$ Hepes buffer ( $\mathrm{pH} 8.0 ; 0.1 \%$ sodium azide) or with $75 \mu \mathrm{l}$ if plasma contained an angiotensin-converting enzyme inhibitor, $50 \mu \mathrm{l}$ of ACE substrate ( ${ }^{3} \mathrm{H}$-Hippuryl-Glycyl-Glycine solution) was added to $50 \mu \mathrm{l}$ of diluted plasma. Diluted plasma and ACE substrate were incubated at $37^{\circ} \mathrm{C}$ for 60 minutes. Incubation was stopped with $1.0 \mathrm{ml}$ of $0.1 \mathrm{~N} \mathrm{HCl}$ and $1.0 \mathrm{ml}$ ethyl acetate. After mixing for 4-5 seconds on a Vortex mixer, the solution was centrifuged at $2200 \mathrm{r}$. p.m. for 10 minutes. $300 \mu \mathrm{l}$ of the upper ethyl acetate layer and $10 \mathrm{ml}$ of scintillation fluid (Formula-989, NEN Research Products, Boston, Massachusetts, USA) were counted for $1 \mathrm{~min}$ in a liquid scintillation counter (Beckman LS1801, USA).

ACE-activity, expressed as nanomoles of hippuric acid generated in $1 \mathrm{~min}$ per $\mathrm{ml}$ plasma, was calculated according to a standard formula of the radioassay test set.

\subsection{DNA CONTENT}

Arterial DNA content was determined according to an assay previously described by Labarca and Paigen (1980) and modified by Brayden et al (1983) and De Mey et al (1991). The proximal femoral artery segments (section 2.2.6) were gently pulled over the shaft of a hypodermic needle $(0.5 \mathrm{~mm})$ to clear the 
lumen and to remove the endothelium, whereafter the segments were solubilized overnight in $100 \mu \mathrm{l} 1 \mathrm{~N} \mathrm{NaOH}$. Thereafter, $10 \mu$ s samples were neutralized in 1 $\mathrm{ml}$ phosphate buffer $\left(\mathrm{pH}=7.4 ; 1.05 \mathrm{M} \mathrm{K}_{2} \mathrm{HPO}_{4} .3 \mathrm{H}_{2} \mathrm{O} ; 0.16 \mathrm{M} \mathrm{KH}_{2} \mathrm{PO}_{4}\right.$ ). After adding $1 \mathrm{ml}$ of Hoechst solution $(93.6 \mu \mathrm{l} / \mathrm{h}$ bisbenzimidazole (Hoechst 33258); France Biochem, Bierges, Belgium) and mixing, the DNA content was measured fluorometrically (excitation wave lenght $360 \mathrm{~nm}$, emission wavelenght 460nm; SPF-500C AMINCO spectrofluorometer). Calf thymus DNA (Sigma, St. Louis, MO, USA) was used as a standard.

\section{$2.7 \quad$ STATISTICS}

In the following chapters different statistical methods were used to compare data in several experimental groups.

* Student's t-test for paired observations. This method was used to compare two corresponding values in the same group of rats.

* Student's t-test for unpaired observations. This method was used for comparisons of two groups of unpaired values.

* One-way analysis of variance and a modified t-test for overall comparisons of the experimental groups according to Bonferroni and for multiple comparisons to the same control group according to Dunnett (Wallenstein et al., 1980).

* Two-way analysis of variance and a simple main effects test for comparison of the subgroups (commercial available software Crunch, Crunch Software Corporation, Oakland, Ca, USA).

Data are expressed as means \pm SEM. Differences were regarded to be statistically significant if $\mathrm{p}<0.05$.

\section{$2.8 \quad$ DRUGS}

The following drugs were used in the present thesis:

* $\left[\mathrm{Val}^{5}\right]$-angiotensin I and $\left[\mathrm{Val}^{5}\right]$-angiotensin II, phenylephrine, serotonin, acetylcholine and SIN-1,

* captopril (a generous gift from Bristol-Myers Squibb, Woerden, the Netherlands),

* enalaprilate and lisinopril (a generous gift from Merck Sharp and Dohme, Haarlem, the Netherlands),

* zabiciprilate (a generous gift from Servier, Courbevoie, France),

* DuP753 (losartan; a generous gift from du Pont de Nemours \& Company, Wilmington, Del., USA), and

* felodipine (a generous gift from dr. B. Meems, Astra Pharmaceutica, Rijswijk, the Netherlands).

The structural formulas of the therapeutic agents are represented in figure 2.1. 
CAPTOPPIL<smiles>CC(CS)C(=O)N1CCCC1C(=O)O</smiles>

ENALAPRLATE<smiles>CC(NC(CCc1ccccc1)C(=O)O)C(=O)N1CCCC1C(=O)O</smiles>

LISINOPRIL<smiles>CCC(NC(CCc1ccccc1)C(=O)O)C(=O)N1CCCC1C(=O)O</smiles>

ZABICIPRILATE<smiles>CC(NC(CCc1ccccc1)C(=O)O)C(=O)N1C2CCC(CC2)C1C(=O)O</smiles>

\section{DUP753 $=$ LOSAFTAN}<smiles>[3H]n1nnnc1-c1ccccc1-c1ccc(Cn2c(CCCC)nc(Cl)c2CO)cc1</smiles>

FELOOIPINE

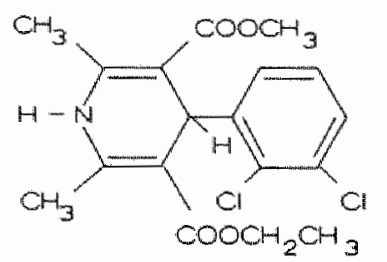

Figure 2.1 Structural formula of the therapeutic agents used in the present thesis. 


\section{CHAPTER 3}

\section{Central and regional hemodynamic effects of non-hypotensive doses of ACE-inhibitors in hypertension and heart failure}

\subsection{INTRODUCTION}

The renin-angiotensin system (RAS) plays an important role in the humoral control of cardiovascular homeostasis. Besides a circulating RAS, local systems have been described (Dzau, 1987a). These latter may play a role in local control of perfusion, and thereby organ function in normal and pathophysiological conditions. Angiotensin I converting enzyme (ACE) inhibitors may inhibit both the local and circulating system (Dzau, 1987a; Cushman et al., 1989a,b). In this respect, the reduction of renal resistance following administration of ACEinhibitors has been suggested to derive from inhibition of a local renal RAS (Drexler et al., 1987; Richer et al., 1987). Interpretation of experiments in which blood pressure is reduced by injection of antihypertensive agents is, however, complicated by possible autoregulatory mechanisms that will tend to maintain blood flow as blood pressure falls. Therefore, in the present chapter we studied the effects of non-hypotensive doses of 2 structurally different ACEinhibitors, enalaprilate and captopril, on regional hemodynamics in the rat. Furthermore, we compared effects in normal rats, spontaneously hypertensive rats and rats with heart failure following myocardial infarction, in order to study the relative contribution of the RAS in these conditions. 


\subsection{MATERIALS AND METHODS}

\subsubsection{Animals}

Experiments were performed in male spontaneously hypertensive rats (SHR) and normotensive Wistar-Kyoto (WKY) rats. Animals weighed $250-350 \mathrm{~g}$ at the start of the protocol.

\subsubsection{Surgery}

\section{Coronary artery ligation}

Myocardial infarction (MI) was induced in a group of WKY rats by coronary artery ligation under pentobarbital anesthesia as described in section 2.2.1. Animals were allowed to recover for 4 weeks before implantation of an electromagnetic flow probe or Doppler flow probes.

\section{Implantation of electromagnetic flow probes}

Under pentobarbital anesthesia animals were implanted with an electromagnetic (EM) flow probe as described in section 2.2.2. Before implantation of the arterial and venous catheters for central hemodynamic experiments, the animals were allowed to recover from surgery for 3-6 days.

Implantation of Doppler flow probes

Animals were implanted under pentobarbital anesthesia with Doppler flow probes on left renal artery, mesenteric superior artery and abdominal aorta as described in section 2.2.3.

Before implantation of arterial and venous catheters for regional hemodynamic experiments, the animals were allowed to recover for 3-6 days.

\section{Implantation of catheters}

In central hemodynamic experiments animals were cannulated with an arterial catheter in abdominal aorta for blood pressure measurements, a venous catheter for i.v. bolus injections and a venous pressure catheter for venous pressure measurements as described in section 2.2.4. In regional hemodynamic experiments animals were cannulated only with an arterial and venous catheter. The animals were allowed to recover from surgery for 1-4 days. 


\subsubsection{Measuring protocols}

\section{Dose finding study}

In pilot experiments, the doses of the ACE-inhibitors which give a comparable inhibition of pressor responses of i.v. angiotensin I, were determined. In anesthetized WKY rats $(280-320 \mathrm{~g})$ rats, cannulated with an arterial and venous catheter, dose response curves of angiotensin I pressor-responses were obtained following saline, enalaprilate, or captopril. The doses used in the following hemodynamic experiments were $3 \mathrm{mg} / \mathrm{kg}$ body weight for captopril and 0.1 $\mathrm{mg} / \mathrm{kg}$ body weight for enalaprilate. The $E D_{50}$ for angiotensin I pressor responses were after saline $0.69 \pm 0.11 \mu \mathrm{g} / \mathrm{kg} \quad(\mathrm{n}=12)$, after enalaprilate $4.84 \pm 0.88 \mu \mathrm{g} / \mathrm{kg}(\mathrm{n}=6)$ and after captopril $7.94 \pm 2.44 \mu \mathrm{g} / \mathrm{kg}(\mathrm{n}=6)$. The $\mathrm{ED}_{50}$ after enalaprilate and captopril were not significantly different and furthermore, the ACE-inhibitors induced a comparable shift (7-11-fold) of the angiotensin II dose-response curve.

\section{Central hemodynamic studies}

The acute effects of saline, captopril, and enalaprilate on central hemodynamics were investigated in conscious WKY, SHR and MI $(n=9-13)$. I.v. bolus injections were given in a random order. The minimal time interval between two experiments within a rat was $48 \mathrm{~h}$. Mean arterial pressure (MAP), heart rate (HR), cardiac output (CO) and central venous pressure (CVP) were measured as described in section 2.3.1.

After equilibration for $45-60 \mathrm{~min}$, baseline values for all variables were obtained during 10-20 min before the bolus injection. Pilot studies showed that maximal inhibition of the pressor response to $0.45 \mu \mathrm{g} / \mathrm{kg}$ angiotensin I by the ACE-inhibitors is obtained at 10-15 min after injection. Therefore, the values of all variables were averaged between 10-15 min after injection of saline or ACEinhibitors.

\section{Regional hemodynamic studies}

Acute effects of saline, captopril, and enalaprilate on regional hemodynamics were investigated in conscious WKY, SHR and MI $(n=13-16)$. Drugs and saline were administered as i.v. bolus injections in a random order. The minimal time interval between two experiments within a rat was $48 \mathrm{~h}$. MAP, HR, renal blood flow (RBF), mesenteric blood flow (MBF) and hindquarter blood flow (HBF) were measured as described in section 2.3.1.

After equilibration for $40-60 \mathrm{~min}$, baseline values for all variables were obtained during 10-20 min before bolus injection. After injection of saline, captopril, or enalaprilate changes in MAP, HR, flows and calculated vascular resistances were averaged over 5 -min periods for $60 \mathrm{~min}$ to determine maximal changes. 
Furthermore, acute effects of bolus injections of angiotensin I (0.017-0.45 $\mu \mathrm{g} / \mathrm{kg})$ on regional hemodynamics were investigated in conscious SHR $(\mathrm{n}=6-8)$.

\subsubsection{Infarct size}

At the end of the experiments the MI rats were killed by arresting the hearts in diastole with $1 \mathrm{ml} \mathrm{KCl} \mathrm{i.v,} \mathrm{under} \mathrm{pentobarbital} \mathrm{anesthesia.} \mathrm{Infarct} \mathrm{sizes} \mathrm{were}$ measured as described in section 2.4.1.

\subsubsection{Data analysis}

At 5 weeks infarcts smaller than $21 \%$ do not have measurable hemodynamic consequences (Schoemaker et al., 1991). Therefore, only rats with infarct sizes larger than $21 \%$ were used in the MI group.

Total peripheral resistance (TPR) was computed as described in section 2.3.1. Vascular resistances (renal vascular resistance: RVR; mesenteric vascular resistance: MVR; hindquarter vascular resistance: HVR) were computed as described in section 2.3.1.

Changes in blood flow and vascular resistance are expressed as percentage changes from control.

Baseline values and the effects of saline and ACE-inhibitors within a rat model were compared by one-way ANOVA and Dunnett's test.

Table 3.1 Baseline values of central hemodynamics in WKY, SHR and MI in central and regional hemodynamic experiments.

\begin{tabular}{|c|c|c|c|}
\hline & WKY & SHR & $M I$ \\
\hline \multicolumn{4}{|c|}{ Central hemodynamic experiments } \\
\hline$H R(b p m)$ & $371 \pm 12$ & $386 \pm 14$ & $341 \pm 5$ \\
\hline$M A P(m m H g)$ & $120 \pm 2$ & $143 \pm 3^{\circ}$ & $106 \pm 3^{*}$ \\
\hline $\mathrm{CO}(\mathrm{ml} / \mathrm{min})$ & $91 \pm 4$ & $97 \pm 4$ & $73 \pm 3 * 6$ \\
\hline $\mathrm{CVP}\left(\mathrm{CmH}_{2} \mathrm{O}\right)$ & $2.55 \pm 0.38$ & $0.80 \pm 0.27^{\circ}$ & $2.65 \pm 0.92$ \\
\hline$T P R(\mathrm{mmHg} \cdot \mathrm{min} / \mathrm{ml})$ & $1.26 \pm 0.10$ & $1.51 \pm 0.07$ & $1.48 \pm 0.09$ \\
\hline Infarct size $(\%)$ & -- & - & $38.6 \pm 1.9$ \\
\hline \multicolumn{4}{|c|}{ Regional hemodynamic experiments } \\
\hline$H R(b p m)$ & $328 \pm 9$ & $324 \pm 4$ & $344 \pm 10$ \\
\hline MAP (mmHg) & $119 \pm 3$ & $148 \pm 3^{*}$ & $109 \pm 3^{*}$ \\
\hline Infarct size $(\%)$ & - & -- & $34.0 \pm 2.9$ \\
\hline
\end{tabular}



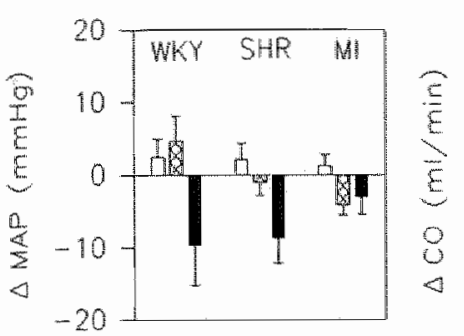
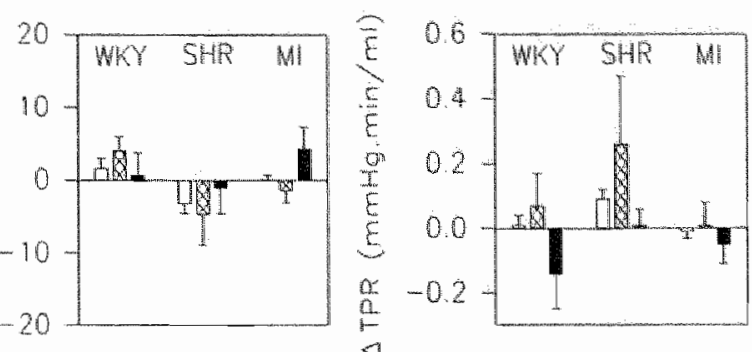

soline enoloprilote $0.1 \mathrm{mg} / \mathrm{kg}$

captopril $3 \mathrm{mg} / \mathrm{kg}$

Figure 3.1 Effects of saline, enalaprilate and captopril on mean arterial pressure, cardiac output, and total peripheral resistance in WKY, SHR and MI rats.

\subsection{RESULTS}

\subsubsection{Central hemodynamics}

Baseline values of central hemodynamics are summarized in table 3.1. MAP was significantly higher in SHR and significantly lower in MI compared to WKY. Furthermore, CVP was significantly lower in SHR compared to WKY and $\mathrm{CO}$ was significantly lower in MI compared to both WKY and SHR.

As seen in figure 3.1, both enalaprilate and captopril at the doses used had no significant effects on MAP (captopril: $-9.7 \pm 5.5,-8.7 \pm 3.5$, and $-3.0 \pm 2.4$ $\mathrm{mmHg}$ in WKY, SHR and MI, respectively), CO and TPR in all three rat models.

\subsubsection{Regional hemodynamics}

Baseline values of MAP and HR in these experiments are summarized in table 3.1. Again, MAP was significantly higher in SHR and significantly lower in MI compared to WKY. As seen in figure 3.2, both ACE-inhibitors had also in these experiment no significant effects on MAP in all three rat models except for enalaprilate which decreased MAP in WKY slightly but significantly $(\mathbf{- 8 . 3} \pm 1.1$ $\mathrm{mmHg}$ ). The ACE-inhibitors had no effects also on MBF and HBF.

In contrast, both captopril and enalaprilate increased RBF in MI (enalaprilate: $10.3 \pm 2.4 \%$, captopril: $10.1 \pm 2.0 \%$ ), whereas captopril also increased RBF in WKY $(12.5 \pm 5.1 \%)$. These increases in RBF are associated with no effect on MAP, whereas the slight decrease in MAP of enalaprilate in WKY is associated with no effect on RBF.

The effects on RBF and MAP resulted in a decrease in RVR (figure 3.3). This decrease was also significant for both ACE-inhibitors in MI (enalaprilate: 

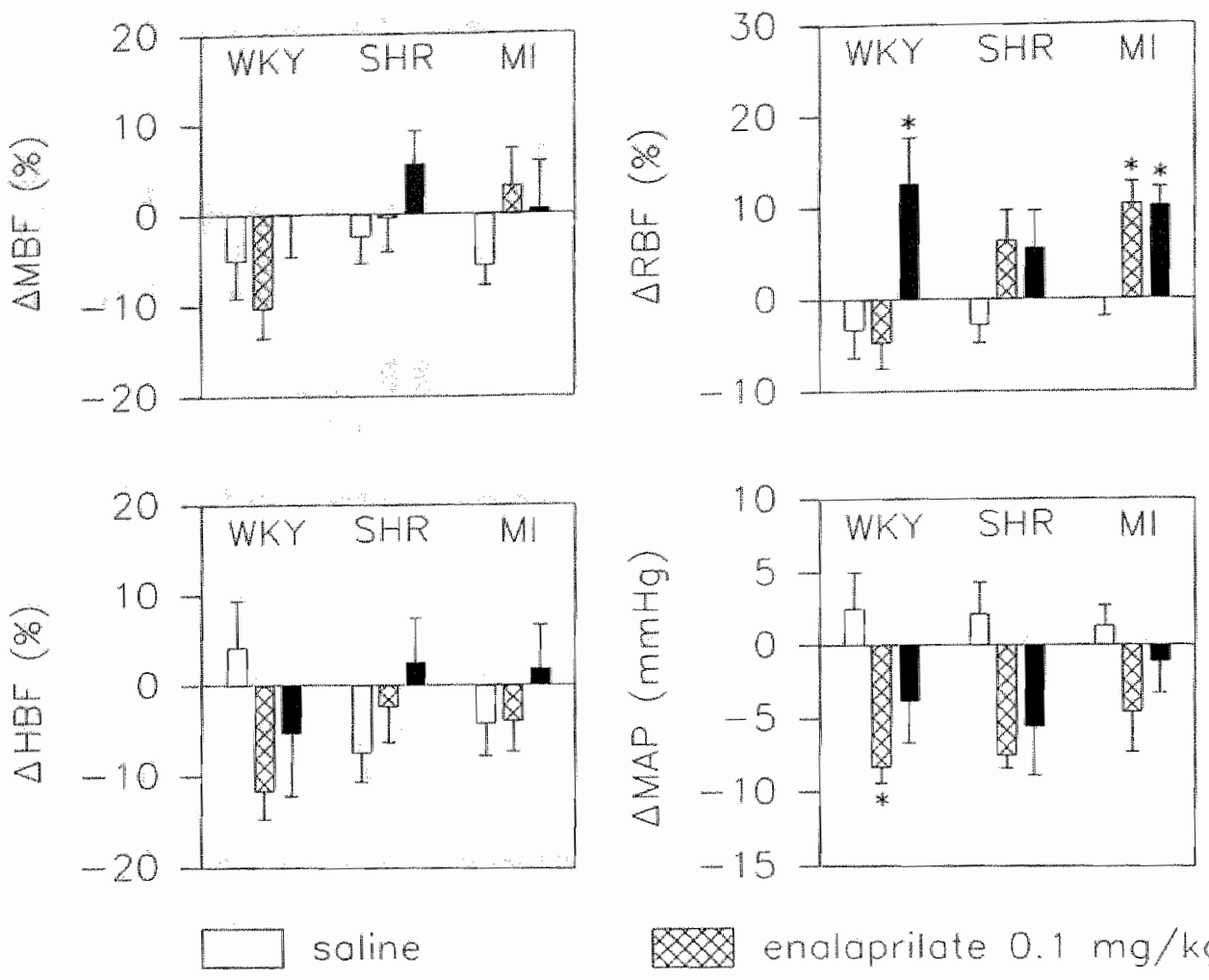

\section{enalaprilote $0.1 \mathrm{mg} / \mathrm{kg}$}

coptopril $3 \mathrm{mg} / \mathrm{kg}$

Figure 3.2 Maximal effects of saline, enalaprilate and captopril on mesenteric, hindquarter, and renal blood flow and on mean arterial pressure in WKY,SHR and MI rats.

$-13.4 \pm 1.0 \%$, captopril: $-10.1 \pm 2.1 \%)$ and for captopril in WKY $(-11.8 \pm 4.1 \%)$.

As seen for MBF and HBF, the ACE-inhibitors had no effect on MVR and HVR in all three rat models, except for enalaprilate which decreased MVR significantly in MI (enalaprilate: $-9.7 \pm 2.8 \%$ ).

To investigate whether the preferential renal vasodilatation is a consequence of a greater sensitivity of the renal vascular bed for the vasoconstrictor action of circulating angiotensin II, the effects of angiotensin I on resistance in renal, mesenteric and hindquarter bed were measured in SHR. As seen in figure 3.4, angiotensin I had no effect on hindquarter vascular resistance and increased renal and mesenteric vascular resistance to the same extent. 

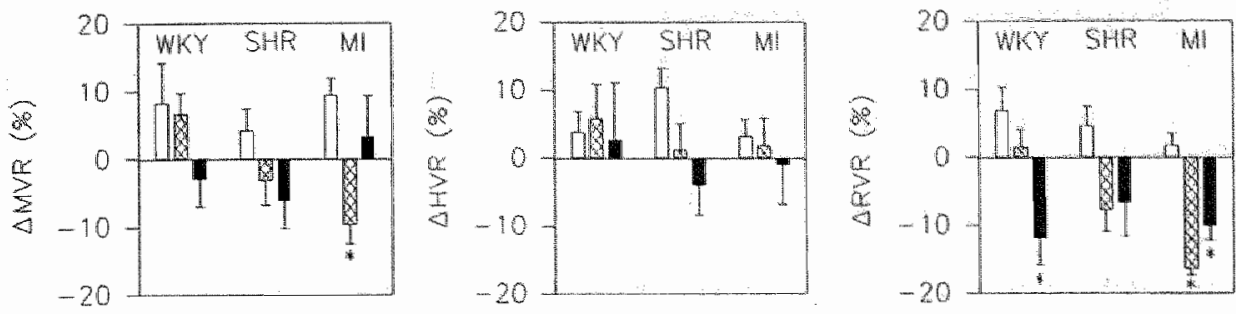

Soline enoloprtote $0.1 \mathrm{mg} / \mathrm{kg}$ coptopril $3 \mathrm{mg} / \mathrm{kg}$

Figure 3.3 Maximal effects of saline, enalaprilate, and captopril on mesenteric (MVR), hindquarter (HVR), and renal vascular resistance (RVR) in WKY, SHR and MI rars.

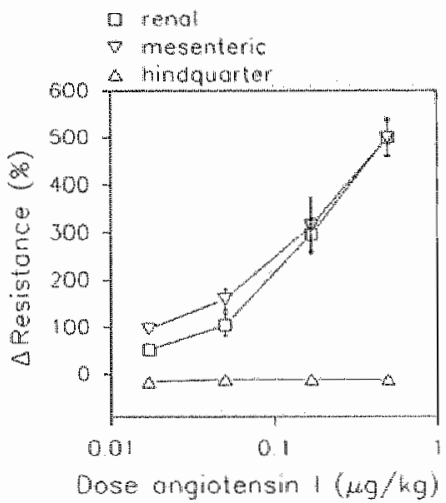

Figure 3.4 Effect of angiotensin I on renal, mesenteric and hindquarter vascular resistance in SHR.

\subsection{DISCUSSION}

Previous studies into the acute regional hemodynamic effects of blood pressure reducing doses of ACE-inhibitors in SHR (Smits and StruykerBoudier, 1984; Richer et al., 1987), rats with myocardial infarction (Drexler et al., 1987) and Brattleboro rats (Muller et al., 1990) indicate that the blood pressure reduction is associated with a preferential renal vasodilatation. It is, however, not clear whether this effect is dependent upon an autoregulatory effect which would tend to reduce renal resistance in the face of blood pressure reduction. Therefore, in the present study we compared the effect of two ACEinhibitors in animal models for hypertension (SHR) and heart failure (rats with MI) at doses that did not have appreciable central hemodynamic effects. Marginal decreases in MAP were associated with unchanged cardiac output and total peripheral resistance, but increased renal blood flow, which was most pro- 
nounced in MI rats.

Based on pilot-experiments, we chose doses of 0.1 and $3 \mathrm{mg} / \mathrm{kg}$ for enalaprilate and captopril, respectively. The only statistically significant effect that we observed on blood pressure was in normotensive WKY rats in the regional hemodynamic studies, where enalaprilate lowered blood pressure by $8 \pm 1$ mmHg. In all other experiments, changes in blood pressure were not statisticallly significant and not clinically relevant.

In the central hemodynamic studies, we did not observe any effects on cardiac output and peripheral resistance. This is in contrast with findings in a previous study where we reported a decrease in total peripheral resistance following injection of $10 \mathrm{mg} / \mathrm{kg}$ captopril in SHR (Smits and Struyker-Boudier, 1984). Also in patients with moderate to severe heart failure, captopril has been shown to reduce total peripheral resistance acutely (Kugler et al., 1982; Nicholls et al., 1982; Powers et al,, 1982). Thus, the lack of effect on peripheral resistance in the present study is probably related to the relatively small doses of the ACEinhibitors we used.

In regional hemodynamic studies, captopril consistently increased renal blood flow in all three rat models we studied, although the increase did not reach statistical significance in SHR. As an exception, enalaprilate did not exhibit a renal vasodilator effect in normotensive WKY. The increase in blood flow was round $10 \%$ of resting blood flow. In contrast, neither of the other two regional flows that we measured (mesenteric and skeletal muscle flow) exhibited any changes.

Several explanations may be offered for the preferential renal dilatation. First of all, renal specificity may derive from the interaction of ACE-inhibitors with prostaglandins or the kallikrein-kinin system. In normotensive rats, captopril but not enalaprilate has a direct stimulatory effect on renal prostaglandin $E_{2}$ synthesis (Katayama et al., 1989). From our observations that, at least in SHR and MI rats, enallaprilate and captopril both dilate the renal vasculature, makes this explanation less likely. Blockade of the renin-angiotensin system as well as an increase of bradykinin contributed to renal vasodilatation by enalapril in sodiumrestricted dogs (Zimmerman et al., 1990). In conscious rats, however, intrarenal infusion of bradykinin does not result in renal vasodilatation (Smits and Brody, 1984).

An alternative explanation may be that the rat kidney is more sensitive for the vasoconstrictor action of circulating angiotensin II than the mesenteric and

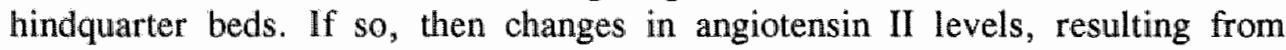
conversion of angiotensin I by ACE, would be reflected in preferential renal resistance changes following injections of angiotensin $I$. However, in the present study we found the renal and mesenteric vascular bed to constrict similarly to exogenous angiotensin I in the conscious rat, making this possibility less likely.

Finally, the specific dilatation of the renal circulation may depend upon the 
interaction of the ACE-inhibitors with an intrarenal renin-angiotensin system (Dzau, 1987a; Re and Rovigatti, 1988). In view of the above observations with respect to angiotensin I, it would seem that the combined circulating and local systems are similarly active in mesentery and kidney of SHR. The preferential renal vasodilatation may then be based upon greater affinity of ACE-inhibitors for renal $\mathrm{ACE}$, than for mesenteric $\mathrm{ACE}$. This is corroborated by the observation that at equivalent inhibitory activities of captopril and enalapril in serum, the inhibition of kidney ACE was almost complete $(95-99 \% 1 \mathrm{hr}$ after oral dose), whereas the inhibition of $\mathrm{ACE}$ in heart, lung, brain and aorta varied from 10-80\% (Cushman et al., 1989a,b).

The specific renal vasodilatation observed here may contribute significantly to the long-term hemodynamic effects of ACE-inhibitors. Renal vasodilatation may not only contribute to control of preload, for instance in heart failure, but may also result in reduction of total peripheral resistance, through autoregulatory mechanisms (Struyker Boudier, 1980; Ackermann et al., 1983). In fact, in SHR (Richer et al., 1987) and in hypertensive patients (Ventura et al., 1985; Kubo et al., 1987), a sustained reduction of renal vascular resistance during long-term treatment has been observed. As observed by several investigators (Cohen and Kurz, 1982; Unger et al., 1985), the antihypertensive effect is not correlated with the inhibition of circulating $A C E$ but with the inhibition of $A C E$ in vascular wall and kidney, which supports the potential importance of the renal effect in the present study.

In conclusion, low doses of captopril and enalaprilate that had marginal, clinically not relevant, effects on blood pressure caused preferentially renal vasodilatation without influencing total peripheral resistance in myocardial infarction rats and low doses of captopril also in normotensive rats. This suggests an important role of the local intrarenal renin-angiotensin system in the regulation of renal resistance especially in heart failure. 


\section{CHAPTER 4}

\section{Hindlimb perfusion model}

\subsection{INTRODUCTION}

As described in the previous chapter, the ACE-inhibitors captopril and enalaprilate at non-hypotensive doses increased preferably renal flow and decreased renal resistance, especially in heart failure. This suggests that the local renin-angiotensin system (RAS) in the renal arterial wall may play a role in the regional hemodynamic effects in normal and also in pathophysiological conditions. This role of local RAS in blood pressure regulation is supported by other investigators, who found that inhibition of local ACE in aorta and kidney and not inhibition of plasma $\mathrm{ACE}$ is responsible for the antihypertensive activity of ACE-inhibitors (Cohen and Kurz, 1982; Unger et al., 1985). Furthermore, local RAS in heart and brain have been suggested to play a role in compensatory mechanisms following ischemia (Waldemar and Paulson, 1989; Fleetwood et al., 1991; Lindpaintner and Ganten, 1991).

The local RAS also seems to play a role in ischemia of skeletal muscle. This is suggested by observations in patients with a combination of hypertension and intermittent claudication. Symptoms of intermittent claudication did not worsen (Roberts et al., 1987a) or even improved (Catalano and Libretti, 1985; Bernardi et al., 1988) in these patients after antihypertensive therapy with ACE-inhibitors 
in contrast to other antihypertensives (Lepäntalo, 1984; Roberts et al., 1987a).

However, the functional role of the local RAS in ischemia of skeletal muscle is not yet clear. Therefore, in the next part of this thesis further investigations of the functional role of the local RAS in normal animals and in animals with ischemia of skeletal muscle are performed. Investigation of the role of the local RAS in whole animals is complicated by influences of for instance the central nervous system and the circulating components of the RAS. Therefore, to investigate the local RAS without these influences experiments have to be performed in an in-situ perfused animal model. An animal model in which blood components and influences of the central nervous system can be eliminated is the hindlimb perfuision model (Ross, 1972). In this model the central nervous system has no activity and artificial fluid instead of blood can be used for perfusion of the hindlimbs. Furthermore, alterations in reactivity of the vascular bed following acute and chronic ischemia of skeletal muscle and the role of the local RAS can be investigated in this hindlimb perfusion model.

In the present chapter an extensive characterization of the hindlimb perfusion model is presented.

\subsection{HINDLIMB PERFUSION MODEL}

\subsubsection{Surgery}

A modified hindlimb preparation according to Ross (1972) was used. Animals were anesthetized with sodium pentobarbital $(60 \mathrm{mg} / \mathrm{kg}$ i.p.). The abdomen was opened and the intestines were put aside in saline-wetted gauze. Ligatures (4-0 silk) were tied around the iliolumbar, the internal spermatic, the hypogastric, and the superficial epigastric vessels on each side, and around the bladder and the seminal vesicles (figure 4.1). Two ligatures were tied around the inferior mesenteric artery and the upper and lower end of the descending colon to remove the intestines from the rectum. The abdominal aorta, inferior caval vein and both common iliac arteries were dissected free. After orthograde cannulation of the aorta with PE-100 (internal diameter $0.86 \mathrm{~mm}$ ) and retrograde cannulation of the vena cava with PT-53 (internal diameter $1.0 \mathrm{~mm}$ ) just below the kidneys, the perfusion was initiated.

\subsubsection{Perfusion}

The hindlimbs were perfused with a modified Krebs-Ringer solution $(\mathrm{NaCl}$ : $118.5 \mathrm{mM} ; \mathrm{MgSO}_{4}: 1.2 \mathrm{mM} ; \mathrm{KH}_{2} \mathrm{PO}_{4}: 1.2 \mathrm{mM} ; \mathrm{NaHCO}_{3}: 25 \mathrm{mM} ; \mathrm{CaCl}_{2}: 2.5$ $\mathrm{mM}$; KCl: $15 \mathrm{mM}$; glucose: $11.1 \mathrm{mM}$; dextran 70,000-90,000: $60 \mathrm{~g} / \mathrm{l})$. The 


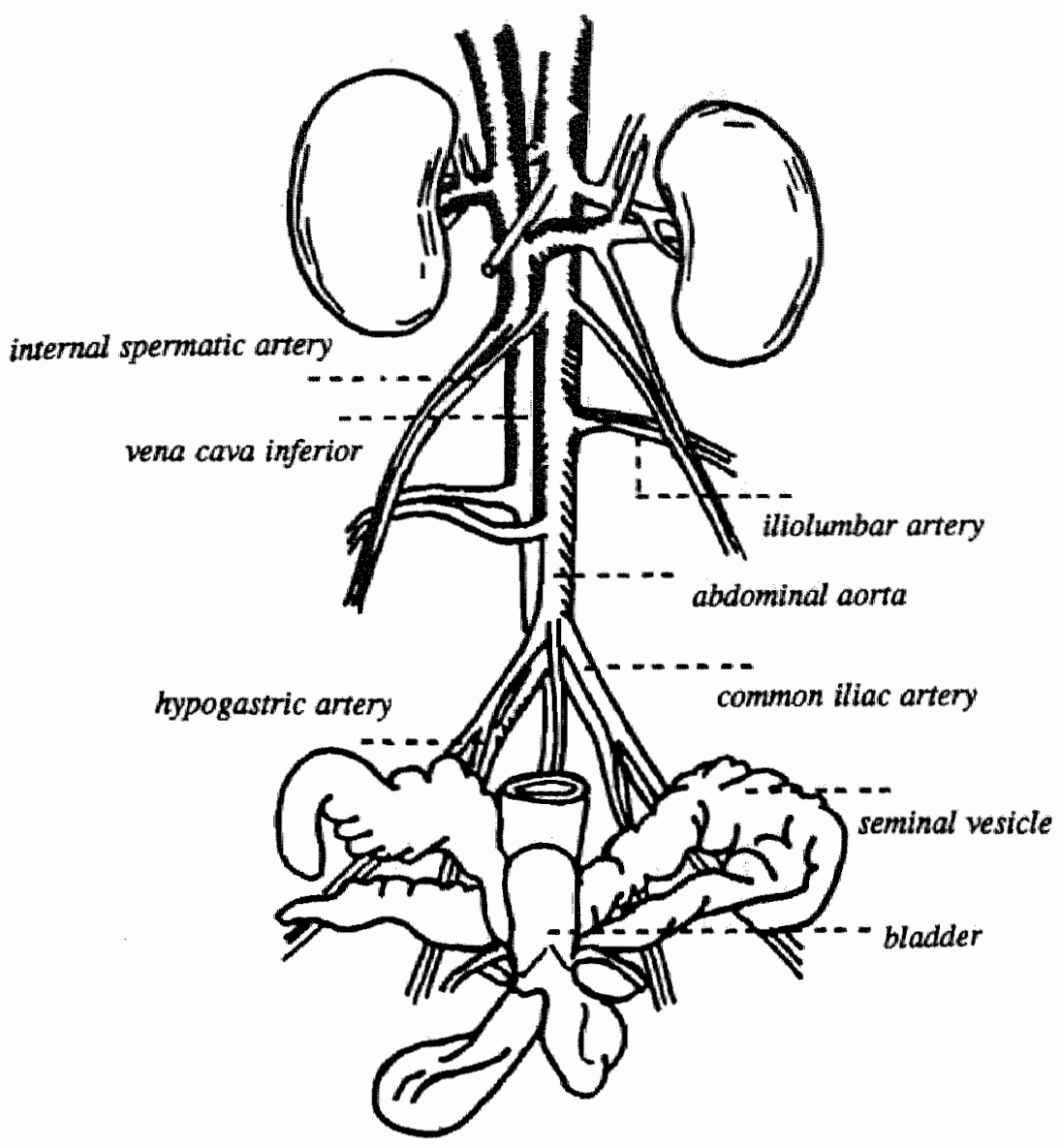

Figure 4.1 Schematic representation of the abdominal cavity.

solution was maintained at $37^{\circ} \mathrm{C}$ with a waterbath and was gassed with $95 \% \mathrm{O}_{2}$ and $5 \% \mathrm{CO}_{2}$ to obtain a $\mathrm{pH}$ of 7.4 . Cardiac arrest was produced by an intracardiac injection of a saturated $\mathrm{KCl}$ solution. To avoid extensive leakage of the perfusion solution, the hindlimbs were not separated from the donor rat. Small amounts of leakage fluid (less than $2 \mathrm{ml} / \mathrm{h}$ ) were removed from the abdomen by extraction with a silastic drain and application of a negative pressure. The rat was placed on a pad of $37^{\circ} \mathrm{C}$ to controll temperature.

As shown in figure 4.2, the hindlimbs were perfused using a peristaltic pump (RCT E-25, Reichelt Chemie Technik, Heidelberg, Germany) via a bubbletrap, which served also as a windkessel. The perfusion pressure was controlled by regulating the outlet of the bubbletrap by a valve. Baseline perfusion pressure 


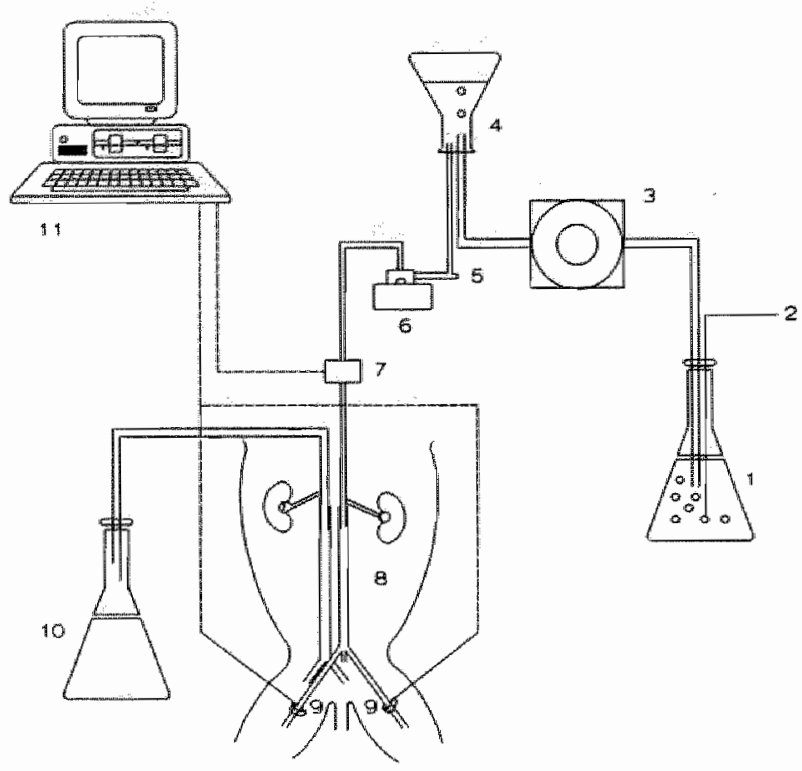

Figure 4.2 Experimental set-up of the hindlimb perfusion model.

$I=$ modified Krebs-Ringer solution; $2=95 \% \mathrm{O}_{2}$ and $5 \% \mathrm{CO}_{3} ; 3=$ peristaltic pump; $4=$ bubble rrap; $5=$ sleeve for injections and infusions; $6=$ stirring motor and rod; $7=$ pressure transducer; $8=$ hindlimb preparation; $9=$ electromagnetic flow probes; $10=$ collecting reservoir; $11=$ computer

was maintained between 40 and $50 \mathrm{mmHg}$. The venous outflow was collected in a reservoir.

\subsubsection{Measurements}

To measure flow in the hindlimb preparation, electromagnetic (EM) flow probes $(0.6 \mathrm{~mm}$; Skalar, Delft, the Netherlands) were placed on both common iliac arteries and connected to a sine-wave electromagnetic flowmeter (Skalar, Delft, the Netherlands). Zero flow was obtained after closing the illiac arteries distal to the EM probes with a blood vessel occluder with Delrin ${ }^{\mathbb{R}}$ or stainless steel tweezers (maximal vessel diameter 0.8-1.5 mm; Skalar, Delft, the Netherlands). To measure perfusion pressure, a low volume displacement pressure transducer (CP-01, Century Technology Company, Inglewood, CA, USA) was connected to the inflow tubing proximal to the aorta.

The signals of perfusion pressure (P) and flow in both common iliac arteries $\left(F_{L}, F_{R}\right)$ were recorded continuously on a Grass model $7 D$ polygraph (Grass 
Instruments, Quincy, Mass, USA) and on a real-time data processing system (Instrumental Services of the University of Limburg, Maastricht, the Netherlands). Drugs were injected or infused directly into the perfusion circuit through a silicon sleeve attached to the tubing, proximal to a magnetic stirrer and the pressure transducer.

\subsubsection{Perfusion characteristics}

Physiological flow: in the hindlimb perfusion model both physiological flow or pressure can be used. Physiological flow in the perfusion model probably results in normal shear stress and thus normal endothelial cell function. Normal endothelial cell function is important for investigations of the local ACE.

Furthermore, physiological pressure in the perfusion model resulted in an extensive development of oedema in the hindlimbs, whereas oedema was prevented at the perfusion pressure which was associated with physiological flow (40-50 $\mathrm{mmHg}$ ). Therefore, in the present experiments we chose for physiological flow conditions.

Oedema: although experiments were performed at a perfusion pressure of 40 $50 \mathrm{mmHg}$, oedema can develop if the perfusion fluid is not iso-oncotic. The perfusion fluid can be made iso-oncotic with for instance $6 \%$ albumin, $4 \%$ dextran 40,000 or $6 \%$ dextran 70,000 . Due to gassing with $95 \% \mathrm{O}_{2}$ and $5 \%$ $\mathrm{CO}_{2}$, addition of albumin causes foaming of the perfusion fluid. Therefore, in the present experiments the perfusion fluid contained $6 \%$ dextran $70,000-90,000$ (average approx. 71,000; clinical grade).

Mixing: in pilot experiments injection or infusion of phenylephrine resulted in differences in resistance increases in left and right hindlimb of control animals. As visualized with methylene blue, injections or infusions resulted in an inhomogeneous distribution of the injection or infusion fluid in the perfusion fluid. Mixing of both fluids distal to the injection sleeve with a magnetic stirrer at maximal rotation of the small stirring rod resulted in homogeneity and also in comparable responses to vasoconstrictors in both hindlimbs.

\subsubsection{Responsiveness}

Continuous infusions of phenylephrine and noradrenalin resulted in sustained dose-dependent increases in resistance of the hindlimbs. In contrast, continuous infusion of angiotensin I or angiotensin II resulted in transient increases in resistance. Further increase of the infusion rate did not alter resistance. This phenomenon is probably due to tachyphylaxis of the system to angiotensins. 


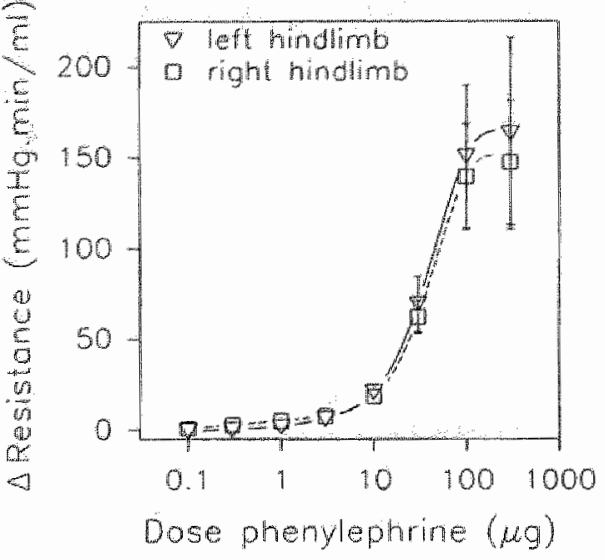

Figure 4.3 Dose response curve of phenylephrine

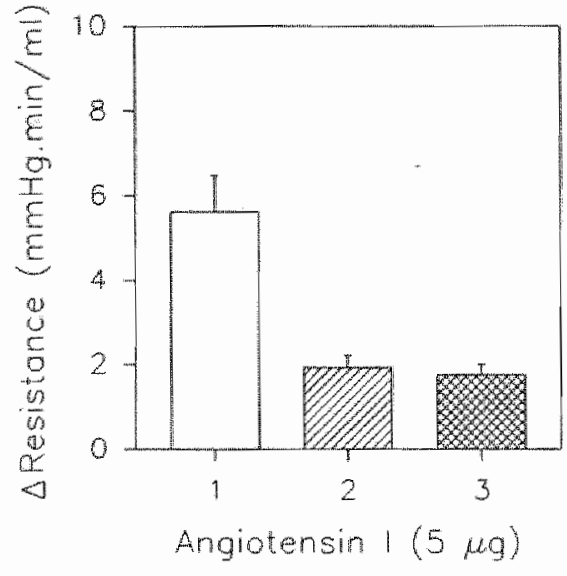

Figure 4.4 Subsequent doses of angiotensin $I$

Injections of phenylephrine resulted in a dose-dependent transient increase in resistance. These responses can be expressed as maximal changes of resistance (figure 4.3). Also injections of angiotensin I and II resulted in a transient increase in resistance, but maximal changes were much lower than maximal changes obtained with phenylephrine. Small resistance changes following angiotensin I in the vascular bed of the hindquarter in comparison to other vascular beds have alleady been observed in the previous chapter. Furthermore, subsequent injections of the same dose (figure 4.4) or two subsequent dose-response curves of angiotensin I or II did not result in comparable resistance

changes. This phenomenon is also likely to be due to tachyphylaxis. To diminish tachyphylaxis and its effects on experimental outcome, several precautions were made:

* generation of dose-response curves with injections of [ $\left.\mathrm{Val}^{5}\right]$-angiotensin I and $\left[\mathrm{Val}^{5}\right]$-angiotensin II instead of human angiotensin I and II.

* Lindsey et al. (1987) described a prevention of tachyphylaxis by a continuous precontraction with noradrenaline. To avoid interferences between angiotensin II and noradrenaline, precontraction was obtained with an additional amount of $\mathrm{KCl}$ in the perfusion fluid $(15 \mathrm{mM}$ instead of $4.7 \mathrm{mM} \mathrm{KCl})$ in the present experiments.

* minimal time interval between two subsequent doses was 15 minutes.

* each dose-response curve was generated in a separate hindlimb preparation. Although tachyphylaxis did not disappear following these precautions, the doseresponse curves of angiotensin I and II were reproducible (figure 4.5 and 4.6). 


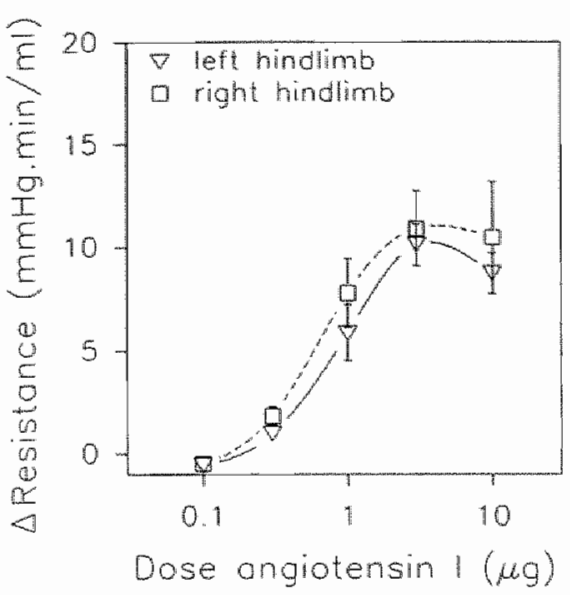

Figure 4.5 Dose-response curve of angiotensin I in left and right hindlimb.

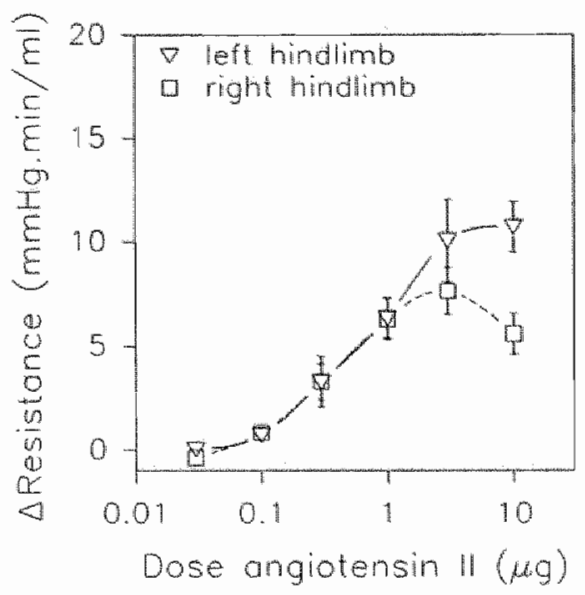

Figure 4.6 Dose-response curve of angiotensin $I$ in left and right hindlimb.

\subsubsection{Calculations}

Total resistance $(R)$ and resistance in left $\left(R_{L}\right)$ and right $\left(R_{R}\right)$ hindlimb were computed, according to equation (1), (2) and (3) resp.

$$
\begin{aligned}
& R=\frac{P}{F_{L}+F_{R}} \\
& R_{L}=\frac{P}{F_{L}} \\
& R_{R}=\frac{P}{F_{R}}
\end{aligned}
$$

Responses were expressed as maximal absolute changes in resistance $(\Delta \mathrm{R})$. The dose at half-maximal effect $\left(E_{5_{0}}\right)$ and the maximal resistance increase $\left(\Delta \mathrm{R}_{\max }\right)$ of vasoconstricting substances were computed by fitting the responses to a sigmoidal curve, using the equation:

$$
\Delta R=\frac{\Delta R_{\mathrm{mmax}} * D^{n}}{E D_{s_{0}}^{n}+D^{n}}
$$

where $\mathrm{D}=$ dose of vasoconstricting substances; $\mathbf{n}=$ Hill-coefficient.

The $\mathrm{ED}_{50}$ will be used as a standard for the sensitivity and $\Delta \mathrm{R}_{\max }$ as a standard for the reactivity of the vascular bed for the vasoconstricting substances. 
$\therefore \quad$ 


\section{CHAPTER 5}

\section{Angiotensin converting enzyme inhibition in perfused hindlimbs and in vivo}

\section{$5.1 \quad$ INTRODUCTION}

The existence of local renin angiotensin systems (RAS), besides the classical blood-borne system, is now generally accepted. These local systems have been identified in a number of tissues such as brain, kidney, heart, pancreas and blood vessel walls (Dzau et al., 1988; Lindpaintner et al., 1988; Re and Rovigatti, 1988; Unger et al., 1988; Chappell et al., 1991; Weishaar et al., 1991). Not only may these latter play a role in the local regulation of blood flow, but they have also been implied in the antihypertensive action of angiotensin converting enzyme (ACE) inhibitors (Cohen and Kurz, 1982; Unger et al., 1985; Dzau, 1987). In blood vessel walls, ACE is not only present in endothelium but a considerable amount of enzyme activity persists following removal of this cell layer and seems to be localized within vascular smooth muscles (Velletri and Bean, 1982; Urabe et al., 1987; Pipili et al., 1989). If these local systems are indeed involved in the actions of ACE-inhibitors, then the ability of ACE-inhibitors to reach these systems from the circulation may be an important determinant for their actions (Mizuno et al., 1988; 1990; Cushman et all, 1989 a,b; Higashimori et al., 1991).

In the present study we used the hindlimb perfusion model described in the previous chapter to investigate functional responses (resistance changes) to exogenous angiotensin $I$. In the perfused system, there is no circulating $A C E$ and, thus, any responses should depend upon local $\mathrm{ACE}$, providing they can be blocked specifically by $\mathrm{ACE}$-inhibitors. In this respect, we compared potency 
ratios of 4 structurally different $\mathrm{ACE}$-inhibitors (captopril, enalaprilate, lisinopril and zabiciprilate) in vivo, by measuring inhibition of the angiotensin I pressor response and plasma ACE-activity in intact animals. Based on dose ratios obtained in these experiments, we infused the ACE-inhibitors in the perfused hindlimb preparation to study inhibition of the local angiotensin I response.

As the hindlimb perfusion model will also be used for investigations of changes of the local renin angiotensin system in a combination of peripheral ischemia and hypertension (chapter 6 and 7), spontaneously hypertensive rats were used in the present chapter.

\subsection{MATERIALS AND METHODS}

\subsubsection{Animals}

Experiments were performed in male spontaneously hypertensive rats (SHR). Animals weighed $290-360 \mathrm{~g}$ at the start of the protocoll.

\subsubsection{Surgery}

Rats were anesthetized with pentobarbital and prepared for hindlimb perfusion as described in section 4.2.1. After initiation of the perfusion, electromagnetic flow probes were placed on both common iliac arteries.

\subsubsection{Measuring protocols}

Dose comparison: plasma ACE in vivo

To determine inhibition of ACE in whole animals by saline, enalaprilate, lisinopril, zabiciprilate and captopril, SHR were cannulated with an arterial and venous catheter as described in section 2.2.4. Blood samples were taken from conscious animals at $15 \mathrm{~min}$ after i.v. injection. This time interval was chosen because pilot-studies showed a maximal inhibition of pressor response to $150 \mathrm{ng}$ angiotensin I by the ACE-inhibitors at $15 \mathrm{~min}$ after injection. The doses used were for enalaprilate, lisinopril and zabiciprilate 0.01 and $0.1 \mathrm{mg} / \mathrm{kg}$ body weight and for captopril 0.3 and $3 \mathrm{mg} / \mathrm{kg}$ body weight.

ACE-activity was measured as described in section 2.5 .

Dose comparison: hemodynamics in vivo

Dose-response curves of angiotensin I were generated in anesthetized animals, cannulated with an arterial catheter for blood pressure measurements and a venous catheter for $i . v$. drug injections, under normal conditions and during 


\section{ACE-inhibition.}

Changes in mean arterial pressure (MAP) after i.v. bolus injections of [Val $\left.{ }^{5}\right]$ angiotensin $\mathbb{I}(0.01-30 \mu \mathrm{g})$ were obtained following an i.. . bolus injection of saline, enalaprilate, lisinopril, zabiciprilate or captopril, starting at $15 \mathrm{~min}$ after the ACE-inhibitor injection. The doses used were for enalaprilate, lisinopril and zabiciprilate $0.1 \mathrm{mg} / \mathrm{kg}$ body weight and for captopril $3 \mathrm{mg} / \mathrm{kg}$ body weight.

\section{ACE-inhibition in perfused hindlimbs}

The hindlimb preparation was allowed to equilibrate for 30-45 min to achieve a steady-state level of perfusion pressure and flows. Dose-response curves of $\left[\mathrm{Val}^{5}\right]$-angiotensin $\mathrm{I}(0.3-300 \mu \mathrm{g})$ and $\left[\mathrm{Val}^{5}\right]$-angiotensin II $(0.1-10 \mu \mathrm{g})$ were generated under control conditions and during continuous infusion of enalaprilate, lisinopril, zabiciprilate or captopril. The doses for enalaprilate, lisinopril and zabiciprilate were 25 and $250 \mathrm{ng} / \mathrm{min}$ and for captopril 0.75 and 7.5 $\mu \mathrm{g} / \mathrm{min}$. The ratio of the doses in the hindlimb experiments corresponds with the ratio of equipotent doses in vivo.

Each dose-response curve was generated in a separate hindlimb preparation and minimal time interval between two injections angiotensin I or II was 15 min. The first bolus injection of angiotensin I or II during ACE-inhibition was given $15 \mathrm{~min}$ after starting the infusion. At the start and at the end of an experiment, $30 \mu \mathrm{g}$ phenylephrine was injected for evaluation of responsiveness of the hindlimb preparation. Only the results of experiments on preparations with normal responses to phenylephrine were used.

Perfusion pressure $(\mathrm{P})$ and flow $\left(\mathrm{F}_{\mathrm{L}}\right.$ and $\left.\mathrm{F}_{\mathrm{R}}\right)$ in both common iliac arteries were monitored continuously.

\subsubsection{Data analysis}

Resistance in left $\left(R_{L}\right)$ and right $\left(R_{R}\right)$ hindlimb, half-maximal effective dose $\left(E D_{50}\right)$ and maximal effect $\left(\Delta R_{\text {max }}\right)$ of angiotensin I and II were computed as described in section 4.2.6. Responses of angiotensin I and II were expressed as absolute maximal resistance changes.

Control values and effects of ACE-inhibitors were compared by one-way analysis of variance and Bonferroni's and Dunnett's test.

\subsection{RESULTS}

\subsubsection{Dose comparison}

To find comparable doses of the ACE-inhibitors in whole animals, the influences of the ACE-inhibitors on plasma ACE-activity and on angiotensin I 


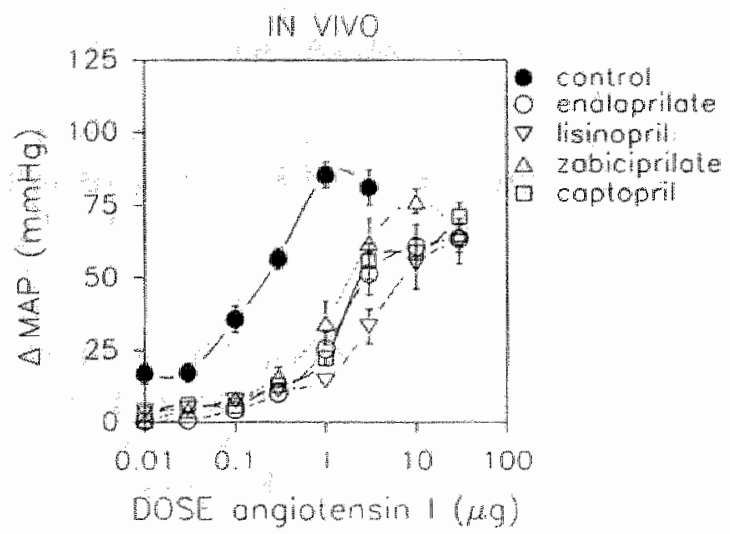

Figure 5.1 Effect of enalaprilate, lisinopril, zabiciprilate (all: $0.1 \mathrm{mg} / \mathrm{kg}$ ) and captopril $(3$ $\mathrm{mg} / \mathrm{kg}$ ) on the pressor-response curve of angiotensin I in vivo.

pressor responses in vivo were tested.

All ACE-inhibitors at high doses (enalaprilate, lisinopril, zabiciprilate: 0.1 $\mathrm{mg} / \mathrm{kg}$; captopril: $3 \mathrm{mg} / \mathrm{kg}$ body weight) inhibited plasma $\mathrm{ACE}$-activity almost completely and to the same extent (ACE-activity: control, 140.5 \pm 5.7 ; enalaprilate, $1.39 \pm 0.66$; lisinopril, $1.85 \pm 0.70$; captopril, $2.34 \pm 0.29$; zabiciprilate, $1.51 \pm 0.58 \mathrm{nmol} / \mathrm{min} / \mathrm{ml}$ plasma; $\mathrm{N}=5-8$ ).

At low doses (enalaprilate, lisinopril, zabiciprilate: $0.01 \mathrm{mg} / \mathrm{kg}$; captopril:0.3 $\mathrm{mg} / \mathrm{kg}$ body weight), the ACE-inhibitors reduced plasma ACE-activity also to

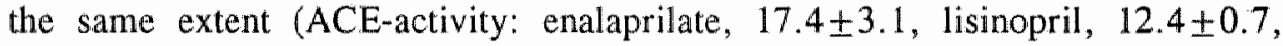
captopril, $13.2 \pm 2.4$, zabiciprilate, $10.8 \pm 1.2 \mathrm{nmol} / \mathrm{min} / \mathrm{ml}$ plasma; $\mathrm{N}=3-6$ ).

In the hemodynamic experiments, all $\mathrm{ACE}$-inhibitors increased $\mathrm{ED}_{50}$ of angiotensin I (control: $0.21 \pm 0.03(\mathrm{~N}=12)$; enalaprilate: $1.45 \pm 0.27 \quad(\mathrm{~N}=6)$; lisinopril: $4.18 \pm 0.92(\mathrm{~N}=6)$; captopril: $2.38 \pm 0.73 \quad(\mathrm{~N}=6)$; zabiciprilate: $1.93 \pm 0.42 \mu \mathrm{g}(\mathrm{N}=6))$, whereas maximal increase in MAP was not influenced in anesthetized rats (figure 5.1). The increase in $E_{50}$ of angiotensin I by lisinopril was significantly different compared to control, enalaprilate and zabiciprilate.

\subsubsection{Hindlimb experiments}

Baseline values of pressure and total flow are summarized in table 5.1. Both pressure and flow were not significantly different between the groups.

Angiotensin II as well as angiotensin I increased resistance in perfused hindlimbs (figure 5.2). Although maximal effects were comparable (Ang I: $2.7 \pm 0.3$; Ang II: $2.2 \pm 0.2 \mathrm{mmHg} \cdot \mathrm{min} / \mathrm{ml}), \mathrm{ED}_{50}$ for angiotensin I was higher than for angiotensin II (Ang I: $1.64 \pm 0.3$; Ang II: $0.52 \pm 0.08 \mu \mathrm{g}$ ). 
Table 5.1 Baseline values of perfusion pressure and tolal fow in the hindlimb experiments.

\begin{tabular}{lccccccc} 
& & \multicolumn{4}{c}{ Angiotensin I } & \multicolumn{2}{c}{ Angiotensin II } \\
& Dose & $N$ & $P$ & $F_{T}$ & $N$ & $P$ & $F_{T}$ \\
Control & & 8 & $44.1 \pm 0.7$ & $7.3 \pm 0.5$ & 10 & $44.2 \pm 0.8$ & $7.6 \pm 0.5$ \\
Enalaprilare & 25 & 7 & $44.5 \pm 0.5$ & $7.3 \pm 0.4$ & & & \\
& 250 & 8 & $42.2 \pm 0.7$ & $7.6 \pm 0.3$ & 7 & $44.1 \pm 1.1$ & $7.5 \pm 0.6$ \\
Lisinopril & 25 & 7 & $41.5 \pm 0.4$ & $8.4 \pm 0.8$ & & & \\
& 250 & 7 & $43.3 \pm 0.9$ & $7.1 \pm 0.4$ & 7 & $44.1 \pm 0.5$ & $8.0 \pm 0.5$ \\
Captopril & 750 & 7 & $42.7 \pm 0.5$ & $9.2 \pm 0.4$ & & & \\
& 7500 & 8 & $42.2 \pm 0.8$ & $7.7 \pm 0.7$ & 7 & $42.8 \pm 1.1$ & $7.6 \pm 0.7$ \\
& 25 & 7 & $44.7 \pm 1.1$ & $8.0 \pm 0.8$ & & & \\
Zabiciprilate & 250 & 7 & $43.6 \pm 0.6$ & $7.5 \pm 0.8$ & 7 & $44.8 \pm 0.5$ & $8.3 \pm 0.5$
\end{tabular}

P: perfusion pressure $(m m \mathrm{mg}) ; F_{\mathrm{T}}$ : total flow $(\mathrm{ml} / \mathrm{min})$; Dose: $\mathrm{ng} / \mathrm{min}$.

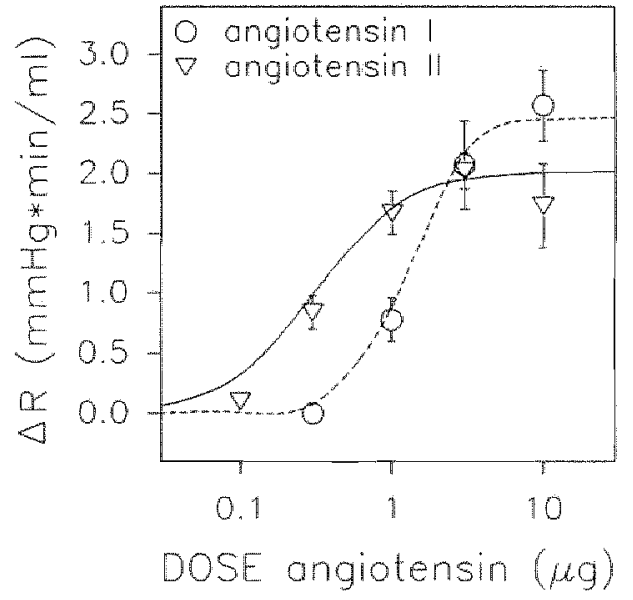

Figure 5.2 Dose-response curves of angiotensin $I$ and $I I$ in the hindlimb perfusion model
To investigate whether ACE plays a role in the effects of angiotensin $I$, the influences of ACE-inhibitors on the angiotensin I and II responses were tested. Continuous infusion of the high doses of ACE-inhibitors had no effect on $\mathrm{ED}_{50}$ and $\Delta \mathrm{R}_{\max }$ of angiotensin II (figure 5.3). In contrast, both low and high doses of ACEinhibitors increased $\mathrm{ED}_{50}$ and decreased $\Delta \mathrm{R}_{\max }$ of angiotensin I dose-dependently (figure 5.4). $E_{50}$ and $\Delta \mathrm{R}_{\max }$ of angiotensin $\mathrm{I}$ during $A C E$-inhibition are summarized in table 5.2.

At high doses, the increase in $\mathrm{ED}_{50}$ and decrease in $\Delta \mathrm{R}_{\max }$ of angiotensin I by $A C E$-inhibition were significant compared to control. At these doses, the changes in $\mathrm{ED}_{50}$ and $\Delta \mathrm{R}_{\max }$ were not different between the ACE-inhibitors. In contrast, at low doses only captopril increased $\mathrm{ED}_{50}$ of angiotensin I significantly compared to control, whereas the 

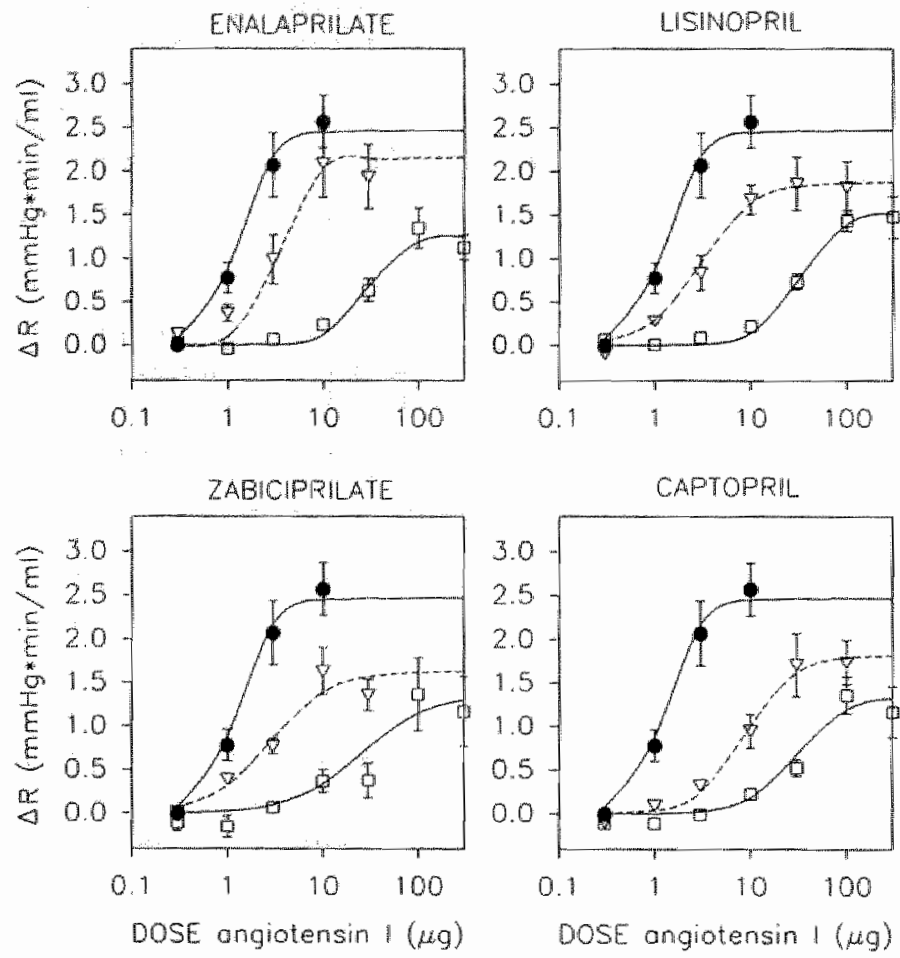

- control q law dase a high dose

Figure 5.3 Effect of enalaprilate, lisinopril, zabiciprilate (all: 25 and $250 \mathrm{ng} / \mathrm{min}$ ) and captopril ( 0.75 and $7.5 \mu \mathrm{g} / \mathrm{min}$ ) on the dose-response curve of angiotensin 1 .

Table $5.2 E D_{50}$ and maximal increase in resistance of angiotensin $I$ during low and high doses of ACE-iwhibitors.

$\begin{array}{lrlllll} & \text { Dose } & E D_{\text {so }} & \Delta R_{\text {max }} & \text { Dose } & E D_{\text {so }} & \Delta \boldsymbol{R}_{\text {max }} \\ \text { Control } & & 1.64 \pm 0.39 & 2.66 \pm 0.30 & & & \\ \text { Enalaprilate } & 25 & 3.71 \pm 0.58 & 2.25 \pm 0.43 & 250 & 32.8 \pm 3.7^{*} & 1.39 \pm 0.22^{* *} \\ \text { Lisinopril } & 25 & 3.69 \pm 0.78 & 1.99 \pm 0.28 & 250 & 29.0 \pm 3.7^{*} & 1.51 \pm 0.16^{*} \\ \text { Captopril } & 750 & 9.09 \pm 1.10^{*} & 1.88 \pm 0.34 & 7500 & 32.2 \pm 2.4^{*} & 1.39 \pm 0.19^{* *} \\ \text { Zabiciprilare } & 25 & 2.65 \pm 0.21 & 1.68 \pm 0.26 & 250 & 37.9 \pm 8.3^{*} & 1.58 \pm 0.40^{* *}\end{array}$

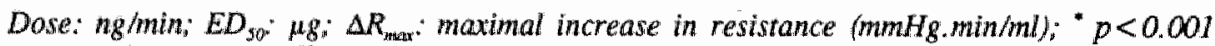
compared to control; " $p<0.05$ compared to control; " $p<0.001$ compared to control and other ACE-inhibitors. 


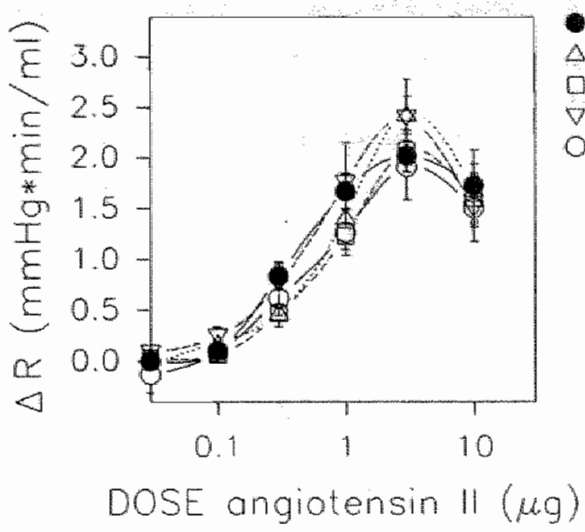

control

enoloprilote

lisinopril

zabiciprilate

captopril

Figure 5.4 Effects of high doses of enalaprilate, lisinopril zabiciprilate and captopril on the dose-response curve of angiotensin $I I$.

increase in $\mathrm{ED}_{50}$ was also significantly different from the other ACE-inhibitors tested. At low doses, $\Delta \mathrm{R}_{\max }$ was not significantly affected.

\section{$5.4 \quad$ DISCUSSION}

The aim of the present study was to investigate inhibition of local ACE in relation to inhibition of circulating $\mathrm{ACE}$ by ACE-inhibitors. To exclude the circulating RAS a hindlimb perfusion model was used. Both angiotensin I and II cause dose-dependent vasoconstrictions. The constrictor responses to angiotensin I but not II are dose-dependently inhibited by ACE-inhibitors, suggesting that the angiotensin I effect depends upon ACE-dependent conversion to angiotensin II.

Baseline values of pressure and flow were comparable in the experimental groups. The hindlimbs were perfused under physiological flow conditions but not under physiological pressure conditions to avoid development of oedema. These circumstances corresponded to circumstances used in most other hindlimb perfusion experiments (Bomzon and Naidu, 1985; Lindsey et al., 1987b; Mizuno et al., 1990).

Recently, local generation and metabolism of angiotensin I and II in the perfused hindlimbs have been reported (Mizuno et al., 1988b; Hilgers et al., 1989). To investigate functional relevance of local RAS, responses of angioten$\sin$ I and II on resistance were investigated in the perfused hindlimbs. Both angiotensin I and II increased resistance in the hindlimb perfusion model. The $\mathrm{ED}_{50}$ of angiotensin II was about 3 times less than the $\mathrm{ED}_{50}$ of angiotensin I, which suggests that the conversion of angiotensin I to angiotensin II during a single passage is about $30 \%$. These data are comparable with earlier experi- 
ments in which angiotensin I conversion varied from $20-50 \%$ in hindlimb vasculature and in kidney (Bendhack et al., 1986; Schmidt et al., 1986; Lindsey et al., 1987b; Hilgers et al., 1989).

To investigate whether the responses to angiotensin I depend upon conversion to angiotensin II by $A C E$, the influences of $A C E$-inhibitors on the angiotensin I and II effects were tested. ACE-inhibition had no effect on $E D_{50}$ and $\triangle R_{\max }$ of angiotensin $\mathbb{I}$, whereas $\mathrm{ED}_{50}$ of angiotensin $\mathbb{I}$ increased and $\Delta \mathrm{R}_{\max }$ decreased dose-dependently. The increase in $\mathrm{ED}_{50}$ for angiotensin I responses by the $\mathrm{ACE}$ inhibitors is consistent with the presence of an active ACE in the hindlimb perfusion model. Similar inhibition of functional responses to angiotensin I were reported in isolated kidney (Schmidt et al., 1986), mesenteric bed (Weishaar et al., 1991) and hindlimbs (Mueller and Cohen, 1983). In the latter preparation, also the generation of angiotensin II as determined by chemical analysis, was inhibited by ACE-inhibitors (Oliver and Sciacca, 1984; Nakamaru et al., 1987; Mizuno et al., 1988b, 1990; Hilgers et al., 1989). In contrast, other investigators reported a lack of inhibition of functional responses of exogenous angioten$\sin I$ in perfused hindlimbs and mesenteric bed (Bendhack et al., 1986; Lindsey et al., 1987b). The doses of angiotensin I and II used by these investigators were lower than the doses which belong to the linear part of the sigmoidal curve in the present study, which may explain the lack of effect in their studies.

The decrease in $\Delta R_{\max }$ suggests non-competitive inhibition of ACE. The reason for that is not yet clear. A possible explanation is the short contact time between angiotensin I and vascular $\mathrm{ACE}$, to which $\mathrm{ACE}$-inhibitors bind competitively but tightly (Schullek and Wilson, 1989). The suggestion that contact time may play a role, is supported by the lack of effect on $\Delta R_{\max }$ after ACE inhibition in a closed circuit perfusion model in which contact time between angiotensin I and the complex of ACE and ACE-inhibitor was greater than in our model (Schmidt et al., 1986). Another possibility is an almost completely inhibited vascular $\mathrm{ACE}$. In the present experiments, in the presence of an ACE-inhibitor, the $\mathrm{ED}_{50}$ of angiotensin II was about 60 times less than the $\mathrm{ED}_{50}$ of angiotensin I, which suggests that the maximal conversion of angiotensin I to angiotensin II by $\mathrm{ACE}$ is about $1-2 \%$. The increase in resistance may, however, be a direct angiotensin I effect (Peach, 1977) or a non-specific effect by conversion with a different tissue angiotensin II generating enzyme, such as a chymostatin-sensitive angiotensin II generating enzyme (CAGE; Okunishi et al., 1984; Okamura et al., 1990) or kallikrein (Ideishi et al., 1990).

In contrast to the lower doses (see below), at high doses the increase in $\mathrm{ED}_{50}$ was not different between the ACE-inhibitors. This may be explained on the basis of the same arguments in the previous paragraph, and suggests a degree of non-specificity. At low doses, the increase in $\mathrm{ED}_{50}$ of angiotensin I was greater for captopril compared to the other ACE-inhibitors tested. The greater increase in $\mathrm{ED}_{50}$ by captopril may be a consequence of a higher dose, which is 30 times 
the doses of enalaprilate, lisinopril and zabiciprilate. However, at the same doseratio the $A C E$-inhibitors inhibited plasma $A C E$-activity in vivo to the same extent. The greater increase in $E_{50}$ by captopril in the perfused hindlimbs is therefore not likely to be a consequence of the higher dose. This suggestion is further supported by results obtained from hemodynamic measurements in vivo. Except for lisinopril, the ACE-inhibitors were equipotent in inhibiting angiotensin I pressor responses in vivo. This suggests that captopril is more potent in inhibiting local ACE than the other ACE inhibitors. The more specific inhibition of local ACE by captopril was previously found, as inhibition of ACE in heart and aorta was greater for captopril compared to enalaprilate and lisinopril (Cushman et al., 1989a,b).

A possible explanation for differences in the potency to inhibit vascular ACE may be due to the localization of $\mathrm{ACE}$ in the vessel wall. After removal of the endothelium, ACE is still present (Velletri and Bean, 1982; Urabe et al., 1987; Pipili et al., 1989). Thus, the endothelial cell is not the only location of ACE in the vessel wall. In rat aorta, the media and adventitia contain ACE (Velletri and Bean, 1982), whereas also interstitial fibroblasts have been suggested to contain ACE (Pipili et al., 1989). Moreover, it has been suggested that ACE in endothelium is not mainly responsible for local activation of angiotensin I (Urabe et al., 1987). Therefore, the ability of the ACE inhibitors to penetrate into media and adventitia may determine differences in inhibiting vascular ACE. In this regard, physico-chemical properties, such as lipophilicity of the ACE-inhibitor, may be an important factor in determining inhibition of vascular ACE (Mizuno et al, 1988b, 1990; Higashimori et al., 1991).

In conclusion, the hindlimb perfusion model is a reproducible model for investigations of functional local angiotensin I and II responses. As the responses of angiotensin I but not of angiotensin II can be inhibited dose-dependently by ACE-inhibitors, ACE is suggested to be active. In this model captopril may be more potent in inhibiting local ACE than the other ACE-inhibitors tested. 



\section{CHAPTER 6}

\section{Vascular responsiveness in acute and chronic ischemic skeletal muscle}

\subsection{INTRODUCTION}

Chronic obstructive peripheral arterial disease, usually manifested as intermittent claudication, is an important clinical problem, which is responsible for considerable morbidity and increased cardiovascular mortality in humans over 55 years of age. The cause is almost always atherosclerosis in femoral and iliac arteries (Radack and Wyderski, 1990). In mild ischemia, flow in lower extremities decreases to levels that are inadequate to support metabolic demands of tissue during physical exercise, whereas in severe ischemia blood flow can not support metabolic demands of tissue both during physical exercise and in rest. To conform blood flow and oxygen supply, several acute and chronic compensatory mechanisms are activated, such as metabolic and structural adaptations in skeletal muscles (Ludatscher et al., 1981; Harris et al., 1986; Heppenstall et al., 1986; Idström et al., 1990) and structural adaptation of resistance vessels (Folkow et al., 1971; Bund et al., 1991). Furthermore, generation of a collateral circulation can restore blood supply to the ischemic region (Fernandez et al., 1982, 1985; Barie and Mullins, 1988). Collateral vessels and normal vascular beds are not comparable, as collateral vessels showed a hyperreactivity to substances like serotonin (Verheyen et al., 1988, 1991), a thromboxane $A_{2}$ analogue (Verheyen et al., 1989) and noradrenaline (Williams and Saelens, 1983). This is probably due to differences in vascular structure and sensitivity of receptor-linked mechanisms. 
One of the humoral mechanisms involved in mechanisms following ischemia of skeletal muscle may be the local renin angiotensin systems (RAS), identified in a number of tissues (Ikemoto et al., 1986; Dzau, 1988; Lindpaintner et al., 1988; Unger et al, 1988; Rosenfeld and Zabludowski, 1989). Local RAS are proposed to play a role in the humoral compensatory mechanisms activated in ischemia of heart and brain (Waldemar and Paulson, 1989; Fleetwood et al. 1991; Lindpaintner and Ganten, 1991). Furthermore, hypoxia can induce synthesis of local ACE in endothelial cells (King et al., 1989) and angiotensin II is suggested to be one of the locally active growth factors, which can induce recruitment of preexisting vessels and neovascularization (Fernandez et al., 1982, 1985; Wang and Prewitt, 1990; Le Noble et al., 1991).

In patients with intermittent claudication hypertension is one of the factors, which worsens prognosis in these patients (Hertzer, 1991). Therefore, antihypertensive therapy is very important in these patients. However, antihypertensive therapy can cause a further reduction of blood flow in the ischemic legs (Bogaert and Clement, 1983; Lepäntalo, 1984; Hiatt et al., 1985; Roberts et al., 1987a; Bernardi et al., 1988). The present experiments were performed in spontaneously hypertensive rats to investigate the combination of hypertension and skeletal muscle ischemia.

The aim of the present study was to investigate the role of local RAS in the compensatory mechanisms due to hindlimb ischemia. Therefore, functional responses to angiotensin I, angiotensin II and phenylephrine were obtained in an animal model with severe ischemia. Ischemia was induced by partial occlusion of the left common iliac artery, so both structural changes of existing vessels and development of collateral vessels could be investigated. To distinguish acute and chronic compensatory involvement of the local RAS, functional responses were obtained $45 \mathrm{~min}$ and 4 weeks after induction of ischemia.

\subsection{MATERIALS AND METHODS}

\subsubsection{Animals}

Experiments were performed in male spontaneously hypertensive rats (SHR). Animals weighed $270-310 \mathrm{~g}$ at the start of the protocol for chronic ischemia experiments, and $320-360 \mathrm{~g}$ at the start of the protocol for control and acute ischemia experiments. 


\subsubsection{Surgery}

\section{Chronic ischemia}

Rats were anesthetized with ether and a partial occlusion of the left common iliac artery was induced as described in section 2.2.5. Hindlimb perfusion experiments were started 4 weeks after induction of hindlimb ischemia.

\section{Hindlimb perfusion}

Rats were anesthetized with pentobarbital and prepared for hindlimb perfusion as described in section 4.2.1. After initiation of the perfusion, electromagnetic flow probes were placed on both common iliac arteries.

\subsubsection{Measuring protocols}

The hindlimb preparation was allowed to equilibrate for $30-45 \mathrm{~min}$ to achieve a steady-state level of perfusion pressure and flows. Immediately after equilibration dose-response curves of $\left[\mathrm{Val}^{5}\right]$-angiotensin I $(0.1-10 \mu \mathrm{g}),\left[\mathrm{Val}^{5}\right]$-angiotensin II $(0.03-10 \mu \mathrm{g})$ or phenylephrine $(0.1-300 \mu \mathrm{g})$ were generated in control and chronically ischemic animals.

In acute ischemia dose-response curves were generated $45 \mathrm{~min}$ after initiation of ischemia by partial occlusion of the left common iliac artery as described in section 2.3.3.

Each dose-response curve was generated in a separate hindlimb preparation and minimal time interval between two injections angiotensin I or II was 15 min. Before and after the generation of a dose-response curve of angiotensin I or II, $30 \mu \mathrm{g}$ phenylephrine was injected for evaluation of responsiveness of the hindlimb preparation.

Perfusion pressure $(P)$ and flow $\left(F_{L}\right.$ and $F_{R}$ ) in both common iliac arteries were monitored continuously.

\subsubsection{Data analysis}

Resistance in left $\left(R_{L}\right)$ and right $\left(R_{R}\right)$ hindlimb, half-maximal effective dose $\left(E D_{50}\right)$ and maximal effect $\left(\Delta R_{\max }\right)$ of angiotensin I and II and phenylephrine were computed as described in section 4.2.6.

Responses of the vasoconstrictor agents were expressed as absolute maximal resistance changes.

Values of control, acutely ischemic and chronically ischemic hindlimb experiments were compared by one-way analysis of variance and Bonferroni and Dunnett's test or Student's t-test for unpaired observations. Values of left and right hindlimb were compared by Student's t-test for paired observations. 


\subsection{RESULTS}

\subsubsection{Acute ischemia}

To compare the reactivity of the left and right hindlimb, the ratio of maximal resistance changes of the left and right hindlimb ( $\Delta \mathrm{R}_{\max }$ left/ $\Delta \mathrm{R}_{\max }$ right) were computed. As shown in figure 6.1 , the ratios of effects on resistance induced by angiotensin I, angiotensin II or phenylephrine were flow-dependently increased. Therefore, mean values were calculated separately for mild (residual left flow: 40-75\%) and severe ischemia (residual left flow: <40\%).

Baseline resistances of both hindlimbs in control and acute ischemia groups are summarized in table 6.1. Due to a decreased flow, the resistance of the left

Table 6.1 Baseline resistances of left and right hindlimb in control and acurely ischemic rats.

$\begin{array}{lccc} & N & R_{L} & R_{R} \\ \text { CONTROL } & 27 & 20.1 \pm 0.9 & 19.3 \pm 1.1 \\ \text { ISCHEMIA mild } & 10 & 35.9 \pm 2.3^{*} & 18.2 \pm 0.8 \\ \text { ISCHEMIA severe } & 33 & 164.0 \pm 22.5^{*} & 17.9 \pm 0.9\end{array}$

$R_{L}$ and $R_{R^{*}}$ resistance in lefi and right hindimib $(\mathrm{mmHg} . \mathrm{min} / \mathrm{ml}) ;{ }^{*} p<0.05$ compared to control and mild ischemia.
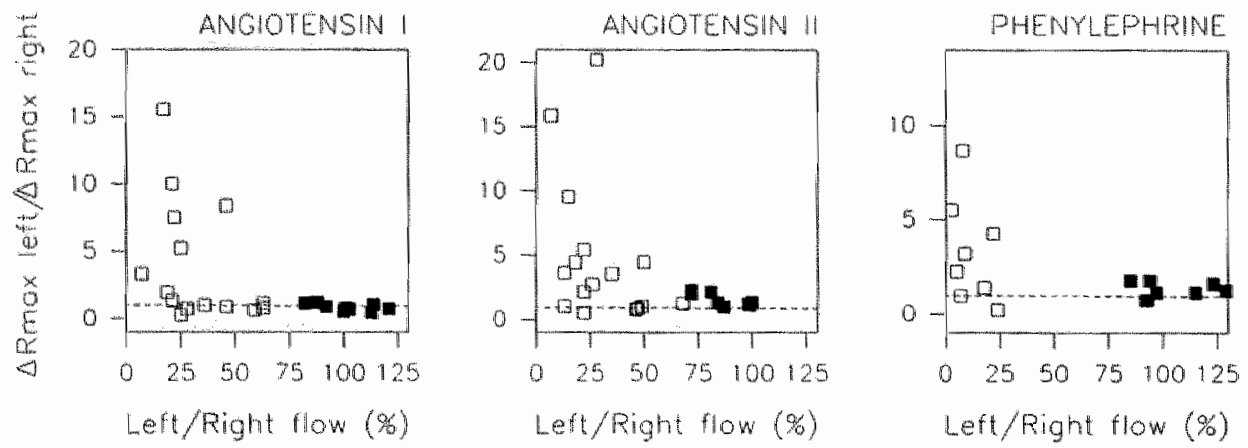

- control a ischemia

Figure 6.1 Ratio of angiotensin I, angiotensin II and phenylephrine responses in left and right hindlimb in relation to residual left flow in control and acuse ischemia. 
Table $6.2 \mathrm{ED}_{50}$ and maximal increase in resistance of angiorenim $I_{\text {, angiotensin } I I}$ and phenylephrine in left and right hindlimb of control and acutely ischemic rats.

\begin{tabular}{|c|c|c|c|c|c|c|}
\hline & \multicolumn{2}{|c|}{ ANGIOTENSIN I } & \multicolumn{2}{|c|}{ ANGIOTENSIN $I I$} & \multicolumn{2}{|c|}{ PHENKLEPHRINE } \\
\hline & Left & Right & Left & Right & Left : & Right \\
\hline CONTROL & $N=9$ & & 9 & & 10 & \\
\hline$E D_{50}$ & $1.09 \pm 0.15$ & $1.13 \pm 0.23$ & $1.19 \pm 0.29$ & $0.50 \pm 0.13$ & $56.3 \pm 13.5$ & $43.5 \pm 7.8$ \\
\hline$\Delta R \max$ & $11.1 \pm 1.16$ & $13.2 \pm 2.31$ & $12.1 \pm 1.56$ & $8.5 \pm 0.94$ & $225 \pm 66$ & $181 \pm 28.3$ \\
\hline $\begin{array}{l}\text { ISCHEMIA } \\
\text { mild }\end{array}$ & $N=5$ & & 5 & & & \\
\hline$E D_{50}$ & $1.10 \pm 0.37$ & $0.79 \pm 0.05$ & $0.32 \pm 0.04^{*}$ & $0.42 \pm 0.06$ & & \\
\hline$\Delta R_{\max }$ & $14.0 \pm 4.13$ & $9.5 \pm 1.70$ & $17.5 \pm 7.98$ & $10.2 \pm 1.62$ & & \\
\hline$\%$ flow & $55.4 \pm 3.9$ & & $52.0 \pm 4.1$ & & & \\
\hline $\begin{array}{l}\text { ISCHEMIA } \\
\text { severe }\end{array}$ & $N=12$ & & 9 & & 9 & \\
\hline$E D_{50}$ & $1.25 \pm 0.31$ & $0.81 \pm 0.07$ & $0.48 \pm 0.13$ & $0.39 \pm 0.10$ & $16.7 \pm 7.4^{4}$ & $34.6 \pm 10.4$ \\
\hline$\Delta R_{\max }$ & $34.3 \pm 11.2$ & $9.5 \pm 1.41$ & $35.3 \pm 3.93^{* *}$ & $6.9 \pm 1.58$ & $443 \pm 175$ & $285 \pm 123$ \\
\hline \% flow & $20.0 \pm 2.4$ & & $20.1 \pm 2.3$ & & $12.0 \pm 2.5$ & \\
\hline
\end{tabular}

$E D_{50^{*}} \mu g ; \Delta R_{\max }$ maximal increase in resistance $(\mathrm{mm} / \mathrm{g} . \mathrm{min} / \mathrm{ml}) ;{ }^{*} p<0.05$ compared to control," $p<0.05$ compared to contralateral hindlimb.

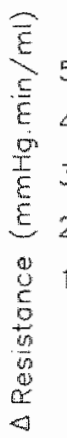

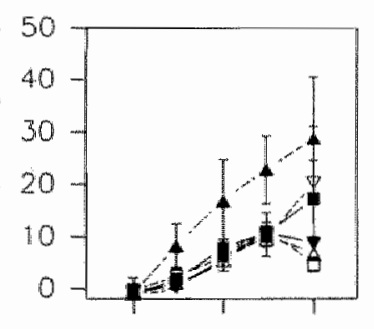

0.1

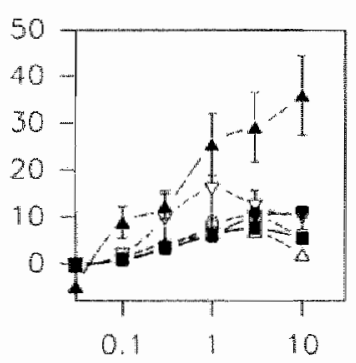

DOSE angiotensin $\|(\mu g)$

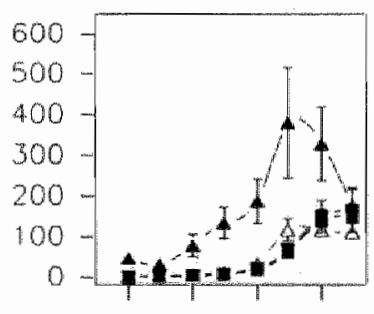

$0.1,10 \quad 100$

DOSE phenylephrine (a.g)

DOSE angiotensin $1(\mu \mathrm{g})$

$\checkmark$ lefi

$\nabla$ terl

4 er
- right hindlimb

- right hindlimb

$\Delta$ right hindimb

Figure 6.2 Angiotensin 1 , angiotensin II and phenylephrine responses in control and acure ischemia. 
hindlimb increased in mild ischemia and significantly in severe ischemia compared to control. The resistance of the right hindlimb was not affected.

As depicted in figure 6.2 and table $6.2, \mathrm{ED}_{50}$ and $\Delta \mathrm{R}_{\max }$ were comparable in both hindlimbs of control rats. In contrast, $\Delta R_{\max }$ of angiotensin $I$, angiotensin II and phenylephrine was increased in left hindlimb in the severe ischemia group, whereas the corresponding right hindlimb and both hindlimbs in the mild ischemia group had no increased reactivity. The increase of $\Delta R_{\max }$ was only significant for angiotensin II responses compared to control and contralateral hindlimb. Acute ischemia had no effect on $\mathrm{ED}_{50}$ of angiotensin I, angiotensin II and phenylephrine, except for $\mathrm{ED}_{50}$ of phenylephrine in severely ischemic hindlimb and of angiotensin II in mild ischemia due to a slightly increased $\mathrm{ED}_{50}$ in the left hindlimb in control animals.

Table 6.3 Baseline resistances of left and right hindlimb in control and chronically ischemic rats.

$\begin{array}{llcc} & N & R_{L} & R_{R} \\ \text { CONTROL } & 27 & 20.1 \pm 0.9 & 19.3 \pm 1.1 \\ \text { ISCHEMIA mild } & 28 & 23.1 \pm 1.37^{\sharp} & 14.5 \pm 0.7 \\ \text { ISCHEMIA severe } & 32 & 140.8 \pm 25.3^{* / 4} & 16.9 \pm 0.6\end{array}$

$R_{L}$ and $R_{R^{*}}$ resistance of left and right hindlimb $(\mathrm{mmHg} . \mathrm{min} / \mathrm{mll}) ;{ }^{*} p<0.05$ compared to control and mild ischemia; $" p<0.05$ compared to contralateral hindlimb.
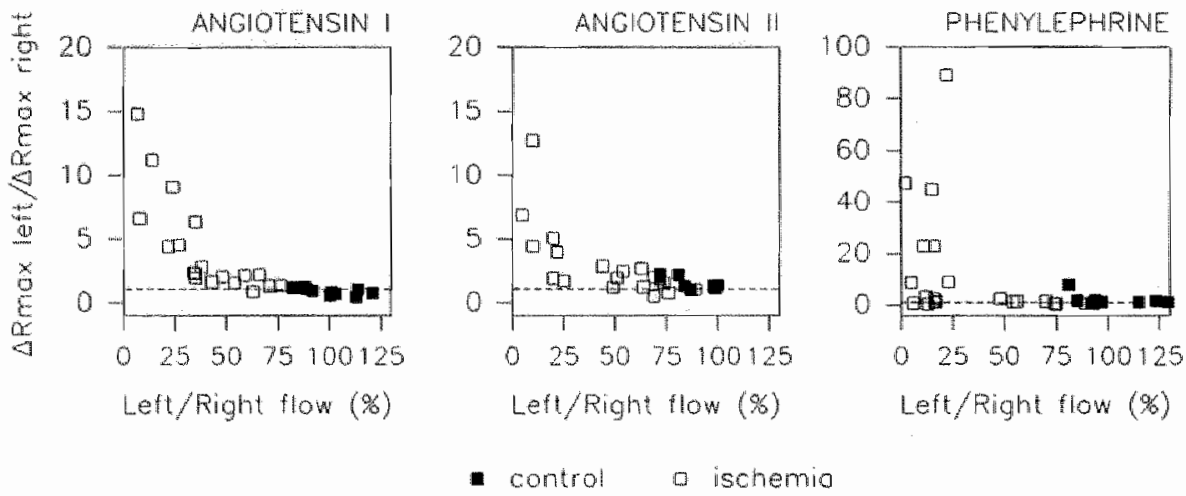

Figure 6.3 Ratio of angiotensin I, angiotensin II and phenylephrine responses in left and right hindlimb in relation to residual left flow in control and chronic ischemia. 


\subsubsection{Chronic ischemia}

As shown in figure 6.3, the ratios of maximal effects on resistance of angiotensin I, angiotensin II and phenylephrine were also flow-dependent. Therefore, chronic ischemia was divided into mild (residual left flow: 40-75\%) and severe ischemia (residual left flow $<40 \%$ ).

Baseline values of resistance of both hindlimbs in control, mild and severe ischemia are summarized in table 6.3. Resistance of the left hindlimb increased with decreased residual flow. Severe ischemia increased resistance of the left hindlimb significantly compared to control and mild ischemia. Resistance of the right hindlimb decreased slightly but significantly in the mild ischemic group, whereas severe ischemia had no effect on right hindlimb.

As depicted in figure 6.4 and table $6.4, \mathrm{ED}_{50}$ and $\Delta \mathrm{R}_{\max }$ were comparable for both hindlimbs in control rats. Comparable with data obtained in acute ischemia, $\Delta \mathrm{R}_{\max }$ of angiotensin I, angiotensin II and phenylephrine was increased in left hindlimb in severe ischemia, whereas the corresponding right hindlimb and both hindlimbs in mild ischemia were not influenced. The increase in $\Delta \mathbf{R}_{\max }$ was significant for angiotensin I and angiotensin II compared to control and contralateral hindlimb. Furthermore, in mild ischemia angiotensin I increased $\Delta R_{\max }$ of left hindlimb significantly compared to the contralateral

Table $6.4 E_{50}$ and maximal increase in resistance of angiotensin $I$, angiotensin $I I$ and phenylephrine in both hindlimbs of control and chromically ischemic rats.

\begin{tabular}{|c|c|c|c|c|c|c|}
\hline & \multicolumn{2}{|c|}{ ANGIOTENSIN I } & \multicolumn{2}{|c|}{ ANGIOTENSIN II } & \multicolumn{2}{|c|}{ PHENYLEPHRINE } \\
\hline & Left & Right & Left & $R i g h t$ & Left & Right \\
\hline CONTROL & $N=9$ & & 9 & & 10 & \\
\hline$E D_{50}$ & $1.09 \pm 0.15$ & $1.13 \pm 0.23$ & $1.19 \pm 0.29$ & $0.50 \pm 0.13$ & $56.3 \pm 13.5$ & $43.5 \pm 7.8$ \\
\hline$\Delta R \max$ & $11.1 \pm 1.16$ & $13.2 \pm 2.31$ & $12.1 \pm 1.56^{47}$ & $8.5 \pm 0.94$ & $225 \pm 66$ & $18 I \pm 28.3$ \\
\hline ISCHEMIA & & & & & & \\
\hline mild & $N=9$ & & 12 & & 7 & \\
\hline$E D_{50}$ & $1.80 \pm 0.27$ & $0.95 \pm 0.08$ & $0.52 \pm 0.08^{*}$ & $0.44 \pm 0.06$ & $39.1 \pm 4.0^{4}$ & $27.0 \pm 1.7$ \\
\hline $\begin{array}{l}\Delta R_{\max } \\
\% \text { flow }\end{array}$ & $\begin{array}{l}9.7 \pm 1.15^{f \prime} \\
63.2 \pm 4.8\end{array}$ & $5.9 \pm 0.89$ & $\begin{array}{l}9.7 \pm 1.36 \\
64.5 \pm 3.8\end{array}$ & $6.8 \pm 0.76$ & $\begin{array}{l}82.8 \pm 8.1 \\
66.6 \pm 5.5\end{array}$ & $75.7 \pm 10.7$ \\
\hline ISCHEMIA & & & & & & \\
\hline severe & $N=11$ & & 9 & & 10 & \\
\hline $\begin{array}{l}E D_{50} \\
\Delta R_{\text {max }} \\
\text { oflow }\end{array}$ & $\begin{array}{l}1.00 \pm 0.17 \\
44.0 \pm 9.41^{*} \\
25.4 \pm 3.4\end{array}$ & $\begin{array}{l}0.92 \pm 0.13 \\
7.4 \pm 0.82\end{array}$ & $\begin{array}{l}0.56 \pm 0.11 \\
42.3 \pm 12.9^{*} \\
17.7 \pm 2.5\end{array}$ & $\begin{array}{l}0.41 \pm 0.07 \\
7.9 \pm 1.00\end{array}$ & $\begin{array}{l}24.7 \pm 5.6 \\
35.6 \pm 109 \\
16.1 \pm 1.2\end{array}$ & $\begin{array}{l}34.6 \pm 7.4 \\
146 \pm 34\end{array}$ \\
\hline
\end{tabular}




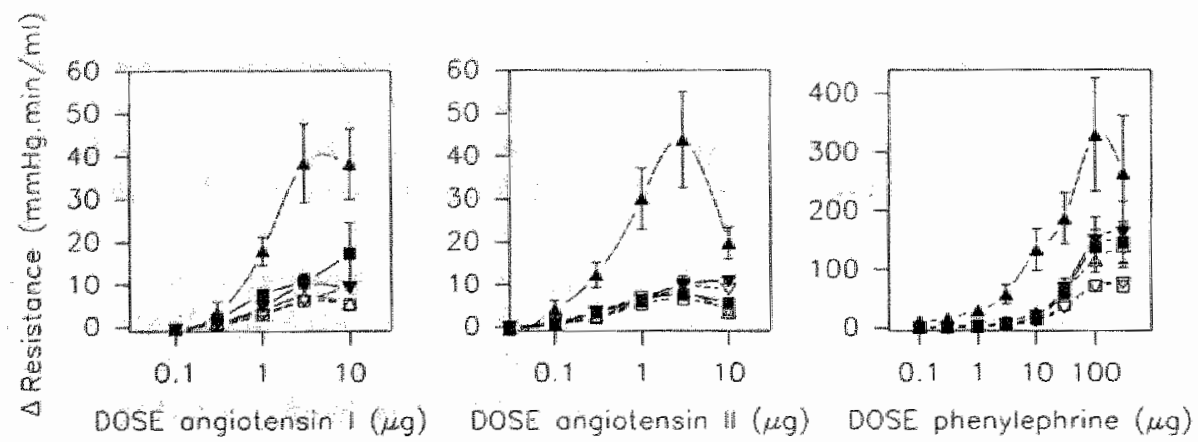

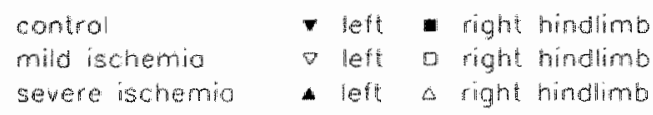

Figure 6.4 Angiotensin I, anglotensin II and phenylephrine responses in control and chronic ischemia.

hindlimb. Chronic ischemia had no effect on $\mathrm{ED}_{50}$ of angiotensin $\mathrm{I}$, angiotensin II and phenylephrine in both hindlimbs, except in left mild ischemic hindlimb.

\subsection{DISCUSSION}

To investigate the role of local RAS in acute and long-term compensatory mechanisms following ischemia in skeletal muscle, functional responses to angiotensin I, angiotensin II and phenylephrine were studied in the perfused hindlimb model with unilateral ischemia. To achieve acute and chronic ischemia of skeletal muscle, the left common iliac artery was partially occluded. Acute ischemia was induced in the perfused hindlimb preparation and chronic ischemia for 4 weeks before hindlimb perfusion experiments.

Reactivity (maximal increase in resistance) to angiotensin I, angiotensin II and phenylephrine increased in severely ischemic hindlimb in both acute and chronic ischemia, whereas sensitivity $\left(\mathrm{ED}_{50}\right)$ was not influenced. In contrast, acute and chronic mild ischemia had no or marginal effects on sensitivity and reactivity to angiotensin I, angiotensin II and phenylephrine. This suggests a non-selective hyperreactivity of the severely ischemic hindlimb.

In control animals baseline resistances of both hindlimbs were comparable. Following acute or chronic ischemia, baseline resistance of the left hindlimb in acute and chronic ischemia was inversely related to resting flow. In contrast, baseline resistance of the right (non-ischemic) hindlimb was not influenced, except for resistance in chronically mild ischemia.

Baseline resistances of control animals in the present experiment were comparable with the intrinsic resistances at maximal dilatation in sham animals 
observed by Verheyen et al. (1991). In contrast, complete occlusion of the femoral artery induced by these investigators caused a much lower intrinsic resistance of the chronically ischemic hindlimbs than the baseline resistance of acutely and chronically ischemic hindlimbs in the present experiments. The higher baseline resistances in the present experiments are not likely to be due to constriction of the ischemic vascular bed. More likely, a greater reduction of blood flow and thus a more severe ischemia results from partial occlusion of the common iliac artery than from complete occlusion of the femoral artery.

In both acute and chronic ischemia reactivity of the ischemic hindlimb was related to the severity of ischemia. A residual flow in the ischemic hindlimb of more than $40 \%$ had no effect on maximal reactivity, whereas maximal reactivity increased if residual flow was lower than about $40 \%$. Therefore, both acute and chronic ischemia were divided into mild and severe ischemia. A 50-60\% reduction of flow seems to be a critical point for functional changes. This reduction results in flow levels that are inadequate to support the metabolic demands of resting tissue (Kwasnik et al., 1991).

To conform blood supply and oxygen demand in the ischemic hindlimb, several acute and chronic adaptive mechanisms are activated. Acutely, several metabolic changes, such as an increased oxydative capacity (Hammarsten et al., 1980), a decreased muscle $\mathrm{pH}$ (Kwasnik et al., 1991) and disturbances of purine metabolism (Harris et al., 1986; Idström et al., 1990), have been described. Later, changes in ultrastructure of muscles and capillaries occur (Ludatscher et al., 1981; Gidlöf et al., 1987). In the present study, responsiveness of hindlimbs was assessed in acutely ischemic animals $45 \mathrm{~min}$ after induction of partial occlusion. As degenerative alterations of a diversity of intracellular structures of skeletal muscle occurred after 6-7 h (Ludatscher et al., 1981) and only a minor part of the capillaries were damaged after $90-180 \mathrm{~min}$ of total occlusion (Gidlöf et al., 1987), muscle and capillary damage seem not likely to occur in the present acute ischemia model.

Chronically, structural adaptations of vesse』 wall and skeletal muscle were probably initiated due to a decreased blood pressure and flow in ischemic hindlimb. Chronic hypotension in hindlimbs results in structural changes of resistance vessels, such as reduction in media thickness, media cross-sectional area and media/lumen ratio (Folkow et al., 1971; Bund et al., 1991). Furthermore, development of collateral vessels to restore blood flow and oxygen supply has been described (Conrad et al., 1971; Barie and Mullins, 1988; Adair et al., 1990). Collateral circulation can develop in two phases: a fast (minutes) vasodilatation of preexisting vessels and a slow (days) formation of new vessels and anatomical increase in collateral vessel size (Fernandez et al., 1982, 1985; Barie and Mullins, 1988).

The renin angiotensin system has been suggested to play a role in adaptation processes due to ischemia in heart and skeletal muscle (Fernandez et al., 1982, 
1985; Remme, 1986; Lindpaintner and Ganten, 1991). Furthermore, hypoxia influenced local ACE synthesis and activity (King et al., 1989). To investigate the role of the renin angiotensin system in compensatory mechanism after acute and chronic ischemia of skeletal muscle functional responses of angiotensin I, angiotensin II and phenylephrine were obtained in a perfused hindlimb model.

Maximal resistance changes to all vasoconstrictors investigated were only increased in severely ischemic hindlimbs. The reason for this is not yet clear. Possible explanations may be an increased sensitivity of receptors for the corresponding agonists in severe ischemia and/or an increased sensitivity of receptorlinked mechanisms. The hypersensitivity is not specific for angiotensin II and phenylephrine, since Verheyen et al. described also a hyperreactivity for serotonin $(1988,1991)$ and a thromboxane $A_{2}$ analogue (1989). These investigators suggested that alterations in reactivity are probably not related to differences in sensitivity of the receptors, but to differences in vascular structure or sensitivity of receptor-linked mechanisms. Alterations in receptor-linked mechanisms may explain the hyperreactivity for angiotensin II, phenylephrine and also for serotonin (Verheyen et al., 1988, 1991) and the thromboxane $A_{2}$ analogue (Verheyen et al., 1989), since the second messenger systems of the corresponding receptors are the same (Watson and Abbott, 1992). The receptor-linked hyperreactivity has been proposed to be related to $\mathrm{Ca}^{2+}$ entry, as only $\mathrm{Ca}^{2+}$ entry blockade can reduce the increased vasoconstriction due to the thromboxane $\mathrm{A}_{2}$ analogue (Verheyen et al., 1989). However, this proposed increase in $\mathrm{Ca}^{2+}$ entry may also result from ultrastructural changes of blood vessels.

An alternative explanation for the non-selective hyperreactivity may be the development of collaterals. The collateralized circulatory beds may be hyperreactive to vasoconstrictors in comparison to normal beds due to an increased vessel wall thickness of collaterals (Barie and Mullins, 1988; Verheyen et al., 1991) or due to a diminished innervation of collateral vessels, which results in hypersensitivity of postsynaptic receptors (Williams and Saelens, 1983).

In conclusion, increased resistance changes in acute and chronic severe ischemia are observed for angiotensin I, angiotensin II and phenylephrine and previously for serotonin and a thromboxane $A_{2}$ analogue. Thus, hyperreactivity of the vascular bed of the ischemic hindlimb is not specific. The hyperreactivity may be due to alterations of receptor-linked mechanisms or to acute and chronic ultrastructural changes of blood vessels. In chronic ischemia also development of collateral vessels may be involved.

The reactivity $\left(\Delta \mathrm{R}_{\max }\right)$ was comparable for angiotensin I and II. Therefore, the increased responsiveness to angiotensin I in severe ischemia seems to be the result of increased responsiveness to angiotensin II and not the consequence of increased conversion of angiotensin I. Thus, activation of local ACE seems not to be involved in ischemia. 


\section{CHAPTER 7}

\section{Skeletal muscle ischemia and antihypertensive therapy}

\subsection{INTRODUCTION}

As described in the previous chapter, partial ligation of common iliac artery results in ischemia of skeletal muscle and thus in initiation of several adaptive and compensatory mechanisms. Peripheral vascular disease in humans usually results in intermittent claudication, manifested in a reduced walking distance due to pain in the leg (Hertzer, 1991). The amount of exercise at which the symptoms begin for the first time is usually at a constant level. The symptoms cornpletely resolve within several minutes after discontinuing exercise and occur again at approximately the same distance once activity has been resumed. First treatment guidelines for intermittent claudication are loss of weight, an appropriate diet, physical exercise, abstinence from smoking and correction of high blood pressure (Verstraete, 1982). Furthermore, several treatment regimens are possible. Surgical correction, such as removal of obstructive thrombi or atheroma, balloon angioplasty, percutaneous atherectomy and thrombolytics can be considered (Graor and Whitlow, 1990; Kriessmann, 1990; Earnshaw, 1991). Drug therapy of intermittent claudication is usually focused on increasing diameter of existing and collateral vessels and on reversal of the decreased erythrocyte deformability and the increased blood viscosity in peripheral arterial disease (Verstraete, 1982; Radack and Wyderski, 1990).

Hypertension in patients with intermittent claudication needs special attention. Hypertension increases the incidence of coronary artery disease, which is one of 
the complicating factors of peripheral vascular disease (Hertzer, 1991). Therefore, treatment of hypertension is one of the first guidelines in management of intermittent claudication: Reduction in blood pressure with several $\beta$-blockers or captopril in normal hypertensives results in a decreased flow to the legs (Roberts et al., 1987b). This can be deleterious for the ischemic leg. In contrast to the reduction of limb flow in normal hypertensives with captopril, no reduction in limb flow is observed in patients with a combination of hypertension and intermittent claudication. Both a preserved (Roberts et al., 1987a) and an increased limb flow (Catalano and Libretti, 1985) have been described, which resulted in a sustained (Roberts et al., 1987a) or increased (Catalano and Libretti, 1985; Bernardi et al., 1988) pain-free and maximum walking distance on a treadmill. Other antihypertensives, such as $\beta$-blockers, methyldopa and calcium-antagonists, did not improve or decreased ischemic limb hemodynamics (Bogaert and Clement, 1983; Lepäntalo, 1984; Hiatt et al., 1985; Roberts et al., 1987a; Bernardi et al., 1988). The reason for the differences between ACEinhibitors and other antihypertensives is not yet clear, but the differences have been suggested to depend on preferential vasodilatation of the collaterals by captopril (Roberts et al., 1987a; Bernardi et al., 1988).

The role of local renin angiotensin systems in ischemia has been demonstrated by an activation of the local angiotensin II production in myocardial ischemia (Santos et al., 1990; Hirsch et al., 1991) and of local ACE in pulmonary endothelial cells after hypoxia (King et al., 1989). Furthermore, angiotensin II has been described to play a role in neovascularization (Fernandez et al., 1982, 1985; Wang and Prewitt, 1990; Le Noble et al., 1991).

To investigate the role of the renin angiotensin system in the compensatory mechanisms following chronic ischemia of skeletal muscle, the effects of chronic treatment with the ACE-inhibitors captopril and zabiciprilate on hyperreactivity of angiotensin I, angiotensin II and phenylephrine in the vascular bed of the chronic partial ischemic hindlimb have been investigated in the perfused hindlimb model. Furthermore, the $\mathrm{AT}_{1}$-receptor antagonist DuP753 has been studied to elucidate more specifically the role of inhibition of angiotensin II. The calcium entry blocker felodipine was used to compare effects of equivalent blood pressure reductions.

\subsection{MATERIALS AND METHODS}

\subsubsection{Animals}

Experiments were performed in male spontaneously hypertensive rats (SHR). Animals weighed $270-290 \mathrm{~g}$ at the start of the chronic ischemia protocol. 


\subsubsection{Dose finding studies}

Comparable chronic doses of the ACE-inhibitors captopril and zabiciprilate and the $A T_{1}$-antagonist DuP753 in inhibiting the pressor effects of circulating angiotensin I or II, and comparable antihypertensive doses of captopril, zabiciprilate, DuP753 and the calcium entry blocker felodipine were determined in two distinct ways.

Angiotensin responses:

* To determine a chronic dose of zabiciprilate comparable with captopril at a rate of $0.5 \mathrm{mg} / \mathrm{kg} . \mathrm{h}$, animals were treated with zabiciprilate at rates of $0.0017,0.005$ or $0.017 \mathrm{mg} / \mathrm{kg}$. h or with captopril at rates of 0.1 or 0.5 $\mathrm{mg} / \mathrm{kg}$.h for 4-5 days. Therefore, osmotic minipumps (Alzet 2001 or $2 \mathrm{MLI}$; Alza, Palo Alto, USA) were implanted subcutaneously between the shoulder blades. Animals were cannulated with an arterial catheter in the abdominal aorta for blood pressure measurements and a venous catheter for i. w. bolus injections.

Dose-response curves for angiotensin I were generated in anesthetized untreated animals and treated animals. Changes in mean arterial pressure (MAP) after i.v. bolus injections of $\left[\mathrm{Val}^{5}\right]$-angiotensin $\mathrm{I}(0.01-30 \mu \mathrm{g})$ were measured.

* A chronic dose of DuP753 comparable with captopril at a rate of $0.5 \mathrm{mg} / \mathrm{kg} . \mathrm{h}$ was previously determined by Smits et al. (1991). The shift in $\mathrm{ED}_{50}$ for angiotensin II after DuP753 at a rate of $0.625 \mathrm{mg} / \mathrm{kg}$.h was about 32 -fold, whereas the shift in $\mathrm{ED}_{50}$ for angiotensin I after captopril at a rate of 0.5 $\mathrm{mg} / \mathrm{kg} . \mathrm{h}$ was about 17 -fold in anesthetized animals.

\section{Blood pressure reduction:}

* To compare doses of felodipine with doses of the ACE-inhibitors and DuP753, chronically ischemic animals (section 2.2.5) were treated with captopril $(0.5 \mathrm{mg} / \mathrm{kg} . \mathrm{h})$, zabiciprilate $(0.025 \mathrm{mg} / \mathrm{kg} . \mathrm{h})$, DuP753 $(0.625$ $\mathrm{mg} / \mathrm{kg} . \mathrm{h})$ or felodipine $(0.042,0.125$ and $0.42 \mathrm{mg} / \mathrm{kg} . \mathrm{h})$. After 4 weeks of treatment animals were cannulated with an arterial catheter in carotid artery and mean arterial pressure (MAP) was measured in conscious treated and untreated animals.

\subsubsection{Hindlimb experiments}

Surgery: chronic ischemia

Rats were anesthetized with ether and a partial occlusion of the left common iliac artery was induced as described in section 2.2.5. Hindlimb experiments 
were started 4 weeks after induction of hindlimb ischemia.

\section{Treatment:}

Immediately after induction of ischemia, animals were treated for 4 weeks with comparable doses of captopril $(0.5 \mathrm{mg} / \mathrm{kg}$.h; Alzet 2001), zabiciprilate $\left(0.025 \mathrm{mg} / \mathrm{kg} . \mathrm{h}_{;}\right.$Alzet 2ML2), DuP753 $(0.625 \mathrm{mg} / \mathrm{kg} \cdot \mathrm{h}$; Alzet 2002) or felodipine $(0.042$ and $0.42 \mathrm{mg} / \mathrm{kg}$.h; Alzet 2002 and 2001) or received no treatment. Therefore, osmotic minipumps (Alza, Palo Alto, USA) were implanted subcutaneously between the shoulder blades. The minipumps 2002 and $2 \mathrm{ML} 2$ were replaced after 2 weeks, whereas the minipumps 2001 and $2 \mathrm{ML1}$ were replaced every week under light ether anesthesia. Captopril was dissolved in saline, zabiciprilate and DuP753 in distilled water and felodipine in 100\% PEG400.

\section{Surgery: hindlimb perfusion}

Rats were anesthetized with pentobarbital and prepared for hindlimb perfusion as described in section 4.2.1. After initiation of the perfusion, electromagnetic flow probes were placed on both common iliac arteries.

\section{Measuring protocols:"}

The hindlimbs were allowed to equilibrate for 30-45 min to achieve a steadystate level of perfusion pressure and flows. Dose-response curves of angiotensin $I$ and angiotensin II were generated in untreated and treated animals. Phenylephrine dose-response curves were only generated in untreated animals or animals treated with DuP753. Therefore, $\left[\mathrm{Val}^{5}\right]$-angiotensin $\left[(0.1-10 \mu \mathrm{g})\right.$, [Val $\left.{ }^{5}\right]$-angiotensin II $(0.03-10 \mu \mathrm{g})$ and phenylephrine $(0.1-300 \mu \mathrm{g})$ were injected. Each doseresponse curve was generated in a separate hindlimb preparation. Minimal time interval between two bolus injections of angiotensin I or II was $15 \mathrm{~min}$. Before and after the generation of a dose-response curve of angiotensin I or II, $30 \mu \mathrm{g}$ phenylephrine was injected for evaluation of responsiveness of the hindlimb preparation.

Perfusion pressure $(P)$ and flow $\left(F_{L}\right.$ and $\left.F_{R}\right)$ in both common iliac arteries were monitored continuously.

\subsubsection{Data analysis}

Resistance in left $\left(R_{L}\right)$ and right $\left(R_{R}\right)$ hindlimb, half-maximal effective dose $\left(E D_{50}\right)$ and maximal effect $\left(\Delta R_{\max }\right)$ of angiotensin $I$ and II and phenylephrine were computed as described in section 4.2.6.

Values from two groups of chronic ischemic animals were compared by Student's t-test for unpaired observations. Values from more than two groups chronic ischemia animals were compared by one-way analysis of variance and 
Bonferroni and Dunnett's test. Values from left and right hindlimb were compared by Student's t-test for paired observations.

\subsection{RESULTS}

\subsubsection{Dose findings studies}

Angiotensin I responses in vivo

Both captopril and zabiciprilate increased $\mathrm{ED}_{50}$ for angiotensin I dose-dependently after chronic treatment (table 7.1). However, even the highest dose tested of zabiciprilate resulted in a lower shift of angiotensin I dose-response curve than after captopril $(0.5 \mathrm{mg} / \mathrm{kg} . \mathrm{h})$. Therefore, in further experiments zabiciprilate was administered at a rate of $0.025 \mathrm{mg} / \mathrm{kg} . \mathrm{h}$.

\section{Blood pressure reduction}

The blood pressure reduction of captopril $(0.5 \mathrm{mg} / \mathrm{kg} . \mathrm{h})$ and zabiciprilate $(0.025 \mathrm{mg} / \mathrm{kg} . \mathrm{h}$ ) was comparable in chronic ischemic rats (control: $193 \pm 8$ $\mathrm{mmHg}$; captopril: $157 \pm 10 \mathrm{mmHg}$; zabiciprilate: $158 \pm 9 \mathrm{mmHg} ; \mathrm{N}=3-4)$. DuP753 resulted in a larger blood pressure reduction $(138 \pm 4 \mathrm{mmHg} ; \mathrm{N}=3)$. Felodipine was administered at two different rates, one resulting in a comparable blood pressure reduction as the ACE-inhibitors and one resulting in a comparable blood pressure reduction as DuP753 (felodipine $0.042 \mathrm{mg} / \mathrm{kg} . \mathrm{h}$ : $164 \pm 1 \mathrm{mmHg}$; felodipine $0.42 \mathrm{mg} / \mathrm{kg} . \mathrm{h}: 131 \pm 3 \mathrm{mmHg}$ ).

Table $7.1 E D_{50}$ for angiotensin I after chronic trearment with several doses of captopril or zabiciprilate.

$\begin{array}{llll} & N & \text { dose }(\mathrm{mg} / \mathrm{kg} \cdot \mathrm{h}) & E D_{50}(\mu \mathrm{g}) \\ \text { control } & 4 & & 0.083 \pm 0.01 \\ \text { captopril } & 4 & 0.1 & 0.140 \pm 0.01 \\ \text { captopril } & 4 & 0.5 & 0.700 \pm 0.21 \\ \text { zabiciprilate } & 4 & 0.0017 & 0.266 \pm 0.04 \\ \text { zabiciprilate } & 4 & 0.005 & 0.362 \pm 0.06 \\ \text { zabiciprilate } & 4 & 0.017 & 0.510 \pm 0.10\end{array}$




\subsubsection{Hindlimb experiments}

Baseline resistances of both hindlimbs in treated and untreated animals are surnmarized in table 7.2. Treatment of ischemic rats with captopril, zabiciprilate, DuP753 or felodipine did not affect baseline resistances of both hindlimbs, except for DuP753 in the right hindlimb.

In the hindlimb perfusion model, $\mathrm{ED}_{50}$ for angiotensin I increased slightly in both hindlimbs after chronic treatment with captopril and zabiciprilate (2-3 fold; table 7.3, figure 7.1). $\mathrm{ED}_{50}$ for angiotensin I increased significantly only in the left hindlimb after zabiciprilate. This low shift is in contrast to the dose finding studies in which $\mathbb{E D}_{50}$ for angiotensin I increased about 10 fold after the same doses of captopril and zabiciprilate. The increase in $\Delta \mathrm{R}_{\max }$ in the left hindlimb due to ischemia was not influenced by the ACE-inhibitors. Furthermore, captopril and zabiciprilate had no significant effects on dose-response curves of angiotensin II, but $\Delta \mathbf{R}_{\max }$ in left hindlimb tended to increase (table 7.3).

Following felodipine treatment, $\mathrm{ED}_{50}$ and $\Delta \mathrm{R}_{\max }$ for angiotensin II did not change significantly, although $E_{50}$ decreased in both hindlimbs and $\Delta \mathrm{R}_{\max }$ increased in the left hindlimb compared to control (table 7.3 and figure 7.2).

In contrast to the $\mathrm{ACE}$-inhibitors, the $\mathrm{AT}_{1}$-antagonist DuP753 completely inhibited both angiotensin I and II responses $\left(E_{50}\right.$ for angiotensin I and II: $>300 \mu \mathrm{g}$ ). Treatment with DuP753 resulted in a greater shift in the hindlimb experiments (angiotensin I $>300$ fold; angiotensin II $>600$ fold) than in vivo.

As shown in table 7.4 and fugure 7.3 , both $E D_{50}$ and $\Delta R_{\max }$ for phenylephrine in both hindlimbs were not significantly different in untreated and DuP753 treated rats, although $\Delta \mathrm{R}_{\max }$ in left hindlimb tended to return to control values.

Table 7.2 Baseline resistances of left and right hindlimb in treated and untreated rats.

$\begin{array}{lccccc} & \text { dose } & N & \% & R_{L} & R_{R} \\ \text { control } & & 25 & 17.2 \pm 1.4 & 121.7 \pm 13.7 & 17.4 \pm 0.7 \\ \text { captopril } & 0.500 & 21 & 14.9 \pm 1.7 & 185.7 \pm 36.8 & 20.7 \pm 1.2 \\ \text { zabiciprilate } & 0.025 & 14 & 16.9 \pm 2.9 & 189.1 \pm 42.2 & 19.8 \pm 0.6 \\ \text { DuP753 } & 0.625 & 7 & 17.1 \pm 2.3 & 171.6 \pm 33.6 & 27.5 \pm 4.5^{*} \\ \text { felodipine } & 0.420 & 8 & 10.6 \pm 1.9 & 184.5 \pm 38.4 & 16.8 \pm 2.7\end{array}$

dose: $\mathrm{mg} / \mathrm{kg} . \mathrm{h}_{;}$\%: residual flow left hindlimb; $R_{L}$ and $R_{R^{*}}$ resistance in left and right hindlimb (mmHg.min/ml); ${ }^{*} p<0.05$ compared to control and other treatments. 
Table $7.3 \mathrm{ED}_{50}$ and maximal increase in resistance for angiotensin I and anglotensin $I I$ in left and right hindlimb in wntreated and treated rats.

$$
E D_{50} \text { left } E D_{50} \text { right } \Delta R_{\max } \text { left } \Delta R_{\max } \text { right } \% \text { flow }
$$

Angiotensin I

$\begin{array}{llllll}\text { Control } & 0.93 \pm 0.11 & 0.89 \pm 0.20 & 56.6 \pm 13.4^{*} & 6.86 \pm 0.65 & 19.4 \pm 3.8 \\ \text { Captopril } & 2.13 \pm 0.49 & 2.19 \pm 0.85 & 38.4 \pm 7.9^{*} & 7.27 \pm 0.89 & 17.7 \pm 3.1 \\ \text { Zabiciprilate } & 2.53 \pm 0.41^{*} & 1.52 \pm 0.31 & 55.9 \pm 10.2^{H} & 8.16 \pm 1.59 & 17.7 \pm 4.6 \\ \text { Angiotensin II } & & & & & \\ \text { Control } & 0.56 \pm 0.13 & 0.44 \pm 0.07 & 47.9 \pm 13.7^{*} & 8.26 \pm 1.06 & 16.8 \pm 2.6 \\ \text { Captopril } & 0.84 \pm 0.42 & 0.29 \pm 0.04 & 79.3 \pm 22.8^{*} & 6.08 \pm 0.51 & 13.5 \pm 1.5 \\ \text { Zabiciprilate } & 0.54 \pm 0.17 & 0.37 \pm 0.06 & 93.1 \pm 35.8 & 10.9 \pm 1.2 & 16.0 \pm 3.8 \\ \text { Felodipine } & 0.25 \pm 0.04 & 0.27 \pm 0.05 & 123.1 \pm 35.1^{H} & 10.5 \pm 0.84 & 10.6 \pm 1.9\end{array}$

untreated rats: $N=7-8$; captopril $(0.5 \mathrm{mg} / \mathrm{kg} . \mathrm{h}): \mathrm{N}=9-10$; zabiciprilate $(0.025 \mathrm{mg} / \mathrm{kg} . \mathrm{h})$ : $N=7$; felodipine $(0.42 \mathrm{mg} / \mathrm{kg} . \mathrm{h}): N=7 ; E D_{50}: \mu \mathrm{g} ; \Delta R_{\max }:$ maximal increase in resistance $(\mathrm{mmH} H \mathrm{~min} / \mathrm{ml}) ; \quad{ }^{*} \quad p<0.05$ compared to control; $p<0.05$ compared to contralateral hindlimb.

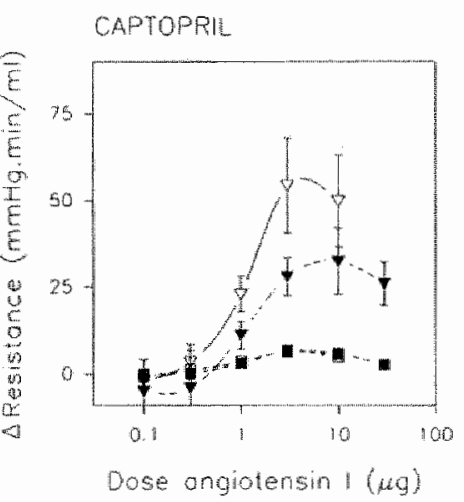

$\begin{array}{ll}\text { untroted } & \forall \\ \text { reoled } & - \text { left }\end{array}$
ZABICIPRILATE

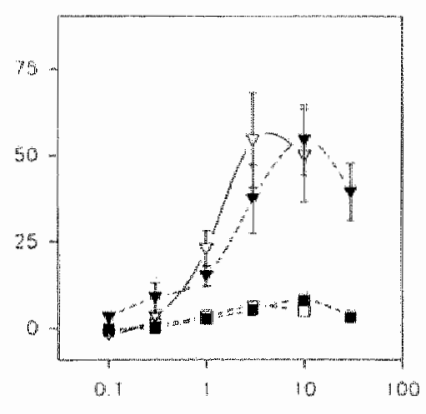

Dose ongrotansin 1(jeg)

a right hindimb

- right hindimb

Figure 7.1 Dose-response curves of angiotensin I in untreated, captopril treated $(0.5 \mathrm{mg} / \mathrm{kg} . \mathrm{h})$ or zabiciprilate treated $(0.025 \mathrm{mg} / \mathrm{kg} . \mathrm{h})$ ischemic animals. 


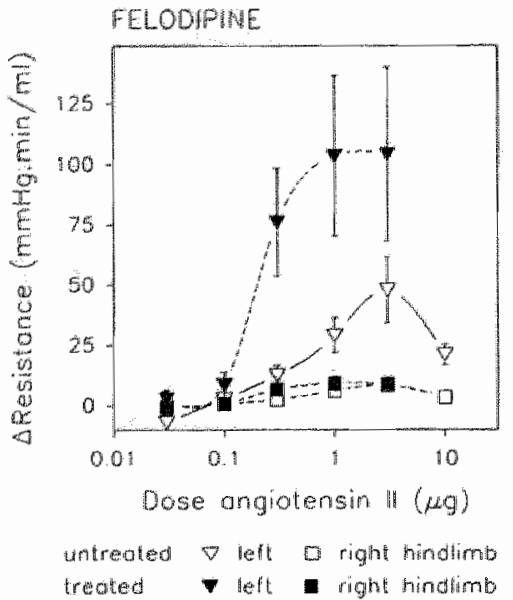

Figure 7.2 Dose-response curves of angiotensin II in untreated and felodipine treated $(0.42 \mathrm{mg} / \mathrm{kg} . \mathrm{h})$ ischemic animals.

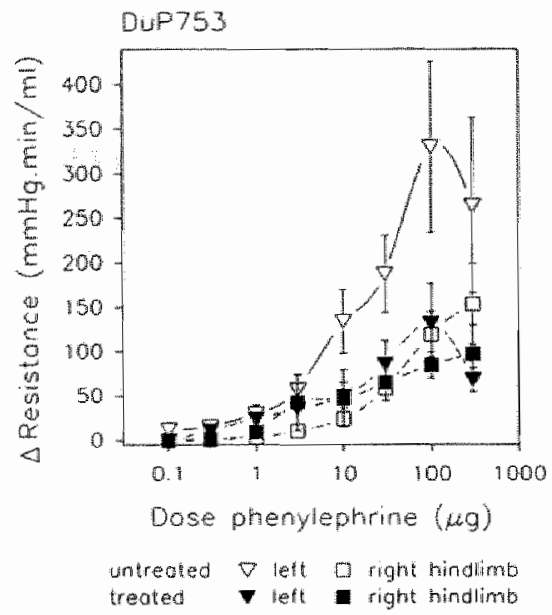

Figure 7.3 Dose-response curves of phenylephrine in unreated and DuP753 treated $(0.625 \mathrm{mg} / \mathrm{kg} . \mathrm{h})$ ischemic animals.

Table $7.4 E_{50}$ and maximal increase in resistance for phenylephrine in left and right hindlimb in control rats and rats treated with DuP753.

\begin{tabular}{lllll} 
& Control & \multicolumn{3}{c}{ DuP753 } \\
& left & right & left & right \\
$E D_{50}$ & $24.7 \pm 5.6$ & $34.9 \pm 7.4$ & $35.6 \pm 14.0$ & $39.7 \pm 23.0$ \\
$\Delta R_{\max }$ & $356.1 \pm 108.5$ & $146.2 \pm 34.4$ & $199.7 \pm 99.0$ & $126.3 \pm 31.0$ \\
$\%$ flow & $16.1 \pm 1.2$ & & $17.1 \pm 2.3$ &
\end{tabular}

control: $N=10 ;$ DuP753 $(0.625 \mathrm{mg} / \mathrm{kg} . \mathrm{h}): \mathrm{N}=7 ; E D_{S 0 ;} \mu \mathrm{g} ; \Delta R_{\text {max }}$ : maximal increase in resistance $(\mathrm{mmHg} . \mathrm{min} / \mathrm{ml})$.

\subsection{DISCUSSION}

As observed in the experiments presented in the previous chapter, acute and chronic ischemia of skeletal muscle resulted in an non-selective hyperreactivity of the vascular bed of the ischemic limb. In the present chapter, the involvement of local renin-angiotensin systems in adaptation processes after skeletal muscle ischemia was further investigated. To this end, ischemic animals were treated chronically with the ACE-inhibitors captopril and zabiciprilate, or with the $\mathrm{AT}_{1}$ antagonist DuP753. Thereafter, the effects on hyperreactivity of angiotensin I, 
angiotensin II and phenylephrine were investigated. To elucidate the effect of blood pressure reduction on hyperreactivity of the ischemic vascular bed, an additional group of animals were chronically treated with comparable antihypertensive doses of the calcium entry blocker felodipine.

The ACE-inhibitors had no effect on hyperreactivity of the ischemic hindlimb to angiotensin I and II. In contrast, chronic treatment with DuP753 resulted in a complete inhibition of angiotensin I and II responses. The phenylephrine responses returned to normal reactivity in the ischemic vascular bed after DuP753.

DuP753 at the doses used resulted in a greater blood pressure reduction than captopril and zabiciprilate. This is in agreement with the slightly greater reduction of peripheral resistance observed in myocardial infarction following chronic DuP753 treatment than following captopril treatment (Smits et al., 1991).

None of the antihypertensives used had any significant influences on baseline resistances of both hindlimbs, except on the resistance of the non-ischemic hindlimb in DuP753 treated animals. The lack of effect on baseline resistances is not surprising, as the vascular bed in the perfused hindlimbs has been suggested to be almost maximally dilated (see previous chapter; Verheyen et al., 1991). The proposed preferential vasodilatation of collaterals following captopril treatment in patients with intermittent claudication (Roberts et al., 1987a; Bernardi et al., 1988) is not likely to be noticed in the present hindlimb perfusion model.

The $\mathrm{AT}_{1}$-antagonist DuP753 completely inhibited the responses of angiotensin $I$ and II in both perfused hindlimbs $\left(E D_{50}>300 \mu \mathrm{g}\right)$. In fact, evaluation of angiotensin I and II responses following DuP753 treatment was not possible. The inhibition of angiotensin II responses was much more pronounced in the hindlimb experiments than in vivo. This is probably due to compensatory sensory reflex mechanisms present in vivo, as previously described after occlumsion and compression of the hindlimbs (Osterziel et al., 1984; Julius et al., 1986). DuP753 treatment reduced the reactivity to phenylephrine in the ischemic vascular bed almost to normal. This cannot be explained by the systemic blood pressure reduction following chronic treatment with DuP753, since a comparable antihypertensive dose of felodipine did not reduce hyperreactivity to angiotensin II in the ischemic hindlimb. The normal reactivity of phenylephrine after DuP753 treatment suggests involvement of the $\mathrm{AT}_{1}$-receptor in the non-selective hyperreactivity.

In contrast to DuP753, the ACE-inhibitors had no effect on angiotensin II responses, whereas $\mathrm{ED}_{50}$ for angiotensin I increased slightly (2-3 fold). In vivo, the increase in $\mathrm{ED}_{50}$ of angiotensin I was about 10-fold. A possible explanation for this discrepancy may be a wash-out of the ACE-inhibitor during hindlimb perfusion experiments. Although we cannot exclude this explanation, no differences in inhibition of a high dose of angiotensin I at the start or at the end of the 
experiments were observed in pilot experiments. An alternative explanation may be a greater contribution of other tissue angiotensin II generating enzymes in the conversion of angiotensin I into angiotensin II during chronic ACE-inhibition. Possible enzymes are a chymostatin-sensitive angiotensin II generating enzyme (CAGE), trypsin or kallikrein (Arakawa and Maruta, 1980; Maruta and Arakawa, 1983; Okunishi et al., 1984; Lanzillo et al., 1986; Ideishi et al., 1990; Okamura et al., 1990; Urata et al., 1990a,b). An important role of these enzymes in the generation of angiotensin $I I$ in ischemic situations has been demonstrated in dogs with myocardial infarction (Gondo et al., 1989) and patients with congestive heart failure (Urata et al., 1990a). These enzymes may be responsible for the lack of effect of ACE-inhibitors on hyperreactivity to angiotensin I, and this suggests no involvement of ACE in the observed hyperreactivity.

The $\mathrm{AT}_{1}$-receptor, thus, may be involved in non-selective hyperreactivity of the vascular bed. In untreated animals local stimulation of the $\mathrm{AT}_{1}$-receptor in the vascular bed of the ischemic hindlimbs may result in an increased reactivity. This may be due to an increase in receptor number, in local angiotensin II synthesis or in activation of the second messenger system of the $\mathrm{AT}_{1}$-receptor. An increased activity of local renin angiotensin systems in ischemic conditions has been previously described in experimental heart failure (Santos et al., 1990; Hirsch et al., 1991) and in pulmonary endothelial cells following hypoxia (King et al., 1989), whereas unchanged receptor-number has been described in heart failure (Urata et al., 1989). Changes in stimulus/contraction coupling system, resulting in an increased release of intracellular calcium, may explain the hyperreactivity to both angiotensin II and phenylephrine, because the second messenger systems of the $\mathrm{AT}_{1}$-receptor and the $\alpha_{1}$-receptor are the same. This also explains the hyperreactivity to serotonin and a thromboxane $A_{2}$ analogue observed by Verheyen et al. $(1988,1989,1991)$. Changes in the stimulus/ contraction coupling system can be investigated in in vitro experiments.

Besides an increase in intracellular calcium, angiotensin II also induces sodium entry in vascular smooth muscle cells (Brock et al., 1982; Bingham Smith and Brock, 1983). This leads to slight cell membrane depolarization, resulting in activation of calcium conductance or voltage-dependent $\mathrm{Na}^{+}-\mathrm{Ca}^{2+}$ exchange (Lang and Blaustein, 1980; Brading and Lategan, 1985; Sage et al., 1991). The sodium entry pathway has been described to be sensitive for the angiotensin antagonist saralasin and for amiloride, suggesting a $\mathrm{Na}^{+} / \mathrm{H}^{+}$exchange (Bingham Smith and Brock, 1983). This latter also suggests an important role of angiotensin II in the regulation of intracellular $\mathrm{pH}$. In physiological conditions angiotensin II induces a transient decrease in intracellular $\mathrm{pH}$, followed by a slow increase to normal (Barrett et al., 1989) or even to an increased $\mathrm{pH}$ by stimulation of the $\mathrm{Na}^{+} / \mathrm{H}^{+}$-antiporter (Hatori et al., 1987). Besides stimulation of the $\mathrm{Na}^{+} / \mathrm{H}^{+}$-antiporter activity by angiotensin II, this 
antiporter activity has been described to increase with decreased intracellular $\mathrm{pH}$ (Frelin et al., 1988). Such a reduction in $\mathrm{pH}$ may result from a higher intracellular $\mathrm{CO}_{2}$ content or from the proton generation in anaerobic glycolysis following ischemia (Dennis et al., 1991).

Both the slight depolarization of the cell membrane by sodium entry and the modulation of intracellular $\mathrm{pH}$ influence contractility of vascular smooth muscle cells (Lang and Blaustein, 1980; Brading and Lategan, 1985; Frelin et al., 1988; Sage et al., 1991). Both processes can be inhibited by an angiotensin antagonist. Therefore, these mechanisms may offer an explanation for hyperreactivity of a diversity of vasoconstrictors and also for the reduction of the hyperreactivity to phenylephrine by DuP753.

In conclusion, the previously (chapter 6) observed hyperreactivity for angiotensin I, angiotensin II and phenylephrine in the chronic ischemic vascular bed is not influenced by chronic treatment with the ACE-inhibitors captopril and zabiciprilate, and the calcium entry blocker felodipine, but is reduced following DuP753 treatment. This suggests an increased stimulation of the $\mathrm{AT}_{1}$-receptor in untreated ischemic animals, probably due to an activation of the local renin angiotensin system in the vascular ischemic bed. 


\section{Morphology and reactivity of isolated femoral arteries of animals with skeletal muscle ischemia}

\subsection{INTRODUCTION}

In the chronic ischemia model the vascular bed of the ischemic hindlimb exhibited a non-selective hyperreactivity to vasoconstrictor agents (chapter 6). Both changes in the pre-existing vessels, such as adaptive structural changes in response to reduced pressure and flow distal to the occlusion (Langille and O'Donnell, 1986), and development of the collateral vessels may be involved in this hyperreactivity.

Hyperreactivity of the ischemic hindlimb vascular bed has been previously described by Verheyen et al $(1988,1989,1991)$. In this model, in which the femoral artery had been occluded, collaterals were proposed to be responsible for the observed hyperreactivity to serotonin and a thromboxane $A_{2}$ analogue. Collateralized vascular beds have been suggested to be hyperreactive as a result of increased vessel wall thickness (Barie and Mullins, 1988; Samani and Swales, 1991) or diminished innervation density of the collateral vessels, resulting in postsynaptic hypersensitivity (Williams and Saelens, 1983), compared to preexisting vessels.

In the present ischemia model also the pre-existing vessels distal to the occlusion may be responsible for the non-selective hyperreactivity. Alterations in blood pressure have been described to change the morphology and reactivity of blood vessels (Folkow et al., 1970, 1971; Arner et al., 1984; Bund et al., 
1991). Sensitivity and maximal responsiveness to vasoconstrictor agents in perfused hindlimbs were greater in hypertensive rats than in normotensive rats (Folkow et al., 1970). Increased media thickness (wall to lumen ratio) has been suggested to account for most of the increased reactivity in SHR (Folkow, 1982). Furthermore, chronic reduction of the blood pressure in the vascular bed of hindlimbs of SHR and WKY caused a decreased reactivity and sensitivity for vasoconstrictors (Folkow et al., 1971). This is supported by recent observations of Bund et al (1991). They found for both WKY and SHR a smaller reactivity and smaller media thickness, cross-sectional area and media to lumen ratio in resistance-sized arteries isolated from femoral vascular beds that had been protected from the increase in blood pressure associated with aging.

Not only blood pressure reduction, but also blood flow reduction may account for changes in reactivity of pre-existing vessels in the present ischemia model. Previously, in a comparable ischemia model (partial occlusion of the abdominal aorta) only alterations of morphology and maximal contractility have been studied (Arner et al., 1984).

In the present study we investigated whether changes in pre-existing arteries may contribute to vascular hyperreactivity following chronic ischemia. The pharmacological properties of isolated femoral arteries of the ischemic and contralateral hindlimb were studied in vitro. Furthermore, mechanical and morphological characteristics were investigated to explore the role of structural adaptations. Since protection from the increase in blood pressure associated with aging in SHR resulted in a comparable reactivity of post-ligated vessels in SHR and normal vessels in WKY (Folkow et al., 1971; Bund et al., 1991), partial occlusion of the common iliac artery was induced in both WKY and SHR.

The femoral arteries of the ischemic hindlimbs will be referred to as poststenotic arteries, whereas the femoral arteries of the contralateral hindlimb will be referred to as control arteries in the present experiments.

\subsection{MATERIALS AND METHODS}

\subsubsection{Animals}

Experiments were performed in male Wistar-Kyoto (WKY) and spontaneously hypertensive rats (SHR). Animals weighed $270-300 \mathrm{~g}$ at the start of the experiments. 


\subsubsection{Surgery}

Chronic ischemia

Rats were anesthetized with ether and a partial occlusion of the left common iliac artery was induced in WKY and SHR as described in section 2.2.5. Experiments were started 4 weeks after induction of hindlimb ischemia.

\section{Vessel isolation}

Following blood pressure measurements, both left and right femoral arteries were isolated and divided into segments as described in section 2.2.6. The segments were used for determination of DNA content (section 2.6) and for measurements of mechanical activity (section 2.3.4) and structural properties (section 2.4.3).

\subsubsection{Measuring protocols}

\section{Blood pressure measurements}

Animals were anesthetized with ether and mean arterial pressure was measured in both hindlimbs 4 weeks after induction of ischemia (section 2.3.1). For that purpose, an arterial catheter was implanted in both the left (post-stenotic) and right (control) saphenous artery as described in section 2.2.4.

\section{Mechanical properties and reactivity}

Arterial segments were mounted in a myograph as described in section 2.3.4. The post-stenotic and control femoral arteries were mounted in the same myograph. The vessel segments were allowed to equilibrate for $30 \mathrm{~min}$, whereafter mechanical and pharmacological experiments were performed.

Mechanical experiments: the vessel segments were incubated in calcium-free Krebs-Ringer solution, containing $50 \mathrm{nM}$ of the $\alpha_{1}$-blocker prazosin and $100 \mathrm{nM}$ of the $\beta$-blocker propranolol $\left(\mathrm{KRB}_{1}\right)$ to block effects of endogenously released noradrenaline (Vanhoutte et al., 1981). The segments were slowly stretched to a diameter of $350 \mu \mathrm{m}$. Following stress relaxation the vessels were exposed to a stepwise cumulative stimulation procedure. The vessels were exposed (cumulatively) at $4 \mathrm{~min}$ intervals to $2.5 \mathrm{mM}$ calcium, $33 \mathrm{mM}$ potassium, $125 \mathrm{mM}$ potassium and $10 \mu \mathrm{M}$ serotonin. After reaching a stable maximal response, the vessels were relaxed by washing with calcium-free $\mathrm{KRB}_{1}$. The cumulative stimulation procedure was repeated every $30 \mathrm{~min}$ with intermittent stepwise increases $(100 \mu \mathrm{m})$ in vessel diameter $(\max .1050 \mu \mathrm{m})$.

The segment length was not altered significantly by increasing the vessel diameter to $1050 \mu \mathrm{m}$. Wall tension in $\mathrm{KRB}_{\mathbb{1}}$ at diameters between 300 and 1050 
$\mu \mathrm{m}$ represented resting wall tension ( $\mathrm{RWT}$ ), as in pilot experiments no reduction of wall tension after acetylcholine (ACh; 0.01-10 $\mu \mathrm{M}$ ) or the NO generating sydnonimine SIN-1 (1-30 $\mu \mathrm{M}$; Feelisch et al., 1989) was observed. Furthermore, the levels of wall tension obtained at various diameters in the combined presence of $2.5 \mathrm{mM}$ calcium, $125 \mathrm{mM}$ potassium and $10 \mu \mathrm{M}$ serotonin could not be increased further by $30 \mathrm{nM}$ of the potent vasoconstrictor argininevasopressin. This indicates maximal activation of the contractile apparatus.

At each diameter wall tension (WT) and active wall tension (AWT $_{\mathrm{D}}$ ) at all steps of the stimulation procedure were recorded. Maximal active wall tension $\left(A W T_{\text {max }}\right.$ ), the stiffness of the resting preparations $(\beta)$ and the diameter of resting vessels exposed to a transmural pressure of $100 \mathrm{mmHg}\left(D_{100}\right)$ were calculated as described in section 2.3.4.

Pharmacological experiments. these experiments were performed at the individual $D_{\text {opt }}$ of the vessel segments, in Krebs-Ringer solution containing $2.5 \mathrm{mM}$ calcium but no $\alpha_{1}$ and $\beta$-blocker $\left(\mathrm{KRB}_{2}\right)$. The vessel segments were allowed to equilibrate for $45 \mathrm{~min}$. Concentration response curves were constructed for serotonin (0.01-10 $\mu \mathrm{M})$ and phenylephrine (PE; 0.1-100 $\mu \mathrm{M})$. No concentration response curves were constructed for angiotensin I and II, as pilot experiments demonstrated a low contractile (and inadequate reproducible) response of the femoral arteries to these substances. Furthermore, concentration-response curves for acetylcholine $(\mathrm{ACh} ; 0.01-10 \mu \mathrm{M})$ and $\operatorname{SIN}-1(0.1-30 \mu \mathrm{M})$ were constructed following precontraction with $10 \mu \mathrm{M}$ serotonin. To evaluate the responsiveness of the various vessel segments to changes in membrane potential, the segments were exposed to $20 \mathrm{mM}$ potassium in resting conditions and after precontraction with $100 \mu \mathrm{M}$ PE.

The experiments were terminated by exposing the vessel segments at $D_{o p t}$ and $37^{\circ} \mathrm{C}$ to $4 \%$ phosphate buffered formalin $(\mathrm{pH} 7.4)$.

\subsubsection{Histology and morphometry}

The vessel segments fixed at $\mathrm{D}_{\text {opt }}$ in the myograph (section 2.4.3) were embedded in paraffin and sections $(4 \mu \mathrm{m})$ were cut transversely. They were stained with Elastin-Van Gieson for measurement of internal circumference (IC) and media cross sectional area (CSA) as described in section 2.4.3. Optimal lumen diameter $\left(D_{\text {opt }}\right)$, mean media thickness $\left(M_{t}\right)$ and active wall stress at optimal diameter were calculated (section 2.4.3).

Furthermore, the sections were stained with hematoxylin-eosin to estimate the number of arterial smooth muscle cell nuclei and calculate nuclear density from number of nuclei and CSA (section 2.4.3). 


\subsubsection{DNA content}

After clearing the lumen and removing the endothelium in proximal femoral artery segments with a hypodermic needle $(0.5 \mathrm{~mm})$, the segments were solubilized in $1 \mathrm{~N} \mathrm{NaOH}$ and the DNA content was measured fluorometrically as described in section 2.6 .

\subsubsection{Data analysis}

Values from post-stenotic and control vessel segments of WKY and SHR were compared by two way analysis of variance and an adequate test for comparison of the subgroups (simple main effects test; commercial available software Crunch, Crunch Software Corporation, Oakland, Ca, USA).

\subsection{RESULTS}

\subsubsection{Blood pressure measurements}

Partial occlusion of the left common illac artery resulted in a reduction of the pulse pressure distal to the ligature. The absolute and relative blood pressures in post-stenotic and control saphenous arteries in WKY and SHR with unilateral hindlimb ischemia are summarized in table 8.1. Both blood pressures in WKY were significantly lower than in SHR. The blood pressure in the post-stenotic saphenous artery was significantly decreased compared to the control artery for both WKY and SHR.

Table 8.1 Blood pressure in post-stenotic and control saphenous artery of anesthetized WKY and SHR.

$\begin{array}{lcccl} & N & P_{\text {POST }} & P_{\text {CONTROL }} & P_{\text {POSTICONTROL }} \\ W K Y & 10 & 22 \pm 2.8^{*} & 76 \pm 6.4 & 0.27 \pm 0.01 \\ \text { SHR } & 9 & 48 \pm 5.7^{*} & 101 \pm 4.5^{*} & 0.46 \pm 0.05^{*}\end{array}$

$P_{\text {POST }}$ and $P_{\text {CONTROL }}$ : blood pressure in post-stenotic and control artery resp. (mmHg); $P_{P O S T / C O N T R O L}$ : ratio of blood pressure in post-stenotic and control artery;" $P<0.05$ compared to WKY; ${ }^{*} P<0.05$ compared to control artery. 


\subsubsection{Morphological properties}

Morphological, biochemical and mechanical parameters in post-stenotic and control femoral arteries of WKY and SHR are summarized in table 8.2. The media CSA of the post-stenotic femoral artery of both WKY and SHR was significantly reduced compared to the control artery. The reduction was significantly greater in SHR than WKY (WKY: $-25.9 \pm 3.4 \%$; SHR: $-36.0 \pm 3.3 \%$ ). The reduction of CSA was accompanied by a significant increase in nuclear density, but no changes in DNA content. This suggests that the decrease in CSA in the post-stenotic artery of WKY and SHR did not result from a reduction of arterial smooth muscle cell number, but rather from a decrease in cell volume. Major changes in extracellular elastic components seem unlikely, as arterial stiffness was not altered in the post-stenotic vessels of WKY.

$\mathrm{D}_{\text {opt }}$ was significantly reduced in the post-stenotic femoral arteries of both WKY and SHR. D 100 of vessels of SHR was significantly smaller than of vessels of WKY. Both in WKY and SHR, $D_{100}$ of post-stenotic vessels was slightly larger than that of control arteries. This reached statistical significance in SHR. Although both $D_{\text {opt }}$ and $M_{t}$ decreased in post-stenotic vessels, the $W / L$

Table 8.2 Morphological, biochemical and mechanical parameters of post-stenotic and control femoral arteries of $W K Y$ and SHR.

$\begin{array}{lllll} & \text { WKY post } & \text { WKY control } & \text { SHR post } & \text { SHR control } \\ N & 9 & 10 & 12 & 12 \\ C S A & 68.4 \pm 2.3^{*} & 93.4 \pm 3.4 & 69.7 \pm 3.8^{*} & 103.8 \pm 3.3^{*} \\ D_{\text {opt }} & 654 \pm 14^{*} & 728 \pm 16 & 631 \pm 11^{*} & 690 \pm 11 \\ D_{100} & 934 \pm 31 & 904 \pm 42 & 833 \pm 21^{*} & 780 \pm 18^{*} \\ M_{t} & 31.7 \pm 0.1^{*} & 38.9 \pm 1.4 & 33.3 \pm 1.5^{*} & 44.9 \pm 0.8^{*} \\ W / L & 0.097 \pm 0.003 & 0.108 \pm 0.005 & 0.106 \pm 0.005^{*} & 0.130 \pm 0.002^{*} \\ N D & 388 \pm 15^{*} & 298 \pm 10 & 487 \pm 21^{*} & 311 \pm 10 \\ D N A & 0.56 \pm 0.04 & 0.54 \pm 0.02 & 0.67 \pm 0.03 & 0.60 \pm 0.04 \\ \beta & 5.98 \pm 0.30 & 5.61 \pm 0.15 & 6.85 \pm 0.38^{*} & 5.84 \pm 0.22\end{array}$

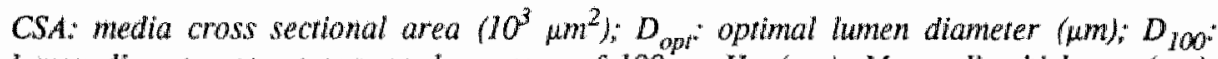
lumen diameter at a transmural pressure of $100 \mathrm{mmH}(\mu \mathrm{m}): M_{r}$ media thickness $(\mu \mathrm{m})$; $W / L$ : wall to tumen rario $=2 M_{t} / D_{\text {ops: }}$ ND: nuclear density $\left(\mathrm{mm}^{-2}\right) ;$ DNA: DNA content in femoral artery ( $\mu \mathrm{g} / \mathrm{mm})$; $\beta$ : index for stiffness of the resting wall $\left(\mathrm{mm}^{-1}\right)$; ${ }^{*} \quad P<0.05$ compared to $W K Y_{*}$ " $P<0.05$ compared to contralateral antery. 
Table 8.3 Maximal active wall tension and maximal active wall stress in post-srenotic and control femoral antery of WKY and SHR.

$\begin{array}{lllll} & W K Y \text { post } & \text { WKY control } & \text { SHR post } & \text { SHR control } \\ A W T_{\max } & 6.75 \pm 0.58^{*} & 9.83 \pm 0.95 & 6.81 \pm 0.41^{\text {H }} & 10.87 \pm 0.59 \\ A W S_{\max } & 189 \pm 26 & 224 \pm 37 & 204 \pm 10^{\#} & 246 \pm 17\end{array}$

AWT $T_{\text {max" }}$ maximal active wall tension (mN/mm): $A W S_{\text {max }}$ maximal active wall srress $\left(\mathrm{mN} / \mathrm{mm}^{2}\right) ;$; $P<0.05$ compared to control hindlimb.

at $D_{\text {opt }}$ did not change significantly in the post-stenotic vessels of WKY. It was reduced (normalized ?) significantly in post-stenotic vessels of SHR.

\subsubsection{Maximal contractility}

The maximal contractile response to the combination of $2.5 \mathrm{mM}$ calcium, 125 $\mathrm{mM}$ potassium and $10 \mu \mathrm{M}$ serotonin was comparable in SHR and WKY (table 8.3). Both in WKY and SHR the maximal response (AWT max ) was decreased in the post-stenotic femoral arteries.

Maximal active wall stress ( $A W S_{\max }$ ) did not differ significantly between post-stenotic and control WKY arteries. This suggests that the reduced maximal contractile reactivity of the post-stenotic artery was due to a smaller muscle mass. In SHR, however, also AWS $\max$ was significantly reduced.

\subsubsection{Contractile responses to depolarizing and pharmacological stimuli}

Over a broad range of diameters, the relative maximal response to potassium (125 mM) was comparable in post-stenotic and control vessels of both WKY and SHR (figure 8.1). However, at $\mathrm{D}_{\text {opt }}$, which was smaller in post-stenotic vessels than in control vessels, the relative maximal response was increased in poststenotic vessels in SHR.

The relationship between the relative response of the arteries to an intermediate concentration of potassium $\left(\mathrm{K}_{33} / \mathrm{K}_{125}\right)$ and diameter (D) is depicted in figure 8.2. With increasing distension, contractile responses to the mild stimulus $\left(\mathrm{K}_{33}\right)$ increased progressively in both types of arteries of WKY and SHR. The relative reactivity of post-stenotic arteries to $K_{33}$ was increased independently of the vessel diameter in both WKY and SHR. At optimal diameter, the response to $\mathrm{K}_{33}$ was increased in the post-stenotic vessels compared to the control vessels. 

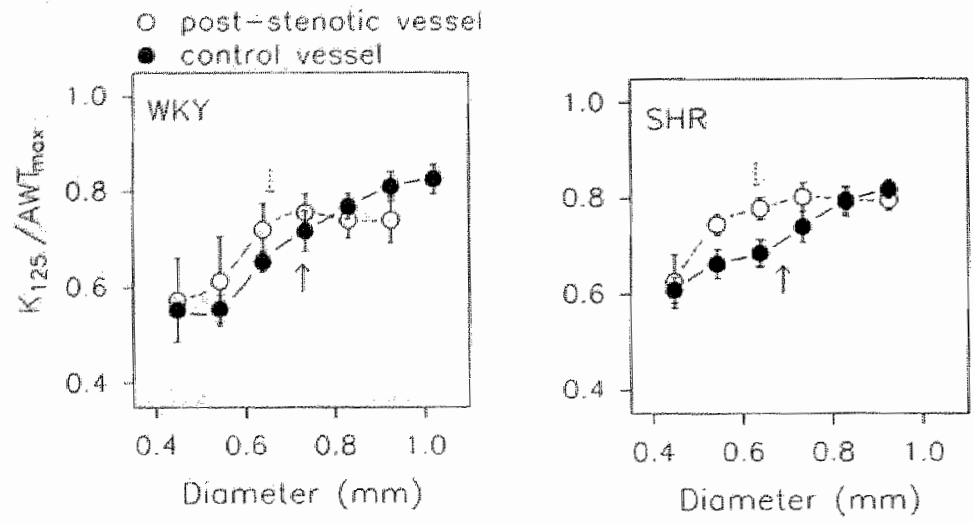

Figure 8.1 Relative maximal response to porassium $\left(K_{125} / A W T_{m a x}\right)$ in relation to diameter in control and post-stenotic vessels of WKY and SHR (arrows: $D_{o p}$ ).
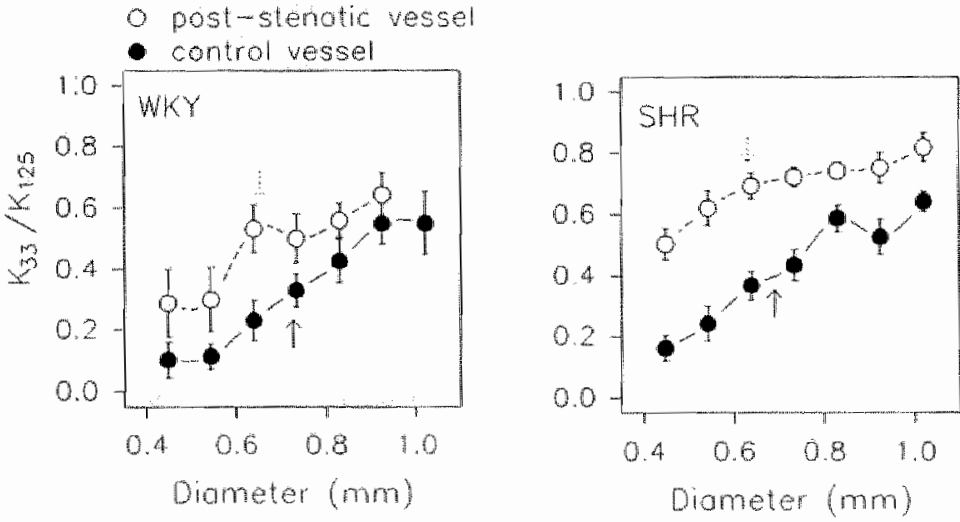

Higure 8.2 Relative reactivity to $33 \mathrm{mM}$ potassium $\left(K_{33} / K_{225}\right)$ in relation to diameter in control and post-stenotic vessels of WKY and SHR (arrows: $D_{\text {opt }}$.

Thus, arteries from the ischemic vascular bed, although hyporeactive, were found to be hypersensitive to a depolarizing stimulus.

Sensitivity and relative maximal responses (AWT/AWT $T_{\max }$ at $\mathrm{D}_{\text {opt }}$ ) to serotonin and phenylephrine are summarized in table 8.4 and figures 8.3 and 8.4 . In post-stenotic vessels, the $\mathrm{ED}_{50}$ for serotonin and phenylephrine were lower in post-stenotic than control vessels for both WKY and SHR. The increase in sensitivity was significant only in SHR. Relative maximal responses to phenylephrine and serotonin were increased in post-stenotic vessels, except for seroto- 

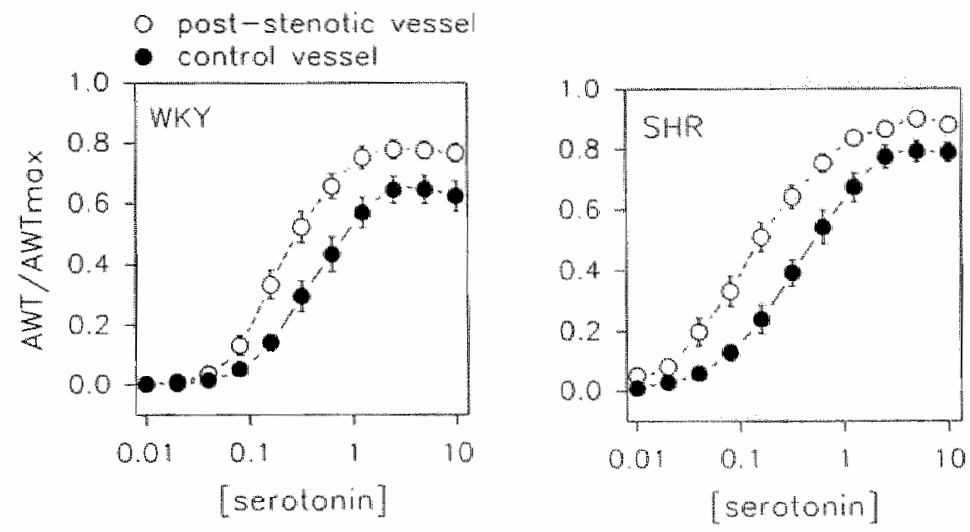

Figure 8.3 Relative response curve of serotonin (AWT/AWT, in control and post-stenotic vessels of WKY and SHR.
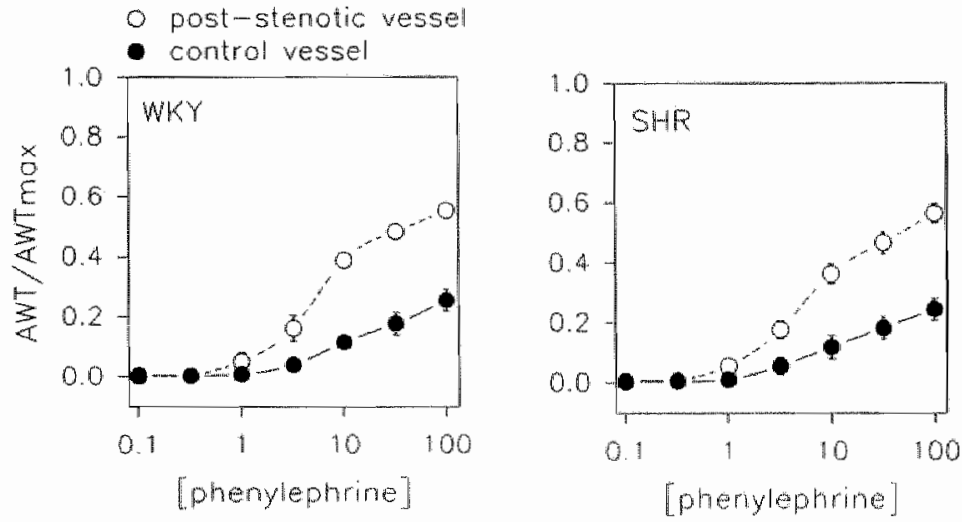

Figure 8.4 Relative response curve of phenylephrine (AWT/AWT $T_{\max }$ ) in control and poststenotic vessels of WKY and SHR.

nin in SHR. The relative maximal responses to phenylephrine were comparable in WKY and SHR, whereas for serotonin they were significantly greater in SHR than in WKY. This inter-strain difference persisted in vessels from the ischemic side.

\subsubsection{Responses to relaxing interventions}

Sensitivity and maximal response (\% relaxation) to $\mathrm{SIN} \times 1$ and acetylcholine 
Table 8.4 senstivity and relative maximal responsiveness to serotonin and phenylephrine in post-stemonic and control femoral artery of WKY and SHR.

\begin{tabular}{|c|c|c|c|c|}
\hline & $W K Y$ post & WKY control & SHR post & SHR control \\
\hline \multicolumn{5}{|l|}{ Serotomn } \\
\hline$E D_{50}$ & $0.23 \pm 0.04$ & $0.47 \pm 0.11$ & $0.15 \pm 0.03^{\#}$ & $0.45 \pm 0.09$ \\
\hline$A W T / A W T_{\max }$ & $0.79 \pm 0.04^{1 / 4}$ & $0.67 \pm 0.05$ & $0.90 \pm 0.02^{*}$ & $0.85 \pm 0.04^{*}$ \\
\hline \multicolumn{5}{|l|}{ Phenylephrine } \\
\hline$E D_{50}$ & $5.80 \pm 0.89$ & $16.8 \pm 5.21$ & $14.3 \pm 4.9^{15}$ & $32.5 \pm 10.3$ \\
\hline$A W T / A W T_{\max }$ & $0.55 \pm 0.03^{15}$ & $0.26+0.04$ & $0.62 \pm 0.04^{4}$ & $0.34 \pm 0.04$ \\
\hline
\end{tabular}

Table 8.5 Sensirivity and maximal relaxing responses to SIN-1 and acerylcholine in poststenotic and control femoral artery of WKY and SHR.

WKY post WKY control SHR post SHR control

\section{SIN-1}

$\begin{array}{lllll}E D_{50} & 12.73 \pm 4.19 & 2.83 \pm 0.43 & 43.79 \pm 10.73^{*} & 14.98 \pm 5.66 \\ \% \text { relaxarion } & 104 \pm 3 & 102 \pm 1 & 75 \pm 5^{*} & 81 \pm 4^{*}\end{array}$

\section{Acetylcholine}

$\begin{array}{lllll}E D_{50} & 0.50 \pm 0.18 & 2.56 \pm 1.71 & 0.72 \pm 0.20 & 1.69 \pm 0.49 \\ \text { \% reluxation } & 83 \pm 5 & 83 \pm 4 & 62 \pm 7^{*} & 43 \pm 7^{*}\end{array}$

\% relaxation. maximal relaxing response after precontaction with $10 \mu M$ serotonin; $E D_{50} \cdot 10^{7} M_{*}^{*} P<0.05$ compared to $W K Y_{;} * P<0.05$ compared to contralateral artery.

are summarized in table 8.5 and figures 8.5 and 8.6. $E_{50}$ for $\mathrm{SIN}_{-1}$ was significantly higher in post-stenotic vessels of SHR, whereas $E_{50}$ for $A C h$ tended to be lower. The maximal relaxing responses to SIN-1 and $\mathrm{ACh}$ were not altered in post-stenotic vessels of WKY. In contrast, the relaxing responses to ACh in SHR (diminished compared to WKY) were higher in post-stenotic than 

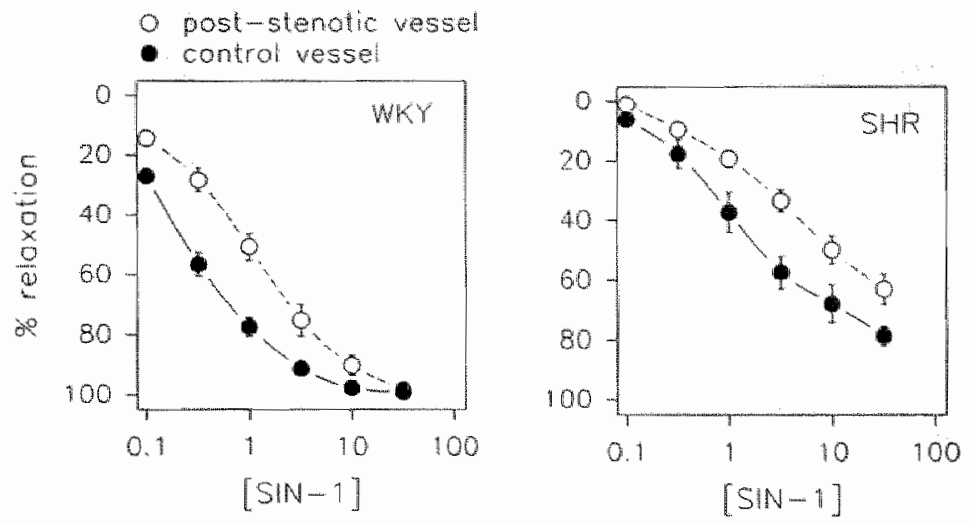

Figure 8.5 Relaxing responses to $S I N-1$ in control and post-stenotic vessels of WKY and SHR.
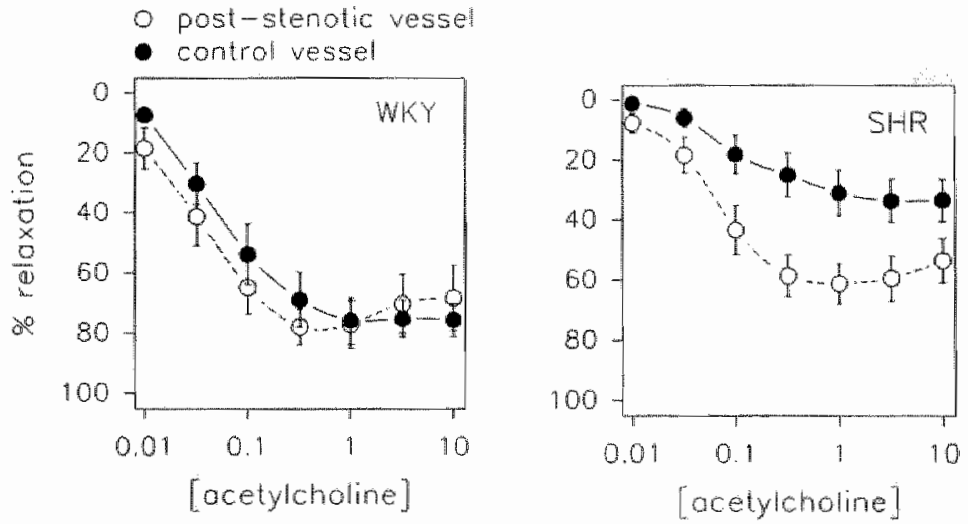

Figure 8.6 Relaxing responses to acetylcholine in control and post-stenoric vessels of WKY and SHR.

in control vessels, suggesting a partially normalization (control vessels of WKY) of the relaxing properties of post-stenotic vessels in SHR.

To investigate effects of changes in membrane potential on membrane reactivity, responses to moderate elevation of the extracellular potassium concentration $(20 \mathrm{mM})$ were investigated at rest and after precontraction with $100 \mu \mathrm{M}$ phenylephrine (figures 8.7 and 8.8). This intervention initially causes membrane hyperpolarization through activation of electrogenic sodium transport 


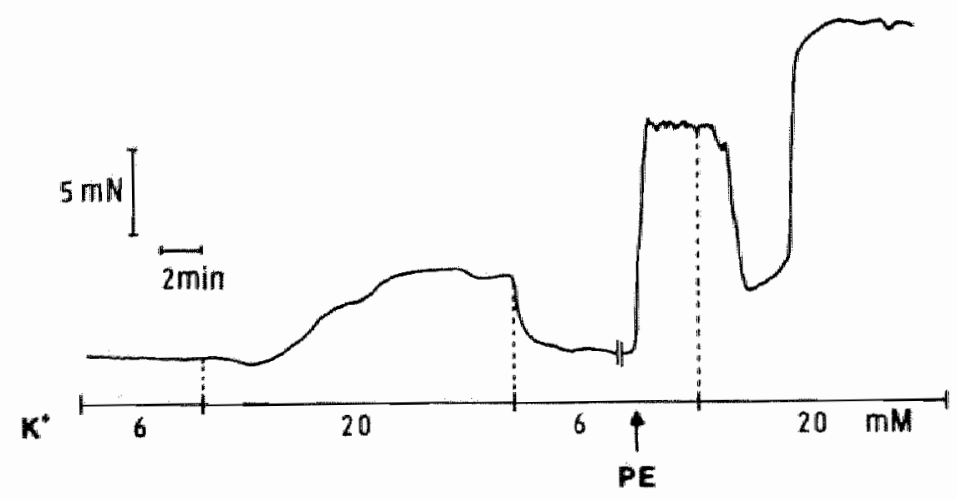

Figure 8.7 Typical tracing of responses to moderate elevation of the extracellular potassium concentration at rest and after precontraction with $100 \mu M$ phenylephrine.

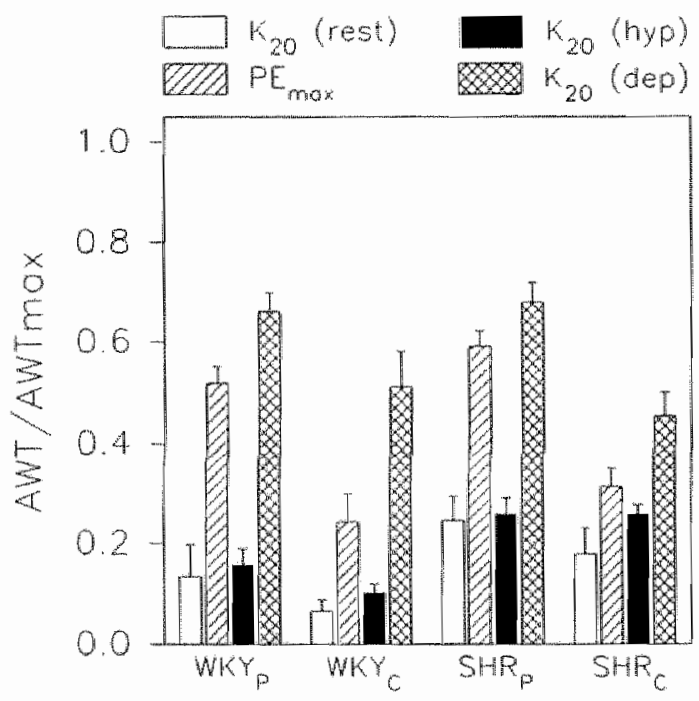

Figure 3.8 Relative response to potassium (AWT/AWT $T_{\text {max }}$ ) before and after precontraction with phenylephrine in control and post-stenotic vessels of WKY and SHR.

and subsequently depolarizes smooth muscle (De Mey and Vanhoutte, 1982). The hyperpolarization results in relaxation of precontracted vessels. The contractile responses to $20 \mathrm{mM}$ potassium and phenylephrine were increased in the post-stenotic vessel, as already described above. Furthermore, the initial relaxation in response to potassium observed in $\mathrm{PE}$-precontracted vessels was greater in the post-stenotic femoral arteries than in the control arteries of both WKY and SHR. This greater relaxation suggests an altered ion balance in post- 
stenotic vessels, resulting in a change in resting membrane potential. This is supported by the observation, that the contractile response ultimately reached in control arteries exposed to $100 \mu \mathrm{M}$ PE and $20 \mathrm{mM}$ potassium were comparable to those observed in post-stenotic vessels exposed to $100 \mu \mathrm{M} P E$ and normal potassium concentration.

\subsection{DISCUSSION}

To investigate the role of changes of pre-existing vessels in hyperreactivity of the vascular bed in the ischemic hindlimb, structure and reactivity of the femoral artery in left and right hindlimb were investigated in vitro. To investigate the possibility that alterations of post-stenotic vessels in SHR result in a normalization of the vessel properties (normotensive animals), partial occlusion of the common iliac artery was induced in both normotensive (WKY) and hypertensive animals (SHR).

The partial occlusion resulted in a persistent reduction of blood pressure and flow in the saphenous artery. The blood pressure reduction was most pronounced in WKY. In post-stenotic arteries, cross sectional area was reduced, associated with an increase in nuclear density but no effect on DNA content. Furthermore, both wall thickness and optimal diameter were decreased in poststenotic vessels, resulting in a preserved wall to lumen ratio in WKY and a decreased ratio in SHR. In contrast to optimal diameter, the diameter at a transmural pressure of $100 \mathrm{mmHg}\left(D_{100}\right)$ was slightly increased in post-stenotic vessels. Maximal active wall tension (at optimal diameter) in post-stenotic vessels was diminished in both WKY and SHR. The maximal relaxing responses were not altered in WKY and were partly restored for acetylcholine in post-stenotic arteries of SHR. In contrast, the relative maximal response to the vasoconstrictors phenylephrine (SHR) and serotonin (WKY and SHR) and the sensitivity to potassium (WKY and SHR) and phenylephrine (SHR) were increased in femoral arteries of the ischemic hindlimbs. Furthermore, in post-stenotic arteries the (initial) dilatation to potassium in phenylephrine-precontracted post-stenotic vessels was increased, suggesting that increased sensitivity and reactivity may be caused by a slight depolarization of the smooth muscle cells in post-stenotic vessels.

Both in WKY and SHR the partial occlusion of the common iliac artery resulted in a pronounced reduction in blood pressure in the ischemic hindlimb. Although the imposed iliac artery diameter was $0.15 \mathrm{~mm}$ in both WKY and SHR, the blood pressure not only remained significantly higher in SHR than in WKY, but also the extent of blood pressure lowering differed between the two strains. The slightly smaller optimal diameter of the control femoral arteries in SHR compared to WKY suggests that the inter-strain difference in blood pressure reduction may depend on a smaller vessel diameter of normal common 
iliac arteries in SHR than in WKY. Furthermore, smaller vessel diameters in hypertensive animals have been previously described for cerebral (Baumbach and Heistad, 1989) and skeletal muscle arterioles (Le Noble et al., 1990), for mesenteric arteries (Morton et al., 1990), for arteries of the thoracodorsal pathway (Schmid-Schönbein et al., 1986) and renal arteries (De Mey et al., 1991), whereas no difference in internal diameter of thoracic and abdominal aorta have been observed between WKY and SHR (Stacy and Prewitt, 1989).

Following occlusion of the common iliac artery, femoral artery media thickness, optimal diameter and cross sectional area were decreased in both WKY and SHR. In SHR this resulted in a decreased wall to lumen ratio. In control vessels both cross sectional area and media thickness were significantly larger in SHR compared to WKY, whereas they were comparable in the post-stenotic vessels. The changes in vessel media were associated with an increase in media nuclear density and an unchanged DNA content. This suggests no change in the number of arterial smooth muscle cells in the media, but probably a decrease in cell volume. Comparable morphological changes have been observed previously in resistance arteries from femoral vascular beds that had been protected from the increase in blood pressure associated with aging (Folkow et al., 1971; Bund et al., 1991). In these experiments the prevention of high blood pressure development resulted in a comparable structure of vessels of ligated SHR and unligated WKY, suggesting that structure of the vessel wall is mainly determined by local perfusion pressure. There is no indication whether a possible flow reduction in this model plays a role in the structural alterations of the vessel wall. Our data indicate that pressure (and flow) reduction can not only prevent structural changes in SHR (Folkow et al., 1971; Bund et al., 1991), but also reverse them. This demonstrates the dynamic nature of arterial structure.

The sensitivity and maximal responses to the vasodilators acetylcholine and SIN-1 did not change significantly in post-stenotic vessels in WKY. In SHR the endothelium-dependent responses to acetylcholine (Furchgott, 1983) were markedly increased in post-stenotic vessels. Several authors previously described reduced endothelium-dependent relaxations in arteries of adult SHR (De Mey and Gray, 1985; Tesfamariam and Halpern, 1988; Vanhoutte, 1989; Marshall and Kontos, 1990). Furthermore, observations in young prehypertensive SHR and those following long-term antihypertensive treatments (De Mey and Gray, 1985; Shultz and Raij, 1989; Clozel et al., 1990) suggested that this diminished relaxation develops as a secondary adaptation to elevated blood pressure. This is supported by our finding that acetylcholine-induced relaxation is restored in the post-stenotic vessels of SHR. This indicates the reversibility of the adaptation process. Thus, as endothelium-dependent relaxing responses of the post-stenotic arteries were rather increased than decreased, our observations exclude a major role for altered endothelium-dependent vascular reactivity in the femoral arteries of the ischemic hindlimb. 
The diminished media cross sectional area and the slight increase in stiffness of the vessel wall may both lead to a diminished maximal contractility (Folkow et al., 1970; Morton et al., 1990; Bund et al., 1991). In the present experiments maximal contractility (maximal active wall tension) in response to a combination of calcium, potassium and serotonin was decreased in the post-stenotic vessels of WKY and SHR. Thus, the diminished absolute maximal contractility of poststenotic vessels suggests that structural adaptation of the post-stenotic vessels to diminished blood pressure is not responsible for the observed non-selective hyperreactivity in the ischemic vascular bed (chapter 6). It is not yet clear how a loss of pulse pressure (due to the ligature) and the reduction of intra-arterial flow after occlusion influences the structure and reactivity of the post-stenotic vessels.

Although the absolute maximal reactivity of the post-stenotic femoral arteries was decreased, the relative reactivity to serotonin and phenylephrine was increased in arteries of the ischemic hindlimbs. Furthermore, partial occlusion of the iliac artery resulted in an increased sensitivity to potassium, serotonin and phenylephrine. The lack of influence of partial occlusion of the iliac artery on the relative maximal response to potassium suggests no alteration in the relationship between the electro-mechanical and pharmaco-mechanical-coupling in the smooth muscle cells of the post-stenotic arteries (Somlyo and Somlyo, 1968, 1970). The increased reactivity to vasoconstrictor agents is in agreement with the observed hyperreactivity of the vascular bed in ischemic hindlimbs to angiotensin I and II and phenylephrine (chapter 6) and to serotonin (Verheyen et al., 1991) and a thromboxane $A_{2}$ analogue (Verheyen et al., 1989). However, these observations in a major blood flow and pressure reducing model are in contrast to observations in a model in which blood pressure (and probably also blood flow and pulse pressure) is only moderately reduced (Folkow et al., 1971; Field and Soltis, 1985; Bund et al., 1991). In this model a hyporeactivity and hyposensitivity to noradrenaline were observed. This may suggest that major blood flow and/or pulse pressure alterations are important determinants for reactivity changes of post-stenotic vessels.

A possible basis for the non-selective hyperreactivity to vasoconstrictors may be alterations of cell membrane properties or receptor-linked mechanisms of the vessel wall. Changes in receptor-linked mechanisms are not likely to be solely involved in the altered reactivity, since hyperreactivity and/or hypersensitivity were observed for potassium and a diversity of vasoconstrictor agents (present chapter and chapter 6; Verheyen et al., 1989, 1991). To investigate possible changes in cell membrane potential, the responses to moderate elevation of extracellular potassium concentration were investigated at rest and after precontraction with phenylephrine. Exposure of the precontracted vessels to potassium results in a transient hyperpolarization (relaxation), due to stimulation of the electrogenic sodium pump, followed by a moderate depolarization (contraction; 
De Mey and Vanhoutte, 1982). In the present experiments the relaxation due to hyperpolarization was increased in femoral arteries of chronically ischemic hindlimbs. This suggests that the electrogenic sodium transport can be activated to a greater extent in post-stenotic arteries, raising the possibility that under normal conditions the membrane at rest could be less depolarized in smooth muscle cells from post-stenotic vessels compared to control vessels. This is supported by the observation that exposure of the control vessels to a moderate elevation of extracellular potassium after a slight depolarization of these vessels (precontraction with phenylephrine) results in a similar response as observed in post-stenotic vessels under normal conditions. Such a slight depolarization in post-stenotic vessels may underlay non-selective hypersensitivity and hyperreactivity (Hermsmeyer, 1982; Harder and Hermsmeyer, 1983).

Changes in cell membrane permeability for cations or changes in the activity of the electrogenic sodium pump, which remain to be directly demonstrated, may be responsible for an increase in intracellular sodium concentration. Furthermore, the previously discussed (chapter 7) stimulation of the $\mathrm{Na}^{+} / \mathrm{H}^{+}$. antiporter by hypoxia or angiotensin II may play a role in chronic ischemia (Brock et al., 1982; Bingham Smith and Brock, 1983; Kuriyama et al., 1988).

In conclusion, structural adaptation of the femoral artery to diminished blood pressure distal to the occlusion seems to be responsible for a decrease in maximal reactivity in femoral arteries in ischemic hindlimbs, but may not explain the non-selective relative hyperreactivity and sensitivity to vasconstrictors. Changes in sensitivity and reactivity are probably due to alterations in ionic handling by vascular smooth muscle cells of post-stenotic vessels and do not seem to be due to changes in endothelial-relaxing influences on vascular smooth muscle tone. 


\section{CHAPTER 9}

\section{Chronic ischemia and neovascularization}

\subsection{INTRODUCTION}

Several acute and chronic adaptations in skeletal striated and vascular smooth muscle cells are the result of blood flow and pressure reduction in the hindlimbs. In the previous chapters of the present thesis responsiveness of the vascular bed in ischemic hindlimbs and the influences of antihypertensive therapy were investigated.

Besides metabolic changes to conform blood supply and oxygen demand (Ludatscher et al., 1981; Elander et al., 1985; Harris et al., 1986; Heppenstall et al., 1986; Idström et al., 1990; Kwasnik et al., 1991), restoration of blood supply to the ischemic regions can be achieved by development of collateral vessels (Fernandez et al., 1982, 1985; Barie and Mullins, 1988). Generation of new capillaries has been described for hypoxic situations following endurance training and chronic electrical stimulation of skeletal muscles (Myrhage and Hudlicka, 1978; Hudlicka, 1982; Hudlicka and Price, 1990b). Ischemia of skeletal muscle following occlusion of an iliac or femoral artery also resulted in growth of capillaries, visualized by corrosion casts (Conrad et al., 1971; Verheyen et al., 1984). Additionally, capillary growth has been demonstrated in the oxidative soleus muscle in the ischemic hindlimb (Drexler et al., 1986). Howev$\mathrm{er}$, in glycolytic and oxidative glycolytic skeletal muscles of rats, chronic 
ischemia did not result in an increased capillary to fiber ratio (Hudlicka and Price, 1990a). Furthermore, changes in capillary to fiber ratio in gastrocnemius muscles of patients with intermittent claudication have been described to be decreased (Clyne et al., 1985), increased (Hammarsten et al., 1980) or not influenced (Clyne et al., 1982).

Capillary growth in skeletal muscle has not only been observed in hypoxia following blood flow reduction, but also after chronic treatment with vasodilators, which results in an increase in blood flow (Tornling et al., 1980; Ljungqvist et al., 1984; Ziada et al., 1984, 1989; Sillau and De Lourdes Philippi, 1987). However, an increased blood flow in ischemic muscles by the xanthine derivatives pentoxifylline or torbafylline had no effect on capillarity of combined glycolytic and oxidative glycolytic skeletal muscles (Hudlicka and Price, 1990a).

The influences of ischemia have been investigated most extensively in glycolytic or oxidative glycolytic muscles. As capillarity of normal skeletal muscles depends on fiber type composition (Gray and Renkin, 1978; Ripoll et al., 1979; Hudlicka, 1982, 1985; Hudlicka et al., 1987), the effects of chronic ischemia may also depend on muscle fiber type. Therefore, in the present experiments effects of severe chronic ischemia on capillarity were investigated in the soleus muscle (oxidative fibers) and in the type II-muscle fiber part (glycolytic and oxidative glycolytic fibers) of the gastrocnemius muscle in both ischemic and contralateral hindlimbs of hypertensive animals.

As angiotensin II has been described to have growth promoting activities (Naftilan et al., 1989; Paquet et al., 1990; Scott-Burden et al., 1990; Schelling et al., 1991) and to stimulate new vessel formation (Fernandez et al., 1982, 1985; Le Noble et al., 1991), also influences of ACE-inhibition and AT antagonism on capillarity in chronic ischemic skeletal muscles were investigated. To elucidate the role of blood pressure reduction on capillarity, chronic treatment with the calcium entry blocker felodipine at comparable antihypertensive doses was studied.

\subsection{MATERIALS AND METHODS}

\subsubsection{Animals}

Experiments were performed in male spontaneously hypertensive rats (SHR). Animals weighed $270-290 \mathrm{~g}$ at the start of the chronic ischemia protocol. Control (untreated non-ischemic) animals weighed $320-360 \mathrm{~g}$ at the start of the experiments, as the weight of animals with chronic ischemia was $320-360 \mathrm{~g}$ after 4 weeks of ischemia. 


\subsubsection{Surgery and treatment}

Rats were anesthetized with ether and a partial occlusion of the common iliac artery was induced as described in section 2.2.5. Immediately after induction of ischemia, animals were treated for 4 weeks with captopril $(0.5 \mathrm{mg} / \mathrm{kg} . \mathrm{h})$, zabiciprilate $(0.025 \mathrm{mg} / \mathrm{kg} . \mathrm{h})$, DuP753 (0.625 mg/kg.h) and felodipine (0.042 and $0.42 \mathrm{mg} / \mathrm{kg} . \mathrm{h}$ ) or received no treatment. All drugs were administered in osmotic minipumps (Alzet, Palo Alto, USA), which were implanted subcutaneously as described in section 7.2.3.

The inhibition of angiotensin pressor responses in vivo was comparable for zabiciprilate, captopril and DuP753 (section 7.2.2 and 7.3.1). The antihypertensive effects were comparable for zabiciprilate, captopril and felodipine $(0.042$ $\mathrm{mg} / \mathrm{kg}$.h) and comparable for DuP753 and felodipine $(0.42 \mathrm{mg} / \mathrm{kg} . \mathrm{h}$ ) (section 7.3.1).

\subsubsection{Skeletal muscle preparation}

Following completion of perfusion experiments (section 7.2.3), soleus (SOL) and gastrocnemius muscle (GAS) of both hindlimbs were dissected free in control animalls, and in treated and untreated chronically ischemic animals. In case of fiber size measurements in control and untreated chronic ischemic animals, only blood pressure measurements (section 7.2.2) and no hindlimb perfusion experiments preceded the removal of muscles to avoid influences of possible generation of oedema due to perfusion.

Muscles were frozen in liquid nitrogen and stored at $-20^{\circ} \mathrm{C}$, whereafter sections $(12 \mu \mathrm{m})$ were cut transversely on the cryostat microtome. GAS and SOL were both stained for alkaline phosphatase, whereas GAS was also stained for type II-muscle fiber as described in section 2.4.2.

\subsubsection{Measuring protocols}

The origin of all samples for morphometry was blinded to the investigator. The number of capillaries and fibers in GAS and SOL of both hindlimbs in control and treated and untreated chronically ischemic animals were counted microscopically, whereafter capillary to fiber ratio $(\mathrm{C} / \mathrm{F})$ was computed as described in section 2.4.2. As the $\mathrm{C} / \mathrm{F}$ depends on muscle fiber type, only the type II-muscle fiber part of the heterogenous GAS (Sillau and Banchero, 1978; Ripoll et al., 1979; Hudlicka, 1982, 1985; Armstrong and Phelps, 1984) was counted for the number of capillaries and fibers.

To investigate whether changes in $\mathrm{C} / \mathrm{F}$ are a consequence of changes in total number of fibers, total muscle size was measured (section 2.4.2). This was only 
possible in SOL, as C/F in GAS was obtanned only in the type II-muscle fiber part.

Furthermore, fiber size was measured in both SOL and GAS in control and untreated chronic ischemic animals and total number of fibers $\left(F_{\text {total }}\right)$ was computed (section 2.4.2).

\subsubsection{Data analysis}

Values of control and untreated chronic ischemic animals were compared by Student's t-test for unpaired observations. Values of treated and untreated chronic ischemic animals were compared by one-way analysis of variance and Bonferroni and Dunnett's tests. Values of left and right hindlimb were compared by Student"s t-test for paired observations.

\subsection{RESULTS}

\subsubsection{Chronic ischemia}

In chronic ischemic animals, skeletal muscles of the ischemic hindlimb did not exhibit signs of atrophy and had a normal appearance, except for a slight decrease in muscle mass compared to the contralateral muscles.

$\mathrm{C} / \mathrm{F}$ in the type II-muscle fiber part of GAS was lower than C/F in SOL (type I-muscle fibers) independently of ischemia, as shown in table 9.1 .

Table 9.1 Capillary to fiber ratio and muscle fiber size in gasrocnemius and soleus muscle of left and righ hindimb in control and chronically ischemic rats.

\begin{tabular}{lllllll}
\multicolumn{6}{c}{ M. Gastrocnemius } & M. Soleus \\
Control & CFF & $336 \pm 7$ & Left & Right & Left & Right \\
& FS & & $3055 \pm 0.05$ & $1.41 \pm 0.06$ & $2.83 \pm 0.05$ & $2.80 \pm 0.09$ \\
Ischemia & CIF & $335 \pm 5$ & $1.50 \pm 0.05^{*}$ & $1.40 \pm 0.04$ & $3.18 \pm 0.09^{* \#}$ & $2.82 \pm 0.05$ \\
& FS & & $2908 \pm 61$ & $3056 \pm 111$ & $2372 \pm 71^{* \#}$ & $3081 \pm 78$
\end{tabular}

control: $N=9$; ischemic rats: $N=12$; C/F: capillary to fiber ratio: $F S$ : fiber size $\left(\mu m^{2}\right)$; $B W=$ body weight $(g) ;{ }^{*} p<0.05$ compared to control: " $p<0.05$ compared to contralateral muscle. 


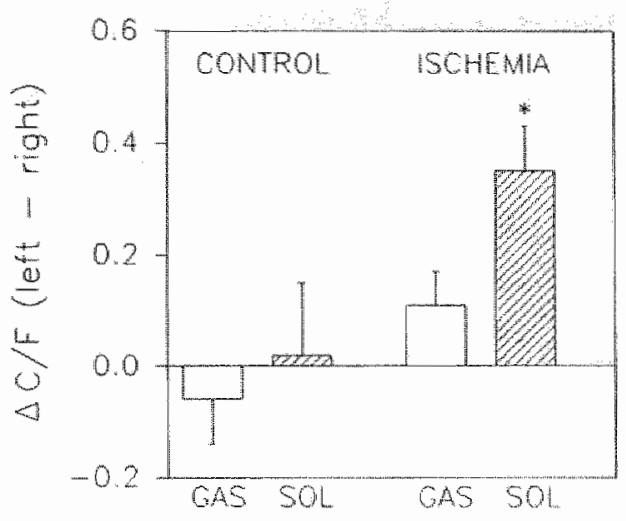

Figure 9.1 The difference in capillary to fiber ratio (C/F) between left and right soleus and gastrocnemius muscles.

In chronically ischemic hindlimbs muscle fiber size was reduced significantly in SOL. Furthermore, chronic ischemia of the left hindlimb increased $\mathrm{C} / \mathrm{F}$ in left SOL significantly compared to control and contralateral muscle, whereas $\mathrm{C} / \mathrm{F}$ in left GAS was significantly increased compared to control only (table 9.1). The difference between $\mathrm{C} / \mathrm{F}$ in left and right muscles was increased in both GAS and SOL, but was only significant in SOL (figure 9.1). This increase in $\mathrm{C} / \mathrm{F}$ in SOL was the result of an increased total capillary number and not of a decreased total fiber number (table 9.2). Moreover, total fiber number even increased significantly in ischemic SOL compared to the contralateral muscle. Chronic ischemia had no influence on muscle fiber size and capillarity in the right GAS and SOL.

\subsubsection{Therapy}

Vasodilator treatment resulted in muscular atrophy in the region of the vastus lateralis muscle of the ischemic hindlimb in $45-73 \%$ of the ischemic animals (lowest: fellodipine $(0.42 \mathrm{mg} / \mathrm{kg} . \mathrm{h}) 45 \%$; highest: felodipine $(0.042 \mathrm{mg} / \mathrm{kg} . \mathrm{h})$ $73 \%$; untreated ischemia: $0 \%$ ). Body weight after 4 weeks of treatment with DuP753 or the high dose of felodipine was significantly lower than body weight of untreated ischemic animals (table 9.3), although body weight was comparable at the start of the experiments.

Zabiciprilate or captopril treatment had no influence on $\mathrm{C} / \mathrm{F}$ in GAS. In contrast, $\mathrm{C} / \mathrm{F}$ was decreased in left and right GAS following treatment with DuP753 or felodipine (table 9.3). The difference between left and right GAS did not change following treatment (figure 9.2). 
Table 9.2 Total muscle fiber number in soleus muscle of left and right hindimb in control, untreated and treated ischemic animals.

$\begin{array}{lclll} & N & \text { Dose } & \text { Left } & \text { Right } \\ \text { Control } & 9 & & 2911 \pm 204 & 3076 \pm 184 \\ \text { Untreated ischemia } & 15 & & 3309 \pm 191^{\#} & 2864 \pm 92 \\ \text { Captopril } & 14 & 0.500 & 3438 \pm 198 & 3335 \pm 102 \\ \text { Zabiciprilate } & 12 & 0.025 & 3473 \pm 171 & 3900 \pm 476 \\ \text { DuP753 } & 12 & 0.625 & 2883 \pm 148 & 3182 \pm 117 \\ \text { Felodipine } & 12 & 0.042 & 3341 \pm 116 & 3333 \pm 157 \\ \text { Felodipine } & 7 & 0.420 & 3211 \pm 149 & 3313 \pm 161\end{array}$

Dose: $\mathrm{mg} / \mathrm{kg} . \mathrm{h}$; $p<0.05$ compared to contralateral hindlimb.

Table 9.3 Capillary to fiber ratio in soleus and gastrocnemius muscle of left and right hindimb in unireated and treated chronically ischemic rats.

\begin{tabular}{|c|c|c|c|c|c|c|c|}
\hline & & & & M. Gastrocn & nemius & M. Soleus & \\
\hline & $N$ & $B W$ & $\%$ flow & Left & Right & Left & Right \\
\hline Untreated & 12 & $335 \pm 5$ & $17.4 \pm 2.1$ & $1.50 \pm 0.05$ & $1.40 \pm 0.04$ & $3.18 \pm 0.09^{4}$ & $2.82 \pm 0.05$ \\
\hline Captopril & 14 & $330 \pm 5$ & $12.5 \pm 2.1$ & $1.46 \pm 0.04$ & $1.42 \pm 0.04$ & $2.92 \pm 0.09$ & $2.84 \pm 0.05$ \\
\hline Zabiciprilate & 12 & $338 \pm 4$ & $16.0 \pm 2.9$ & $1.40 \pm 0.02$ & $1.48 \pm 0.04$ & $3.08 \pm 0.06$ & $3.00 \pm 0.05$ \\
\hline DuP753 & 9 & $306 \pm 5^{*}$ & $15.0 \pm 2.4$ & $1.24 \pm 0.06^{*}$ & $1.27 \pm 0.04$ & $2.76 \pm 0.07^{*}$ & $2.82 \pm 0.10$ \\
\hline Felodipine (L) & 12 & $342 \pm 5$ & $9.5 \pm 0.9$ & $1.30 \pm 0.03^{*}$ & $1.37 \pm 0.04$ & $3.19 \pm 0.08^{17}$ & $2.93 \pm 0.08$ \\
\hline Felodipine $(H)$ & 7 & $271+10^{*}$ & $9.4 \pm 0.6$ & $1.20 \pm 0.04^{*}$ & $1.18 \pm 0.03^{*}$ & $2.74 \pm 0.08^{*}$ & $2.86 \pm 0.05$ \\
\hline
\end{tabular}

Vasodilator therapy had no effect on $\mathrm{C} / \mathrm{F}$ in right $\mathrm{SOL}$. In contrast, $\mathrm{C} / \mathrm{F}$ in left SOL decreased significantly following DuP753 and the high dose of felodipine compared to untreated left SOL. The increased difference in capillarity of left and right SOL following chronic ischemia was abolished by zabiciprilate, captopril, DuP753 and high dose of felodipine. The abolishment was 


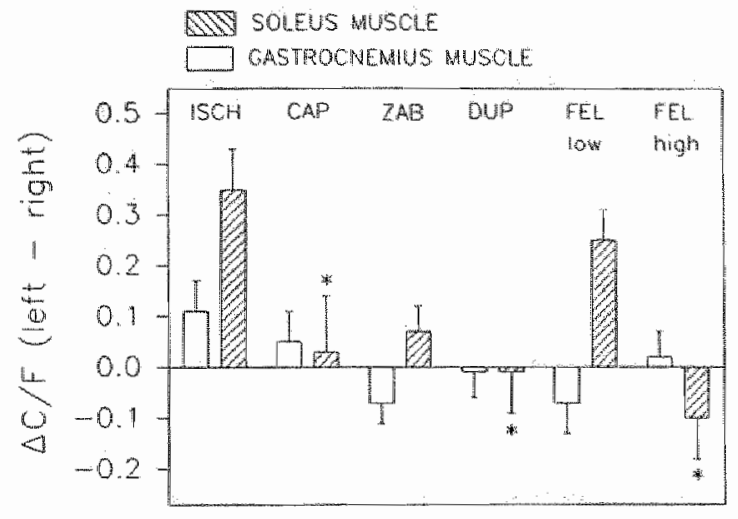

Figure 9.2 The difference in capillary to fiber ratio (C/F) between left and right soleus muscle in untreated and treated ischemic animals.

significant for captopril, DuP753 and felodipine (figure 9.2). Therapy had no influence on total fiber number of SOL in both hindlimbs (table 9.2). Therefore, the changes in $\mathrm{C} / \mathrm{F}$ following therapy were not the result of changes in total fiber number.

\section{$9.4 \quad$ DISCUSSION}

Following partial ligation of the common iliac artery in the hindlimb of the rat, residual flow was less than 30-40 percent, resulting in severe ischemia and, presumably, initiation of several compensatory mechanisms, such as metabolic changes (Elander et al., 1985; Harris et al., 1986; Heppenstall et al., 1986; Idström et al., 1990; Erney et al., 1991; Kwasnik et al., 1991) and structural adaptations of resistance vessels (Ludatscher et al., 1981; Gidlöf et al., 1987). One of the consequences of skeletal muscle ischemia is a (non-specific) hyperreactivity for vasoconstrictor agents of the vascular bed of the ischemic hindlimb, as seen in chapter 6. Furthermore, an adaptation to a diminished oxygen supply by development of collateral vessels has been described (Adair et al., 1990). To investigate possible development of new vessels following chronic ischemia of skeletal muscle, the amount of fibers and capillaries, expressed as capillary to fiber ratio, and fiber size were determined in two different skeletal muscles of both hindlimbs, the predominantly slow oxidative (type I-muscle fiber) soleus muscle and the fast glycolytic and oxidative glycolytic part (type IImuscle fibers) of the gastrocnemius muscle. Furthermore, the effects of ACEinhibition and angiotensin II antagonism on the capillary to fiber ratio in chronic ischemic animals were studied to investigate the possible role of the renin angiotensin system in neovascularization. As a control for the antihypertensive 
effect, also the calcium entry blocker felodipine was investigated at comparable antihypertensive doses.

Neovascularization in skeletal muscle was investigated by staining the capillaries for alkaline phosphatase. This staining method has been reported to visualize the total number of capillaries, comparable with the number obtained by electron microscopy (Hudlicka et al., 1987; Hudlicka and Price, 1990b). Since capillary density depends on fiber size (Loats et al., 1977; Sillau and Banchero, 1978; Hudlicka, 1982), the number of capillaries was expressed as capillary to fiber ratio.

Chronic ischemia caused a decrease in fiber size and an increase in capillary to fiber ratio predominantly in the oxidative soleus muscle of the ischemic hindlimb. The increase in capillary to fiber ratio in soleus muscle was abolished by chronic therapy with captopril, zabiciprilate and DuP753. The low dose of felodipine had no effect on capillarity, whereas the high dose of felodipine abolished the capillary growth in chronic ischemia.

Both in control and ischemic muscles the capillary to fiber ratio was higher in soleus than in the type II-muscle fiber part of the gastrocnemius. This difference has been suggested to depend on aerobic metabolism and thus oxidative capacity of skeletal muscles (Gray and Renkin, 1978; Ripoll et al., 1979; Hudlicka, 1982, 1985; Hudlicka et al., 1987).

Chronic ischemia decreased fiber size and increased capillary to fiber ratio significantly only in soleus muscle compared to both control and contralateral muscle. The effects on capillarity and fiber size in ischemic gastrocnemius muscle were comparable with the effects previously observed in tibialis anterior muscle and extensor digitorum longus muscle of rats (Hudlicka and Price, 1990a), both predominantly type II-muscle fibers (Armstrong and Phelps, 1984). Furthermore, a decreased fiber size and a small or no effect on capillarity in total gastrocnemius muscle have been observed in patients with intermittent claudication (Hammarsten et al., 1980; Clyne et al., 1982, 1985). This decrease in fiber size in ischemic skeletal muscle has been suggested to compensate for the reduced oxygen supply by decreasing the oxygen diffusion distance (Clyne et al., 1982; Aalkjaer, 1990; Adair et al., 1990). Therefore, the reduction in fiber size predominantly in soleus muscle may be one of the compensatory mechanisms following hypoxia.

The increase in capillarity was higher in soleus than in gastrocnemius muscle. This higher sensitivity of soleus muscle for ischemic conditions has been described previously (Karpati et al., 1974) and may depend on the higher oxidative metabolic demand of the oxidative soleus muscle compared to the mixed glycolytic and oxidative glycolytic gastrocnemius muscle (Gray and Renkin, 1978; Ripoll et al., 1979; Hudlicka, 1985; Hudlicka et al., 1987).

An increase in capillary to fiber ratio may be caused by a decrease in total fiber number. However, in ischemic soleus total fiber number was increased. 
Such a generation of muscle fibers has been previously described in damaged muscles following excessive training, injury, and ischemia of skeletal muscle (Carlson and Faulkner, 1983; Armstrong et al., 1991). Moreover, an increase in total muscle fiber number may compensate for a diminished force development in ischemic muscles (Hanzlikova and Gutmann, 1979).

An alternative explanation for the capillarity increase may be hypoxia of the skeletal muscles or the pressure drop distal to the occlusion. They may both be a trigger for development of collaterals (Conrad et al., 1971; Hudlicka, 1982, 1985). Hypoxia induces a decrease in intracellular $\mathrm{pH}$ and production of vasoactive metabolites (adenosine) and autocrine factors (angiotensin II) in hypoxic tissues (Aalkjaer, 1990; Adair et al., 1990). These consequences of hypoxia have been suggested to be major determinants of blood vessel growth (Fernandez et al., 1982, 1985; Dusseau and Hutchins, 1988; Adair et al., 1989; Aalkjaer, 1990).

The hypothesis that there is a role of the renin angiotensin system in neovascularization is supported by the observations that chronic treatments with the ACE-inhibitors captopril and zabiciprilate can abolish the increased capillarity in ischemia, whereas a comparable antihypertensive dose of the calcium entry blocker felodipine had no effect. The role of the $\mathrm{AT}_{1}$-receptor in the neovascularization could not be elucidated, as both DuP753 and a comparable antihypertensive dose of felodipine abolished the increased capillarity in ischemia. This suggests that at higher doses the blood pressure reduction becomes more important in the abolishment of neovascularization.

The lack of increase in capillarity in ischemic soleus muscle following therapy suggests a lack of compensation of the diminished flow in the muscle and thus a deleterious effect on the muscle. This is supported by the occurrence of atrophy in the region of the vastus lateralis muscle in the ischemic hindlimb after the treatment with all antihypertensives, whereas no such atrophy was observed in untreated ischemic animals. The atrophy observed in felodipine treated animals is in contrast to previously described attenuation of muscle damage by prevention of increased intracellular calcium levels by calcium entry blockers (Armstrong et al., 1991).

A role of the renin angiotensin system in vessel growth has previously been demonstrated in normal skeletal muscle by Wang and Prewitt (1990). They observed a reduction in small arteriolar density after chronic treatment with captopril. This is in contrast to the effects of other antihypertensives on capillarity in normal skeletal muscles. Chronic vasodilation with isoprenaline (Sillau and De Lourdes Philippi, 1987), prazosin (Ziada et al., 1989), dipyridamole (Tornling et al., 1980; Ljungqvist et al., 1984), adenosine (Ziada et al., 1984) or the xanthine derivative HWA 285 (Ziada et al., 1984) resulted in an increase in capillarity in oxidative and glycolytic muscles. This increase in capillarity in normal skeletal muscle has been suggested to be initiated by a blood flow 
increase due to vasodilatation, demonstrated by an increase in capillarity by prazosin only in tissues where it increases blood flow (Ziada et al., 1989). However, in ischemic skeletal muscles vasodilatation does not seem to play a role in neovascularization. Chronic treatment with the xanthine derivatives pentoxifylline or torbafylline, resulting in an increase in blood flow and a slight decrease in blood pressure, did not change capillarity in ischemic tibialis anterior and extensor digitorum longus muscles (Hudlicka and Price, 1990a).

The present experiments suggest that ACE-inhibition and angiotensin IIantagonism have no beneficial effect in ischemia of skeletal muscle, as the compensatory increase in capillarity following chronic ischemia in soleus muscle was abolished. This is in contrast with the beneficial effects of captopril on maximal and pain-free walking distance in patients with intermittent claudication and hypertension (Catalano and Libretti, 1985; Bernardi et al., 1988). In these patients captopril has been suggested to cause no reflex vasoconstriction as observed by other antihypertensives (Roberts et al., 1987a; Bernardi et al., 1988). The discrepancy between captopril treatment in patients and treatment with captopril and zabiciprilate in the present chronic ischemia animal model may relate to the onset of therapy. In patients captopril treatment usually starts after clinical manifestation of the disease, so capillary growth has already been initiated. In contrast, treatment was started immediately after induction of ischemia in the animals, resulting in a prevention of development of capillary growth.

In summary, chronic ischemia of skeletal muscle results in an increased capillarity of predominantly soleus muscle. Chronic treatments with the ACEinhibitors captopril and zabiciprilate prevent the capillary growth, which could not be mimicked by a dose of felodipine with comparable antihypertensive activity. This suggests involvement of the renin angiotensin system in the neovascularization in chronic ischemia. The inhibitory effects on neovascularization of the $\mathrm{AT}_{1}$ antagonist DuP753 and a dose of felodipine with comparable antihypertensive activity in chronic ischemia may be due to pronounced blood pressure reductions. 


\section{CHAPTER 10}

\section{General discussion}

\subsection{GENERAL}

Both local and circulating renin angiotensin systems play an important role in the cardiovascular homeostasis under physiological and pathophysiological conditions. The major autocrine and paracrine functions of the local renin angiotensin systems have been suggested to be involved in intermediate (hours) and long-term (days) regulation of arterial pressure, cardiac function and volume homeostasis (Hall et al., 1986; Dzau, 1988; Rosenfeld and Zabludowski, 1989; Lindpaintner and Ganten, 1991). Recently, local renin angiotensin systems have been implied also in ultra-long-term (weeks-years) cardiovascular control, through regulation of vessel and heart structure by growth promoting activities, e.g. hyperplasia, hypertrophy and new vessel formation (Fernandez et al., 1985; Re and Rovigatti, 1988).

In hypertension, the inhibition of local ACE probably plays a more important role in the antihypertensive effects of ACE-inhibitors than the inhibition of plasma ACE (Cohen and Kurz, 1982; Dzau, 1987a; Urabe et al., 1987). In heart failure, cardiac angiotensin II seems to be involved in disturbances of cardiac metabolism and in ventricular remodeling processes ( $\mathrm{Li}$ and $\mathrm{Chen}, 1987$; Weber and Janicki, 1989; Hirsch et al., 1990; Osterziel et al., 1990; Lindpaintner and Ganten, 1991; Morgan and Baker, 1991; Van Krimpen et al., 1991a), whereas other local systems may be involved in peripheral vascular compensatory mechanisms. 


\subsection{LOCAL RENIN ANGIOTENSIN SYSTEMS}

The local renin angiotensin system of the renal vascular bed seems to play an important role in the control of renal resistance. This has been demonstrated in the present thesis following $A C E$ inhibition at non-hypotensive doses in an experimental model for heart failure (chapter 3 ) as well as in previous studies with hypotensive doses of ACE-inhibitors in both experimental hypertension and heart failure (Smits and Struyker-Boudier, 1984; Drexler et al., 1987; Richer et al., 1987; Muller et al., 1990). The ACE-inhibitors decreased resistance in the renal vascular bed and not in the mesenteric vascular bed, although the reactivity of both vascular beds to angiotensin I is comparable. The preferential renal vasodilatation may depend upon greater affinity of the ACE-inhibitors for renal $\mathrm{ACE}$ than for mesenteric ACE. This is supported by the observations that equivalent inhibitory activity of the ACE-inhibitors in plasma was associated with differences in inhibition of tissue ACE. For enalaprilate and captopril the inhibition of plasma and kidney ACE has been described to be almost complete, whereas the inhibition in other tissues varied from 10-80\%. This has been proposed to be due to differences in tissue penetration (Cushman et al., 1989a,b).

In our hindlimb perfusion model, the inhibition of local ACE was studied without interference of components of the circulating renin angiotensin system. The local renin angiotensin system in the vascular bed of the hindlimb has been described to be of functional relevance, although the reactivity of the vascular bed of the hindlimbs in vivo and in the in-situ perfused hindlimbs is low (chapter 5; Mueller and Cohen, 1983; Oliver and Sciacca, 1984; Nakamaru et al., 1987; Mizuno et al., 1988b, 1990; Hilgers et al., 1989). In contrast to inhibition of plasma ACE, the inhibition of local ACE by the ACE-inhibitors was not comparable in the hindlimb perfusion model (chapter 5). Again, this discrepancy between local and plasma ACE inhibition may be explained by differences in diffusion characteristics of the ACE-inhibitors. This is supported by the observations that local ACE is not only located on the membrane of endothelial cells of the vessel wall, but also in media, adventitia and interstitial fibroblasts of the vessel wall (Velletri and Bean, 1982; Urabe et al., 1987; Pipili et al., 1989).

\subsection{ACE-INHIBITORS AND LOCAL RENIN ANGIOTENSIN SYSTEMS}

The diffusion characteristics of the ACE-inhibitors may play an important role in the inhibition of local ACE and, thus, in effects of the ACE-inhibitors both in normal and pathophysiological situations. The diffusion characteristics of the 
ACE-inhibitors depend on lipophilicity.

Because of oral bioavailability, most ACE-inhibitors are prodrug esters and must be hydrolyzed before they are biologically active. Therefore, the penetration of the ACE-inhibitors into tissues also depend on the location of hydrollysis of the prodrug. Several drugs, such as zofenopril (Cushman et al., 1989b), are deesterified rapidly in tissue cells. These drugs might accumulate in the tissues by entering the tissue as inactive prodrugs, where they are converted to the active drug, which might not leave the tissue easily. Most prodrug ACE-inhibitors, however, are hydrolyzed in the liver (Ondetti, 1988). In this case, the lipophilicity of the active drug defines the penetration into the tissues, resulting in an almost non-selective inhibition of tissue ACE (except for $A C E$ in brain).

The inhibition of tissue ACE by ACE-inhibitors depends primarily on their lipophilicity, providing no major guideline for the choice of ACE-inhibitor in the treatment of hypertension and heart failure. Preferential inhibition of ACE in a specific tissue can only be achieved by administration of a prodrug ACEinhibitor, which is converted into the active drug predominantly in the target tissue (drug targeting; Smits and Thijssen, 1986).

\subsection{ISCHEMIA OF SKELETAL MUSCLE: PATHOPHYSIOLOGY AND COMPENSATORY MECHANISMS}

Both acute and chronic ischemia of skeletal muscle cause hyperreactivity of the ischemic vascular bed to the vasoconstricting substances angiotensin I, angiotensin II and phenylephrine (chapter 6). This hyperreactivity can be abolished by angiotensin II antagonism with DuP753 (chapter 7). The femoral arteries of the chronically ischemic hindlimb show a structural adaptation to the diminished blood pressure and flow, resulting in a decreased absolute maximal contractility (chapter 8 ). In contrast, the sensitivity and relative reactivity of the post-stenotic femoral artery to depolarizing (potassium) and vasoconstricting substances (serotonin and phenylephrine) are increased, whereas the relaxing properties are not altered. Furthermore, chronic ischemia of skeletal muscle induces neovascularization in the oxidative soleus muscle (chapter 9). This neovascularization can be inhibited by chronic treatment with moderately antihypertensive doses of ACE-inhibitors, and by chronic treatment with excessively antihypertensive doses of DuP753 or felodipine.

Possible adaptation mechanisms involved in the observed hyperreactivity and neovascularization in the vascular bed of ischemic hindlimbs will be discussed below. 


\subsubsection{Structural vascular alterations}

In the ischemia model used in the present thesis both flow and pressure were reduced distally to the ligature in the ischemic hindlimb. Structural adaptation (alterations in media thickness, cross sectional area and wall to lumen ratio) of the vessel wall to local blood pressure and consequent reactivity changes have been observed in vessels of normotensive and hypertensive animals (Folkow et al., 1970; Folkow, 1982; Arner et al., 1984) and in vessels that have been protected from the increase in blood pressure associated with aging (Folkow et al., 1971; Bund et al., 1991). The structural changes in these latter vessels were comparable with the changes observed in our model, suggesting an adaptation to diminished blood pressure. The structural changes in our model were associated not only with a decrease in (absolute) maximal contractility, but also with an increase in sensitivity and relative reactivity to depolarizing and vasoconstricting substances. This is in contrast to the decrease in relative reactivity of the above described vessels (exposed to a lower blood pressure), suggesting a lack of involvement of the structural adaptation of the vessel wall of pre-existing vessels to the diminished blood pressure in the non-selective (relative) hyperreactivity of the vascular bed in ischemic hindlimbs. A major determinant for adaptive processes resulting in a non-selective (relative) hyperreactivity of pre-existing vessels may be the chronic flow (and/or pulse pressure) reduction, as comparable reactivity changes have been observed in a model in which blood flow and probably not blood pressure is reduced (Verheyen et al., 1989, 1991; cf. chapter 8).

One of the vascular compensatory mechanisms to increase blood flow in the ischemic hindlimb may be development of collaterals. Acutely, this can be achieved by recruitment of pre-existing vessels and chronically by formation of new vessels (Fernandez et al., 1982, 1985; Barie and Mullins, 1988).

Not only the pre-existing vessels, but also the collateralized vascular bed may account for the observed hyperreactivity of the vascular bed in the ischemic hindlimb (Verheyen et al., 1991). This collateralized vascular bed has been proposed to be hyperreactive due to a greater thickness of the vessel wall (Barie and Mullins, 1988; Samani and Swales, 1991) or a smaller innervation density of the collateral vessels, resulting in postsynaptic hypersensitivity (Williams and Saelens, 1983).

\subsubsection{Alterations of receptor-linked mechanisms}

Inhibition of the $\mathrm{AT}_{1}$-receptor with DuP753 resulted in an abolition of the non-selective hyperreactivity. This suggests involvement of mechanisms related to the $\mathrm{AT}_{1}$-receptor in the development of hyperreactivity.

In patients with congestive heart failure alterations of $\mathrm{AT}_{1}$ - and $\mathrm{AT}_{2}$-receptor 


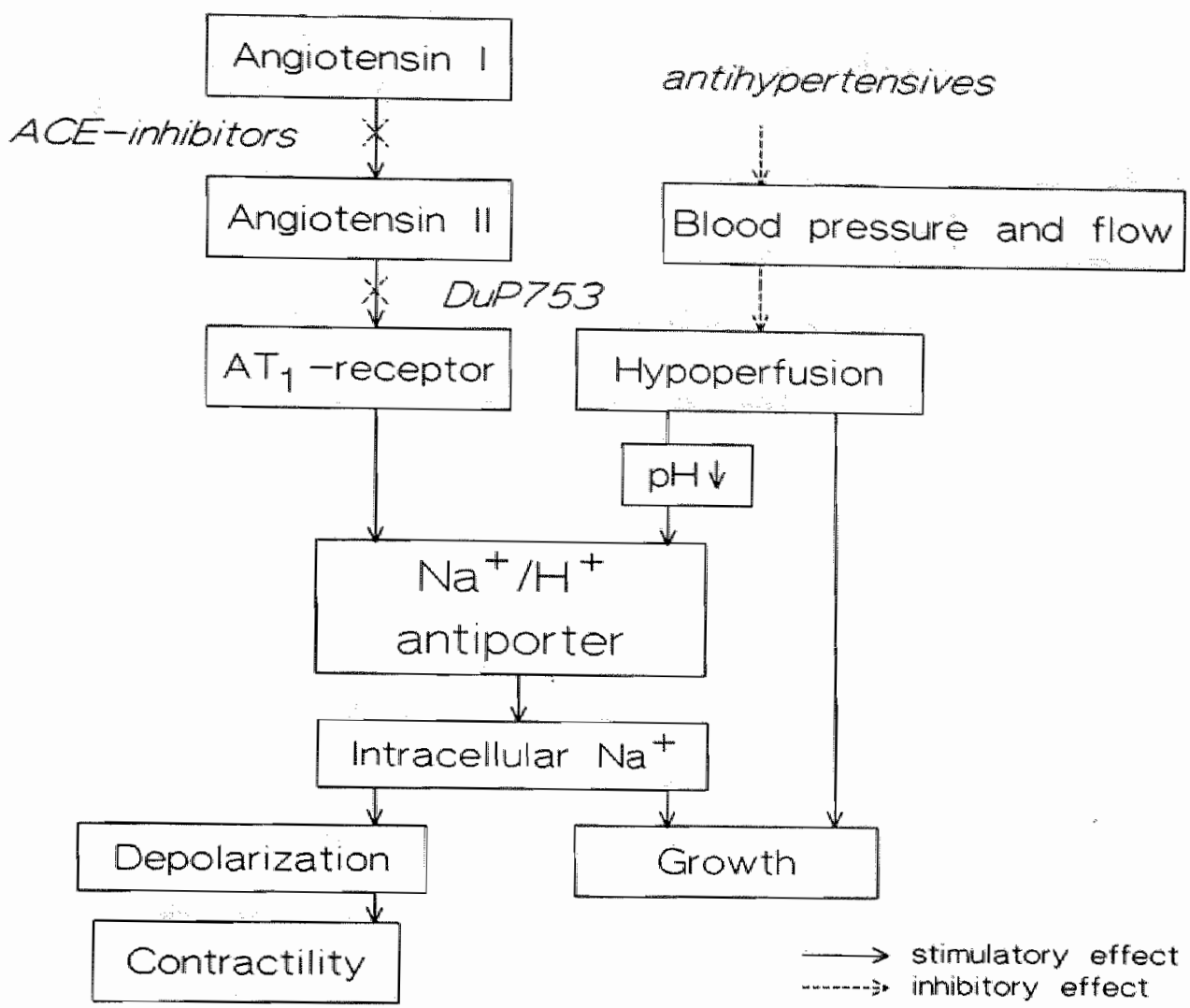

Figure 10.1 Role of angiotensin $I I$ and hypoperfusion in adaptive mechanisms following ischemia of skeletal muscie as suggested in our experiments.

numbers in the heart have been proposed (Rogg et al., 1991 and personal communication). Furthermore, in experimental heart failure (Hirsch et al., 1991), in pressure overload ventricular hypertrophy (Schunkert et al., 1990) and in hypoxia of pulmonary endothelial cells (King et al., 1989) an increased activity of local renin angiotensin systems has been described. In the present ischemic preparation a similar activation may occur. However, the involvement of the local renin angiotensin system and the $\mathrm{AT}_{1}$-receptor in the increased reactivity to phenylephrine (chapter 6 and 8), serotonin (chapter 8; Verheyen et al., 1988, 1991) and a thromboxane $A_{2}$ analogue (Verheyen et al., 1989) is not yet clear. One of the possibilities may be an increased receptor-mediated activation of the second messenger system, which is the same for the $\mathrm{AT}_{1^{-}}, \alpha_{1^{-}}$, $5 \mathrm{HT}_{2}$ - and thromboxane receptor (Watson and Abbott, 1992). However, this does not explain the relative hyperreactivity for potassium (chapter 8).

An alternative explanation may be an increase in sodium entry by elevated 
angiotensin II concentrations wia the $\mathrm{Na}^{+} / \mathrm{H}^{+}$antiporter (figure 10.1; Hatori et al., 1987; Barrett et al., 1989). This $\mathrm{Na}^{+} / \mathrm{H}^{+}$-exchange has been described to be sensitive not only for amiloride, but also for saralasin (Bingham Smith and Brock, 1983). This suggests a receptor-dependent stimulation of the $\mathrm{Na}^{+} / \mathrm{H}^{+}$ antiporter by angiotensin II. Stimulation of the $\mathrm{Na}^{+}$influx slightly depolarizes vascular smooth muscle cells, resulting in an activation of calcium conductance or voltage-dependent $\mathrm{Na}^{+}-\mathrm{Ca}^{2+}$ exchange (Lang and Blaustein, 1980; Brading and Lategan, 1985; Sage et al., 1991). The appearance of a slight depolarization of the cell membrane is supported by the observation that relaxation due to hyperpolarization by a moderate increase in extracellular potassium concentration is increased in vascular smooth muscle cells of femoral arteries of ischemic hindlïmbs, probably due to an increased intracellular sodium concentration (chapter 8). Such a slight depolarization in vessels of the ischemic hindlimbs may underlie non-selective hypersensitivity and hyperreactivity (Hermsmeyer, 1982; Harder and Hermsmeyer, 1983). The role of angiotensin II and the $\mathrm{AT}_{1}$ receptor in the alterations of the membrane potential was demonstrated by the abolishment of the hyperreactivity to phenylephrine by DuP753 in the vascular bed of the ischemic hindlimb. Thus, the stimulation of $\mathrm{Na}^{+}$influx by angiotensin II, the consequent depolarization of the cell membrane and the possibility to increase calcium influx may provide an explanation for non-selective hyperreactivity of the vascular bed of the ischemic hindlimbs (figure 10.1).

In contrast to previously observed abolishment of the hyperreactivity to a thromboxane $A_{2}$ analogue by the (acutely administered) calcium entry blockers flunarizine and nifedipine (Verheyen et al., 1989), chronic treatment with the calcium entry blocker felodipine had no effect on hyperreactivity. The above proposed calcium influx does not seem to be influenced, suggesting a lack of involvement of the vascular voltage-operating channel in the non-selective hyperreactivity in our ischemia model.

\subsubsection{Ultrastructural alterations in blood vessels and skeletal muscle}

During ischemia several metabolic changes occur acutely in the vascular smooth muscle cells and skeletal muscle. One of the metabolic indices of tissue perfusion is resting muscle $\mathrm{pH}$, as demonstrated by a stepwise reduction in femoral blood flow in a hindlimb perfusion model by Kwasnik et al (1991; review Dennis et al., 1991). Intracellular $\mathrm{pH}$ plays an important role in the activity of enzymes and ion transport mechanisms (Aalkjaer, 1990).

Congestive heart failure in humans (Urata et al., 1990) and ischemia in dog hearts (Gondo et al., 1989) result in an important contribution of kallikrein or kallikrein-like proteases to the conversion of angiotensin I into angiotensin II. This may depend upon a decreased intracellular $\mathrm{pH}$ at which these enzymes 
have a higher activity, and suggests that a diminished intracellular $\mathrm{pH}$ in chronic ischemia of skeletal muscle decreases the contribution of ACE in the generation of angiotensin II. A diminished contribution of ACE is supported by the observation that chronic ACE-inhibition hardly prevents angiotensin II formation in the perfused hindlimbs (chapter 7).

Furthermore, abnormal $\mathrm{pH}$ control in ischemia of skeletal muscle causes a disturbance of transport mechanisms that affect the regulation of intracellular $\mathrm{pH}$, resulting in a stimulation of the $\mathrm{Na}^{+} / \mathrm{H}^{+}$exchange, the chloride-bicarbonate exchange and the sodium-dependent bicarbonate transport (Aalkjaer, 1990). As described above, an increased $\mathrm{Na}^{+} / \mathrm{H}^{+}$exchange causes an increased intracellular $\mathrm{Na}^{+}$concentration and thus a slight depolarization of the cell membrane, resulting in an activation of the calcium influx. Thus, a decreased intracellular $\mathrm{pH}$ in hypoxia and/or an increased angiotensin II generation may be responsible for the (non-selective) hyperreactivity of the vascular bed in both the acutely and chronically ischemic hindlimb, since they can both activate the $\mathrm{Na}^{+} / \mathrm{H}^{+}$exchange and induce a slight depolarization of the cell membrane (figure 10.1).

Also, hypoxia (and the consequent reduction of $\mathrm{pH}$ ) has been proposed to initiate a variety of signals that lead to growth of blood vessels (Aalkjaer, 1990; Adair et al., 1990). An increase in vascularity promotes oxygen delivery to the tissue cells by decreasing diffusion distances, increasing capillary surface area and blood flow. The reduction in $\mathrm{pH}$ can stimulate the $\mathrm{Na}^{+} / \mathrm{H}^{+}$-antiporter, resulting in an increase in intracellular sodium concentration (figure 10.1). The role of sodium in growth has been described previously in pressure loaded cardiomyocytes and in a pressure overload heart model (Cooper IV et al., 1989; Kent et al., 1989). This link between the $\mathrm{Na}^{+} / \mathrm{H}^{+}$-antiporter and growth implies also a link between the $\mathrm{AT}_{1}$-receptor and growth. Other determinants of blood vessell growth are vasoactive metabolites (adenosine), autocrine factors (angiotensin II; Fernandez et al., 1982, 1985; Dusseau and Hutchins, 1988; Adair et al., 1989; Le Noble et al., 1991), mechanical factors (Adair et al., 1990) and polypeptide growth factors (Rozengurt, 1986; Eisenstein, 1991).

In patients with intermittent claudication a small or no effect on capillarity has been demonstrated in the gastrocnemius muscle (Hammarsten et al., 1980; Clyne et al., 1982, 1985). In these patients the decrease in diffusion distance by a decreased surface area of the muscle fibers instead of an increased capillarity has been suggested to compensate for the reduced oxygen supply. In the present thesis both an increase in capillarity and a decrease in surface area of muscle fibers have been observed in the oxidative soleus muscle, whereas in the gastrocnemius muscle we noted no changes in surface area and capillarity (chapter 9). Unchanged capillarity has also been demonstrated in tibialis anterior and extensor digitorum longus muscles (both heterogenous fiber types) in rats with ischemia (Hudlicka and Price, 1990a). This suggests a higher sensitivity of oxidative fibers than of glycolytic and oxidative glycolytic fibers for hypoxic 
situations.

Furthermore, blood flow reduction induces several metabolic adaptations in skeletal muscle tissues. An adaptive increase in oxidative enzyme capacity, illustrated by an increase in citrate-synthase and cytochrome $c$ oxidase, has been described in ischemic soleus and extensor digitorum longus muscles (Elander et al., 1985; Erney et al., 1991) as well as alterations in intramuscular metabolite concentrations (Elander et al., 1985; Harris et al., 1986; Idström et al., 1990). The degree of ultrastructural damage and the reversibility depend upon the duration of ischemia (Harris et al., 1986; Idström et al., 1990).

\subsection{ISCHEMIA OF SKELETAL MUSCLE: THERAPY}

Antihypertensive therapy is one of the first guidelines in management of hypertension in patients with intermittent claudication. However, reduction in blood pressure with antihypertensives may result in a decreased flow ("steal" phenomenon) to the ischemic legs (Roberts et al., 1987b). This can be catastrophic for the ischemic leg. In the present thesis the role of inhibition of the renin angiotensin system and the consequent blood pressure reduction in the adaptive mechanisms in chronic ischemia skeletal muscle were investigated.

The non-selective hyperreactivity, probably caused by a slight depolarization of the vascular smooth muscle cell membrane, in the vascular bed of ischemic hindlimbs was not influenced by ACE-inhibition and the calcium entry blocker felodipine, whereas DuP753 abolished it. This suggests that substances that prevent or abolish alterations in sodium-ion balance of the cell membrane of vascular smooth muscle may have beneficial therapeutic effects in chronic ischemia of skeletal muscle (figure 10.1).

In contrast to the lack of effect of ACE-inhibition with captopril or zabiciprilate on hyperreactivity, these substances abolished the increase in capillarity in the oxidative soleus muscle. Since a comparable antihypertensive dose of felodipine did not prevent neovascularization, this phenomenon is independent of blood pressure reduction and thus seems to depend on ACE-inhibition. Both circulating and local angiotensin II may be involved in the vessel growth in ischemic muscles. The difference in neovascularization between ischemic and contralateral soleus muscle is probably due to differences in local effects of angiotensin II, as also observed for the reactivity of the vascular bed. A greater blood pressure reduction by both DuP753 and felodipine also inhibited the increase in capillarity in the soleus muscle. This suggests that only greater blood pressure reductions are important in the prevention of neovascularization.

In normal skeletal muscles, chronic vasodilatation by a diversity of substances resulted in an increase in capillarity (Tornling et al., 1980; Ljungqvist et al., 1984; Ziada et al., 1984, 1989; Sillau and De Lourdes Philippi, 1987). The increased blood flow has been suggested to be the trigger for capillary growth, 
as capillarity increase is specific for tissues in which the vasodilators increased blood flow (Ziada et al., 1989). In contrast, vasodilatation in ischemic skeletal muscle by pentoxifylline, torbafylline or buflomedil did not result in neovascularization (Hudlicka and Price, 1990a). The abolishment of the neovascularization by a high dose of the preferential skeletal muscle vasodilator felodipine (Ljung, 1990) observed in our ischemia model suggests that the beneficial neovascularization in ischemic skeletal muscle may be inhibited by a great blood pressure reduction. Probably, the "steal" phenomenon also contributes.

The renin angiotensin system seems to be involved in neovascularization following chronic ischemia of skeletal muscle, since at comparable antihypertensive doses the ACE-inhibitors prevented capillary growth, whereas felodipine did not. The abolition of the capillary growth in ischemic animals treated with the ACE-inhibitors seems to be in contrast with the beneficial effects of captopril on maximal and pain-free walking distance in hypertensive patients with intermittent claudication (Catalano and Libretti, 1985; Bernardi et al., 1988). However, this discrepancy may depend on the onset of therapy. In our ischemia model treatment started immediately after induction of ischemia, whereas treatment in patients with intermittent claudication usually starts after clinical manifestation of the disease. Thus, in patients development of collaterals has already been established at the start of the treatment. Since the beneficial effects of captopril in these patients have been suggested to be due to preferential dilatation of the collaterals in the ischemic region (Roberts et al., 1987a; Bernardi et al., 1988), possible beneficial effects of captopril can not be observed in our ischemia model.

\subsection{GENERAL CONCLUSION AND OUTLOOK}

Local renin angiotensin systems play a role in local control of blood flow in pathophysiological situations, such as hypertension and heart failure. Differences in ACE inhibition in the tissues seem to depend on diffusion of the ACEinhibitors into the tissues. In the case of prodrugs not only diffusion but also conversion into the active drug can play a role in the degree of local ACE inhibition. This suggests that the choice of the ACE-inhibitor in treatment of for instance hypertension or heart failure depends on the target tissues.

Adaptive mechanisms in ischemia of skeletal muscle include structural adaptation of pre-existing vessels to diminished blood pressure, (relative) hyperreactivity of the vascular bed of the ischemic hindlimb to vasoconstricting substances, and neovascularization. Inhibition of the renin angiotensin system by ACE-inhibitors or the $\mathrm{AT}_{1}$-antagonist $\mathrm{DuP753}$ can alter these processes, suggesting involvement of the renin angiotensin system in adaptive mechanisms in ischemia of skeletal muscle. The hyperreactivity of the vascular bed seems to be induced by a slight depolarization of the cell membrane of vascular smooth 
muscle cells, probably caused by alterations of sodium transport mechanisms. Both hypoxia and increased angiotensin II concentrations, demonstrated by abolishment of the non-selective hyperreactivity by DuP753, may be responsible for these alterations. This suggests that substances like amiloride and DuP753, which can influence sodium transport mechanisms and thus prevent the depolarization of the cell membrane, may have beneficial therapeutic effects in patients with intermittent claudication.

Neovascularization in ischemia of skeletal muscle can be inhibited by blockade of the renin angiotensin system and by large blood pressure reductions. These observations may have consequences for the treatment of hypertension in patients with intermittent claudication or patients predisposed for peripheral artery disease: In patients in which development of collaterals has not yet been established, antihypertensive treatment, resulting in an excessive blood pressure reduction, or treatment with inhibitors of the renin angiotensin system can be catastrophic. However, treatment of hypertension is one of the first treatment guidelines in these patients. A good balance between treatment of hypertension and beneficial adaptations in patients with peripheral arterial diseases may be achieved by treatment with low doses of the antihypertensives or abstinence of antihypertensive treatment at the beginning of the disease, whereas the antihypertensive treatment can be extended after development of collaterals. Treatment with ACE-inhibitors or angiotensin II-antagonists at the beginning of the disease should be avoided. Their place in the treatment of hypertension in patients with established intermittent claudication needs further investigation. 


\section{REFERENCES}

Aalkjaer C. Regulation of intracellular $\mathrm{pH}$ and its role in vascular smooth muscle function. $y$ Hypertension 8, 197-207, 1990.

Ackermann DM, Blumberg AM, McCafferty IP, Sherman SS, Weinstock J, Kaiser C and Berkowitz B. Potential usefulness of renal vasodillators in hypertension and renal disease: SK\&F82526. Ped Proc 42, 186-190, 1983.

Adair TH, Montani J-P, Strick DM and Guyton AC. Vascular development in chick embryos; a possible role for adenosine. Am J Physiol 256, H240-H246, 1989.

Adair TH, Gay WJ and Montani J-P. Growth regulation of the vascular system: evidence for a metabolic hypothesis. Am I Physiol 259, R393-R404, 1990.

Admiraal PJJ, Danser AHJ, Derkx FHM and Schalekamp MADH. Angiotensin II production in different vascular beds in hypertensive subjects. I Hypertens 9 (Suppl. 6), \$208-\$209, 1991.

Angersbach $D$ and Nichoison $C D$. Enhancement of muscle blood cell flux and $\mathrm{pO}_{2}$ by cromakalim (BRL 34915) and other compounds enhancing membrane $\mathrm{K}^{+}$conductance, but not by $\mathrm{Ca}^{2+}$ antagonists or hydralazine, in an animal model of occlusive arterial disease. Naunyn Schmiedeberg's Arch Pharmacol 337, 341-346, 1988.

Arakawa $\mathrm{K}$ and Maruta $\mathrm{H}$. Ability of kallikrein to generate angiotensin II-like pressor substance and a proposed 'kunin-tensin enzyme system'. Nature 288, 705-706, 1980.

Armstrong RB and Phelps RO. Muscle fiber type composition of the rat hindlimb. An $J$ Anat $171_{*}$ 259-272, 1984.

Armstrong RB, Warren GL and Warren JA. Mechanisms of exercise-induced muscle fitber injury. Sports Med 12, 184-207, 1991.

Arner A, Malmqvist $U$ and Uvelius B. Structural and mechanical adaptations in rat aorta in response to sustained changes in arterial pressure. Acta Physiol Scand 122, 119-126, 1984.

Baker KM, Singer HA and Aceto JF. Angiotensin II receptor-mediated stimulation of cytosolic-fiee calcium and inositol phosphates in chick myocytes. J Pharmacol Exp Ther 251, 578-585, 1989.

Ball SG. The sympathetic nervous system and converting enzyme inhibition. J Cardiovase Pharmacol 8 (Suppl. 10), S17-S21, 1989.

Barie PS and Mullins RJ. Experimental methods in the pathogenesis of limb ischemia. J Surg Res 44, 284-307, 1988.

Barrett PQ, Bollag WB, Isales CM, McCarthy RT and Rasmussen $H$. Role of calcium in angiotensin II-mediated aldosterone secretion. Endocrine Reviews 10, 496-518, 1989.

Baumbach GL and Heistad DD. Remodeling of cerebral arterioles in chronic hypertension. Hypertension 13, 968-972, 1989.

Baur LHB, Schipperheyn JJ "Baan J, Van der Laarse A, Van der Wall EE, Van Dijk AD, Buis B, Manger Cats $V$ and Bruschke $A V G$. Cardiac remodelling and myocardial contractility in patients with congestive heart failure treated with furosenide and enalapril. Basic Res Cardiol 86 (Suppl. 1), 157-163, 1991.

Bendhack LM, Lindsey CJ and Paiwa ACM. Converting enzyme inhibitors decrease kininase but not converting enzyme activity in the rat mesenteric vascular bed. Hypertension 8 (Suppl. 1), 190-194, 1986.

Bernatdi D, Bartoli P, Ferreri A, Brandinelli Geri A and Ieri A. Assessment of captopril and nicardipine effects on chronic occlusive arterial disease of the lower extremity using Doppler ultrasound. Angiology 39, 942-952, 1988.

Bingham Smith $J$ and Brock TA. Analysis of angiotensin-stimulated sodium transport in cultured smooth muscle cells from rat aorta. J Cell Physiol 114, 284-290, 1983. 
Bogaert MG and Clement DL. Lack of influence of propranolol and metoprolol on walling distance in patients with chronic intermittent claudication. Eur Heart J 4, 203-204, 1983.

Bomzon $A$ and Naidu SG. Perfusion of the isolated hind limb. An analysis of the technique. J Pharmacol Methods 14, 285-296, 1985.

Boonen HCM, Schiffers PMH, Fazzi GE, Janssen GMJ; Daemen MJAP and De Mey JGR. DNA synthesis in isolated arteries. Kinetics and structural consequences. Am I Physiol 260, H210-H217, 1991.

Bowa $S$, Goldman WF, Yuan $X I$ and Blaustein $M P$. Influence of $\mathrm{Na}^{*}$ gradient on $\mathrm{Ca}^{2+}$ transients and contraction in viascular smooth muscle. Am J Physiol 259, H409-H423, 1990.

Brading AF and Lategan TW. Na-Ca exchange in vascular smooth muscle. I Hypertension 3, $109-116,1985$.

Braun-Menändez E, Fasciolo JC, Leloir LF and Muñoz JM. La substancia hipertensora de la sangre dell riñón isquemiado. Rev Soc Argent Biol 15, 420-425, 1939.

Brayden JE, Halpern W and Brann LR. Biochemical and mechanical properties of resistance arteries from normotensive and hypertensive rats. Hypertension 5, 17-25, 1983.

Brock TA, Lewis $\mathrm{L}$ and Bingham Smith $\mathrm{J}$. Angiotensin increases $\mathrm{Na}^{+}$entry and $\mathrm{Na}^{+} / \mathrm{K}^{+}$pump activity in cultures of smooth muscle from rat aorta. Proc Natl Acad Sci USA 79, 1438-1442, 1982.

Brody MJ, Fink GD, Buggy J, Haywood JR, Gordon FJ and Johnson AK. The role of the anteroventral third ventricle (AV3V) region in experimental hypertension. Circ Res 43 (Suppl. I), $2-13,1978$.

Brown $\mathrm{G}$ and Douglas $\mathrm{J}$. Effect of angiotensin II infusion in rats on Na,K-ATPase activity in renal corticall microsomal preparations. Arch Biochem Biophys 275, 236-243, 1989.

Brown K. Angiotensin receptors are implicated in the mechanism of mas action. Tips 10, 87-89, 1989.

Brunner HR, Waeber B and Nussberger J. Pharmacology of converting enzyme inhibitors. Clin Exp Theor Pract A9, 275-288, 1987.

Bugge JF, Stokke ES, Viske A and Kill F. Stimulation of renin release by $\mathrm{PGE}_{2}$ and $\mathrm{PGI}_{2}$ infusion in the dog: enhancing effect of ureteral occlusion or administration of ethacrynic acid. Acta Physiol Scand 138, 193-201, 1990.

Bumpus FM, Catt KJ, Chiu AT, DeGasparo $M_{*}$ Goodfriend T, Husain A, Peach MJ, Taylor DG and Timmermans PBMWM. Nomenclature for angiotensin receptors. A report of the nomenclature conmittee of the Council for High Blood Pressure Research. Hypertension 17, 720-721, 1991.

Bund SJ, Wesi KP and Heagerty AM. Effects of protection from pressure on resistance artery morphology and reactivity in spontaneously hypertensive and Wistar-Kyoto rats. Circ Res 68, $1230-1240,1991$

Canneron $\mathrm{HA}$, Waller PC and Ramsey LE. Drug treatment of intermittent claudication: a critical analysis of the methods and findings of published clinical trials, 1965-1985. Br J Clin Pharmac 26, $569-576,1988$.

Campbell DJ. Extrarenal renin and blood pressure regulation. An alternative viewpoint. Am J Hypertens 2, 266-275, 1989.

Carlson BM and Faulkner JA. The regeneration of skeletal muscle fibers following injury: a review. Med Sc Sports Exerc 15, 187-198, 1983.

Catalano $M$ and Libretti $A$. Captopril for the treatment of patients with hypertension and peripheral vascular disease. Angiology 36, 293-296, 1985.

Chang RSL and Lotti VJ. Two distinct angiotensin II receptor binding sites in rat adrenal revealed by new selective nonpeptide ligands. Moll Pharmacol 29, 347-351, 1990.

Chang RSL, Lotti VJ, Chen TB and Faust KA. Two angiotensin II binding sites in rat brain revealed using | ${ }^{125}{ }^{1} \mid \operatorname{sar}^{1}$, ile $^{8}$-angiotensin II and selective nonpeptide antagonists. Biochem Biophys Res Commun 171, 813-817, 1990. 
Chappell $\mathrm{MC}$; Brosnilhan $\mathrm{KB}, \mathrm{Diz} \mathrm{DI}$ and Ferrario $\mathrm{CM}$. Identification of angiotensin-(1-7) un rat brain. J Biol Chem 264, 16518-16523, 1989.

Chappell MC Millsted A, Diz DI, Brosnihan $\mathrm{KB}$ and Ferrario CM. Evidence for an intrinsic angiotensin system in the canine pancreas. I Hypertension 9, 751-759, 1991 .

Chin AT, Herblin WF, McCall DE, Ardecky RJ, Carini DJ, Duncia JV, Pease LJ, Wong PC, Wexler $\mathrm{RR}$, Johnson $\mathrm{AL}$ and Timmermans PBMWM. Identification of angiotensin II receptor subtypes. Biochem Biophys Res Commun 165, 196-203, 1989a.

Chiu AT, McCall DE, Nguyen TT, Carini DJ, Duncia JV, Herblin WF, Uyeda RT, Wong PC, Wexler RR, Johnson AL and Timmermans PBMWM. Discrimination of angiotensin II receptor subtypes by dithiothreitol. Eur J Pharmacol $170,117-118,19896$.

Chiu AT, McCall DE, Aldrich PE and Timmermans PBMWM. [ $\left.{ }^{3} \mathrm{H}\right] \mathrm{DuP} 753$, a highly potent and specific radioligand for the angiotensin II-1 receptor subtype. Biochem Biophys Res Commun 172 ; $1195-1202,1990$.

Clozel $M$, Kuhn $\mathrm{H}$ and Hefti $\mathbb{F}$. Effects of angiotensin converting enzyme inhibitors and of hydralazine on endothelial function in hypertensive rats. Hypertension 16,532-540, 1990.

Clyne CAC, Weller RO, Bradley WG, Silber DI and O'Donnell TF. Ultrastructural and capillary adaptation of gastrocnemius muscle to occlusive peripheral vascular disease. Surgery 92, 434-440, 1982.

Clyne CAC, Mears H, Weller RO and O'Donnell TF. Calf muscle adaptation to peripheral vascular disease. Cardiovase Res 19, 507-512, 1985.

Cody RJ. Conceptual and therapeutic approaches to inhibition of the renin-angiotensin system in chronic heart failure. J Cardiovase Pharmacol 8 (Suppl. 1), S58-S65, 1986.

Coezy E, Darby I, Mizrahi J, Cantau B, Donnadieu M-H, Nussberger J, Eseher E, Chapnick B and Corvol P. Inhibition of angiotensinogen production by angiotensin II anallogues in human hepatoma cell line. Am J Physiol 257, C888-C895, 1989.

Cohen ML and Kurz KD. Angiotensin converting emzyme inhibition in tissues from spontaneously hypertensive rats after treatment with captopril or MK-421. J Pharm Pharmacol 220, 63-69, 1982.

Conrad MC, Anderson III IL and Garrett JB. Chronic collateral growth after femoral artery acclusion in the dog. J Appl Physiol 31, 550-555, 1971.

Cooper IV G, Kent RL and Mann DL. Load induction of cardiac hypertrophy. I Mol Cell Cardiol 21 (Suppl. V), 11-30, 1989.

Correa FMA, Guilhaume SS and Saavedra JM. Autoradiography of angiotensin-converting enzyme in fixed and unfixed rat brain using the specific enzyme inhibitor $\left[I^{125}\right] 351 \mathrm{~A}$ or a polyclonal antibody and $\left[\mathbb{I}^{125}\right]$ staphylococcal protein A. Neurose Let $110,244-248,1990$.

Cushman DW, Wang FL, Fung WC, Grover GJ, Harwey CM, Scalese RJ, Mitch sL and DeForrest JM. Comparisons in vitro, ex vivo, and in vitro of the actions of seven structurally diverse inhibitors of angiotensin conwerting enzyme (ACE). Br J Clin Pharmac 28, $115 S-131 S, 1989$ a.

Cushman DW, Wang FL, Fung WC, Harvey $\mathrm{CM}$ and Deforrest $\mathrm{JM}$. Differentation of angiotensin-converting enzyme (ACE) inhibitors by their selective inhibition of $A C E$ in physiologically important target organs. Am J Hypertens 2, 294-306, 1989b.

Daemen MJAP, Lombardi DM, Bosman FT and Sclowartz SM. Angiotensin II induces smooth muscle cell proliferation in the normal and injured rat arterial wall. Circ Res 68, 450-456, 1991

Danser AHJ, Van den Dorpel MA, Deinum J, Derkx FHM, Franken AAM, Peperkamp E, De Jong PTVM and Schalekamp MADH. Renin, prorenin, and immunoreactive renin in witreous fluid from eyes with and without diabetic retinopathy. J Clin Endocrinol Metab 68, 160-167, 1989.

Dargie HJ. Interrelation of electrolytes and renin-angiotensin system in congestive heart failure. Am J Cardiol 65, 28E-32E, 1990.

Dasarathy $Y$ and Fanburg BL. Elevation of bovine endothelial cell angiotensin converting enzyme by cationphores and inhibition by ouabain. Biochim Biophys Acta 1051, 14-20, 1989. 
Dasarathy $Y$, Stevens $J$, Lanzillo Jf and Fanburg BL. Elevation of angiotensin converting enzyme in bovine endothelial cells quantitated by an ELISA. Life Sci 47, 883-889, 1990.

Dawson JM and Hudlicka $O$. The effects of long term administration of prazosin on the microcirculation in sketetal museles. Cardiovasc Res 23,913-920, 1989.

DeGasparo $M$, Whitebread $S$, Mele $M$, Motani $A S$, Whitconbe PJ, Ramjoue $H-P$ and Kamber $B$. Biochemical characterization of two angiotensin il receptor subtypes in the rat. I Cardiovasc Pharmacol 16 (Suppl. 4), \$31-\$35, 1990.

De Mey JGR and Gray SD. Endothelium-dependemt reactivity in resistance vessels. Prog appl Microcirc 8, 181-187, 1985 .

De Mey JOR and Vanhoutte PM. $\mathrm{Na}^{+}-\mathrm{K}^{+}$exchanges in canine arterial and venous smooth muscle. Am J Physiol 243, H551-H559, 1982.

De Mey JGR, Uitendaal MP, Boonen HCM, Vrijdag MJJF, Daemen MJAP and Struyker-Boudier HAJ. Acute and long-term effects of tissue culture on contractile reactivity in renal arteries of the rat. Circ Res $65,1125-1135,1989$.

De Mey JGR, Dijkstra $\mathbb{E}$, Fazzi $G$ and Janssen GMJ. Growth responses in the arterial wall. Basic Res Cardiol 86 (Suppl. 1), $13-17,1991$

Dennis SC, Gevers $W$ and Opie LH. Protons in ischemia: where do they come from; where do they go to? J Mol Cell Cardiol 23, 1077-1086, 1991.

Derkx FHM. Human prorenin. PhD Thesis, Erasmus University Rotterdam, the Netherlands, 1987.

Drexler $\mathrm{H}_{\text {, Flaim SF }}$, Toggart EJ, Glick MR and Zelis R. Cardiocirculatory adjustments to exercise following myocardial infarction in rats. Basic Res Cardiol 81, 350-360, 1986.

Drexler $H$, Depenbusch JW, Truog AG, Zelis $R$ and Flaim SF. Acute regional vascular effects of intravenous captopril in a rat model of myocardial infarction and failure. J Pharnacol Exp Ther $241,13-19,1987$

Dudley DT, Panek RL, Major TC, Lu GH, Bruns RF, Klinkefus BA, Hodges JC and Weishaar RE. Subclasses of angiotensin II binding sites and their functional significance. Mol Pharmacol 38 , $370-377,1990$.

Duggan KA, Mendelsohn FAO and Levens NR. Angiotensin receptors and angiotensin I-converting enzyme in rat intestine. Am J Physiol 257, G504-G510, 1989.

Dusseau JW and Hutchins PM. Hypoxia-induced angiogenesis in chick chorioallantoic membranes: a role for adenosine. Respiration Physiology 71, 33-44, 1988.

Dzau VJ. Implications of local angiotensin production in cardiovascular physiology and pharmacology. Am J Cardiol 59, 59A-65A, 1987a.

Dzau Vy. Renim-angiotensin system and renal circulation in clinical congestive heart failure. Kidney Int 31 (Suppl. 20), S203-S209, 1987b.

Deau VJ. Circulating versus local renin-angiotensin system in cardiovascular homeostasis. Circulation 77 (Suppl. 1), [4-113, 1988.

Dzau VI. Multiple pathways of angiotensin production in the blood vessel wall: evidence, possibilities and hypotheses. J Hypertension 7, 933-936, 1989

Dzau VJ and Gibbons GH. Autocrine-paracrine mechanisms of vascular myocytes in systemic hypertension. Am J Cardiol 60, 991-103I, 1987.

Dzau VJ, Ingelfingem JR and Pratt RE. Regulation of tissue renin and angiotensin gene expression. J Cardiovaso Pharmacol 8 (Suppl. 10), S11-S16, 1986.

Dzau VJ, Burt DW and Pratt RE. Molecular biology of the renin-angiotensin system. Am J Physiol 255, F563-F573, 1988.

Earnshaw JJ. Thrombolytic therapy in the management of acute limb ischaemia. Br J Surg 78, 261-269, 1991.

Ehlers MRW and Riordan JF. Angiotensin-converting enzyme: new concepts concerning its biological tole. Biochem 28,5311-5318, 1989 
Ehlers MRW, Fox EA, Strydom DI and Riordan JF. Molecular cloning of human testicular angiotensin-converting enzyme: the testis isozyme is identical to the C-terminal half of endothelial angiotensin-converting enzyme. Proc Nat Acad Sci USA 86; 7741-7745, 1989.

Eisenstein R. Angiogenesis in arteries: review. Pharmac Ther $49,1-19,1991$.

Elander A, Idström J-P, Scherstän $\mathbb{T}$ and Bylund-Fellenius A-C. Metabolic adaptation to reduced muscle blood flow. 1. Enzyme and metabolite alterations. Am J Physiol 249, E63-E69, 1985.

Erdös EG. Angiotensin I converting enzyme and the changes in our concepts through the years. Hypertension 16, 363-370, 1990.

Erney TP, Mathien GM and Terjung RL. Muscle adaptations in trained rats with peripheral arterial insufficiency. Am J Physiol 260, H445- $\mathrm{H} 452,1991$.

Feellisch $M$, Ostrowski $\mathrm{J}$ and Noack $\mathrm{E}$. On the mechanism of NO release from sydnonimines. $J$ Cardiovasc Pharmacol 14 (Suppl. 11), SI3-S22, 1989.

Fernandez LA, Caride VJ, Twickler $J$ and Galardy RE. Renin-angiotensin and development of collateral circulation after renal ischemia. Am J Physiol 243, H869-H875, 1982.

Fernandez LA, Twickler J and Mead A. Neovascularization produced by angiotensin II. J Lab Clin Med 105, 141-145, 1985 .

Ferrara LA, Rubba $\mathbb{P}$, lannuzzi A and Fasano ML. Haemodynamic changes in peripheral arterial circulation during antihypertensive treatment with captopril, methyldopa and indapamide. Int $\mathrm{J}$ Clin Pharm Res 4, 389-393, 1984.

Field FP and Soltis EE. Vascular reactivity in the spontaneously hypertensive rat. Effect of high pressure stress and extracellular calcium. Hypertension 7, 228-235, 1985.

Fleetwood $G$, Boutinet $S$, Meier $M$ and Wood JM. Involvement of the renin-angiotensin system in ischemic damage and reperfusion arrhythmias in the isolated perfused rat heart. I Cardiovasc Pharmacol 17, 351-356, 1991.

Folkow B. Physiological aspects of primary hypertension. Physiological Reviews 62, 347-504, 1982.

Folkow $B$ and Sivertsson $R$. Adaptive changes in "reactivity" in wall/lumen ratio in cat blood vessels exposed to prolonged transmural pressure difference. Life Sci 7, 1283-1289, 1968.

Folkow $B$, Hallbäck $M$, Lundgren $Y$ and Weiss $L$. Background of increased flow resistance and vascular reactivity in spontaneously hypertensive rats. Acta Physiol Scand 80, 93-106, 1970.

Folkow B, Gurevich M, Hallbäck M and Lundgren Y. The hemodynamic consequences of regional hypotension in spontaneously hypertensive and normotensive rats. Acta Physiol Scand 83, 532-541, 1971.

Francis GS. The relationship of the sympathetic nervous system and the renin-angiotensin system in congestive heart failure. Am Heart J 118,642-648, 1989

Frelin $C$, Vigne $P$, Ladoux. A and Lazdunski $M$. The regulation of the intracellular pll in cells from vertebrates. Eur J Biochem 174, 3-14, 1988.

Fresion $\mathrm{JL}$ and Guidicelli $\mathrm{JF}$. Vascular effects of captopril and dihydralazine in spontaneously hypertensive rats. Prog appl Microcirc 8, 142-151, 1985.

Frohlich ED. Regression of cardiac hypertrophy and left ventricular pumping ability postregression. J Cardiovase Pharmacol 17 (Suppl. 2), S81-S86, 1991.

Furchgott RF. Role of the endothelium in responses of vascular smooth muscle. Circ Res 53, $557-573,1983$.

Fyhrquist $F$. Clinical pharmacology of the ACE inhibitors. Drugs 32 (Suppl. 5), 33-39, 1986.

Galt SW and Cronenwert JL. The interaction of vasodilating drugs and sympathetic blockade in normal and ischemic canine hindlimbs. J Vasc Surg 13,861-866, 1991.

Geisterfer AAT, Peach MJ and Owens GK. Angiotensin II induces hypertrophy, not hyperplasia, of cultured rat aorta smooth muscle cells. Circ Res $62,749-756,1988$.

Giansante $\mathrm{C}$, Calabrese $\mathrm{S}$, Fisicaro $\mathrm{M}$, Fiotti $\mathrm{N}$ and Mitri $\mathrm{E}$. Treatment of intermittent claudication with antiplatelet agents. J Int Med Res 18, 400-407, 1990. 
Gidlof $A$, Lewis DH and Hammersen $F$. The effect of prolonged total ischemia on the ultrastructure of hurnam skeletal muscle capillaries. A morphometric analysis. Int $J$ Microcirc: Clin Exp 7 , $67-86,1987$.

Gondo M, Maruta Hand Arakaw K. Direct formation of angiotenin II without renin or converting enzyme in the ischemic heart. Jpn Heart J $30,219-229,1989$.

Goodfriend TL. Angiotensins, A family that growths from within. Hypertension 17, 139-140, 1991 .

Graor RA and Whitlow PL. Transluminal atherectomy for occlusive peripheral vascular disease. I Am Coll Cardiol 15, 1551-1558, 1990.

Gray SD and Renkin EM. Microvascular supply in relation to fiber metabolic type in mixed skeletal museles of rabbits. Microvase Res $16,406-425,1978$.

Grima M, Welsch $C$, Michel $B$, Barthelmebs $M$ and Imbs J-L. In vitro tissue potencies of converting enzyme inhibitors. Prodrug activitation by kidney esterase. Hypertension 17, 492-496, $199 \Perp$.

Grover GI, Sleph PG, Dzwonczyk $S$, Wang $P$, Fung W, Tobias D and Cushman DW. Effects of different angiotensin-converting enzyme (ACE) inhibitors on ischemic isolated rat hearts: relationship between cardiac ACE inhibition and cardioprotection. J Pharmacol Exp Ther 257, 919-929, 1991.

Guivernau $M$, Armijo $F$ and Rosas R. Role of sulfhydryl groups in the stimulatory effect of captopril on vascular prostacyclin synthesis. Eur J Pharmacol 198, 1-6, 1991.

Hackenthal E, Paul M, Ganten D and Taugner R. Morphology, physiology, and molecular biology of renin secretion. Physiological Reviews 70, 1067-1116, 1990.

Hall JE, Mizelle HL and Woods LL. The renin-angiotensin system and long-term regulation of arterial pressure. J Hypertension 4, 387-397, 1986.

Hammarsten J, Bylund-Fellinius A-C, Holm J, Scherstän T and Krotkiewski M. Capillary supply and muscle fibre types in patients with intermittent claudication: relationships between morphology and metabolism. Eur J Clin Invest 10, 301-305, 1980.

Hanzlikova $V$ and Gutmann E. Effect of ischemia on contractile and histochemical properties of the rat soleus muscle. Pflugers Arch 379, 209-214, 1979.

Harder DR and Hermsmeyer K. Membrane mechanisms in arterial hypertension. Hypertension 5, 404-408, 1983.

Harris K, Walker PM, Mickle DAG, Harding R, Gatley R, Wilson GJ, Kuzon B, McKee N and Romaschin AD. Metabolic response of skeletal muscle 10 ischemia. Am J Physiol 250, H213-H220, 1986.

Hatori $N$, Fine BP, Nakamura A, Cragoe E and Aviv A. Angiotensin II effect on cytosolic pH in cultured rat wascular snooth muscle cells. J Biol Chem 262, 5073-5078, 1987.

Haywood JR, Shaffer RA, Fastenow C, Fink GD and Brody MJ. Regional blood flow measurement with Doppler flow meter in conscious rats. Am J Physiol 241, H273-H278, 1981.

Heppenstall RB, Scott $\mathbb{R}$, Sapega A, Park YS and Chance B. A comparative study of the tolerance of skeletal muscle to ischemia. Tourniquet application compared with acute compartment syndrome. J Bone J Surg 68A, 820-828, 1986.

Herblin WF, Diamond SM and Timmermans PBMWM. Localization of angiotensin II receptor subtypes in the rabbit adrenal and kidney. Peptides 12, 581-584, 1991.

Hermsmeyer $\mathrm{K}$. Electrogenic ion pumps and other determinants of membrane potential in vascular muscle. The Physiologist 25, 454-465, 1982.

Hertzer NR. The natural history of peripheral vascular disease. Implications for its management. Circulation 83 (Suppl. I), 112-119, 1991.

Hiatt WR, Stoll $S$ and Nies AS. Effect of $\beta$-adrenergic blockers on the peripheral circulation in patients with peripheral vascular disease. Circulation 72, 1126-1231, 1985.

Higashimori K, Gante I. Holzemann G and Inagami T. Significance of vascular renin for local generation of angiotensins. Hypertension 17, 270-277, 1991 . 
Hilgers KF, Kuczera M, Wilheln MJ, Wiecek $A$, Ritz $E$, Ganten $D$ and Mann IFE. Angiotensin formation in the isolated rat hindlimb. J Hypertension 7, 789-798, 1989.

Hirsch AT, Pinto YM, Schunkert H and Dzau VJ. Potential role of the renin-angiotensin system in the pathophysiology of congestive heart failure. Am J Cardiol 66, 22D-32D, 1990.

Hirsch AT, Talsness CE, Schunkert $H$, Paul M and Dzau VJ. Tissue-specific activation of cardiac angiotensin conwerting enzyme in experimental heart failure. Circ Res $69,475-482,1991$.

Hollenberg NK and Williams GH. Angiotensin and the renal circulation in hypertension. Circulation 77 (Suppl. 1), 159-163, 1988.

Horiba $N$, Nomura $K$ and Shizume $K$. Exogenous and locally synthesized angiotensin II and glomerulosa cell functions. Hypertension 15, 190-197, 1990.

Hsueh WA and Baxter JD. Human prorenin. Hypertension 17, 469-479, 1991.

Hubert $\mathrm{C}$, Houot A-M, Corvol $\mathrm{P}$ and Soubrier F. Structure of the angiotensin I-converting enzyme gene. J Biol Chem 266, 15377-15383, 1991.

Hudlicka O. Growth of capillaries in skeletal and cardiac muscle. Circ Res 50, 451-461, 1982.

Hudlicka O. Development and adaptability of microvasculature in skeletal muscle. J Exp Biol 115, 215-228, 1985.

Hudlicka $O$ and Price $S$. Effects of torbafylline, pentoxifylline and buflomedil on vascularisation and fibre type of rat skeletal muscles subjected to limited blood supply. Br J Pharmacol 99, 786-790, 1990 a.

Hudlicka $O$ and Price $S$. The role of blood flow and/or muscle hypoxia in capillary growth in chronically stimulated fast muscles. Pflugers Arch 41, 67-72, 1990b.

Hudlicka $\mathrm{O}$, Hoppeler $H$ and UhImann E. Relationship between the size of the capillary bed and oxidative capacity in various cat skeletal muscles. Pflugers Arch 410, 369-375, 1987.

Hughson WG, Mann JE and Garrod A. Intermittent claudication: prevalence and risk factors. $\mathrm{Br}$ Med J 1, 1379-1381, 1978.

Ideishi $M$, Sasaguri $M$, Ikeda $M$ and Arakawa $K$. Angiotensin-converting activity of tissue kallikrein. Nephron 55 (Suppl. 1), 62-64, 1990a.

Ideishi $M$, Sasaguri $M_{0}$. Ikeda $M$ and Arakawa $K$. Substrate-dependent angiotensin II formation in the peripheral circulation. Life Sci 46, 335-34l, $1990 \mathrm{~b}$.

Idström I-P, Soussi B, Elander A and Bylund-Fellenius A-C. Purine metabolism after in vivo ischemia and reperfusion in rat skeletal muscle. Am J Physiol 258, H1668-H1673, 1990.

lizuka $K$, Kamijo $T$, Harada $H$, Akahane $K$, Kubota $T$, Umeyama $H$, Ishida $T$ and Kiso $Y$. Orally potent human renin inhibitors derived from angiotensinogen transition state: design, synthesis, and mode of action. J Med Chem 33, 2707-2714, 1990.

Ikemoto $F$, Tanaka $M$, Itoh $S$, Song $G-B$, Tominaga $M$, Hiruma $M$, Takada $T$, Nakamura $N$ and Yamamoto $\mathrm{K}$. Angiotensin converting enzyme (ACE) in the kidney: contribution to blood pressure regulation and possible role of brush-border $A C E$. J Cardiovasc Pharmacol 8 (Suppl. 10), S69-\$74, 1986.

Ikemoto $\mathrm{F}$, Song G-B, Tominaga M, Kanayama $\mathrm{Y}$ and Yamamoto $\mathrm{K}$. Angiotensin-converting enzyme in the rat kidney. Activity, distribution, and response to angiotensin-converting enzyme inhibitors. Nephron 55 (Suppl. 1), 3-9, 1990.

Inagami $T$, Mizuno $K$, Naruse $M$, Nakamaru M, Naruse $K$, Hoffman $L H$ and McKenzie JC. Active and inactive renin in the adrenal. IHypertension $2,311-319,1989$.

Itoh $H$, Pratt RE and Dzau VJ. Interaction of atrial natriuretic polypeptide and angiotensin II on protooncogene expression and vascular cell growth. Biochem Biophys Res Commun 176, $1601-1609,1991$.

Iwao $H$, Nakamura A, Fukui $K$, Kimura $S$, Tamaki $T$ and Abe $Y$. Endogenous angiotensin II regulates hepatic angiotensinogen production. Life Sci 47, 2343-2349, 1990. 
Jessup M. Angiotensin-converting enzyme inhibitors: are there significant clinical differences? J Am Coll Cardiol 13, 1248-1250, 1989.

Julius 5, Sanchez $\mathrm{R}$ and Brant D. Pressure increase to external hindquarter compression in dogs: a facultative regulatory response. J Hypertension 4 (Suppl. 6), S54-S56, 1986.

Kannel WB and McGee DL. Update on some epidemiologic features of intermittent claudication: the Framingham study. I Am Geriatr Soe 33, 13-18, 1985.

Karpat $G$, Carpenter $S$, Melmed $C$ and Eisen AA. Experimental ischemic myopathy. I Neurol Sci $23,129-161,1974$.

Katayama S, Inaba M, Maruno $Y$, Omoto A, Itabashi A, Kawazu S and Ishii J. Effect of captopril or enalapril on renal prostaglandin $E_{2}$. Prostaglandins $38,401-411,1989$.

Kato $H$, Suzuki $H$, Tajima $S$, Ogata $Y_{\text {, Tominaga }} T$, Sato $A$ and Saruta $T$. Angiotensin II stimulates collagen synthesis in cultured vascular smooth muscle cells. J Hypertension 9, 17-22, 1991.

Kawaguchi $H$, Sawa $H$ and Yasuda $H$. Effect of atrial natriuretic factor on angiotensin converting enxyme. J Mol Cell Cardiol 21, 959-961, 1989.

Kawaguchi $H$, Sawa $H$, lizuka $K$ and Yasuda $H$. Platelet-activating factor stimulates angiotensin converting enzyme activity. J Hypertension 8, 173-177, 1990a.

Kawaguchi $\mathrm{H}$, Sawa $\mathrm{H}$ and Yasuda $\mathrm{H}$. Effect of atrial natriuretic factor on angiotensin converting enzyme. J Hypertension 8, 749-753, $1990 \mathrm{~b}$.

Keil J, Lehnfeld R, Reinhardt HW, Mohnhaupt $R$ and Kaczmarczyk G. Acute effects of angiotensin II on renal haemodynamics and excretion in conscious dogs. Renal Physiol Biochem 12, 238-249, 1989.

Kem DC, Johnson EIM, Capponi AM, Chardonnens D, Lang U, Blondel B, Koshida $\mathrm{H}$ and Vallotion MB. Effect of angiotensin II on cytosolic free calcium in neonatal rat cardiomyocytes. Am J Physiol 261, C77-C85, 1991.

Kent RL, Hoober JK and Cooper IV $G$. Load responsiveness of protein synthesis and adult mammalian myocardium: role of cardiac deformation linked to sodium influx. Circ Res $64,74-85$, 1989.

King SJ, Booyse FM, Lin P-H, Traylor M, Narkates AJ and Oparil S. Hypoxia stimulates endothelial cell angiotensin-converting enzyme antigen synthesis. Am J Physiol 256, C1231-C1238, 1989.

Kohara K, Brosnihan KB, Chappell MC, Khosla MC and Ferrario CM. Angiotensin-(1-7). A member of circulating angiotensin peptides. Hypertension 17, 131-138, 1991.

Kram HB, Gupta SK, Veith FJ and Wengerter KR. Unilateral aortofemoral bypass: a safe and effective option for the treatment of unilateral limb-threatening ischemia. Am J Surgery 162, 155-158, 1991.

Kriessmann A. Peripheral arterial occlusive disease: conservative treatment of intermittent claudication. J Cardiovase Pharmacol 16 (Suppl. 3), S72-S74, 1990.

Kubo $S$, Nishioka A, Nishimura $H$, Kawamura $K$ and Takatsu T. Effects of captopril on cardiorenal hemodynamics in patients with severe chronic congestiwe heart failure. Clin Exp Theor Pract A9, $575-581,1987$.

Kugler J, Maskin C, Frishman WH, Sonnenblick EH and LeJemtel TH. Regional and systemic metabolic effects of angiotensin-converting enzyme inhibition during exercise in patients with severe heart failure. Circulation 66, 1256-1261, 1982.

Kumar $\mathbb{R S}$, Thekkumkara TJ and Sen GC. The mRNAs encoding the two angiotensin-converting isozymes are transcribed from the same gene by a tissue-specific choice of alternative transcription initiation sites. J Biol Chem 266, 3854 3862, 1991.

Kunapuli SP, Benedict $C R$ and Kumar A. Tissue specific hormonal regulation of the rat angiotensinogen gene expression. Arch Biochem Biophys 254, 642-646, 1987.

Kuriyama S, Nakamura A, Hopp L, Fine BP, Kino M, Cragoe E and Aviv A. Angiotensin II effect on ${ }^{22} \mathrm{Na}^{+}$transport in vascular smooth muscle cells. J Cardiovase Pharmacol 11, 139-146, 1988. 
Kwasnik EM, Siouffi SY, Lavin PT and Khuri SF. Hemodynamic and metabolic responses to graded microvascular occlusion. J Vasc Surg 13, 867-875, 1991.

Labarca C and Paigen K. A simple, rapid, and sensitive DNA assay procedure. Anal Biochem 102, $344-352,1980$.

Lang $S$ and Blaustein MP. The role of the sodium pump in the control of vascular tone in the rat. Circ Res $46,463-470,1980$.

Langille BL and O'Donnell F. Reductions in arterial diameter produced by chronic decreases in blood flow are endothelium-dependent. Science 231, 405-407, 1986.

Lanzillo JJ, Dasarathy $\mathbf{Y}$, Stevens J and Fanburg BL. Conversion of angiotensin-1 to angiotensin-2 by a latent endothelial cell peptidyl dipeptidase that is not angiotensin-converting enzyme. Biochem Biophys Res Commun 134, 770-776, 1986.

Laragh JH. Extrarenal tissue prorenin systems do exist: are intrinsic vascular and cardiac tissue renins fact or fancy? Am J Hypertens 2, 262-265, 1989.

Le Noble FAC, Hekking JWM, Van Straaten HWM, Slaaf DW and Struyker-Boudier HAJ. Angiotensin II stimulates angiogenesis in the chorio-allantoic membrane of the chick embryo. Eur $\mathbf{J}$ Pharmacol 195, 305-306, 1991.

Le Noble JLML, Smith TL, Hutchins PM and Struyker-Boudier HAJ. Mierovascular alterations in adult conscious spontaneously hypertensive rats. Hypertension 15, 415-419, 1990.

Lenz T, Sealey JE, August $\mathrm{P}$, James GD and Laragh JH. Tissue level of active and total renin, angiotensinogen, human chorionic gonatropin, estradiol, and progesterone in human placentas from different methods of delivery. J Clin Endocrinol Metab 69, 31-37, 1989.

Lepäntalo M. Chronic effects of metoprolol and methyldopa on calf blood flow in intermittent claudication. Br J Clin Pharmac 18, 90-93, 1984.

Lepràn I, Koltai M, Siegmund W and Szekeres L. Coronary artery ligation, early arrhythmias, and determination of the ischemic area in conscious rats. J Pharmacol Methods 9, 219-230, 1983.

Leung KH, Smith RD, Timmermans PBMWM and Chiu AT. Regional distribution of the two subtypes of angiotensin II receptor in rat brain using selective nonpeptide antagonists. Neurosc Let $123,95-98,1991$.

$\mathrm{Li} \mathrm{K}$ and Chen X. Protective effects of captopril and enalapril on myocardial ischemia and reperfusion damage of rat. J Mol Cell Cardiol 19, 909-915, 1987.

$\mathrm{Li} \mathrm{T}$ and Zimmerman BG. In vivo comparison of renal and femoral vascular sensitivity and local angiotensin generation. Hypertension 15, 204-209, 1990.

Lindpaintner $\mathrm{K}$ and Ganten D. The cardiac renin-angiotensin system. An appraisal of present experimental and clinical evidence. Circ Res 68, 905-921, 1991.

Lindpaintner $K$, Jin M, Wilhelm MJ, Suzuki F, Linz W, Schölkens BA and Ganten D. Intracardiac generation of angiotensin and its physiologic role. Circulation 77 (Suppl. I), I18-123, 1988.

Lindpaintner $K_{4}$ Jin $M$, Niedermaier $N$, Wilhelm $M J$ and Ganten D. Cardiac angiotensinogen and its local activation in the isolated perfused beating heart. Circ Res 67, 564-573, 1990.

Lindsey $\mathrm{CJ}$, Bendhack LM and Paiva ACM. Effect of $\mathrm{pH}$ on the inhibition of angiotensin converting activity by enslaprilat in the rat perfused mesenteric vascular bed, J Pharmacol Exp Ther 243, 292-296, 1987a.

Lindsey CJ, Bendhack LM and Paiva ACM. Effects of teprotide, captopril and enalaprilat on arterial wall kininase and angiotensin converting enzyme activity. J Hypertension 5 (Suppl. 2), S711-S76, $1987 \mathrm{~b}$.

Linz W, Schölkens BA, Lindpaintner $K$ and Ganten D. Cardiac renin-angiotensin system. Am J Hypertens 2, 307-310, 1989.

Linz W, Martorana PA and Schölkens BA. Local inhibition of bradykinitn degradation in ischemic hearts. J Cardiovasc Pharmacol 15 (Suppl. 6), S99-S109, 1990.

Ljung B. Vascular selectivity of felodipine: experimental pharmacology. J Cardiovasc Pharmacol 15 (Suppl. 4), S11-S16, 1990. 
Ljungqvist $A_{*}$ Tornling $G$, Unge $G$, Jurdahl $E-B$ and Larsson $B$. Capillary growth in the heart and skeletal muscle during dipyridamole-treatment and exercise. Prog appl Microcirc 4, 9-15, 1984.

Loats JT, Sillau AH and Banchero N. How to quantify skeletal muscle capillarity. Adv Exp Med Biol 94, 41-48, 1977.

Ludatscher RM, Hashmonai M, Monies-Chass I and Schramek A. Progessing alterations in transient ischemia of skeletal museles: an ultrastructural study. Acta anat 111,320-327, 1981.

Lynch KR and Peach MJ. Molecular biology of angiotensinogen. Hypertension 17, 263-269, 1991 .

Man in 't Veld AJ, Schicht IM, Derkx FHM, De Bruyn JHB and Schalekamp MADH. Effects of an angiotensin converting enzyme inhübitor (Captopril) on blood pressure in anephric subjects. $\mathrm{Br}$ Med J 40, 288-290, 1980.

Marshall JJ and Kontos HA. Endothelium-derived relaxing factors. A prospective from in vivo data. Hypertension 16, 371-386; 1990 :

Maruta $\mathbf{H}$ and Arakawa $\mathbf{K}$. Confirmation of direct angiotensin formation by kallikrein. Biochem $\mathrm{J}$ $213,193-200,1983$.

Melby JC. The renin-angiotensin-aldosterone complex. Am J Med 81 (Suppl. 4C), 8-12, 1986.

Miyazaki $M$, Okamura $T$, Okunishi $H$ and Toda $N$. Vascular angiotensin converting enzyme in the development of renal hypertension. J Cardiovasc Pharmacol 8 (Suppl. 10), S58-S61, 1986.

Mizuno $\mathrm{K}$, Higashimori $\mathrm{K}$ and Inagami $\mathrm{T}$. Suppression of angiotensin II release by prostaglandin synthesis inhibitors in hind legs. Hypertension 12, 67.73, 1988a.

Mizuno $K_{\text {; }}$ Nakamura $M$, Higashimori $K$ and Inagami $T$. Local generation and release of angiotensin II in peripheral vascular tissue. Hypertension $11,223-229,1988 \mathrm{~b}$.

Mizuno $K$, Tani $M$, Niimura $S$, Hashimoto $S$, Satoh A, Shimamoto $K$, Inagami $T$ and Fukuchi $S$. Direct evidence for local generation and release of angiotensin il in human vascular tissue. Biochem Biophys Res Commun 165, 457-463, 1989.

Mizuno $K$, Niimura $S$, Tani $M$, Fukuchi $S$ and Inagami $T$. Effect of delapril hydrochloride on angiotensin II release from isolated rat hind legs. Eur J Pharmacol 184, 169-172, 1990.

Morgan HE and Baker KM. Cardiac hypertrophy. Mechanical, neural, and endocrine dependence. Circulation 83, 13-25, 1991.

Morin JP, Moulin B, Borghi $\mathrm{H}$, Grise $\mathrm{P}$ and Fillastre JP. Comparative regional distribution of angiotensin-1-converting enzyme in the rat, rabbit, dog, monkey and human kidney. Renal Physiol Biochem 12, 96-103, 1989.

Morton JJ, Beattie EC, Griffin SA, MacPherson F, Lyall F and Russo D. Vascular hypertrophy, renin and blood pressure in the young spontaneously hypertensive rat. $\mathrm{Cl}$ Sci $79,523-530,1990$.

Mueller SM and Cohen ML. Evidence for a captopril-sensitive angiotensin converting enzyme in the hindquarter vasculature of SHR and WKY. Artery 12, 337-345, 1983.

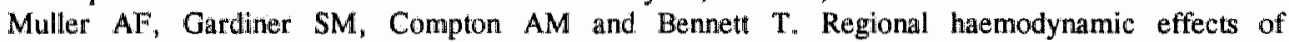
captopril, enalaprilat and lisinopril in conscious water-replete and water-deprived Brattleboro rats. CI Sci 79, 393-401, 1990.

Mulvany MJ and Halpern W. Contractile properties of small arterial resistance vessells in spontaneously hypertensive and normotensive rats. Circ Res 41, 19-26, 1977.

Mulvany MJ and Warshaw DM. The active tension-lenght curve of vascular smooth muscle related to its cellular components. J Gen Physiol 74, 85- $104,1979$.

Myrhage $R$ and Hudlicka $O$. Capillary growts in chronically stimulated adult skeletal muscle as studied by intravital microscopy and histological methods in rabbits and rats. Microvasc Res 16 , $73-90,1978$.

Naftilan AJ, Pratt RE, Eldridge CS, Lin HL and Dzau VJ. Angiotensin II induces c-fos expression in smooth muscle via transcriptional control. Hypertension 13, 706-711, 1989. 
Naftilan AJ, Zuo WM, Inglefinger J, Ryan TJ, Pratt $R E$ and Dzau VJ. Localization and differential regulation of angiotensinogen mRNA expression in the vessel wall. J Cilin Invest 87, 1300-1311, 1991.

Nagano M, Higaki J, Mikami $H$, Nakamura M, Higashimori $K$, Katahira K, Tabuchi $Y$, Moriguchi A. Nakamura F and Ogihara T. Converting enzyme inhibitors regressed cardiac hypertrophy and reduced tissue angiotensin II in spontaneously hypertensive rats. J Hypertension 9, 595-599, 1991.

Nakamaru $M_{3}$ Inagami $T_{\text {}}$ Ogihara $T$ and Kumahara $Y$. Effect of captopril on angiotensin Il release from vascular tissues in rats. Clin Exp Theor Pract $\mathrm{A9}, 477-480,1987$.

Nakamura A, Iwao H, Fukui K, Kimura S, Tamaki T, Nakanishi S and Abe Y. Regulation of liver angiotensinogen and kidney renin mRNA levels by angiotensin II. Am J Physiol 258, E1-E6, 1990.

Navot D, Margalioth EJ, Laufer N, Birkenfeld A, Relou A, Rosler A and Schenker JG. Direct correlation between plasma renin activity and severity of the ovarian hyperstimulation syndrome.

Fertil Steril 48, 57-61, 1987.

Nicholls MG. Update on mortality, heart failure and ACE inhibition. ACE Report 49, 1-8, 1988 .

Nicholls MG, Ikram H, Espiner EA, Maslowski AH, Scandrett MS and Penman T. Hemodynamic and hormonall responses during captopril therapy for heart failure: acute, chronic and withdrawal studies. Am J Cardioll 49, 1497-1501, 1982.

Novo S, Pinto A, Licata G, Davi G, Avellone G, Galati D, Faldetta E and Strano A. Captopril induced modifications of sistemic haemodynamics and of arterial flow at the calf in patients with essential hypertension. Eur Rev Med Pharmac Sc 4, 457-464, 1982.

Okamura $\mathrm{T}$, Okunishi $\mathrm{H}$, Ayajiki $\mathrm{K}$ and Toda $\mathrm{N}$. Conversion of angiotensin $\mathrm{I}$ to angiotensin II in dog isolated renal artery: role of two different angiotensin II-generating enzymes. I Cardiovasc Pharmacol 15, 353-359, 1990.

Okunishi H, Miyazaki $M$ and Toda N. Evidence for a putatively new angiotensin Il-generating enzyme in the vascular wall. I Hypertension 2, 277-284, 1984.

Okunishi $H$, Miyazaki $M$, Okamura $T$ and Toda $N$. Different distribution of two types of angiotensin II-generating enzymes in the aortic wall. Biochem Biophys Res Commun 149, $1186-1192,1987$.

Oliver JA and Sciacca RR. Local generation of angiotensin II as a mechanism of regulation of peripheral vascular tone in the rat. J Clin Invest $74,1247-1251,1984$.

Omata K, Abe K, Tsunoda K, Yasujima M, Chiba S, Sato M, Kudo K and Yoshinaga K. Role of endogenous angiotensin II and prostaglandines in the antihypertensive mechanism of angiotensin converting enzyme inhibitor in hypertension. Clin Exp Theor Pract A9, 569-574, 1987.

Ondetti MA. Structural relationships of angiotensin corverting-enzyme inhibitors to pharmacologic activity. Circulation 77 (Suppl. I), 174-178, 1988.

Osterziel KJ, Julius $S$ and Brant DO. Blood pressure during hindquarter compression in dogs is neurogenic. J Hypertension 2,411-417, 1984.

Osterziel KJ, Dietz R, Schmid W, Mikulaschek K, Manthey J and Kubler W. ACE inhibition improves vagal reactiwity in patients with heart failure. Am Heart $\mathbb{I} 120,1120 \mathrm{~m} 1129,1990$.

Owen NE and Ridge KM. Mechanism of angiotensin II stimulation of $\mathrm{Na}-\mathrm{K}-\mathrm{Cl}$ cotransport of vascular smooth muscle cells. Am I Physiol 257, C629-C636, 1989.

Page IH and Helmer OM. A crystalline pressor substance (angiotonin) resulting from the reaction between renin and renin-activator. J Exp Med 71, 29-42, 1940.

Paquet J-L, Baudouin-Legros M, Brunelle $G$ and Meyer P. Angiotensin II-induced proliferation of aortic myocytes in spontaneously hypertensive rats. I Hypertension 8, 565-572, 1990.

Pauletto P, Nascimben L, Piccolo D, Secchiero S, Vescovo G, Scannapieco G, Dalla Libera L, Carraro U, Pessina. $\mathrm{AC}$ and Dal Palu $C$. Ventricular myosin and creatine-kinase isoenzymes in hypertensive rats treated with captopril. Hypertension 14, 556-562, 1989. 
Peach MJ. Renin-angiotensin system: biochemistry and mechanisms of action. Physiological Reviews $57,313-370,1977$.

Pfeffer $\mathrm{IM}$, Pfeffer MA and Braunwald E. Influence of chronic therapy on the infarcted left ventricle of the rat. Circ Res 57, 84-95, 1985.

Pfeffer MA and Braunwald E. Ventricular remodelling after myocardial infarction. Circulation 81 , $1161-1172,1990$.

Pfeffer MA, Pfeffer JM, Fishbein MC, Fletcher PJ, Sparado J, Kloner RA and Braunwald E. Myocardial infarct size and ventricular function in rats. Circ Res 44, 503-512, 1979.

Phillips MI: Functions of angiotensin in the central nervous system. Ann Rev Physiol 49, 413-435, 1987.

Pi X-J and Chen X. Captopril and ramiprilate protect against free radical injury in isolated working rat hearts. I Mol Cell Cardiol 21, 1261-1271, 1989.

Pinto YM, Van Wijngaarden $J$, Van Gilst WH, De Graeff PA and Wesseling $H$. The effects of short- and long-term treatment with an ACE-inhibitor in rats with myocardial infarction. Basic Res Cardiol 86 (Suppl. 1), 165-172, 1991.

Pipili E, Manopoulos VG, Catravas JD and Maragoudakis ME. Angiotensin converting enzyme activity is present in the endothelium-denuded aorta. Br』 Pharmacol 98, 333-335, 1989.

Pipili-Synetos $\mathbf{E}_{n}$ Sideri E, Catravas JD and Maragoudalkis ME. Endothelium removal does not abolish angiotensin converting enzyme activity from the mesenteric arterial bed of the rat. Biochem Pharmacol 40, 1149-1151, 1990.

Powell JS, Muller RKM, Rouge $M$, Kuhn H, Hefti F and Baumgartner HR. The proliferative response to vascular injury is suppressed by angiotensin-converting enzyme inhibition. J Cardiovasc Pharmacol 16 (Suppl. 4), S42-S49, 1990.

Powers ER, Bamnerman KS, Stone J, Reison DS, Escala EL, Kalischer A, Weiss MB, Sciacca RR and Cannon PJ. The effect of captopril on renal, coronary, and systemic hemodynamics in patients with severe congestive heart failure. Am Heart J 104, 1203-1210, 1982.

Pratt JH, Rothrock JK and Dominguez JH. Evidence that angiotensin-II and potassium collaborate to increase cytosolic calcium and stimulate the secretion of aldosterone. Endocrinology 125, 2463-2469, 1989

Prewitt RL, Cardoso SS and Wood WB. Prevention of arteriolar rarefaction in the spontaneously hypertensive rat by exposure to simulated high altitude. J Hypertension 4, 735-740, 1986.

Przyklenk $K$ and Kloner RA. Relationships between structure and effects of ACE inhibitors: comparative effects in myocardial ischaemic/repertusion injury. $\mathrm{Br} J$ Clin Pharmac 28, 167S-175S, 1989.

Pucell $\mathrm{AG}_{n}$ Hodges JC, Sen $\mathrm{I}$, Bumpus FM and Husain $A_{\text {. }}$ Biochemical properties of the ovarian granulosa cell type 2-angiotensin II receptor. Endocrinology 128, 1947-1959, 1991.

Radack $\mathrm{K}$ and Wyderski RJ. Conservative management of intermittent claudication. Ann Int Med $113,135-146,1990$.

Ralevic V, Kristek $F$, Hudlicka $O$ and Burnstock $G$. A new protocol for removal of the endothelium from the perfused rat thind-limb preparation. Circ Res 64, 1190-1196, 1989.

Re $\mathbb{R}$ and Rovigatti $U$. New approaches to the study of the cellular biology of the cardiovascular system. Circulation 77 (Suppl. D), 114-117, 1988.

Remme WJ. Congestive heart failure - pathophysiology and medical treatment. J Cardiovasc Pharmacol 8 (Suppl. 1), S36-S52, 1986.

Richer $C$, Doussau M-P and Giudicelli J-F. Effects of captopril and enalapril on regional vascular resistance and reactivity in spontaneously hypertensive rats. Hypertension 5, 312-320, 1983.

Richer $C$, Doussau $M \propto P$ and Giudicelli J-F. Systemic and regional hemodynamic profile of five angiotensin I converting enzyme inhibitors in the spontaneously hypertensive rat. Am J Cardiol 59, 12D-17D, 1987. 
Riegger GAI, Wolf $\mathbf{P}$ and Kochsiek $K$. Vasoconstrictor role of vasopressin and angiotensin in experimental aortic stenosis in the rat. J Cardiovase Pharmacol 11, 538-542, 1988.

Ripoll $\mathrm{E}$, Sillau $\mathrm{AH}$ and Banchero $\mathrm{N}$. Changes in the capillarity of skeletal muscle in the growing rat. Pflugers Arch 380, 153-158, 1979.

Roberts DH, McLoughlin GA, Tsao Y and Breckenridge AM. Placebo-controlled comparison of captopril, atenolol, labetolol, and pindolol in hypertension complicated by intermittent claudication; Lancet II, 650-653, 1987a.

Roberts DH, Tsao $Y$, Grimmer SFM, Winstanley PA, Orme MLE and Breckenridge AM. Haemodynamic effects of atenolol, labetolol, pindolol and captopril: a comparison in hypertensive patients with special reference to changes in blood flow, heart rate and left ventricular function. $\mathrm{Br}$ J Clin Pharmac 24, 163-172, $1987 \mathrm{~b}$.

Rogg H, Schnid A and DeGasparo M. Identification and characterization of angiotensin II receptor subtypes in rabbit ventricular myocardium. Biochem Biophys Res Commun $173,416-422,1990$.

Rogg $H$, DeGasparo $M$, Grädel E, Stulz $P$ and Erne P. Identification of angiotensin-Il-receptor subtypes in human atrial tissue. Eur Heart J 12 (abstract suppl), 224, 1991.

Romero JC and Knox FG. Mechanisms underlying pressure-related natriuresis: the role of the renin-angiotensin and prostaglandin systems. State of the art lecture. Hypertension 11, 724-738, 1988.

Rosenfeld JB and Zabludowski J. The renin-angiotensin system, the kidney, and hypertension. J Cardiovasc Pharmacoll 13 (Suppl. 3), S22-S26, 1989.

Rosenschein U, Rozenszajn LA, Kraus L, Marboe CC, Watkins JF, Rose EA, Dawid D, Cannon PJ and Weinstein. JS. Ultrasonic angioplasty in totally occluded peripheral arteries. Initial elinical, histological, and angiographic results. Circulation 83, 1976-1986, 1991.

Ross BD (ed.), Perfusion techniques in biochemistry. Clarendion Press, Oxford, 1972.

Rozengurt E. Early signals in the mitogenic response. Science $234,161-166,1986$.

Ryden $\mathrm{L}$. When and how to use angiotensin-converting enzyme inhibition in congestive heart failure. Am J Cardiol 62, 75A-80A, 1988.

Sage SO, Van Breemen C and Cannell MB. Sodium-calcium exchange in cultured bovine pulmonary artery endothelial cells. J Physiol 440, 569-580, 1991 .

Samani NJ and Swales JD. Molecular biology of the vascular renin-angiotensin system. Blood Vessels 28, 210-216, 1991.

Samani NJ, Swales JD and Brammar WJ. A widespread abnormality of renin gene expression in the spontaneously hypertensive rat: modulation in some tissues with the development of hypertension. Cl Sci 77, 629-636, 1989.

Santos RAS, Brum JM, Brosnithan KB and Ferrario CM. The renini-angiotensin system during acute myocardial ischemia in dogs. Hypertension 15 (Suppl. 1), I121-1127, 1990.

Schelling P, Fischer $\mathrm{H}$ and Ganten D. Angiotensin and cell growth: a link to cardiovaseular hypertrophy? J Hypertension 9, 3-15, 1991.

Schiffrin EL. Vascular receptors for angiotensin, vasopressin, and atrial natriuretic peptide in experimental hypertension. Can J Physiol Pharmacol 67, 1118-1123, 1989.

Schmid-Schönbein GW, Firestone $G$ and Zweifach $B W$. Network anatomy of the arteries feeding the spinotrapezius muscle in normotensive and hypertensive rats. Blood Vessels 23, 34-49, 1986.

Schmidt $M$, Giessen-Crouse E-M, Krieger J-P, Welsch $C$ and Imbs J-L. Effect of angiotensin converting enzyme inhibitors on the vasoconstrictor action of angiotensin I on isolated rat kidney. I Cardiovasc Pharmacol 8 (Suppl. 10), S100-S105, 1986.

Schoemaker RG, Debets JJM, Struyker-Boudier HAJ and Smits JFM. Beneficial themodynamic effects of two week's milrinone treatment in conscious rats with heart failure. Eur $J$ Pharmacol 182, 527-535, 1990. 
Schoemaker $\mathbb{R G}_{n}$ Debets JM, Struyker-Boudier HAJ and Snits JFM. Delayed but not immediate captopril therapy improves cardiac function in conseious rats, following myocardial infarction. J Mol Cell Cardiol 23, 187-197, 1991.

Schrör K. Converting enzyme inhibitors and the interaction between kinins and eicosanoids. I Cardiovasc Pharmacol 15 (Suppl. 6), S60-S68, 1990.

Schullek $J \mathbb{R}$ and Wilson $\mathbb{I B}$. Angiotensin converting enzyme: substrate inhibition. Peptides 10, $431-434,1989$.

Schunkert H, Dzau VJ, Tang SS, Hirseh AT, Apstein CS and Lorell BH. Increased rat cardiac angiotensin converting enzyme activity and mRNA expression in pressure overload left ventricular hypertrophy, Effects on coronary resistance, contractility, and relaxation. I Clin Invest 86, $1913-1920,1990$.

Scott-Burden T, Hahn AWA, Resink TJ and Buhler FR. Modulation of extracellular matrix by angiotensin II; stimulated glycoconjugate synthesis and growth in vascular smooth muscle cells. J Cardiovase Pharmacol 16 (Suppl. 4), \$36-\$41, 1990.

Sealey JE and Rubattu S. Prorenin and renin as separate mediators of tissue and circulating systems. Am J Hypertens 2, 358-366, 1989 .

Shultz PJ and Raij L. Effects of antihypertensive agents on endothelium-dependent and endothelium-independent relaxations. Br J Clin Pharmac 28, 151.S-157S, 1989.

Sillau AH and Banchero N. Skeletal muscle fiber type and capillarity. Proc Soc Exp Biol Med 158, 288-291, 1978.

Sillau AH and De Lourdes Philippi $M$. Long-term isoprenaline administration produces an increase in capillarity in the soleus muscle of the rat. Can J Physiol Pharmacol 65, 303-306, 1987.

Skeggs LT, Marsh WH, Kahn JR and Shumway NP. The purification of hypertensin I. I Exp Med $100,363-370,1954$.

Skeggs LT, Kahn JR and Shumway NP. The preparation and the function of hypertensin-converting enzyme. J Exp Med 103, 295-299, 1956.

Smith TL and Hutchins PM. Central hemodynamics in the developmental stage of spontaneous hypertension in the unanesthetized rat. Hypertension 1, 508-517, 1979.

Smits JFM and Brody MJ. Activation of afferent renal nerves by intrarenal bradykinin in conscious rats. Am J Physiol 247, R1003-R1008, 1984.

Smits JFM and Struyker-Boudier HAJ. Systemic and regional hemodynamics following acute inhibition of angiotensin I-converting enzyme in the conscious spontaneously hypertensive rat. Prog Pharmacol 5, 39-49, 1984.

Smits JFM and Thijssen HHW. Spatial control in drug action: theoretical considerations on the pharmacokinetics of targertained drug delivery. $\| n$ : Rate-controlled dirug administration and action (ed.: Struyker-Boudier HAJ). CRC Press, Boca Raton, USA, 1986, pp. 83-115.

Smits JFM, Coleman TG, Smith TL, Kasbergen CM, Van Essen $H$ and Struyker-Boudier HAJ. Antihypernensive effect of propranolol in conscious spontaneously hypertensive rats: central hemodynamics, plasma volume and renal function during beta-blockade with propranolol. J Cardiovasc Pharmacol 4, 903-914, 1982.

Smits JFM, Schoemaker RG, Daemen MJAP and Debets JJM. Haemodynamic consequences of interference with the renin-angiotensin system following myocardial infarction in rats. $\mathrm{Br} \mathrm{J}$ Pharmacol102, 99P, 1991.

Somlyo AP and Somlyo AV, Vascular smooth muscle. I. Normal structure, pathology, biochemistry, and biophysics. Pharmacol Rev 20, 197-272, 1968.

Somlyo AP and Somlyo AV. Vascular smooth muscle. Il. Pharmacology of normal and hypertensive vessels. Pharmacol Rev 22, 249-353, 1970.

Sonecha TN, Nicolaides AN, Kyprianou P, Zukowski A, Papadakis K, Vasdekis $S$ and Salmasi A-M. The effect of enalapril on leg muscle blood flow in patients with claudication. Inter Angio 9 , $22-24,1990$. 
Speth RC and Kim KH. Discrimination of two angiotensin II receptor subtypes with a selective analogue of angiotensin II, p-aminophenylalanine angiotensin II. Biochem Biophys Res Commun $169,997-1006,1990$.

Spittell JA. Diagnosis and management of occlusive peripheral arterial disease. Curr Problem Cardiol 15, 1-35, 1990.

Stacy DL and Prewitt RL. Effects of chronic hypertension and its reversal on arteries and arterioles. Circ Res 65, 869-879, 1989.

Strano A, Fareed J, Sabba $C$, Albano $O$, Allegra $C$, Carlizza A, Binaghi $F$, Fronteddu $F$, Del Guercio R, Rosaria Arpaia M, Pinto A, Alletto G, Walenga JM, Hoppensteadt D, Nazzari M and Ferrari PA. A double-blind, multicenter, placebo-controlled, dose comparison study of orally administered defibrotide: preliminary results in patients with peripheral arterial disease. Senin Thromb Hemost 17 (Suppl. 2), 228-234, 1991.

Struyker-Boudier HAJ. Dynamic systems analysis as a basis for drug design: application to antihypertensive drug action. In: Drug design (ed.: Ariëns EJ). Academic Press, New York, 1980, pp. 146-191.

Struyker-Boudier HAJ, De Mey JGR, Smits JFM and Nievelstein HMNW. Hemodynamic actions of calcium entry blockers. Prog. Basic Clin Pharmacol 2, 21-66, 1989.

Suki WN. Renal hemodynamic consequences of angiotensin-converting enzyme inhibition in congestiwe heart failure. Arch Int Med 149, 669-673, 1989.

Swedberg $\mathbf{K}$ and Kjekshus $\mathrm{J}$. Effects of enalapril on mortality in severe congestive heart failure: results of the Cooperative North Scandinavian Enalapril Survival Study (CONSENSUS). Am J Cardiol 62, 60A-66A, 1988 .

Tesfamariam B and Halpern W. Endothelium-dependent and endothelium-independent vasodilatation in resistance arteries from hypertensive rats. Hypertension 11, 440-444, 1988.

Tigerstedt $R$ and Bergman PG. Niere und Kreislauf. Skandinav Arch Physiol 8, 223-271, 1898.

Timmermans PBMWM, Carini DJ, Chiu AT, Duncia JV, Price WA, Wells GJ, Wong PC, Wexler RR and Johnson AL. Nonpeptide angiotensin II receptor antagonists: a novel class of antihypertensive agents. Blood Vessels 27, 295-300, 1990.

Timmermans PBMWM, Wong PC, Chiu AT and Herblin WF. Nonpeptide angiotensin II receptor antagonists. Tips $12,55-62,1991$.

Tornling $G$, Adolfsson J, Unge $G$ and Ljungqvist A. Capillary neoformation in skeletal muscle of dipyridamole-treated rats. Arzneim Forsch 30, 791-792, 1980.

Tsutsumi $\mathrm{K}$ and Saavedra JM. Characterization of $\mathrm{AT}_{2}$ angiotensin II receptors in rat anterior cerebral arteries. Am J Physiol 261, H667-H670, 1991.

Unian ME and Linas SL. Angiotensin II surface receptor coupling to inositol triphosphate formation in vascular smooth muscle cells. J Biol Chem 265, 195-200, 1990.

Unger $T$ and Gohlke $P$. Tissue renin-angiotensin systems in the heart and vasculature: possible involvement in the cardiovascular actions of converting enzyme inhibitors. Am J Cardiol 65, 3I-10I, 1990.

Unger T, Ganten D, Land RE and Schölkens BA. Persistent tissue converting enzyme inhibition following chronic treatment with Hoe498 and MK42I in spontaneously hypertensive rats. I Cardiovasc Pharmacol 7, 36-41, 1985.

Unger $T$, Badoer $E$, Ganten $D$, Lang RE and Rettig R. Brain angiotensin: pathways and pharmacology. Circulation 77 (Suppl. I), I40-154, 1988.

Unger T, Gohlke P, Ganten D and Lang RE. Converting enzyme inhibitors and their effects on the renin-angiotensin system of the blood vessel wall. J Cardiovase Pharmacol 13 (Suppl. 3), 58-516, 1989.

Urabe M, Su C and Lee TJ-F. Pre- and postsynaptic effects of angiotensins in the femoral artery of spontaneously hypertensive and Wistar-Kyoto rats. Blood Vessels 24, 1-10, 1987. 
Urata $H$, Healy B, Stewart RW, Bumpus FM and Husain A. Angiotensin II receptors in normal and failing human hearts. J Clin Endocrinol Metab 69, 54-66, 1989.

Urata $H_{\text {, Healy }} \mathrm{B}$, Stewart RW, Bumpus FM and Husain A. Angiotensin II-forming pathways in normal and failing human hearts. Circ Res 66, 883-890, $1990 \mathrm{a}$.

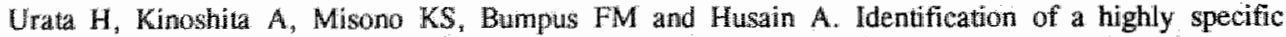
chymase as the major angiotensin lll-forming enzyme in the human heart. I Biol Chem 265 , 22348.22357, 1990b.

Van Batk MA, Struyker-Boudier HAJ and Smits JFM. Antihypertensive mechanisms of beta-adrenoceptor blockade: a review. Clin Exp Theor Pract A7, 1-72, 1985.

Van den Meiracker $A H$, Admiral PJ, Man in 't Veld AJ, Derkx FHM, Ritsema van Eck HJ, Mulder $P$, Van Brummelen $P$ and Schalekamp MADH. Prolonged blood pressure reduetion by orally actiwe renin inhibitor RO 42-5892 in essential hypertension. Br Med J 301, 205-210, 1990.

Van Gilst WH. Protection of the myocardium against pastischemic reperfusion damage. I Cardiovasc Pharmacol 14 (Suppl. 9), \$49-\$54, 1989.

Van Gilst WH, Scholtens E, De Graeff PA, De Langen CDJ and Wesseling H. Differential influences of angiotensin converting-enzyme inhibitors on the coronary circulation. Circulation 77 (Suppl. 1), 124-129, 1988.

Van Heiningen PNM, Batink HD and Van Zwieter PA. Angiotensin II-induced increase in slowly exchanging ${ }^{45} \mathrm{Ca}^{2+}$ in relation to contractile responses of rat and guinea-pig aorta. Naunyn Schmiedeberg's Arch Pharmacol 344, 107-113, 1991.

Vanhoutte PM. Endothelium and control of vascular function. State of the art lecture. Hypertension $13,658-667,1989$

Vanhoutte PM. Vascular effeets of serotonin and ischemia. I Cardiovasc Pharmacol 16 (Suppl. 3), S15-S19, 1990.

Vanhoutte PM, Verbeuren TJ and Webb RC. Local modulation of adrenergic neuroeffector interaction in the blood vessel wall. Physiological Reviews 61, 151-218, 1981.

Van Krimpen C, Schoemaker RG, Cleutjens JPM, Smits JFM, Struyker-Boudier HAJ, Bosman FT and Daemen MJAP. Angiotensin I converting enzyme inhibitors and cardiac remodeling. Basic Res Cardiol 86 (Suppl. 1), 149-155, 1991a.

Van Krimpen C, Smits JFM, Cleutjens JPM, Debets JJM, Schoemaker RG, Struyker-Boudier HAJ, Bosman HAJ and Daemen MAJP. DNA synthesis in the non-infarcted cardiac interstitium after left coronary artery ligation in the rat: effects of captopril. J Mol Cell Cardiol, 1245-1253, $1991 \mathrm{~b}$.

Velletri $\mathbb{P}$ and Bean $B L$. The effects of captopril on rat aortic angiotensin-converting enzyme. J Cardiovase Pharmacol 4, 315-325, 1982.

Ventura HO, Frohlich ED, Messerli FH, Kobrin I and Kardon MB. Cardiovascular effects and regional blood flow distribution associated with angiotensin converting enzyme inhibition (captoprii) in essential hypertension. Am J Cardiol 55, 1023-1026, 1985.

Verheyen $A$, Vlaminckx $E$, Remeysen $P$ and Borgers $M$. The influence of ketanserin, a new $S_{2}$ receptor antagonist on experimentally induced skeletal nuscle myopathy in the rat. Virchows Arch $393,265-272,1981$

Verheyen A, Vlaminckx E, Lauwers F, Van den Broeck C and Wouters L. Serotonin-induced blood. flow changes in the rat hindlegs after unilateral ligation of the femoral artery. Inhibition by the $S_{2}$ receptor antagonist ketanserin. Arch int Pharmacodyn 270, 280-298, 1984.

Verheyen A, Lauwers $F$, Vlaminckx $E$, Wouters $L$ and De Clerck $F$. Effects of wasoactive agonists on peripheral collateral arteries in in situ perfused rat hindquarters. Supersensitivity to serotonin. Int J Microcirc: Clin Exp 7, S132, 1988.

Verheyen $A$, Lauwers $F$, Vlaminckx $E$ and De Clerck $F$. Differential vasoreactivity to the thromboxane $\mathrm{A}_{2}$ mimic $U-46619$ of collateral and normal peripheral bllood vessels in in situ perfused rat hindquarters. Blood Vessels 26, 165-176, 1989.

Verheyen $A$, Lawwers $\mathbb{F}$, Vlaminckx $E$, Wouters $L$ and De Clerck $F$. Oversensitivity to serotonin of 
the collateralized vascular bed in rat hindquarters: mechanisms of increased vasoconstriction. Eur I Pharmacol 194, 209-216, 1991.

Verstraete M. Current therapy for intermittent claudication. Drugs 24, 240-247, 1982.

Waldemar $\mathrm{G}$ and Paulson $\mathrm{OB}$. Angiotensin conwerting enzyme inhibition and cerebral circulation-a review. Br J Clin Pharmac 28, 1775-182S, 1989.

Wallenstein S, Zucker COL and Fleiss JL. Some statistical methods useful in circulation research. Circ Res $47,1-9,1980$.

Wang D-H and Prewitt RL. Captopril reduces aortic and microvascular growth in hypertensive and normotensive rats. Hypertension $15,68-77,1990$.

Watson S and Abbott A. TiPS receptor nomenclature supplement. Tips 12 (Suppl. 1), 1-36, 1992.

Weber KT and Janicki JS. Angiotensin and the remodelling of the myocardium. Br J Clin Pharmac $28,141 \mathrm{~S}-150 \mathrm{~S}, 1989$.

Weishaar RE, Panek RL, Major TC, Simmerman J, Rapundalo ST and Taylor DG. Evidence for a functional tissue renin-angiotensin system in the rat mesenteric vasculature and its involvement in. regulating blood pressure. J Pharmacol Exp Ther 256, 568-574, 1991.

Whitebread S, Mele M, Kamber B and DeGasparo M. Preliminary biochemical characterization of two angiotensin II receptor subtypes. Biochem Biophys Res Commun 163, 284-291, 1989.

Williams GH. Converting-enzyme inhibitors in the treatment of hypertension. N Engl J Med 319, $1517-1525,1988$.

Williams PB. Response to adrenergic agonists and antagonists by collateral arteries from the hind limb of the dog. J Pharmacol Exp Ther 214, 239-245, 1980.

Williams PB. Norepinephrine uptake and efflux from canine peripheral collateral arteries. J Cardiovase Pharmacol 18, 198-206, 1991.

Williams PB and Saelens DA. Release of norepinephrine by electrical field stimulation of collateral arteries from the hindlimb of the dog. J Cardiovase Pharmacol 5, 786-791, 1983.

Williams TA, Hooper NM and Turner AJ. Characterization of neuronal and endothelial forms of angiotensin converting enzyme in pig brain. J Neurochem 57, 193-199, 1991.

Wong PC, Reilly TM and Timmermans PBMWM. Effect of a monoclonal antibody to angiotensin II on hemodynamic responses to noradrenergic stimulation in pithed rats. Hypertension 14, 488-497, 1989.

Wood JM, Mah SC and Schnell C. Comparison of the acute hypotensive effects of renin inhibition, converting enzyme inhibition, and angiotensin Ill antagonism in rats. J Cardiovasc Pharmacol 16 (Suppl. 4), S60-S64, 1990.

Yamada H, Fabris B, Allen AM, Jackson B, Johnston Cl and Mendelsohn FAO. Localization of angiotensin converting enzyme in the rat heart. Circ Res $68,141-149,1991$.

Ziada AMAR, Hudlicka $\mathrm{O}$, Tyler $\mathrm{KR}$ and Wright AJA. The effect of long-term vasodilatation on capillary growth and performance in rabbit heart and skeletal muscle. Cardiovase Res 18, 724-732, 1984.

Ziada AMAR, Hudlicka $O$ and Tyler KR. The effect of long-term administration of $\alpha_{1}$-blocker prazosin on capillary density in cardiac and skeletal muscle. Pffugers Arch 415, 355-360, 1989.

Zimmerman BG. Monoclonal antibodies and nonpeptide antagonists to angiotensin II. Hypertension $15,498-500,1989$.

Zimmerman BG, Raich PC, Vawrek RJ and Stewart JM. Bradykinin contribution to renal blood flow effect of angiotensin converting enzyme inhibitor in the conscious sodium-restricted dog. Circ Res 66, 242-248, 1990 .

Zumstein A, Mathieu O, Howald H and Hoppeler H. Morphometric analysis of the eapillary supply in skeletal muscles of trained and untrained subjects - its limitations in muscle biopsies. Pflugers Arch 397, 277-283, 1983. 


\section{SUMMARY}

Local renin angiotensin systems (RAS) exert autocrine and paracrine influences on local tissue function. Local RAS seem to be involved not only in normal physiology, but also in adaptive mechanisms in pathophysiological situations, such as hypertension and heart failure. As a consequence, inhibition of local angiotensin converting enzyme (ACE) and to a lesser extent inhibition of circulating ACE play a major role in the therapeutic effects of ACE-inhibitors.

In the present thesis the role of local RAS was investigated in normal conditions and in the pathological conditions of hypertension, myocardial infarction and skeletal muscle ischemia. In conscious spontaneously hypertensive rats and rats with myocardial infarction, regulation of regional blood flow by local RAS was investigated with non-hypotensive doses of two structurally different ACE-inhibitors, captopril and enalaprilate (chapter 3). These ACEinhibitors cause preferential renal vasodilatation predominantly in myocardial infarction, which suggests an important role of the renal RAS in the regulation of renal resistance.

Further investigations concerning local RAS were required. Therefore, a rat hindlimb perfusion model was used, in which local RAS could be investigated without interference of the circulating RAS. The characteristics of this model are described in detail in chapter 4. In this model local ACE is active and can be inhibited by the ACE-inhibitors used (captopril, enalaprilate, lisinopril and zabiciprilate; chapter 5). Local ACE can be inhibited more by captopril than by the other ACE-inhibitors used at doses which result in comparable plasma ACE inhibition.

As local RAS play a role in ischemic situations in heart and brain, these systems may also play a role in ischemia of skeletal muscle. This was investigated in spontaneously hypertensive rats, in which skeletal muscle ischemia is induced by partial occlusion of the left common iliac artery. Both acutely and chronically, severe ischemia of skeletal muscle ( $>60 \%$ flow reduction) results in a non-selective hyperreactivity of the vascular bed of the ischemic hindlimb to vasoconstrictor substances (angiotensin I, angiotensin II and phenylephrine). Local ACE seems not to be involved in this hyperreactivity.

The role of local RAS in the non-selective hyperreactivity in chronic ischemia of skeletal muscle was investigated in chapter 7. Chronic antihypertensive treatment of the animals with the ACE-inhibitors captopril and zabiciprilate, and the calcium entry blocker felodipine has no influence on the non-selective hyperreactivity. In contrast, chronic treatment with the $\mathrm{AT}_{1}$-receptor antagonist DuP753 results in a reduction of the hyperreactivity, suggesting an involvement of local RAS and the $\mathrm{AT}_{1}$-receptor in adaptive mechanisms in the vascular bed of the ischemic hindlimb.

Structural and reactivity changes of pre-existing vessels (femoral artery) of 
ischemic hindlimbs were investigated in vitro in chapter 8 . Structural adaptation of the femoral artery to diminished blood pressure and flow in the ischemic hindlimb results in a decreased maximal (absolute) contractility of the artery. Neither structural changes of the vessel wall nor changes of endothelium-dependent relaxing responses can explain the relative hypersensitivity and hyperreactivity to vasoconstrictor substances (serotonin and phenylephrine). The role of alterations of the membrane potential of vascular smooth muscle cells was indirectly investigated by a moderate elevation of extracellular potassium concentration at rest and after precontraction with phenylephrine. Vascular smooth muscle cells of post-stenotic arteries are slightly depolarized, which can be responsible for both the relative hypersensitivity and hyperreactivity to vasoconstrictor substances of post-stenotic arteries.

The effect of chronic ischemia of skeletal muscle on neovascularization in skeletal muscle was investigated in chapter 9. Chronic ischemia of skeletal muscle results in a decrease in fiber size and an increase in capillarity, predominantly in the oxidative soleus muscle. Chronic treatment of animals subjected to skeletal muscle ischemia with moderately antihypertensive doses of the ACEinhibitors captopril and zabiciprilate results in a prevention of the neovascularization, whereas treatment with a similarly antihypertensive dose of the calcium entry blocker felodipine has no effect. A greater blood pressure reduction by felodipine and the $\mathrm{AT}_{1}$-receptor antagonist DuP753 also results in an abolishment of the neovascularization. Both the RAS and blood pressure play a role in neovascularization in skeletal muscle ischemia.

From this thesis it can be concluded that local RAS play a role in regulation of renal vascular resistance predominantly after myocardial infarction. Furthermore, ischemia of skeletal muscle results in structural adaptation of the vessel wall to diminished blood pressure and flow, non-selective hyperreactivity to vasoconstrictor substances, and neovascularization in skeletal muscle. Abolishment of the non-selective hyperreactivity by DuP753 and of the neovascularization by antihypertensive treatment suggest involvement of both local RAS and hypoperfusion in these adaptive mechanisms. 


\section{SAMENVATTING}

Naast een circulerend renine angiotensine systeem bestaan er ook lokale renine angiotensine systemen, die zowel een autocriene als een paracriene invloed kunnen uitoefenen op lokale weefsel functies. Deze lokale systemen lijken niet alleen van belang te zijn in fysiologische omstandigheden, maar ook bij aanpassingsprocessen in pathofysiologische situaties, zoals hypertensie en hartfalen. Ten gevolge daarvan spelen remming van het lokale angiotensine converterend enzym (ACE) en in mindere mate remming van het circulerende ACE een belangrijke rol in de therapeutische effecten van ACE-remmers.

In dit proefschrift is de rol van lokale renine angiotensine systemen bestudeerd in normale omstandigheden en bij hypertensie, hartinfaret en ischemie van het skeletspierweefsel. De regulatie van de bloedstroom in regionale vaatbedden (darmen, nier en skeletspier) door lokale renine angiotensine systemen is onderzocht in wakkere spontaan hypertensieve ratten en in ratten met een hartinfarct (hoofdstuk 3). Lage (niet bloeddrukverlagende) doseringen van twee structureel verschillende ACE-remmers, captopril en enalaprilaat, veroorzaken voornamelijk na een hartinfarct selectief renale vaatverwijding. Dit suggereert dat het renale renine angiotensine systeem een belangrijke rol speelt in de regulatie van de renale weerstand.

De resultaten in vivo vereisten een nadere bestudering van het lokale renine angiotensine systeem. Ter bestudering van het lokale systeem zonder beinvloeding van het circulerende systeem is gebruik gemaakt van een achterpoot. perfusiemodel in de rat. De karakteristieken van dit model zijn in detail beschreven in hoofdstuk 4. Het lokale ACE is functioneel actief in dit perfusiemodel en kan geremd worden door ACE-remmers (captopril, enalaprilaat, lisinopril en zabiciprilaat; hoofdstuk 5). De remming is groter voor captopril dan voor de andere onderzochte ACE-remmers, terwijl bij vergelijkbare doseringen de ACE-remmers het plasma ACE in gelijke mate remmen.

Lokale renine angiotensine systemen spelen een rol bij ischemische situaties in hart en hersenen en mogelijk ook bij ischemia van het skeletspierweefsel. Dit laatste is onderzocht in spontaan hypertensieve ratten, waarbij ischemie van het skeletspierweefsel is veroorzaakt door partiële afbinding van de arteria iliaca van de linker achterpoot. Zowel in acute (45 minuten) als in chronische (4 weken) ischemische achterpoten leidt een bloedstroomvermindering van meer dan $60 \%$ tot een niet-selectieve hyperreactiviteit van het vaatbed van de ischemische achterpoot voor vaatvernauwers (angiotensine I, angiotensin II en fenylefrine). Het lokale ACE lijkt hier geen rol bij te spelen.

De rol van het lokale renine angiotensine systeem in de niet-selectieve hyperreactiviteit is nader bestudeerd in hoofdstuk 7 . Langdurige bloeddrukverlagende behandeling ( 4 weken) van de ischemische ratten met de ACE-remmers captopril of zabiciprilaat of met de calcium-antagonist felodipine heeft geen invloed op de 
niet-selectieve hyperreactiviteit. In tegenstelling tot de behandeling met ACEremmers en calcium-antagonist vermindert een langdurige behandeling met de $\mathrm{AT}_{1}$-receptor-antagonist DuP753 de hyperreactiviteit. Dit suggereert een betrokkenheid van het lokale renine angiotensine systeem en de $\mathrm{AT}_{1}$-receptor in de aanpassingsmechanismen in het vaatbed van de ischemische achterpoot.

Structurele en reactiviteitsveranderingen van bestaande vaten (arteria femoralis) in de ischemische achterpoot zijn in vitro bestudeerd in hoofdstuk 8 . De structurele aanpassing van de arteria femoralis ten gevolge van de afgenomen bloeddruk en bloedstroom leidt tot een vermindering van de maximale (absolute) contractiekracht van de arterie. Zowel de structurele aanpassingen van de vaatwand als de veranderde responsen van endotheel-afhankelijke vaatverwijding kunnen de relatieve toename in reactiviteit en sensitiviteit voor vaatvernauwers (serotonine en fenylefrine) niet verklaren. Mogelijke veranderingen van de membraanpotentiaal van gladde spiercellen is indirect bestudeerd met behulp van een matig verhoogde extracellulaire kaliumconcentratie voor en na vaatvernauwing met fenylefrine. De gladde spiercellen van de vaten uit de ischemische achterpoten zijn enigzins gedepolariseerd, wat de bovenstaande relatieve hyperreactiviteit en -sensitiviteit voor vaatvernauwers kan veroorzaken.

Het effect van chronische ischemie van skeletspierweefsel op nieuwvorming van vaten in skeletspier is bestudeerd in hoofdstuk 9. Chronische ischemie leidt voornamelijk in de musculus soleus tot een afname van de spiervezelgrootte en een toename van het aantal capillairen. Langdurige behandeling (4 weken) van de ischemische ratten met een matig bloeddrukverlagende dosering van de ACEremmers captopril of zabiciprilaat voorkomt een toename in aantal capillairen, terwijl een matig bloeddrukverlagende dosering van de calcium-antagonist felodipine geen effect heeft. Een grotere bloeddrukdaling ten gevolge van felodipine en de $\mathrm{AT}_{1}$-receptor-antagonist DuP753 voorkomt eveneens de toename in capillairen in de musculus soleus van de ischemische achterpoot. Dit suggereert dat zowel het renine angiotensine systeem als bloeddruk een rol spelen bij nieuwvorming van vaten bij ischemie van het skeletspierweefsel.

Uit bovenstaande experimenten kan geconcludeerd worden, dat voornamelijk na een hartinfarct lokale renine angiotensine systemen een rol spelen in de regulatie van de renale vaatweerstand. Ischemie van het skeletspierweefsel leidt tot een structurele aanpassing van de vaatwand, niet-selectieve hyperreactiviteit voor vaatvernauwers en nieuwvorming van vaten in skeletspieren. De vermindering van de niet-selectieve hyperreactiviteit door DuP753 en de vermindering van de nieuwvorming van vaten door bloeddrukverlagende behandeling suggereert een betrokkenheid van zowel het lokale renine angiotensine systeem als hypoperfusie in de aanpassingsmechanismen na ischemie van het skeletspierweefsel. 


\section{CURRICULUM VITAE}

17 augustus 1962

$1974-1980$

$1980-1986$

mei 1987

1988-1992

maart 1992
Geboren te Maastricht

Atheneum B, Stedelijk Lyceum te Maastricht

Studie Farmacie aan de Rijksuniversiteit Utrecht

- bijvak Farmacologie

Apothekersexamen aan de Rijksuniversiteit Utrecht

Aanstelling als assistent in opleiding bij de vakgroep Farmacologie, Cardiovascular Research Institute Maastricht (CARIM) van de Rijksuniversiteit Limburg te Maastricht

Aanstelling bij NWO als post-doc bij de vakgroep Farmacologie (CARIM) van de Rijksuniversiteit Limburg te Maastricht

\section{Lijst van publicaties}

\section{Abstracts}

Vrancken HJMG, Wevers FPJ, Krielaart MJ, Raaijmakers JAM, Kinetics of the receptorbinding of ${ }^{3} \mathrm{H}-(-)-D 888$ in rat heart and lung tissue, Proceedings of the 27th Dutch Federation Meeting (Haren, the Netherlands), 1986.

Wevers FPJ, Vrancken HJMG, Krielaart MJ, Raaijmakers JAM, Filterbinding aspects of the receptorbinding assay for ${ }^{3} \mathrm{H}$-(-)-desmethoxyverapamil, Proceedings of the 27th Dutch Federation Meeting (Haren, the Netherlands), 1986.

Nelissen HJMG, Zeegers HHM, Struijker Boudier HAJ, Smits JFM, The influence of $3 \mathrm{ACE}$ inhibitors on regional hemodynamics in conscious SHR, Fundam Clin Pharmacol 3, 438-439, 1989. 
Nelissen HJMG, Struijker Boudier HAJ, Smits JFM, Influences of captopril, enalaprilate and lisinopril on central and regional hemodynamics in conscious normotensive (WKY), and infarcted (MI) rats, Pharm Wkbl Sci Ed 11 (Suppl. J), J8, 1989 .

Nelissen HJMG, Smits JFM, Acute effects of ACE inhibitors on central and regional hemodynamics in conscious normotensive (WKY) and infarcted (MI) rats, Naunyn Schmiedeberg"s Arch Pharm 341 (Suppl.), R47, 1990.

Nelissen HJMG, Struijker Boudier HAJ, Smits JFM, Central and hemodynamic effects of ACE inhibitors in conscious normotensive (WKY), hypertensive (SHR) and heart failure (MI) rats, Eur J Pharmacol 183, 774, 1990.

Nelissen HJMG, Leenders PJA, Struijker Boudier HAJ, Smits JFM, Angiotensin I converting enzyme (ACE) in the perfused hindlimbs of the rat, Pharm Wkbl Sci Ed 12 (Suppl. H), H9, 1990.

Nelissen HJMG, Leenders PJA, Struijker Boudier HAJ, Smits JFM, Effects of ACE-inhibitors in perfused hindlimbs of the rat, Proceedings of the Second International Symposium on ACE inhibition (London UK), P64, 1991.

Nelissen HJMG, Leenders PJA, Bost GPJ, Smits JFM, Relation between inhibition of angiotensin-converting enzyme (ACE) in vivo and in perfused hindlimbs of the rat, Naunyn Schmiedeberg's Arch Pharm 343 (Suppl.), R70, 1991.

Nelissen HJMG, Leenders PJA, Struijker Boudier HAJ, Smits JFM, Increased responsiveness to angiotensin II and II not affected by ACE-inhibitors in ischemic rat hindlimbs, Pharm Wkbl Sci Ed 13 (Suppl. H), H8, 1991.

Nelissen HJMG, Leenders PJA, Hyperreactivity to vasoconstrictors in ischemic rat hindlimb and the effect of angiotensin-I-converting enzyme (ACE) inhibitors and DuP753, Naunyn Schmiedeberg's Arch Pharm 345 (Suppl.), R86, 1992.

Nelissen HJMG, Leenders PJA, Struijker Boudier HAJ, Smits JFM, Role of the renin-angiotensin system (RAS) in the neovascularization in chronic ischemia of skeletal muscle in rats, FASEB Journal, in press.

Nelissen-Vrancken HJMG, Leenders PJA, Struijker Boudier HAJ, Smits JFM, Vascular adaptations in peripheral ischemia in rats, Proceedings of the 33th Dutch Federation Meeting (Rotterdam, the Netherlands), 1992.

\section{Artikels}

Nelissen-Vrancken HJMG, Struijker Boudier HAJ, ACE-remmers bij hypertensie, Modern Medicine (Special), feb. 1990.

Struijker Boudier HAJ, Messing MWJ, Nelissen HJMG, Huijberts MSP, Le Noble FAC, Smits JFM, Vascular actions of ACE-inhibitors in hypertension: 
structural and functional consequences. In: Current advances in ACE inhibition 2 (eds. G.A. MacGregor et al.), Churchill Livingstone, London, 1991.

Nelissen-Vrancken HJMG, Leenders PJA, Struijker Boudier HAJ, Smits JFM, Renall hemodynamic effects of non-hypotensive doses of ACE-inhibitors in hypertension and heart failure in rats, J Cardiovasc Pharmacol 19, 163-168, 1992.

Nelissen-Vrancken HJMG, Leenders PJA, Bost GPJ, Struijker Boudier HAJ, Smits JFM, Comparison of angiotensin-converting enzyme inhibitors in the rat in perfused hindlimbs and in vivo, Eur $J$ Pharmacol, in press.

Nel issen-Vrancken HJMG, Leenders PJA, Struijker Boudier HAJ, Smits JFM, Increased responsiveness of the vascular bed to angiotensin I, angiotensin II and phenylephrine in acute and chronic ischemic hindlimbs in rats, J Vasc Res, in press. 